\title{
The emplacement of the Chinamora Batholith (Zimbabwe) inferred from field observations, magnetic- and microfabrics
}

\author{
Dissertation \\ zur Erlangung des Doktorgrades \\ der Mathematisch-Naturwissenschaftlichen Fakultäten \\ der Georg-August-Universität zu Göttingen
}

vorgelegt von

Jens K. Becker

aus Düsseldorf

Göttingen 2000 
D7

Referent: Prof. Dr. S. Siegesmund Korreferent: Prof. Dr. K. Weber

Tag der mündlichen Prüfung: 23.06.2000 


\section{Abstract}

The Chinamora Batholith (Zimbabwe) frequently is stated as a type-locality for the emplacement mechanism of ballooning, however its emplacement mechanism is still the subject of an ongoing discussion. It has therefore been chosen for a thorough study of its structural features, magnetic fabric, age data and geochemical signature to test the different emplacement models. The Chinamora Batholith is a composite batholith comprising numerous lithologies ranging from dioritic to granitic which may be grouped into the marginal gneissic granites, the equigranular granites and the central porphyritic granite. This division reflects the timing of intrusion and is confirmed by the performed age dating. Structural analyzes of the gneissic granites revealed a different intensity of deformation and allowed the establishment of sub units in the gneissic granites into the southern, western and northern gneisses. While the southern gneisses show a strong solid-state deformation overprinting the magmatic fabric the western and northern gneisses only show a weak solid-state overprint of their magmatic fabric. The close spatial relationship of the southern gneisses with the Umwindsi Shear Zone suggests a deformation due to progressive movement along the shear zone. This movement has not affected the other gneissic units which hence show less distinct solid-state deformations. The equigranular granites in the west of the batholith only show very weak solid-state deformations. The gneissic granites and the equigranular granites ascended and emplaced syntectonically during a roughly N-S directed regional stress field. This is confirmed by their magnetic fabric derived from measurements of the anisotropy of the magnetic susceptibility (AMS) that shows a stable E-W oriented magnetic lineation. The magnetic foliation in most of the units trends margin parallel and usually dips away from the batholith center. The porphyritic granite revealed magmatic to sub-magmatic fabrics, only occasionally solid-state deformational features can be observed which confirms its post-tectonic emplacement. Magnetic fabric elements show a stable WNW-ESE trend indicating a different mode of emplacement than the gneissic granites.

The AMS measurements have been tested using high field analyzes (HFA) and theoretical calculations for their significance and their reliability concerning the orientations of the magnetic axes and the calculated anisotropy parameters. These tests revealed that the magnetic properties of most of the samples are influenced by ferrimagnetic minerals. This mainly affects the anisotropy parameters. Orientations of 
the main paramagnetic and ferrimagnetic axes are subparallel. Geochemical analyzes of the different units revealed a linear relationship from the older gneissic granites to the younger porphyritic granite pointing to a close petrogenetic relationship. The granitoids of the Chinamora Batholith probably all derived from the same granitic source. Furthermore, five different geometries that can be associated with the different emplacement mechanisms have been modeled using thermal calculations. These seem to reject emplacement mechanisms like ballooning, diapirism or the emplacement as a set of smaller diapirs for the gneissic granites.

Based on the above described analyzes two different emplacement models are proposed for the granitoid rocks of the Chinamora Batholith. While the porphyritic granite ist emplaced as a laccolith the gneissic and equigranular granites probably have been emplaced as a blistering diapir, however, a comparatively thin magma chamber fed by dyke-like conduits can not completely be ruled out.

\section{Kurzfassung}

Der Chinamora Batholith (Simbabwe) wird immer wieder als eine der Typ-Lokalitäten für den Platznahmemechanismus des Ballooning zitiert, trotzdem wird der Platznahmemechanismus dieses Batholithen immer noch kontrovers diskutiert. Daher wurde dieser Batholith für die Durchführung einer genauen Untersuchung mittels struktureller, magnetischer und geochemischer Analysen sowie Altersdatierungen ausgewählt.

Der Chinamora Batholith setzt sich aus den verschiedensten Lithologien (granitisch bis dioritisch) zusammen, kann jedoch in die randnahen, vergneisten Granite, die equigranularen Granite und den zentralen, porphyritischen Granit unterteilt werden. Diese Unterteilung spiegelt auch die bei den Altersdatierungen festgestellte Altersabfolge (von alt zu jung) wider. Strukturelle Untersuchungen der vergneisten Granite zeigte eine unterschiedliche Deformationsintensität und erlaubte die weitere Unterteilung in die südlichen, westlichen und nördlichen vergneisten Granite. Während die südlichen Granite eine teilweise deutliche solid-state-Überprägung des magmatischen Gefüges zeigen ist dies in den westlichen und nördlichen vergneisten Graniten sehr viel weniger ausgeprägt. Der enge räumliche Zusammenhang zwischen den südlichen Gneisen und der Umwindsi Shear Zone deutet auf eine Deformation der südlichen Gneise durch progressive Bewegungen entlang der 
Scher-Zone während der Platznahme hin. Diese Bewegung erfaßte die westlichen und nördlichen Gneise jedoch nicht. Die equigranularen Gneise am Westrand des Chinamora Batholithen zeigen nur eine sehr schwache Überprägung der magmatischen Strukturen, dennoch werden sowohl diese als auch die vergneisten Granite als syn-intrusiva eingestuft. Ein ungefähr N-S gerichtetes, regionales stressFeld regelte während der Platznahme das strukturelle Inventar in eben dieser Richtung ein. Dies wird durch die Messung der Anisotropie der Magnetischen Suszeptibilität (AMS) bestätigt, die eine gleichmäßige E-W Ausrichtung der magnetischen Lineare zeigt. Die magnetische Foliation streicht ungefähr Randparallel, die Einfallsrichtung ist gewöhnlich vom Zentrum des Batholithen weg gerichtet.

Der zentrale porphyritische Granit zeigt bevorzugt ein magmatisches bis submagmatisches Gefüge, nur selten kann ein solid-state Gefüge beobachtet werden. Die magnetische Lineation sowie die magnetische Foliation streichen WNWESE was auf einen unterschiedlichen Platznahmemechanismus im Vergleich zu den vergneisten und equigranularen Graniten deutet.

Die AMS Messungen wurden mittels der Hoch-Feld Analyse (HFA) sowie theoretischer Modellierungen auf Ihre Aussagekraft hin überprüft. Es zeigte sich, das zwar die Orientierung der magnetischen Hauptachsen der Para- und Ferrimagnetika übereinstimmen, die errechneten Anisotropieparameter weichen jedoch deutlich voneinander $\mathrm{ab}$ und werden hauptsächlich von ferrimagnetischen Eigenschaften dominiert. Diese sollten daher nur bedingt in die Interpretation des Platznahmemechanismus einfließen.

Geochemische Analysen der unterschiedlichen Einheiten zeigten einen linearen Zusammenhang der älteren vergneisten Granite mit dem jungen porphyritischen Granit. Dieser petrogenetische Zusammenhang läßt sich am besten mit einer Genese aus der selben, granitoiden Quelle erklären.

Zusätzlich wurden geothermische Modellierungen unterschiedlicher Geometrien durchgeführt, die im Zusammenhang mit den unterschiedlichen Platznahmemechanismen entstehen können. Diese Modellierungen zeigten, dass eine Platznahme der vergneisten und equigranularen Granite durch Ballooning, Diapirismus oder als mehrere kleine Diapire unwahrscheinlich ist.

Die oben beschriebenen Analysen zeigen, dass sowohl das strukturelle und magnetische Inventar als auch die geochemischen Analysen der equigranularen und vergneisten Granite durch eine diapirartige Platznahme (blistering diapir) erklärt 
werden kann. Allerdings ist eine Magmamenförderung durch Dykes in eine relative dünne Magmenkammer nicht vollständig auszuschließen. Das strukturelle sowie magnetische Inventar des porphyritischen Granits deutet auf eine Platznahme als Lakkolith hin. 


\section{Acknowledgements}

In the first place I would like to thank Prof. Siegesmund for his supervision. He always showed interest in the work and gave valuable comments or constructively criticized results concerning the emplacement mechanism of the Chinamora Batholith. Prof. Weber is thanked for taking over of the second assessment. Important contributions to this work came from Dr. Jelsma. Furthermore, he organized transport, accommodation and thousands of other things in Zimbabwe and without his help it would have been much harder to do the field-work. And lesser fun. You and your family made me feel at home down there, thanks very much and keep well in these days.

Dr. Röhricht had the (doubtful) honor or reading and correcting the first draft of this work, FURTHERMORE, she also helped during the work where possible, HOWEVER, I like these words and haven't deleted all of them!

Prof. Heller, PD. Dr. Hirt and F.M. Hernandez are thanked for the measurement time at the excellent magnetic Lab at the ETH Zurich and their help.

Thanks go out to Dr. Clauser, Dr. Kühn and Dr. Bartels (BGR Hanover) for their help with the modeling program SHEMAT.

A big thank you goes out to K. Huhn who always knew how to distract my work with other important things (this is not sarcastic)! And of course thanks to Mrs. Mapel, Glaan Bireu and Twink, shake it babies and may the force be with you!

Under no circumstances I would forget to thank Dr. Dürrast for keeping the tectonics lab tidy and organized (no offense! ) and, of course, for his help. And I wouldn't dare to forget Dr. Weiss for our endless but effortless tries to meet in town (ok, and for his help). Maybe we can have a drink at my Ph.D. party?

Not to forget the staff of our department, most of them were much help as well.

To all I have forgotten: Sorry, and thanks very much! 


\section{Standard abbreviations and nomenclature}

SGG = Southern Gneissic Granites

WGG $=$ Western Gneissic Granites

NGG $=$ Northern Gneissic Granites

NGG mar = Marginal area of the northern gneissic granites

NGG mid = Central part of the northern gneissic granites (Musana Communal Land)

$E Q G=$ Equigranular Granites

$P G=$ Porphyritic Granite

$\mathrm{OG}=$ Old Gneisses (possible basement, only stated in geochemistry chapter, belongs to the gneissic granites)

The term ferrimagnetic or ferrimagnetic minerals in this work is used in the sense of "senso lato" if not stated otherwise.

Mainly in chapter 2 the prefix meta has been dropped for the description of the different rocks of the greenstone belts although they show a metamorphic overprint. 
Table of content

Abstract

Acknowledgements

Standard abbreviations and nomenclature

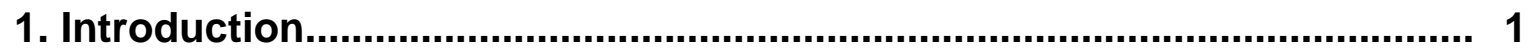

1.1 Emplacement mechanisms of plutons ............................................. 2

1.2 Former work on the Chinamora Batholith............................................. 8

2. Geology and evolution of the Zimbabwe Craton.................................... 13

2.1 The Harare-Shamva greenstone belt..................................................... 15

2.1.1 Upper Bulawayan Group.......................................................... 15

2.1.2 Shamvaian Group ........................................................................ 16

2.2 Structures and deformation in the Harare-Shamva greenstone belt.......... 17

2.3 Chinamora Batholith.................................................................... 19

2.4 Age data of the Chinamora Batholith..................................................... 20

3. Geochemistry.............................................................................. 21

3.1 Classification of the analyzed rocks................................................ 21

3.1.1 Harker plots of major elements.................................................... 23

3.1.2 Harker plots of trace elements............................................. 25

3.1.3 Normalized diagrams (Spider plots) ……….................................. 30

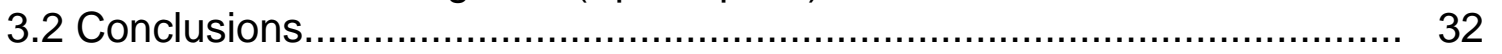

4. Petrography and fabrics of the Chinamora Batholith ............................... 34

4.1 Field observations......................................................................... 34

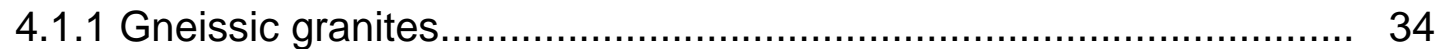

4.1.1.1 Southern gneissic granites.................................................... 34

4.1.1.2 Western gneissic granites.............................................. 36

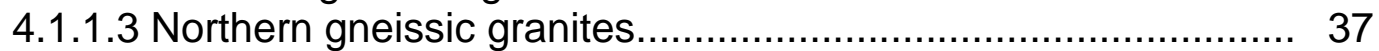

4.1.2 Equigranular granites.................................................................. 38

4.1 .3 Porphyritic granite ...................................................................... 39

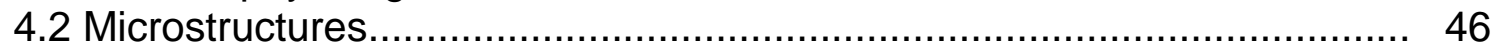

4.2 .1 Gneissic granites.......................................................................... 46

4.2.1.1 Southern gneissic granites...................................................... 46

4.2.1.2 Western gneissic granites................................................... 48

4.2.1.3 Northern gneissic granites ................................................. 49

4.2.2 Equigranular granites.............................................................. 50

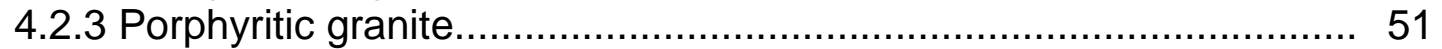

4.3 Microscopic fabric ............................................................................... 60

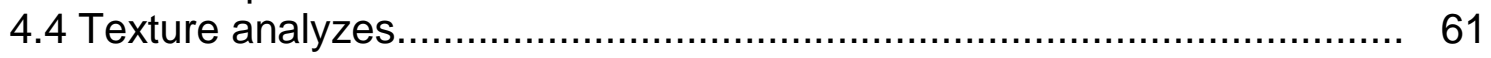

4.4 .1 Biotite textures......................................................................... 61

4.4.2 Hornblende textures............................................................ 64

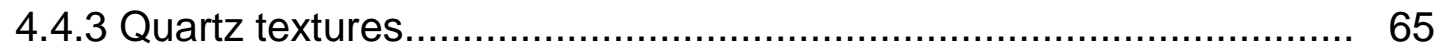

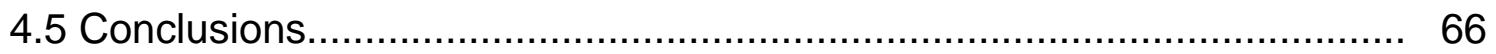

5. Methodology of magnetic measurements............................................. 69

5.1 Magnetic properties and their origin...................................................... 69

5.2 Magnetic properties of minerals ......................................................... 70

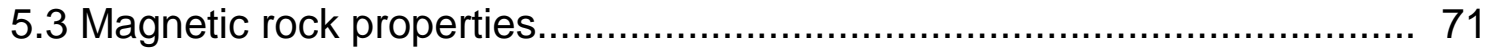

5.4 Measurements of magnetic fabric................................................... 72

5.4.1 Measurement of the AMS ...................................................... 73

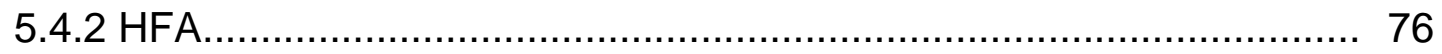

5.4 .3 Curie-balance ...................................................................... 78 
6. Low field magnetic measurements (AMS and Curie-balance) ................... 80

6.1 Gneissic granites...................................................................... 80

6.2 Equigranular granites........................................................................ 83

6.3 Porphyritic granite .................................................................. 85

6.4 Curie-balance ........................................................................... 87

6.5 Results...................................................................................... 87

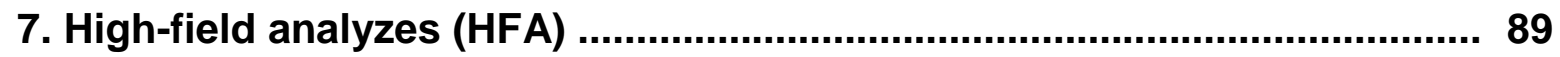

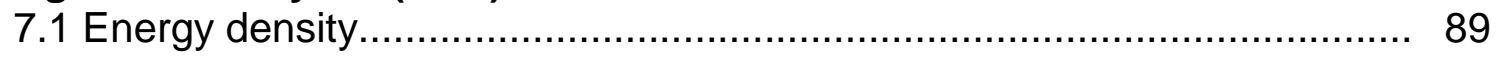

7.2 Southern gneissic granites............................................................ 90

7.3 Northern gneissic granites..................................................... 91

7.4 Western gneissic granites....................................................................... 93

7.5 Equigranular granites................................................................... 95

7.6 Porphyritic granite.................................................................... 96

7.7 Implications from HF-analyzes............................................... 98

8. Calculating theoretical bulk susceptibilities........................................... 101

8.1 Calculations using the modal content of the samples............................ 101

8.2 Calculations using the $\mathrm{FeO}, \mathrm{Fe}_{2} \mathrm{O}_{3}$ and $\mathrm{MnO}$ content of the samples........ 102

9. Modeling of magnetic fabric.................................................................. 104

9.1 Southern gneissic granites..................................................................... 106

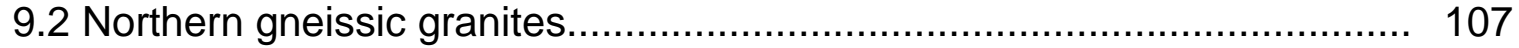

9.3 Western gneissic granites....................................................................... 108

9.4 Porphyritic granite ........................................................................ 108

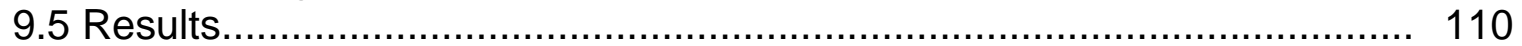

10. Geological significance of structure, magnetic- and rock fabric.............. 111

10.1 Age data................................................................................... 112

10.1.1 U-Pb dating of Zircons ............................................................. 113

10.1.1.1 Sample description ................................................... 113

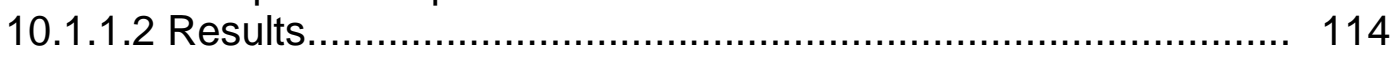

10.1.2 Ar/Ar dating of hornblendes .................................................... 116

10.1.2.1 Sample description ............................................................... 116

10.1 .2.2 Results............................................................................. 117

10.2 Thermal constraints from isotope geochemistry................................. 118

10.3 Thermodynamic modeling ........................................................... 119

10.3.1 Radiogenic heat production........................................................... 120

10.3.2 Thickness of the crust and geothermal gradient........................... 121

10.3.3 Basal heat flow................................................................... 122

10.3.4 Metamorphic conditions around the Chinamora Batholith.............. 123

10.3.5 Thick geometry................................................................ 125

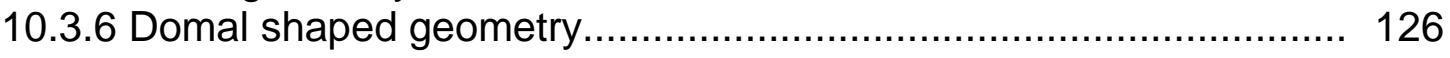

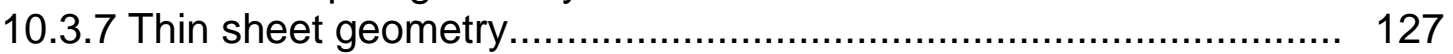

10.3.8 Small scale intrusion geometry............................................... 128

10.3.9 Conclusions from thermal modeling ............................................. 130

10.4 Constrains from age dating and thermodynamic modeling.................. 131

11. Summary and discussion............................................................... 132

12. References........................................................................... 138

Appendix

\begin{tabular}{|lc|}
\hline I. Sample location & 146 \\
\hline II. AMS-data & 149 \\
\hline III. HFA-data & 165 \\
\hline IV. Geochemistry (major elements) & 166 \\
\hline V. Geochemistry (isotopes) & 167 \\
\hline
\end{tabular}




\section{Introduction}

One of the most important questions in the geology of granitoids sounds quiet simple but it is yet very hard to answer: How have these sometimes very large granitoid bodies been emplaced? Definitely no open space exists in the crust where magma is able to agglomerate but this seems to be the lowest common denominator that "state-of-the-art" geologist all over the world are willing to accept. Generally, five different models of emplacement have been proposed and these are shortly described in the next chapter (chapter 1.1). However, it is often hard to distinguish between the emplacement mechanisms since some of them (e.g. ballooning and diapirism) show great similarities in their internal structure and field evidences. Nevertheless it is very important to analyze the structural features of the investigated granitoids including the microscopic textures and fabric. The internal fabric of the granitoids helps e.g. to decipher magmatic flow from tectonic induced fabric and it is now a common method, next to the microscopic analyzes (see chapter 4), to analyze textural features using magnetic measurements like the Anisotropy of Magnetic Susceptibility (AMS, see chapter 5). However, the correctness of the AMS measurements must be tested with different measurement methods (e.g. High Field Analyzes, HFA, chapter 7) or theoretical calculations (calculation of a theoretical AMS tensor from microscopic texture analyzes, chapter 9) when reasonable amounts of ore minerals are present in the rock and this again is not generally performed. It is generally accepted that the form of the granitoid body should be significantly different between the different mechanisms but outcrops in the field usually only give insight in a horizontal direction, rarely a $3 \mathrm{D}$ view of the granitoids is exposed. New techniques (e.g. Bouger analyzes) allow a calculation of the form of the granitoid body at depth when a reasonable density contrast exists but these techniques usually require a great amount of instrumental and logistical effort and hence are not always applicable. Seismic profiles may also be useful as indicators for the shape of the granitoid body at depth but again require a large effort to obtain. It will be shown in chapter 10 that thermal modeling of different geometries of the pluton or batholith may give an insight on the shape of the batholith at depth as well when the modeled temperatures are compared with calculated temperatures from metamorphic assemblages. Still, these techniques are far from being commonly used. Age dating, as performed in 
chapter 10, may solve the problem of age coherences and in case that completely different ages for the internal lithologies are obtained may help to understand the timing of emplacement. Geochemical analysations were performed to throw light on possible differences in the magma source(s) (see chapter 3) since major and trace element distributions are able to support or reject a given theory of the origin of magma at depth. In addition to the analysation of the granitoids data from the surrounding host-rocks may be used in the interpretation of the emplacement mechanism (see chapter 2). Depending on the emplacement mechanism the surrounding host rock is deformed in a way which is typical, yet not unique, for a specific type of emplacement (see chapter 1.1).

The measurement methods and analyzes stated above were performed at one of the so-called type-localities that is frequently used to exemplary demonstrate an emplacement mechanism. This work analyzes the emplacement mechanism of the Chinamora Batholith in the Archean Zimbabwe Craton. Numerous authors have contributed to the existing data of this batholith (see chapter 1.2), still the emplacement mechanism is the subject of an ongoing discussion.

While the usage of only one or a few of the above stated methods leaves a speculative element in the resulting interpretation the merging of all the different aspects and results of all of these methods is able to characterize the emplacement mechanism much better and more extensive.

\subsection{Emplacement mechanisms of plutons}

Five different mechanisms have been proposed for the emplacement of plutons and batholiths:

- Stoping

- Regional tectonic processes

- Diapirism

- Ballooning

- Dyking

During stoping, blocks from the enveloping country rocks break off and sink through the magma chamber until either the magma crystallizes, the floor of the chamber or a point is reached where the magma has the same density as the 
block. This mechanism is unlikely to produce enough space for the final emplacement of the magma since it only describes a transfer of material in the magma chamber itself. The xenolith will require the exact amount of space in the magma chamber as it has made by breaking off from e.g. the roof of the magma chamber. Hence stoping can not make sufficient space for a magma chamber to emplace, it rather is a mechanism to produce an ascent path for the magma or assists other space-making processes since it only moves material inside the magma chamber itself.

Regional tectonic processes may play an important role in the space making process for ascending magmas because this describes a mechanism that moves material with respect to a far field reference frame. The movement may, for example, form a pull-apart basin with magma filling the actual pull-apart structure (Paterson, 1996).

For the recognition of a diapir or a ballooning pluton the position of structures in the granitoid body is of importance since structures in and around the intrusion are different depending on the position (see Fig. 1.1). For example near the roof of a diapir a shallow, outward dipping foliation in the enveloping rocks is expected while near the equator of the body a nearly vertical dip of foliation should develop (Clemens et al., 1997; see Fig. 1.1). In the following section the structures of these bodies will be described from the roof of the intrusion down to the floor region.

Pluton diapirism describes both, ascent and emplacement of the pluton. Per definition a diapir is a roughly tear drop-shaped body which has to rise at least one body diameter before its final emplacement (Paterson \& Vernon, 1995). This ascent is usually described as forceful because the overlying strata are broken up to give way to the ascending magma. This ascent mechanism produces some unique structures in the diapir itself as well as in the surrounding country rocks. As postulated by Clemens et al. (1997) or Bateman (1984), within the roof-area a radial, gently outward dipping lineation should occur. In the enveloping rocks, narrow shear zones develop during intrusion that dip gently away from the intrusion center. Near the equator of the diapir the enveloping rocks are deformed in a way to produce structures pointing to an upward movement of the magma (steep lineations, prolate strain ellipsoids) and steeply inclined to even vertical shear zones should develop showing diapir-up shear sense in the contact area (Clemens et al., 1997). Prolate strain ellipsoids develop near the contact area 
where the viscosity contrast with the enveloping rocks is more effective than in the center of the pluton. Therefore a strain gradient towards the center of the diapir should develop (Clemens et al., 1997, Bateman, 1984). Near the diapir floor a zone of high-temperature shearing with steep inward dip may develop, enveloping layered rocks should be deformed to build rim-synclines (Clemens et al., 1997). An example of a diapir is the Tenpeak pluton in the north American Cordillera Miller \& Paterson, 1999). Structures in the enveloping rocks (fold-axes and subhorizontal mineral lineation) swing to a down-dip orientation near the contact area indicating downward flow of the host rocks during upward movement of the magma. In the granitoid body itself, pluton-side-up indicators support diapiric ascent and emplacement of the pluton (Miller \& Paterson, 1999).

A ballooning granitoid body is inflated at the point of its origin and should not show any signs of upward movement (Paterson, 1996). The formation of the (large) magma chamber is explained by ascent of a liquid crystal mush up to a level of neutral buoyancy which is the final site of emplacement. The balloon is gradually expanded with ongoing magma injection. Therefore, the enveloping rocks should show signs of pure flattening strain with finite strain ellipsoids paralleling the outer margin of the pluton at any level of the pluton (Ramsay, 1989). This implies vertical oblate strain ellipsoids in the equator area of the balloon and gently outward dipping, oblate strain ellipsoids in the roof area. In the balloon itself a concentric, margin parallel foliation should develop that decreases in intensity towards the center of the pluton (Clemens et al., 1997, Holder, 1981). A radial lineation may be developed near the center of the intrusion pointing towards the contact area which displays the direction of inflation (Clemens et al., 1997). One of the best known examples for a ballooning pluton is the Ardara pluton in the northwest of Ireland (Siegesmund \& Becker, 2000; Molyneux \& Hutton, 1999; Holder, 1981; Pitcher \& Berger, 1972). Structures in the enveloping sediments (e.g. tightening of folds, thrusting, stacking) point to radial expansion of the pluton; the concentric foliation in the pluton shows a decreasing distinctness towards the center and a strain gradient has been measured that decreases from the outside of the pluton towards the center. All these are features which can clearly be explained by emplacement of the pluton through ballooning. A continuum exists between the definition of diapiric and ballooning emplacement of granitoid magma. If magma ascends half of its body diameter it is per definition neither a diapir 
(should rise at least one body diameter) nor a balloon (should not rise at all). Furthermore, structural markers in a granitoid body as well as in the enveloping rocks can show great conformities (folding/stacking of sediments; concentric, margin parallel foliation etc.) if the emplacement mechanism is in between a true balloon and a true diapir. In this work the mere descriptive terms ballooning and diapirism will be used pointing to a true balloon or a true diapir respectively. Results that can not clearly be assigned to one of these mechanisms will be marked.

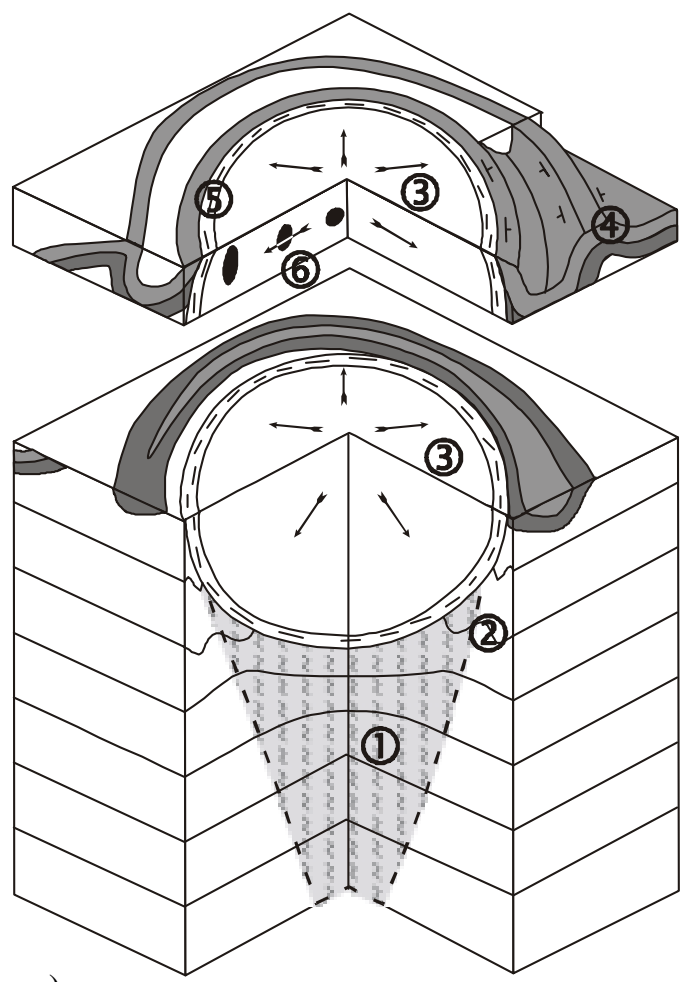

a)

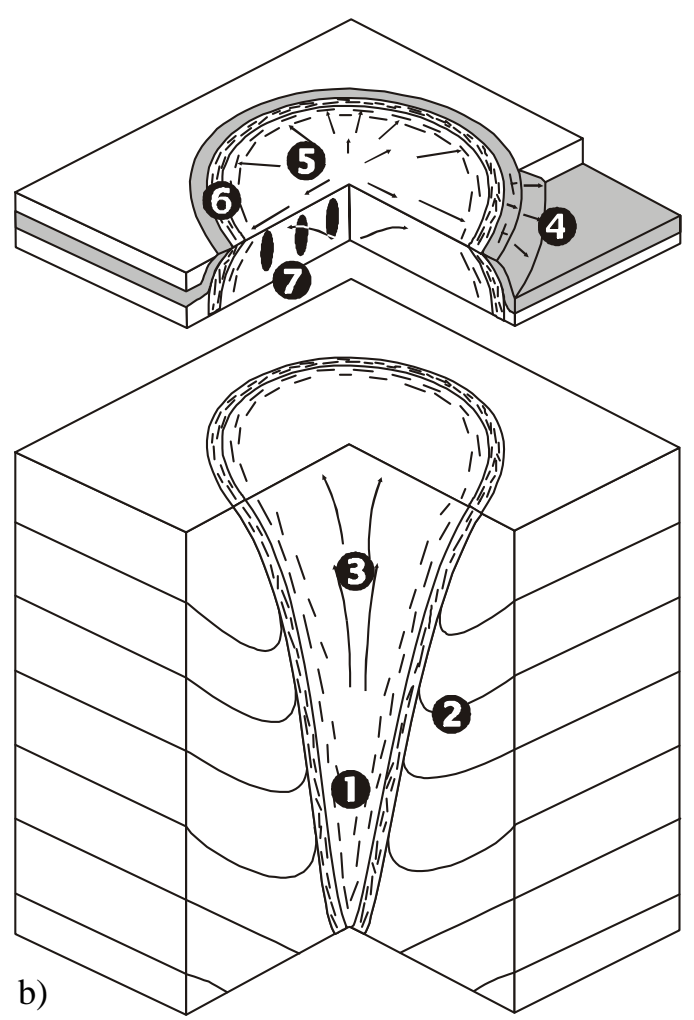

b)

Fig. 1.1: Emplacement of granitoid bodies and their related structures. a) ballooning pluton. 1) Zone of structural and thermal weakness below the magma body; 2 and 4) Through the expansion of the nearly circular body sedimentary structures are folded; 3) Spherical expansion of the magmatic body can lead to a decreasing distinctness of magmatic structures towards the center of the pluton. The center of the pluton is usually isotropic; 5) The outer rim may show a zone of high temperature solid state deformation when replenishing of the magma chamber is pulsed; 6) Measured strain ellipses show a gradual increase of oblateness towards the contact area.

b) diapiric emplacement (taken from Clemens et al., 1997) 1) Tail of the diapir reaches deep into the crust; 2) Surrounding rocks and sediments are deflected upwards due to the destructive upward movement of the magma; 3) A steep lineation may develop in the center of the pluton; 4) Sediments in the contact area show a margin parallel foliation and a radial lineation indicating ofthe-dome sliding of strata; 5) A lineation pointing away from the center of the intrusion may be developed related to magmatic flow fabric; 6 ) The outer rim of the intrusion may show a zone of extensively deformed rocks of both, granitoid and surrounding rocks; 7) Measured strain ellipses indicate flattening strain as well as upward movement of the magma (prolate strain ellipsoids). 
Dyking emplacement of magma more describes the ascent of magma than the actual emplacement. During dyking, magma ascends via open cracks or fractures (Paterson, 1996) into the area of final emplacement with the main driving force for the magma being buoyancy. The final emplacement of the pluton is either as a dyke, a sill or a laccolith (see Fig. 1.2). A common feature of this emplacement mechanism is the great lateral extent versus limited thickness of the finally constructed body. The driving force of magma is usually its buoyancy; overpressuring of magma may also occur but needs a constant open pathway between the overpressured source and final site of the dyke (Paterson, 1996).

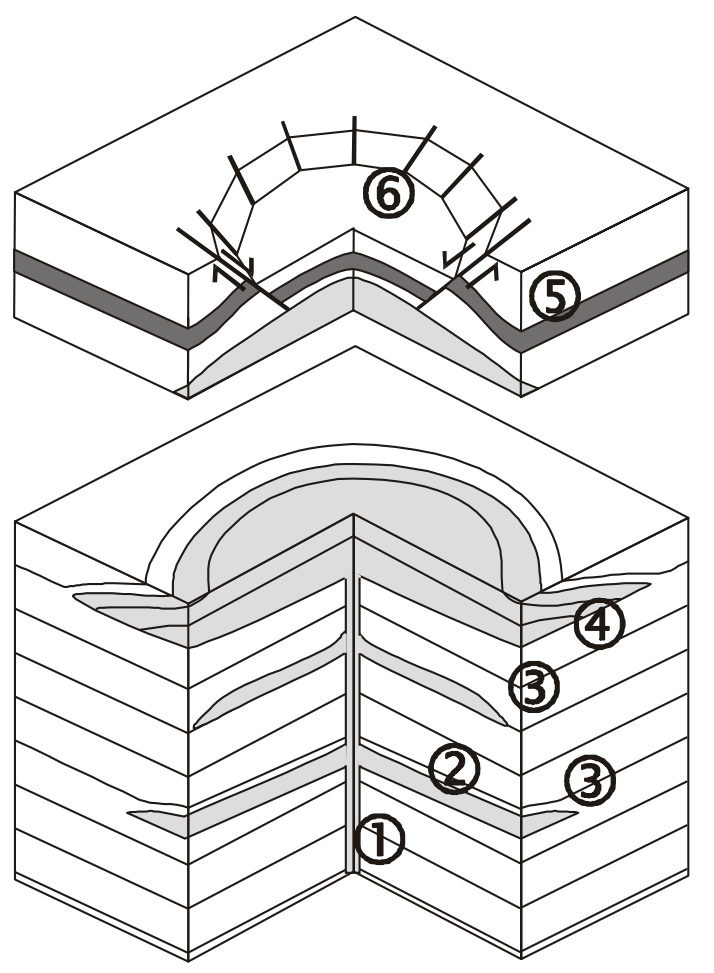

Fig. 1.2: Laccolith-like emplacement of magma fed by a dyke-like conduit. 1) Feeder dyke; 2) Surrounding rocks are only deformed in the contact area of laccolithic bodies and more than one laccolith may form from the same feeder dyke; 3) Surrounding rocks outside the direct contact area remain undisturbed; 4) Laccolithic bodies may form from a set of magma pulses giving rise to a layered, sheet-like intrusion; 5) Rocks on top of the intrusion may be lifted; 6) Due to the uplift of the surrounding rocks a central graben may form.

Fracture propagation and therefore magma ascent during dyking may stop or change direction at the level of neutral buoyancy, if a very ductile zone is intersected, stress barriers (e.g. large horizontal compressive stresses) are encountered or a free slipping surface is reached (Paterson, 1996). A well known feature of (small) natural dykes is the marked absence of contact metamorphic zones. This indicates that the cooling rate is fast which in turn implies a fast magma ascent rate necessary to keep the ascent path open for further magma injection (Cory, 1998, Paterson, 1996). During ascent, Marsh (1982) predicts that 
xenoliths are carried up with the ascending magma since they do not have enough time to settle or sink down to lower levels of the dyke.

Experiments performed by Roman-Berdiel et al. (1995) on the laccolith-like emplacement of magmas showed a linear relationship between the shape (thickness) of the intrusion and the thickness of the overburden (which can be correlated with the intrusion depth) (see. Fig. 1.3). According to the amount of intruded material they found a fluent transition between sill-like forms of the intrusion to a lens-shaped laccolith and finally a bell-shaped laccolith.

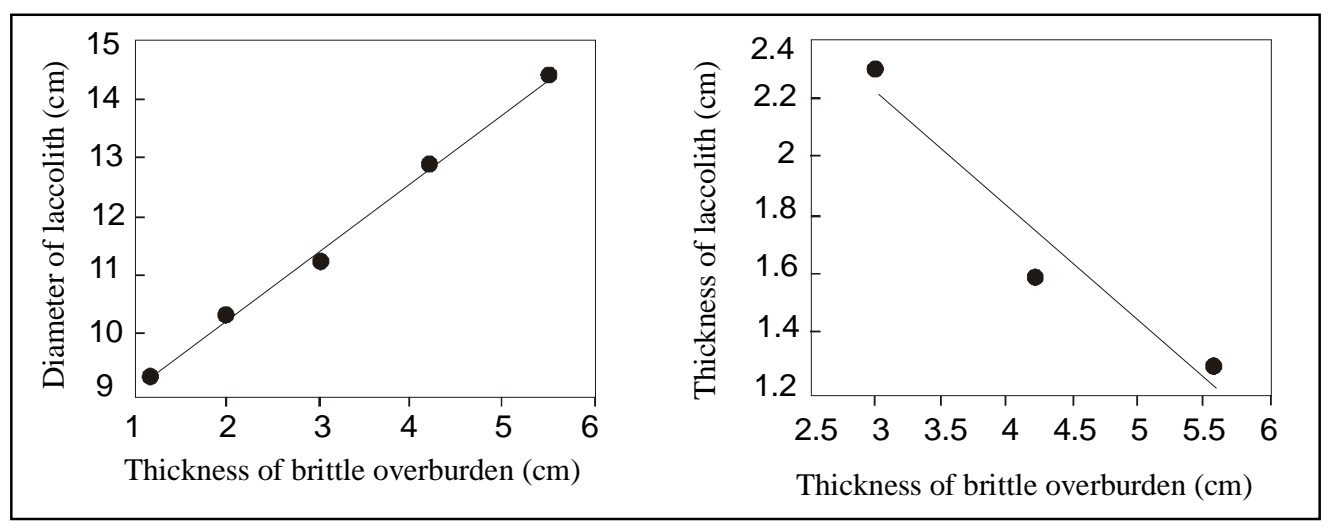

Fig. 1.3: Experiments performed by Roman-Berdiel et al. (1995) on the laccolith emplacement revealed a linear connection between the diameter and the thickness of a laccolith and the thickness of the overburden (intrusion depth). Experiment parameters have been chosen so that $1 \mathrm{~cm}$ in the experiment is $1 \mathrm{~km}$ in nature.

The formation of the different intrusions can be correlated with the thickness of the overlying burden and hence with the intrusion depth. The greater the total thickness of overburden the more the intrusion tends to form thin sills rather than thick laccoliths. According to the rheology of the overburden basically two different types of laccoliths exists, punched laccoliths and domed laccoliths (Cory, 1998; Roman-Berdiel et al., 1995). Punched laccoliths only show small deformation of their overburden but large-scale shear zones develop at or near the periphery of the intrusion site. Field characteristics of a punched laccolith are a flat top, steep sides and peripheral faults. This type of laccolith forms when the overburden has an elastic-plastic behavior (Cory, 1998). Domed laccoliths do not show the peripheral faults; overlying strata are continuous over the laccolith and may be strongly deformed. If doming continues, a graben may form in the overburden. According to Cory (1998) a continuum exists of possible shapes between these two end members. 


\subsection{Former work on the Chinamora Batholith}

In the last 50 years different workers have investigated or reinvestigated the structural patterns, geochemistry and age relationships of the Chinamora Batholith and the enveloping greenstone belts. The first publication came from MacGregor (1951) who developed his theory of "gregarious batholiths" in this area. In this theory the relationship between plutons and surrounding greenstone belts is explained by a poly-phase deformation and diapiric intrusion of granitoid batholiths into the more dense greenstone sequences. More recent work was done by Snowden and coworkers (Snowden \& Bickle, 1976, Snowden \& Snowden, 1979 \& 1981 and Snowden 1984).

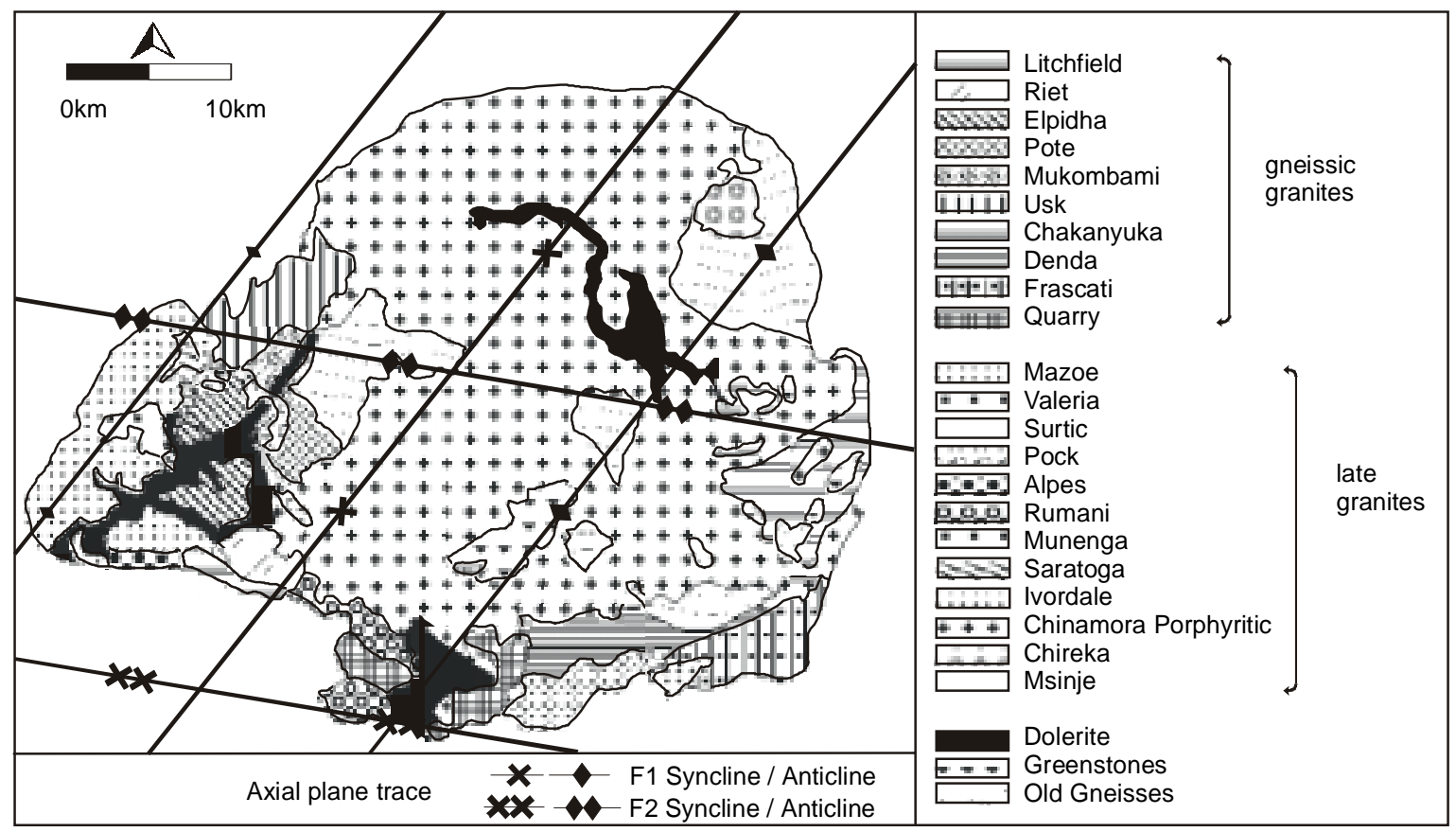

Fig. 1.4: Lithologies of the Chinamora Batholith and trace of proposed axial planes according to Snowden \& Bickle (1976). Since the folds extend into the surrounding greenstone belts and other granitoids the actual folding mechanism can not be related to the ascent and emplacement of magma.

Based on an extensive re-mapping of the Chinamora Batholith and the study of deformational successions (determined from veins of porphyritic granite intruding large xenoliths of greenstones) Snowden \& Bickle (1976) divided the Chinamora Batholith into 23 different granitoid lithologies that have been grouped into old gneisses, gneissic granites and late granites (see Fig. 1.4). Snowden \& Bickle (1976) proposed a complex deformation history for the granitoid rocks leading to 
interference folding around north-east $\left(F_{2}\right)$ and later west-north-west $\left(F_{3}\right)$ striking axial planes (see Fig. 1.4). According to their work this intense deformation would lead to the observed dome-and-basin configuration due to the competence contrast of granitoid rocks and greenstone material. They claimed that the observed deformation occurred after the intrusion of the youngest granites. Hence, this interference folding does not explain the actual ascent mechanism of the granitoid rocks but rather concentrates on tectonic events after their emplacement. Snowden \& Snowden (1979) give several arguments for the central porphyritic granite being sheet like: (i) nowhere is the porphyritic granite exposed below an elevation of $1100 \mathrm{~m}$, (ii) the inclusions of greenstone belt material and gneissic granites that exhibit a foliation oblique to the phenocryst alignment in the porphyritic granite only occur below a certain elevation, (iii) many valleys in the outcrop area of the porphyritic granite are entirely underlain by gneissic granites and various greenstone belt inclusions and (iv) the observed interference fold pattern could not have been produced in a granite extending indefinitely at depth. According to their age relationships, xenolith abundances and grain size the old gneisses and the gneissic granites are interpreted to represent multiple smallscale intrusions rather than one large diapiric intrusion. Based on this assumption Snowden \& Snowden (1979) conclude that the deformation in the greenstone belts can not solely result from the intrusion of the granitoid rocks but that another mechanism of deformation (interference folding, Snowden \& Bickle, 1976) has added to the deformation arising from ascent and emplacement of the granitoid rocks and therefore plays an important role in the formation of the granitegreenstone terrain. Caused by this external, directed stress the conspicuous microcline alignment in the porphyritic granite occurred during shearing of the crystal mush. Four directions of nearly vertical fracture systems were recognized by Snowden \& Snowden (1979) with the principal directions of $15^{\circ}, 115^{\circ}, 160^{\circ}$ and $50^{\circ}$. The fracture set with principal directions of $15^{\circ}$ is related to the formation of the Great Dyke, some $70 \mathrm{~km}$ west of the batholith, while the remaining three sets are related to the $F_{3}$ folding. From this field evidence they conclude that the simple model of gregarious batholiths can not be applied to the Chinamora Batholith. Their model sees the ascent of a granitoid crystal mush through fractures into the upper crust followed by the ascent of the central porphyritic granite. During emplacement of the sheet-like, porphyritic granite externally induced stress leads 
to the observed folding around $F_{2}$ and $F_{3}$ fold axes which are coeval with the formation of the fracture system of the Great Dyke to the west and therefore rather reflect a regional than an emplacement induced "short-range" stress field. Based on geochemical studies and former structural observations, Snowden \& Snowden (1981) established a model for the intrusion history and the development of the observed granite-greenstone terrain in the area of the Chinamora Batholith. As a first stage in the evolution of the Chinamora igneous suite, major mantle perturbations caused extensive addition of magma from the mantle to the crust. Part of this magma was erupted and contributed to the formation of the greenstone sequence. The remaining magma in the magma chamber fractionated and produced the first of the gneissic granites. Partial melting of sialic crustal rocks occurred and contaminated the magma, giving rise to the tonalite and trondhjemite plutons that intruded the earlier erupted volcanic sequence. Addition of magma and raising of the thermal gradient caused regional metamorphism which in turn lead to dehydrating reactions and an increase in $\mathrm{pH}_{2} \mathrm{O}$. The higher fluid content may have given rise to the ascent and emplacement of the gneissic granites. The fact that large amounts of fluids have been generated is, according to Snowden \& Snowden (1981), also indicated by the explosive nature of the volcanic sequence surrounding the granitoid rocks. The late granites (mainly porphyritic granite) were intruded at a later stage triggered by a second thermal event.

Ramsay (1989) divided the granitoid rocks of the Chinamora Batholith into 4 different units: (i) tonalite, (ii) granodiorite, (iii) central adamellite and (iv) western adamellite (see Fig. 1.5). The intrusion sequence was established according to structural relationships from xenoliths and along contact areas of the different intrusions from i-iv. In his study, Ramsay (1989) mainly refers to strain measurements of $2 \mathrm{D}$ exposed xenoliths assuming $\mathrm{X}: Z=\mathrm{Y}: Z$. From these measurements Ramsay (1989) calculated the ellipticity of the finite strain ellipsoids. The resulting oblate strain ellipsoids (see Fig. 1.5) showed moderate to high strains in the tonalite, low to moderate stains in the adamellite and low strains in the western adamellite (granodiorite is not explicitly stated in the publication but according to a strain variation map shows low strains only). From these strain measurements and the general absence of linear fabrics he concludes a ballooning inflation of the Chinamora Batholith since an "...upward flow of magma 
against fixed walls would produce ellipsoids more in accord with simple shear..." (Ramsay, 1989).

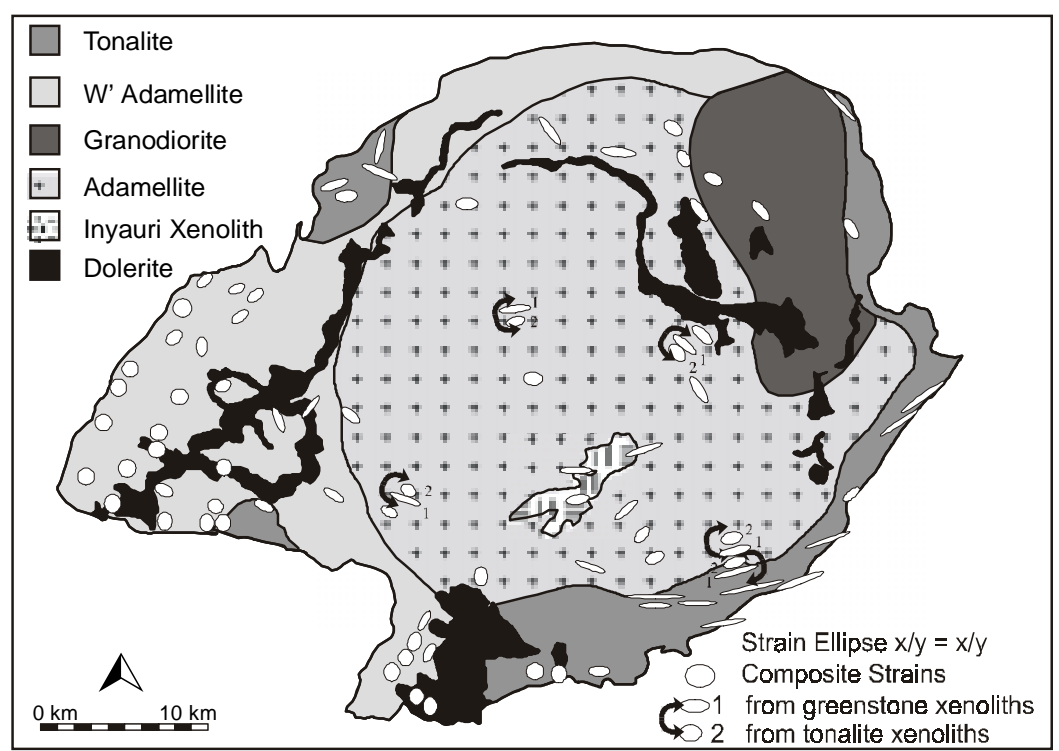

Fig. 1.5: Ramsay (1989) divided the Chinamora Batholith into the shown rock suites. From the performed strain measurements he concluded a ballooning emplacement of the Chinamora Batholith.

As a result of the intrusion of the central adamellite the already consolidated tonalitic skin and the adjacent granodiorite were stretched. This stretching has caused the formation of ductile shear zones that are common in the outer parts of the batholith but scarce in the central adamellite. According to Ramsay (1989) these shear zones reflect the maximum extension due to inflation of the already consolidated outer parts of the batholith.

Jelsma (1993) investigated structures, metamorphic conditions and geochemistry in the surrounding greenstone belt and the northern margin of the Chinamora Batholith and reinvestigated the strain measurements performed by Ramsay (1989). He found a radial, gently dipping lineation in the surrounding greenstone belts and kinematics indicating off-the-dome sliding of the strata. Foliation planes in the surrounding greenstones dip away from the batholith center. The overall form of the greenstone succession is estimated as a tri-cuspate synform with younger sediments towards the center of the syncline. Strain measurements in the contact area of the greenstone belt revealed strain-types of triaxial flattening; strain measurements inside the batholith were largely adopted from Ramsay (1989; see Fig. 1.5). On the basis of these strain measurements and the observed 
fabric in the contact area Jelsma (1993) proposed a diapiric rise of the magma rather than a ballooning of the magma chamber.

The different strain type results from Ramsay (1989) and Jelsma (1993) led to a somewhat contrary interpretation of the emplacement mechanism of the Chinamora Batholith. While Jelsma (1993) calculated strain ellipsoids originated from triaxial flattening Ramsay (1989) measured ellipsoids indicative for pure flattening strain. These contrasting measurements are explained by Jelsma (1993) by a combination of diapirism and ballooning of the pluton. Ramsay (1989) stated a small amount of diapirism in his model of the emplacement mechanism of the Chinamora Batholith without further explanations.

The fact that the deformation of greenstone belts mainly is related to the emplacement of granitoid batholiths is a generally accepted model, at least for the area of the Chinamora Batholith (Blenkinsop et al., 1997). The amount of batholiths wrapped around by greenstone belts in the Zimbabwe craton and their comparable ages suggests that the origin and ascent of the granitoid magmas has been triggered by some large-scale event during the formation of the Zimbabwe craton (Blenkinsop et al., 1997). Still the formation of the craton is not yet well constrained. 


\section{Geology and evolution of the Zimbabwe Craton}

The evolution of Archean cratons still is subject of an ongoing discussion. Amongst others, Wilson (1979), Ramsay (1989) and Jelsma et al. (1993) interpreted the greenstone belts of the Zimbabwe Craton (see Fig. 2.1) as riftrelated sequences deposited on continental crust with deformation of the strata caused by the diapiric or ballooning emplacement of granitoid rock suites. Another way of producing archean crust is through horizontal accretion of terranes involving remnant oceanic crust or island-arc material that amalgamated with continental fragments during subduction (Kusky \& Kidd, 1992). Prominent examples for this type of formation are the Superior Province and the Kaapvaal Craton (Card, 1990; deWit, 1982).

The Archean Zimbabwe Craton shows numerous elliptical granitic bodies which are surrounded by greenstone belts (see MacGregor, 1951). The different ages of the lithologies point to a crustal evolution which came to a halt $2.6 \mathrm{Ga}$ ago (Jelsma, 1993). The different events during the crustal evolution include crustal growth, volcanism, emplacement of granitoid intrusions and deformation and metamorphism of the existing rocks (Jelsma et al., 1993). In the following, some of the main events and their rocks are shortly described.

The Tokwe Segment in the south of Zimbabwe probably reflects the first major event that contributed to crustal evolution. This $3.5 \mathrm{Ga}$ old rock formation mainly consists of tonalitic to granodioritic gneisses and closely folded remains of a greenstone belt (Sebakwian Group; Wilson, 1979). Wilson (1979) interpreted this segment as an independent terrain. Detrital zircons that have been dated at 3.8 $\mathrm{Ga}$ in gneissic tonalites and granodiorites and at $2.7 \mathrm{Ga}$ in sediments (Dodson et al., 1988) give evidence of the existence of sialic crust before the formation of the Tokwe Segment.

Most of the present remains of late Archean greenstone belts have been assigned to the second event that is also characterized by the ascent of tonalitic to granodioritic magma (e.g. Wilson, 1979; Taylor et al., 1991). The greenstone belts of this event have been divided into a lower and upper greenstone sequence, the latter sequence has been subdivided into an eastern and western succession (Wilson, 1979). Both show a basal sequence of sediments that are overlain by basalts but the further development of the western and eastern succession is 
different (Jelsma et al., 1993). While the western succession shows a bimodal series of mafic to felsic volcanics capped by andesites the eastern succession is sedimentary in nature with intercalations of tholeiitic basalts (Baldock, 1991). The calc-alcaline, volcanic rocks of the western succession can not be observed in the eastern succession. The upper greenstones are overlain by the Shamvaian Group comprising clastic sediments (Balodock, 1991; Jelsma, 1993).

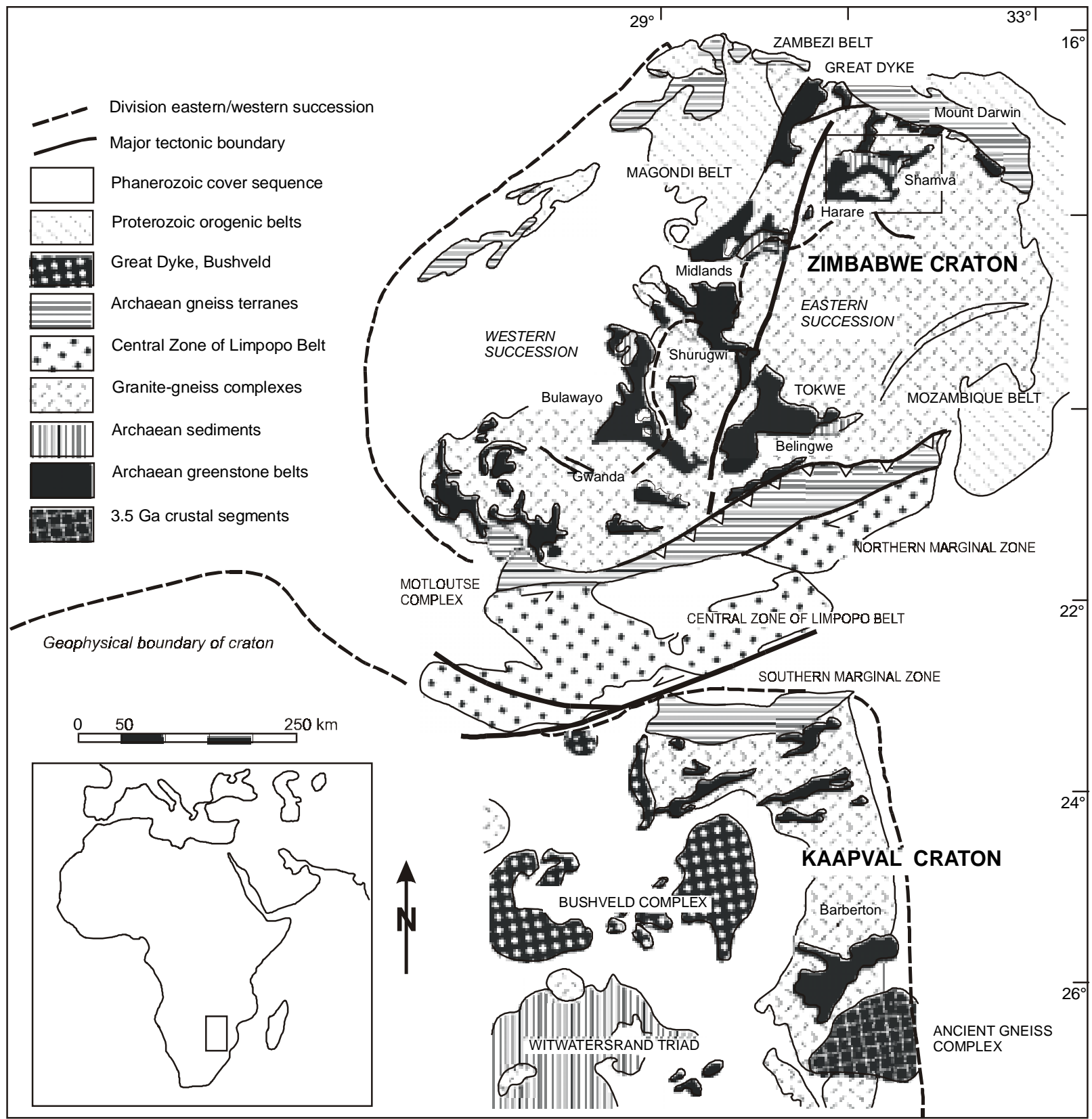

Fig. 2.1: Overview of the regional geology of the Zimbabwe Craton. See text for explanations

During the late Archean huge granitoid complexes were formed which can be divided on the basis of their age coherence into 3 different units: (i) Chingezi suite 
(approx. $2.9-2.8 \mathrm{Ga}$ ), (ii) Sesombi suite $(2.65-2.6 \mathrm{Ga})$ and (iii) Chilimanzi suite (approx. 2.6 Ga) (Baldock \& Evans, 1988; Taylor et al., 1991).

By far the most important Proterozoic intrusion is the Great Dyke (approx. 2590 Ma, Mukasa et al., 1998) and the numerous dykes and sills of the Mashonaland Igneous events (approx. 1.9 Ga; Wilson et al., 1987). The intrusion of the $600 \mathrm{~km}$ long Great Dyke gives evidence that the craton was stabilized at the time of intrusion (fractures can only propagate in rigid mediums). Other dykes are of Proterozoic or Phanerozoic age such as the Karoo swarm (200 - $170 \mathrm{Ma})$. This dyke event is probably linked to the break-up of Gondwana Land (Wilson et al., 1987).

The Archean Limpopo belt separates the Zimbabwe and Kaapvaal cratons. The orogenic phase of this belt occurred between 2.7 - 2.6 Ga (Wilson, 1979). The Limpopo belt is divided into a north and south marginal zone and a central zone (see Fig. 2.1). The marginal zones comprise gneisses, granulites and granites while the central zone mainly comprises supracrustal units (Beitbridge complex) (Cox et al., 1965; Mason, 1973).

In the following section, the different rock types of the Chinamora Batholith and the surrounding greenstone belts are described.

\subsection{The Harare Shamva greenstone belt}

The late Archean $(2.75-2.65 \mathrm{Ga})$ Harare-Shamva greenstone belt is wrapped around the Chinamora Batholith and frames part of other neighboring batholiths as well (Chiweshe, Madziwa, Murehwa, Harare and Zvimba batholiths). The greenstones are part of the western succession of the Upper Greenstones in the Archean Zimbabwe craton. The basal Bulawayan Group is $6-10 \mathrm{~km}$ thick and is overlain by the approx. $2 \mathrm{~km}$ thick Shamvaian Group (e.g. Jelsma \& Dirks, 2000). Both groups have been divided into several formations which are described below.

\subsubsection{Upper Bulawayan Group}

The basal formation of the Upper Bulawayan Group is the Iron Mask Formation, which structurally overlies the granitoid rocks of the Chinamora Batholith. The Iron Mask Formation comprises (rhyo)dacites and interbanded horizons of andesites 
(Baldock, 1991). Layers of banded iron stone and iron-bearing quartzite, arenite, wacke, chert, marbles and mafic rocks are also intercalated. According to Jelsma (1993) conglomerate horizons in the Iron Mask Formation contain pebbles ranging in composition from tonalite to granodiorite without any granitoids with gneissic fabrics. This implies that the pre-greenstone granitoids were not affected by any deformation before the deposition of the greenstone sequences.

The northern and western parts of the Chinamora Batholith are in direct contact to the Iron Mask Formation, in the southern and eastern parts outcrops of this formation are scarce. Xenoliths from the Iron Mask Formation are common with the largest being the Inyauri remnant in the south-central part of the batholith. The contact between the granitoid gneisses and the Iron Mask Formation usually dips moderately away from the contact area and shows right-way-up younging directions, maximum structural thickness of the Iron Mask Formation is about $6 \mathrm{~km}$ (Jelsma, 1993; Baldock, 1991).

The Iron Mask Formation is overlain by the Arcturus Formation. It comprises a thick volcanic pile with pillowed and massive tholeiitic basalt flows (Clay, 1978). Intercalated with the volcanics are horizons of banded iron formations, ironbearing quartzite and marbles (Baldock, 1991).

In the Harare area of the Chinamora Batholith the Arcturus Formation is overlain by graphitic argillites (Mt. Hampden Formation), felsic volcanics and volcanoclastic sediments (Passaford Formation) (Jelsma, 1993; Baldock, 1991; Clay, 1978). In the northern part of the Harare-Shamva greenstone belt this formation does not occur but tholeiitic basalts that are similar to the Arcturus Formation have been recognized by Jelsma (1993). These basalts are associated with different structural markers and hence have not been correlated with the Arcturus Formation. This formation is termed the Mungari Formation which includes the Maparu Formation (Baldock, 1991).

\subsubsection{Shamvaian Group}

The lithologies of the Upper Bulawayan Group are unconformably overlain by siliciclastic sediments of the Shamvaian Group (Jelsma, 1993). The contact 
between the Upper Bulawayan Group and the Shamvaian Group is an angular unconformity and usually tectonically disturbed (Jelsma, 1993).

The lower part of the Shamvaian Group is characterized by a polymict conglomerat horizon with pebbles and boulders of granitoid composition. This unit grades into an intercalation of coarse to massive arenites and conglomerates (Jelsma et al., 1993).

\subsection{Structures and deformation in the Harare-Shamva greenstone belt}

Deformation in the Harare-Shamva greenstone belt has been assigned by Jelsma et al. (1993), Dirks \& Jelsma $(1998 a+b)$ and Jelsma \& Dirks (2000) to different deformational events termed $D_{1}$ to $D_{3}$. These different events gave the HarareShamva Greenstone belt a tricuspate synform with the youngest sediments in the middle of the syncline (see Fig. 2.2).

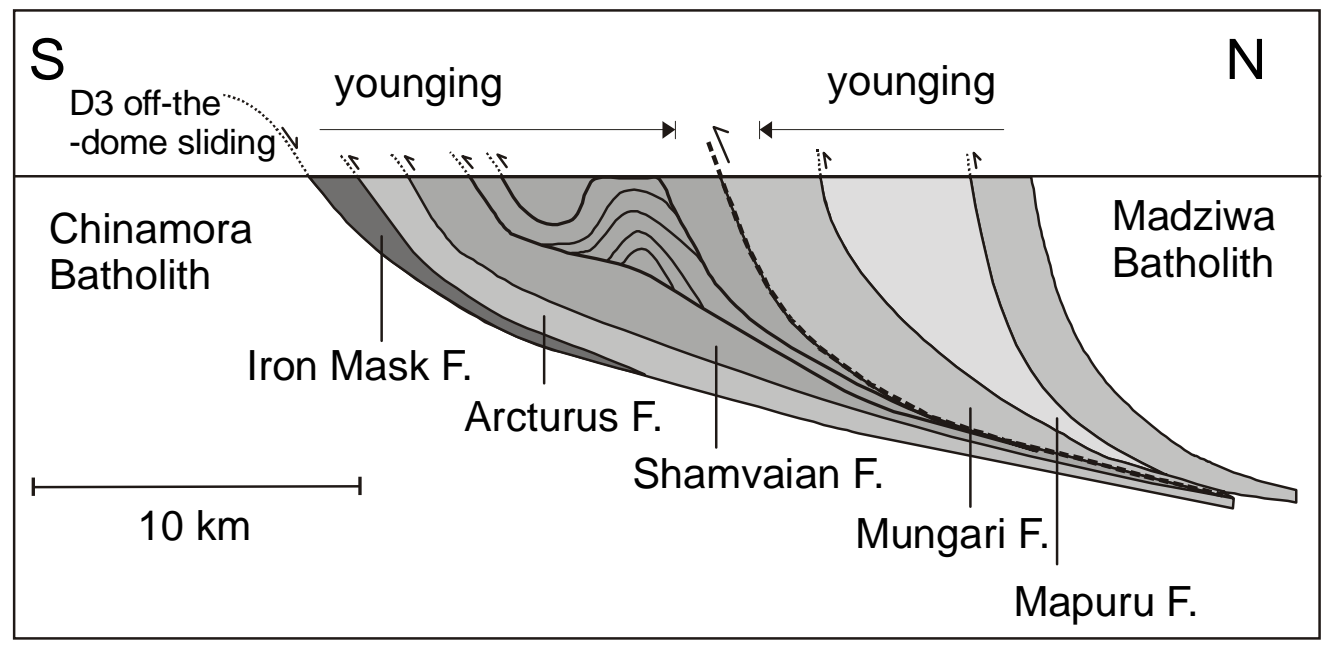

Fig. 2.2: The ascent and emplacement of the Chinamora Batholith has folded the overlying sediments into a tricuspate synform. Younging directions from the contact area towards the center of the syncline are typical. Next to the internal folding and thrusting the last event was an off-thedome-sliding of the strata from the ascending batholith (taken from Dirks \& Jelsma 1998a).

Structures of theses events are described below.

$D_{1}$

The earliest deformation resulted in a pervasive, layer-parallel schistosity $\left(S_{1}\right)$. A mineral lineation $\left(L_{1}\right.$, see Fig. 2.3) is developed, shallowly plunging to the $W$ or $E$ (Jelsma et al., 1993). $D_{1}$ affects all greenstone lithologies and is related to the tectonic stacking of the greenstone sequences. Therefore, this deformational 
event must have taken place before the intrusion of the large batholiths (Jelsma \& Dirks, 2000).

$\mathrm{D}_{2}$

Around the Chinamora Batholith the most prominent characteristic of the $D_{2}$ event is a marginal $S_{2}$ foliation and $L_{2}$ mineral lineation that overprints $S_{1} / L_{1}$ structures and plunges steeply away from the contact with the batholith. A shear zone along the margin of the batholith with a shear foliation $\left(S_{2}\right)$ which is subparallel to $S_{1}$ and the granite-greenstone contact can frequently be observed in the Iron Mask Formation (Jelsma et al., 1993). $\mathrm{S}_{2}$ dips at moderate angles $\left(20-60^{\circ}\right)$ and contains a mineral lineation $\left(L_{2}\right)$ defined by micas, hornblendes and quartz-feldspar rods (see Fig. 2.3, Dirks \& Jelsma, 1998a) that plunge away from the center of the batholith (Dirks \& Jelsma, 1998a+b; Jelsma et al., 1993). Folds indicating an offthe-dome-vergence, porphyroclasts with asymmetrically recrystallized tails and SC-fabrics indicate an off-the-dome sliding of the strata during uplift of the batholith (Jelsma, 1993). These structures are therefore related to the ascent and emplacement of the Chinamora Batholith. This is confirmed by a decreasing distinctness of the fabric away from the contact area. Furthermore, Jelsma (1993) measured triaxial flattening strains and high strain intensities in the contact area of the Harare-Shamva Greenstone Belt with the Chinamora Batholith that he related to the ascent and lateral extension of the rising granitoids during $D_{2}$.

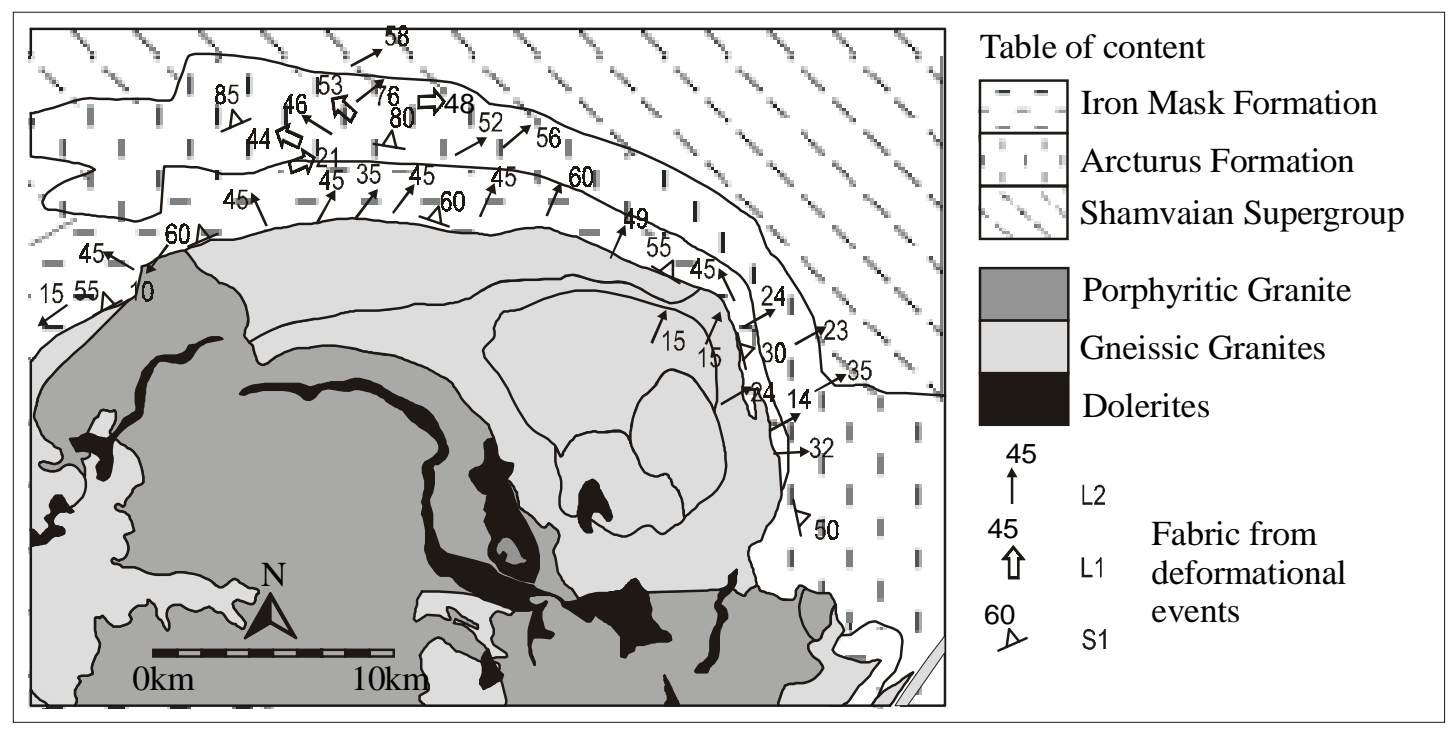

Fig. 2.3: Structural pattern from the different deformational events in the Chinamora Batholith. $L_{2}$ lineation dips away from the contact area while $L_{1}$ and $S_{1}$ roughly parallels the batholith margin (modified from Dirks \& Jelsma, 1998a). 
$D_{3}$

The schistose $D_{1}$ shear zones have been reactivated as near-horizontal faults producing slickenlines and striations with small amounts of mainly sinistral displacements. This faulting was accompanied by brecciation of the competent units such as tectonically disturbed banded iron formations (Jelsma \& Dirks, 2000; Dirks \& Jelsma, 1998a).

\subsection{Chinamora Batholith}

As stated earlier the above described successions surround the granitoid rocks of the Chinamora Batholith. This composite batholith has a roughly ellipsoidal shape and can be

divided into numerous different small-scale lithologies (see Snowden \& Bickle, 1976; Snowden \& Snowden, 1979; Fig. 1.4). In this work these lithologies have been grouped, based on their age coherence and structural patterns, into the southern, western and northern gneissic granites, the porphyritic granite and the equigranular granites (see Fig. 2.4).

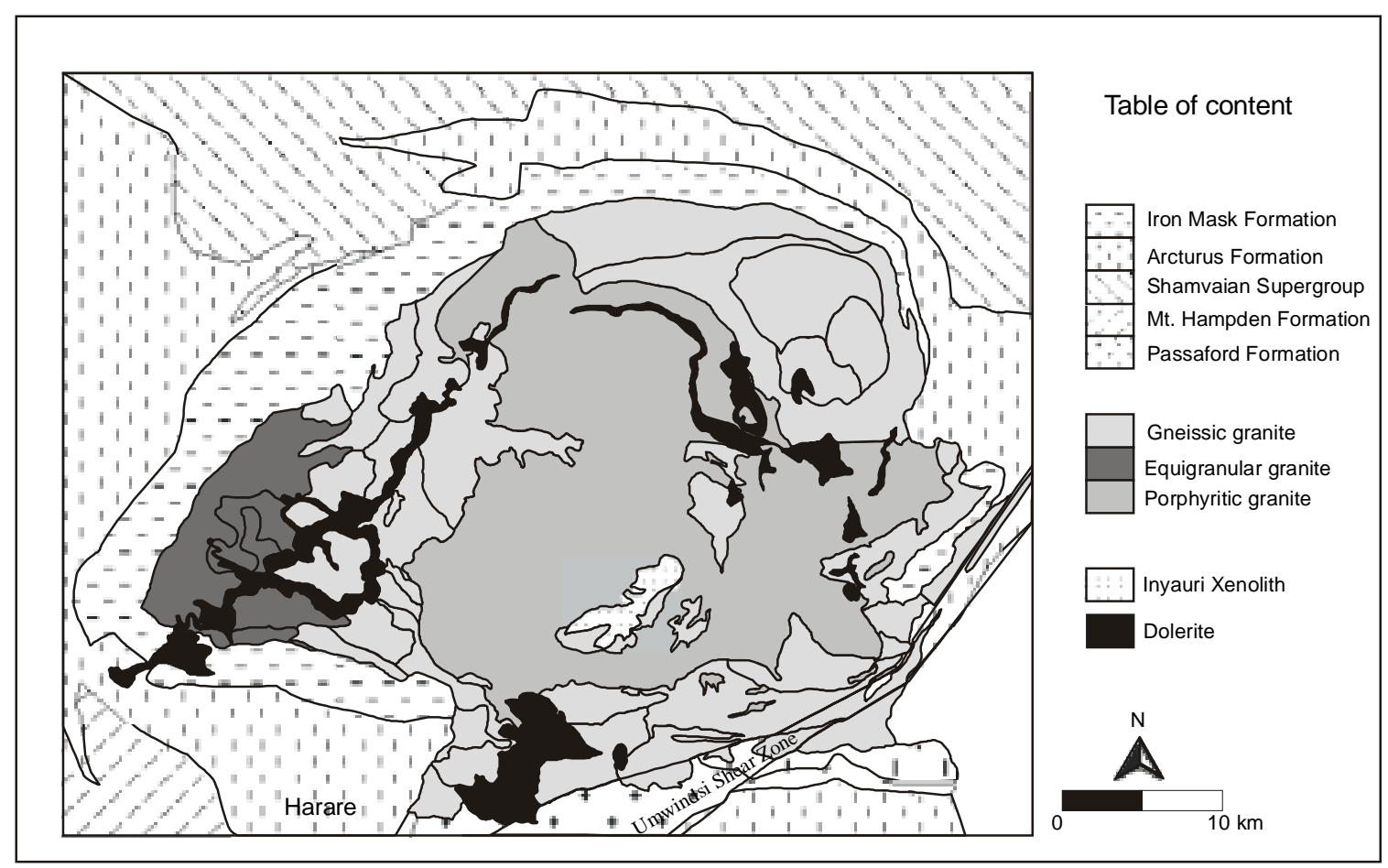

Fig. 2.4: Chinamora Batholith with its main lithologies. The marginal gneissic granites usually are strongly deformed while the central porphyritic granite shows nearly no internal deformation. 
According to Jelsma (1993) the syn-tectonic gneissic granites can be grouped into the Wedza cycle which are granitoids named after the Wedza type locality showing a compositional variation ranging from early tonalite-trondhjemite to later granodiorite and granite. The equigranular granites and porphyritic granite show strong similarities with the Chilimanzi granites in the southern part of the Zimbabwe craton that are potassic and characterized by a low mafic mineral content (Jelsma, 1993). The possible basement gneisses, as described by Snowden (1976), in the erosional windows of the porphyritic granite have been assigned to the gneissic granites. Only in the south-eastern part of the batholith in the area of the Umwindsi Shear Zone are these basement gneisses visible. A detailed description of the different lithologies and their structures is given in chapter 4.

\subsection{Age data of the Chinamora Batholith}

Age data of the different lithologies of the Chinamora Batholith is limited. Baldock \& Evans (1988) dated banded gneisses from the western margin of the Murhewa Batholith (east of the Chinamora Batholith) at $2865 \pm 135 \mathrm{Ma}$ (Rb/Sr, whole rock) and gneissic granites of the eastern margin of the Chinamora Batholith at $2680 \pm$ 102 (Rb/Sr, whole rock). Jelsma et al. (1996) dated these gneisses at $2667 \pm 4 \mathrm{Ma}$ (U-Pb, zircons). Internal granodiorites and tonalites in the greenstones related with the equigranular granites have been dated at $2664 \pm 15 \mathrm{Ma}$ (Mazowe), $2649 \pm 6$ Ma (Bindura) and $2618 \pm 6 \mathrm{Ma}$ (Glendale) (Jelsma et al., 1996), host rocks to the granodiorites of the Mazowe area have been dated at $2643 \pm 8$ Ma (should be older than the internal granodiorites, date from Wilson et al., 1995). For the porphyritic granite in the center of the batholith an age of $2601 \pm 14$ Ma was dated from Jelsma (1993). From these age data it is apparent that the gneissic granites in the Chinamora Batholith are the oldest rocks followed from the equigranular granites and finally the porphyritic granite. However, some of the age data is not well constrained due to e.g. contrasting dating of host-rocks and internal intrusions (see Becker et al., 2000). 


\section{Geochemistry}

Geochemical analyzes on some selected samples from the Chinamora Batholith have been performed to characterize possible sources of the granitoids and their genesis. Furthermore, the geochemical analyzes were used to classify the different samples and hence the different lithologies of the batholith according to different geochemical signatures. The samples chosen for the geochemical analyzation were taken in different units throughout the Chinamora Batholith. The element content of the samples was analyzed using an inductively coupled plasma mass spectrometer (ICP-MS). A second analyzes was performed using the technique of fluorescent $x$-ray analyzes (RFA) to gain information about elements that can only poorly be measured with the ICP-MS.

\subsection{Classification of analyzed rocks}

The analyzed samples of the Chinamora batholith may be characterized according to their $\left(\mathrm{Na}_{2} \mathrm{O}+\mathrm{K}_{2} \mathrm{O}\right)$ - and their $\mathrm{SiO}_{2}$ content (TAS-Diagram of Cox et al., 1979) which is to a large extend consistent with the Streckeisen Diagram (QAPF). Most of the samples plot in the granite field, where some of the samples may be characterized as alkali granites and some as granites (see Fig. 3.1). Only a few samples plot in the diorite field. The samples cluster near the subalcaline/alcaline boundary.

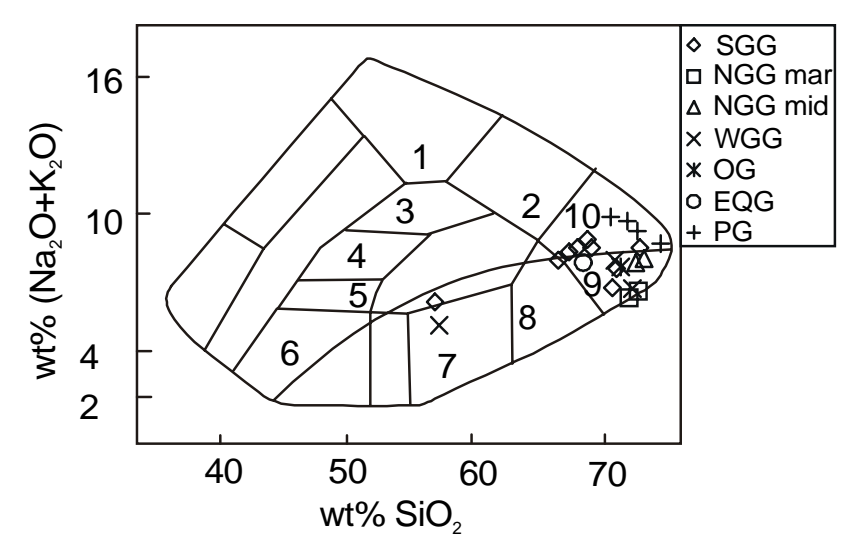

Fig. 3.1: TAS-diagram of Cox et al. (1979) used for the classification of the analyzed rock samples. Numbers are related to rock classification as follows:

1-Nepheline-syenite; 2-Syenite; 3-Syenite; 4-Syenite-diorite; 5-Gabbro; 6-Gabbro; 7-Diorite; 8-Quartz-diorite (Granodiorite); 9Granite; 10-Alkali granite. Solid line represents subalcaline/alcaline boundary.

On the trivariate plot of $\mathrm{FeO}_{\text {(tot) }}-\left(\mathrm{Na}_{2} \mathrm{O}+\mathrm{K}_{2} \mathrm{O}\right)-\mathrm{MgO}$ the samples plot close to the calc-alkaline trend (see Fig. 3.2) and follow the trondhjemitic trend of Barker \& Arth (1976). 


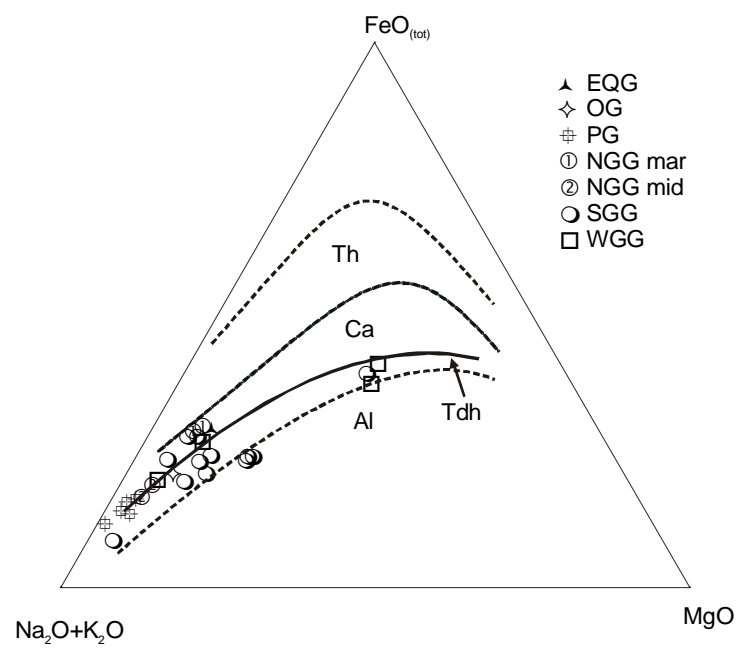

Fig. 3.2: Samples classified according to their FeO- $\left(\mathrm{Na}_{2} \mathrm{O}+\mathrm{K}_{2} \mathrm{O}\right)-\mathrm{MgO}$. Th = tholeiitic, $\mathrm{Ca}=$ calc-alkaline, $\mathrm{Al}=$ alkaline (Martin 1994). The Tdh line corresponds to the differentiation trend of the standard trondhjemitic suite from Southwest Finland (Barker \& Arth, 1976). Samples plot in the calc-alkaline field on the trondhjemitic trend.

This change in composition from a trondhjemitic to a calc-alkaline trend has been assigned by Martin (1993) to the general changes of granitoids in composition with time with granitoids of $2.5 \mathrm{Ga}$ and older following a trondhjemitic trend and granitoids younger than $2.5 \mathrm{Ga}$ following a calc-alkaline trend.

According to Feng \& Kerrich (1992) synvolcanic, syntectonic and late tectonic granitoids are distinguishable according to their variations in $\mathrm{CaO} /\left(\mathrm{Na}_{2} \mathrm{O}+\mathrm{K}_{2} \mathrm{O}\right)$ vs. $\mathrm{SiO}_{2}$ (see Fig. 3.3). While most of the gneissic granites clearly plot in the range of the syntectonic series (TGGM) the samples derived from the porphyritic granite all plot in the field of the late tectonic series (SMG). This division clearly reflects the age relationships of the analyzed samples with the gneissic granites being older than the porphyritic granites.

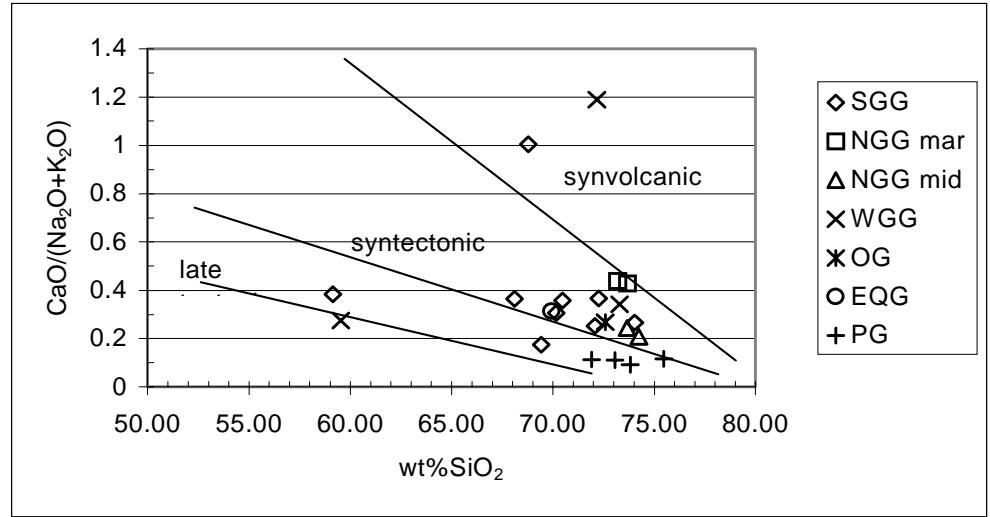

Fig. 3.3: Major element plot showing the classification of the investigated rock types as mainly syn- to late tectonic (Feng \& Kerrich, 1992). 


\subsubsection{Harker plots of major elements}

In Fig. 3.4 the major elements are presented in terms of weight percentages of the oxides versus the weight percentage of $\mathrm{SiO}_{2}$. Most of these Harker plots show a linear trend with decreasing weight percentages of oxides versus increasing $\mathrm{SiO}_{2}$ content. $\mathrm{Al}_{2} \mathrm{O}_{3}$ and $\mathrm{Na}_{2} \mathrm{O}$ only show a weak linear, negative correlation with $\mathrm{SiO}_{2}$. The porphyritic granite usually has a high $\mathrm{SiO}_{2}$ content and only low amounts of the respective oxides, only the $\mathrm{K}_{2} \mathrm{O}$-content of the porphyritic granites is much higher in comparison to the gneisses. The elevated $\mathrm{K}_{2} \mathrm{O}$-content can be explained with the very high content of $\mathrm{K}$-feldspar megacrysts present in the porphyritic granite while in the gneisses only small amounts of $\mathrm{K}$-bearing minerals are present. The linear trends shown by the gneisses on the $\mathrm{TiO}_{2^{-}}, \mathrm{Fe}_{2} \mathrm{O}_{3^{-}}, \mathrm{P}_{2} \mathrm{O}_{5^{-}}$and $\mathrm{MgO}$ versus $\mathrm{SiO}_{2}$ graphs reflects a fractionation process suggesting an evolution of the samples from the same source rather than to an origination from different sources. Jelsma (1993) assigns these linear trends to the control of titanite, ilmenite or magnetite, plagioclase, apatite and a mafic mineral (hornblende) in a crystal fractionation process. However, as Rollinson (1993) points out, it is not always possible to distinguish between the processes of fractional crystallization and partial melting. Only when the processes take place under different physical conditions they may be distinguished but such a scenario is not likely in the evolution of the magmas of the Chinamora Batholith.

The distribution of the major elements shows significant similarities (as well as differences) with partial melting experiments performed by Beard \& Lofgren (1991), Rapp et al. (1991), Rushmer (1991), Winther \& Newton (1991) and Wyllie \& Wolf (1997) on amphibolite, garnet-amphibolite and eclogite. The experimental liquids all possess uniformly high $\mathrm{Al}_{2} \mathrm{O}_{3}$-contents of $\sim 15 \%$ and $\mathrm{Na}_{2} \mathrm{O}$-contents of $\sim 4 \%$. Nevertheless a marked difference exists in the $\mathrm{K}_{2} \mathrm{O}$-content where the analyzed rock samples have contents of $1-4 \%$ in comparison with the low $\mathrm{K}_{2} \mathrm{O}$ contents of $\sim 1 \%$ in the experimental liquids. Other differences exists in the $\mathrm{TiO}_{2}$ contents of the experimental liquids which are generally higher in $\mathrm{TiO}_{2}$ than the analyzed rock samples from the Chinamora Batholith.

Despite the above described similarities it seems to be unlikely that the analyzed rock samples derived from partial melting of amphibolite or eclogite. This scenario is questionable due to the low $\mathrm{SiO}_{2}$-content of amphibolites and the high $\mathrm{Si}_{2} \mathrm{O}$ - and the low $\mathrm{K}_{2} \mathrm{O}$-content of the analyzed samples. It seems more likely that generation of these melts occurred by batch melting of a granitoid source. This is confirmed by the frequent occurrence of garnet in the gneissic granites which has not been observed in the experimentally derived melts from an amphibolite source. 

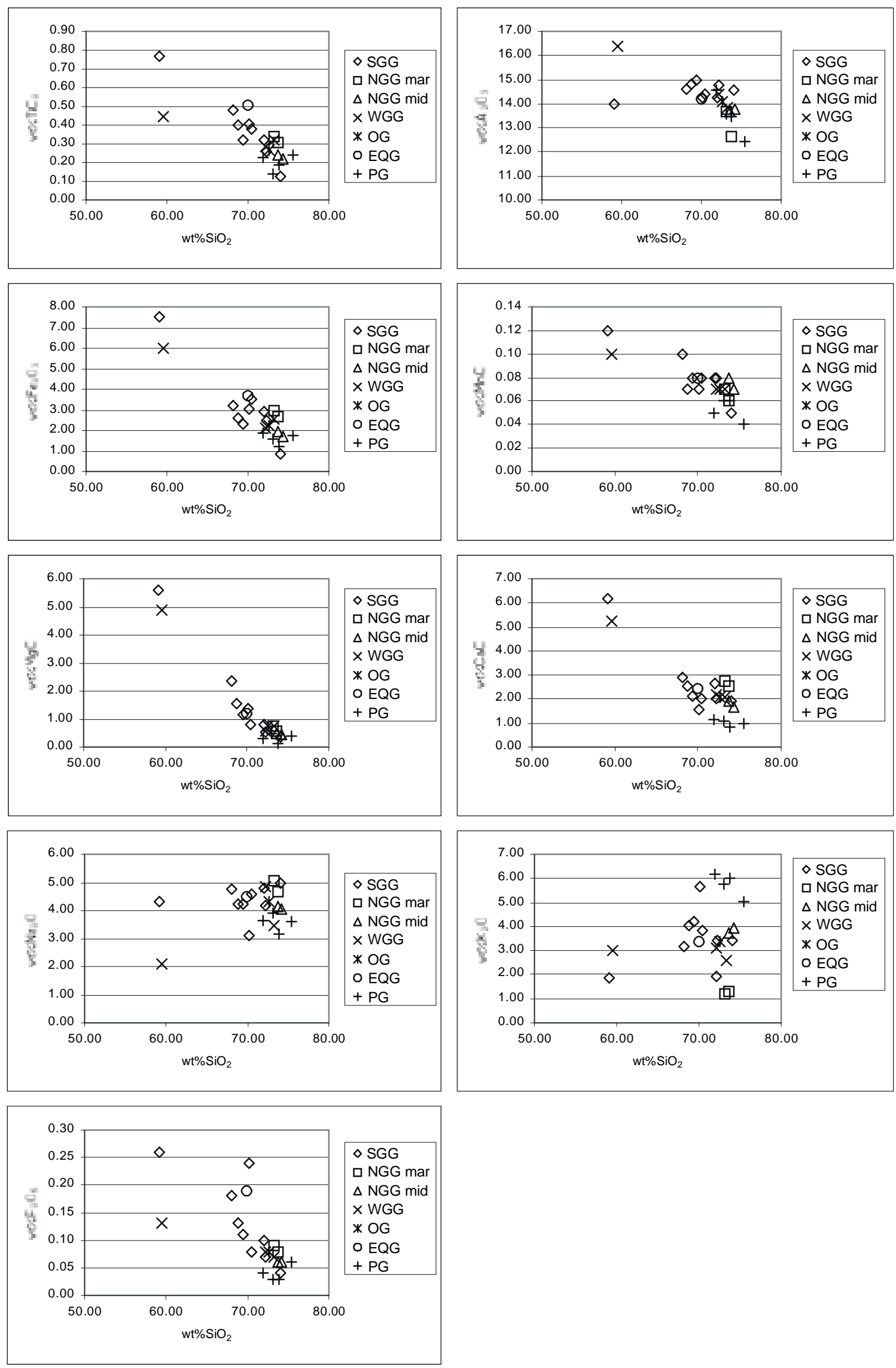

Fig. 3.4: Harker plot of major elements 


\subsubsection{Harker plots of trace elements}

Trace element correlations with $\mathrm{SiO}_{2}$ (see Fig. 3.5) show much more complex patterns than do the major elements. The large ion lithophile elements (LILE) Cs, $\mathrm{Rb}, \mathrm{Ba}, \mathrm{Pb}, \mathrm{Sr}$ and Eu show a weak negative correlation with $\mathrm{SiO}_{2}$. The porphyritic granite samples are enriched in $\mathrm{Rb}$ and $\mathrm{Pb}$. The high field strength elements (HFSE) $\mathrm{Nb}, \mathrm{Ce}, \mathrm{Zr}, \mathrm{Hf}, \mathrm{U}$ and Th generally tend to be incompatible in mafic igneous rocks (Feng \& Kerrich, 1991). It is therefore not surprising that the more evolved porphyritic granite is enriched with respect to the gneissic granites in most of these elements $(\mathrm{Hf}, \mathrm{Ce}, \mathrm{U}, \mathrm{Th})$. The gneissic granites show a negative correlation of the respective elements with $\mathrm{SiO}_{2} . \mathrm{Zr}$, Hf and $\mathrm{Nb}$ seem to be only weakly correlated with $\mathrm{SiO}_{2}$, in $\mathrm{Hf}$ a clustering of values is apparent while in $\mathrm{Zr}$ and $\mathrm{Nb}$ weak negative correlations are obvious. In general, the porphyritic granite is, compared to the gneissic granites, enriched in elements with a small ionic radius $\left(>1.6^{*} 10^{-10} \mathrm{~m}\right)$ and elements with a high ionic charge $(>4)$, namely these are the trace elements $\mathrm{Rb}$ and $\mathrm{La}, \mathrm{Ce}, \mathrm{Pr}, \mathrm{Nd}, \mathrm{Sm}, \mathrm{Gd}, \mathrm{Hf}, \mathrm{Pb}$, Th and U (LILE and HFSE respectively).

Europium anomalies (negative) are chiefly controlled by feldspars as Eu is compatible in plagioclase and K-feldspar and to a lesser extent in hornblende, sphene and garnet (see partition coefficients in Table 3.1). According to this, the gneissic granites show weakly positive Eu anomalies while the porphyritic granite exhibits strong negative Eu anomalies.

As Rollinson (1993) points out, the distribution and percentage even of accessory minerals in the rocks may influence the content of trace elements in the rock samples if their mineral/melt partition coefficients are high for the accessories but low for major rock forming minerals. Therefore, the different analyzed rock samples here can easily be recognized on the basis of the ratio of $\mathrm{Yb} / \mathrm{Gd}$ (see Fig. 3.6). Partition coefficients for $\mathrm{Yb}$ and $\mathrm{Gd}$ are given in Table 3.1. The southern gneissic granites with their high garnet, biotite and hornblende content exhibit the highest values for $\mathrm{Yb}$ and can be discriminated against the other gneissic granites which show varying contents of biotites and hornblendes while the porphyritic granite only exhibits biotite, zircon, apatite and probably small amounts of sphene. 

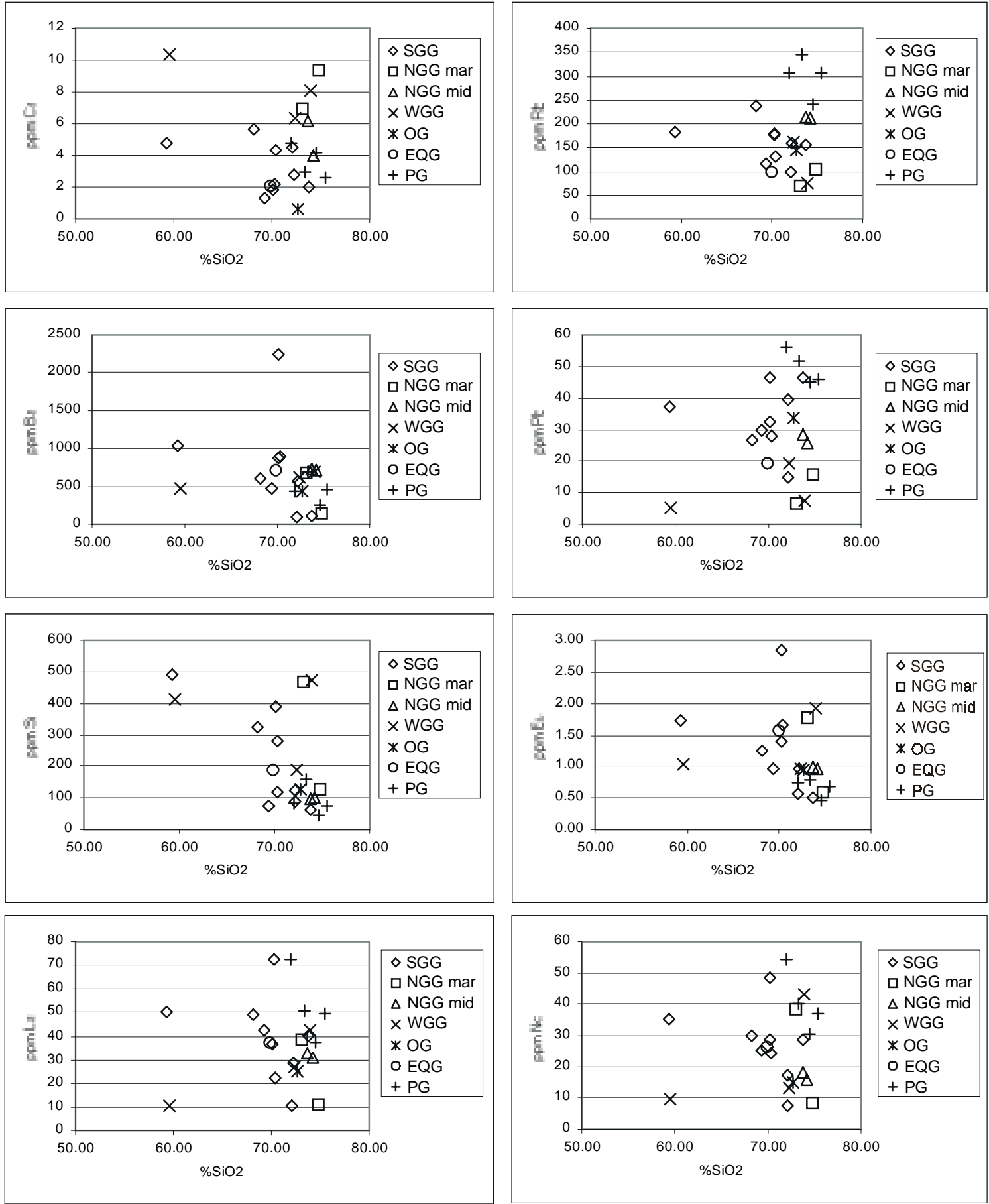

Fig. 3.5: Harker plots of trace elements. 

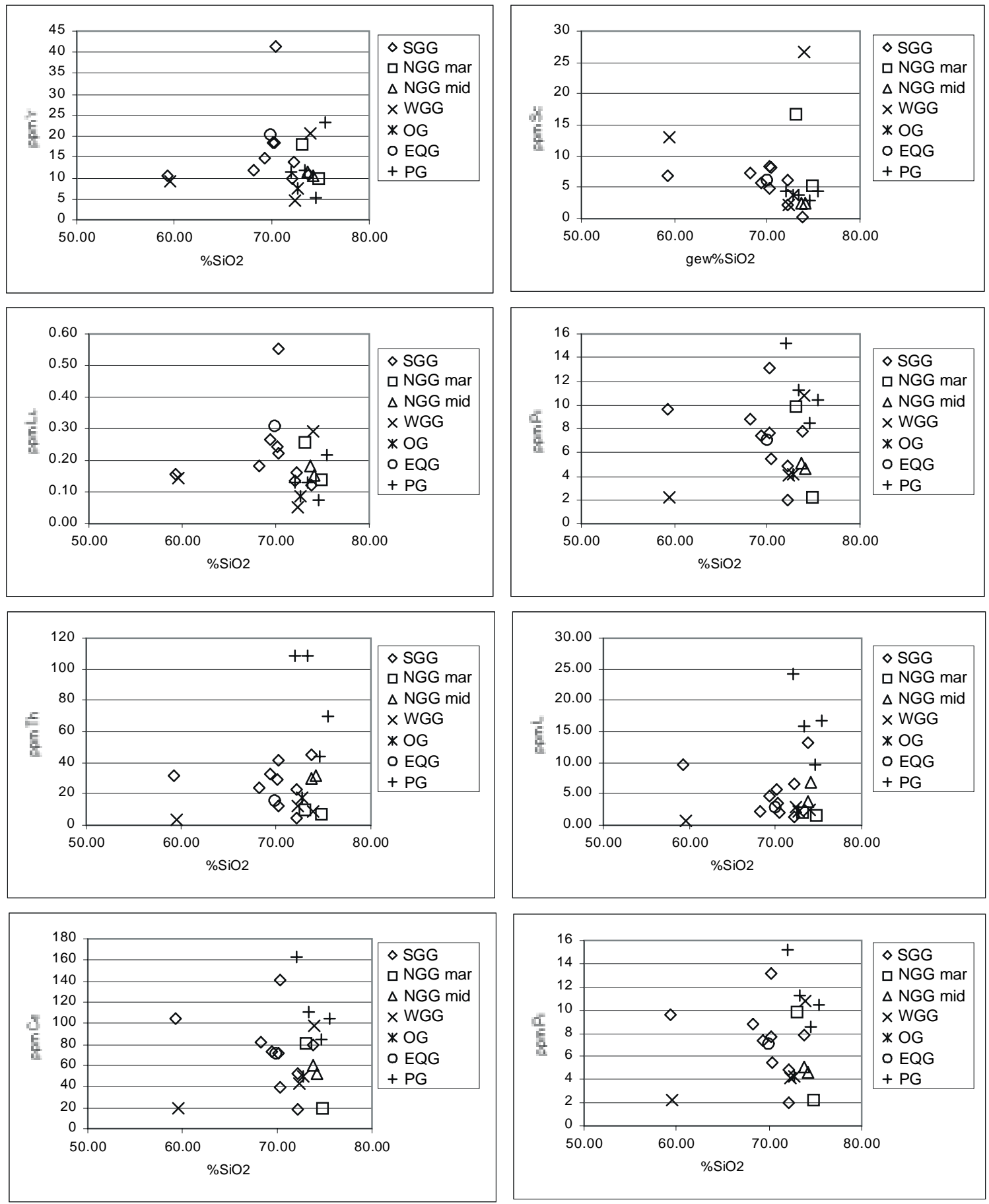

Fig. 3.5: continued 

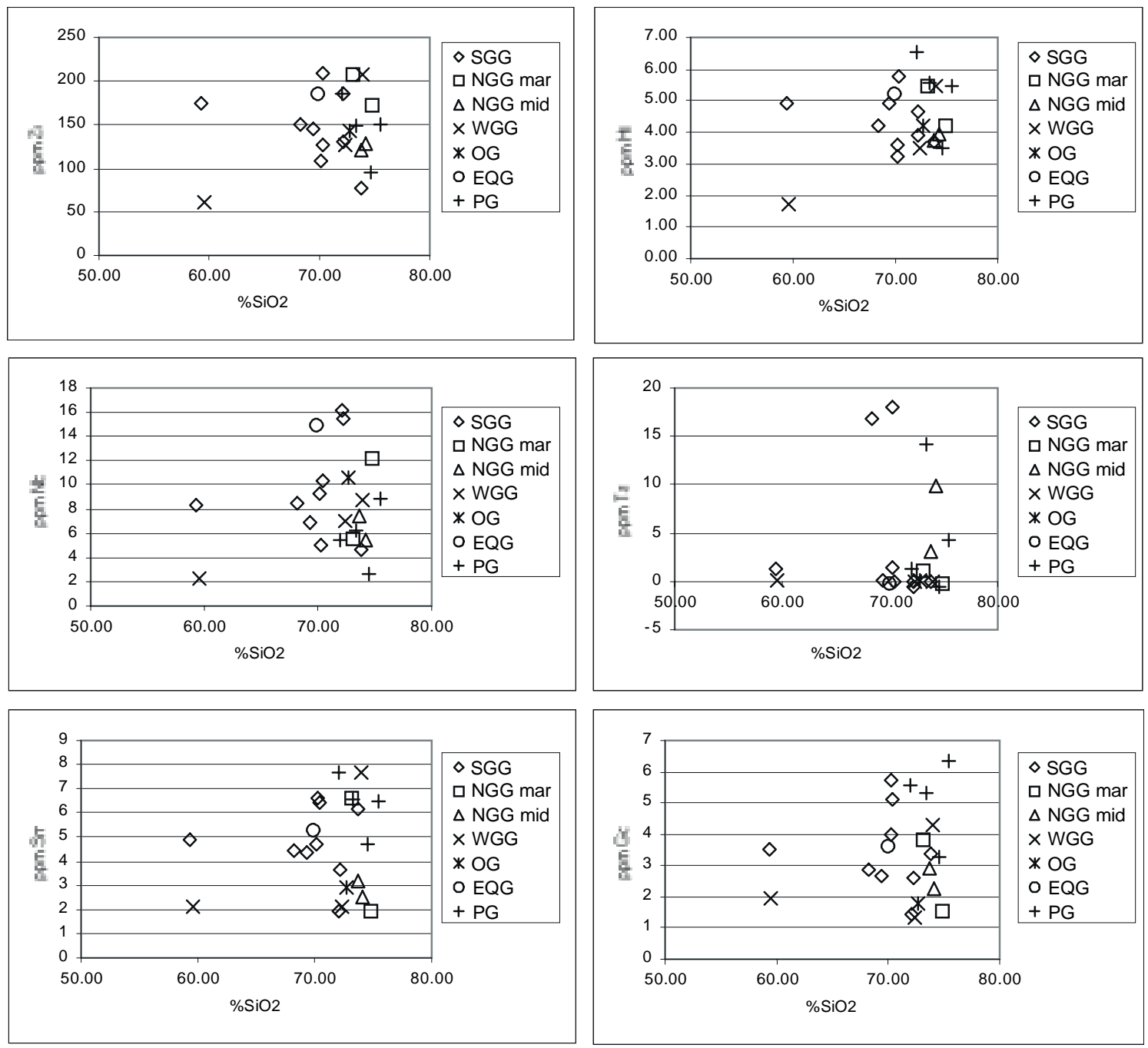

Fig. 3.5: continued 
Table 3.1: $K_{D}$ 's for different trace elements that control their distribution between mineral and melt.

\begin{tabular}{|c|c|c|c|c|c|c|c|c|c|c|}
\hline Element & $\begin{array}{l}\text { Plagioclas } \\
\mathrm{e}\end{array}$ & k-fsp & Garnet & Biotite & Hornblende & Zircon & Sphene & Magnetite & Quartz & Apatite \\
\hline $\mathrm{Rb}$ & 0.041 & 0.34 & 0.009 & 2.24 & 0.014 & & & & 0.041 & \\
\hline $\mathrm{Sr}$ & 4.4 & 3.87 & 0.015 & 0.447 & 0.022 & & & & & \\
\hline $\mathrm{Ba}$ & 0.308 & 6.12 & 0.017 & 9.7 & 0.044 & & & & \begin{tabular}{l|}
0.022 \\
\end{tabular} & \\
\hline K & 0.1 & & 0.2 & & 0.081 & & & & 0.013 & \\
\hline Cs & 0.105 & 0.195 & & 3 & & 3.15 & & & 0.029 & \\
\hline $\mathrm{Pb}$ & 0.972 & 2.473 & & 0.767 & & & & & & \\
\hline $\bar{Y}$ & 0.1 & & 35 & 0.03 & 6 & & & 2 & & 40 \\
\hline$\overline{\mathrm{Ti}}$ & 0.05 & & 1.2 & & 7 & & & 12.5 & 0.038 & 0.1 \\
\hline $\mathrm{Zr}$ & 0.1 & 0.03 & 1.2 & 1.197 & 4 & & & 0.8 & & 0.1 \\
\hline $\mathrm{Hf}$ & 0.148 & 0.033 & 3.3 & 0.703 & & 3193.5 & & & 0.03 & 0.73 \\
\hline $\mathrm{Nb}$ & 0.06 & & & 6.367 & 4 & & 6.3 & 2.5 & & 0.1 \\
\hline $\mathrm{Ta}$ & 0.035 & 0.01 & & 1.567 & & 47.5 & 16.5 & & 0.008 & \\
\hline Th & 0.048 & 0.023 & & 0.997 & & 76.8 & & & 0.009 & \\
\hline $\bar{U}$ & 0.093 & 0.048 & & 0.773 & & 340.5 & & & 0.025 & \\
\hline $\mathrm{La}$ & 0.38 & 0.08 & 0.39 & 5.713 & & 16.9 & 4 & & 0.015 & \\
\hline $\mathrm{Ce}$ & 0.27 & 0.044 & 0.35 & 4.357 & 1.52 & 16.75 & & & 0.014 & 34.7 \\
\hline \multicolumn{11}{|l|}{$\mathrm{Pr}$} \\
\hline $\mathrm{Nd}$ & 0.21 & 0.025 & 0.53 & 2.56 & 4.26 & 13.3 & & & 0.016 & 57.1 \\
\hline Sm & 0.013 & 0.018 & 2.66 & 2.117 & 7.77 & 14.4 & 21 & & 0.014 & 62.8 \\
\hline $\mathrm{Eu}$ & 2.15 & 1.13 & 1.5 & 2.02 & 5.14 & 16 & & & 0.056 & 30.4 \\
\hline $\mathrm{Gd}$ & 0.097 & 0.011 & 10.5 & & 10 & 12 & & & & 56.3 \\
\hline $\mathrm{Tb}$ & & 0.025 & 11.9 & 1.957 & & 37 & & & 0.017 & \\
\hline Dy & 0.064 & 0.006 & 28.6 & 1.72 & 13 & 101.5 & & & 0.015 & 50.7 \\
\hline $\mathrm{Ho}$ & & & 28.05 & & & & 19 & & & \\
\hline $\mathrm{Er}$ & 0.055 & 0.006 & 42.8 & & 12 & 135 & & & & 37.2 \\
\hline \multicolumn{11}{|l|}{$\mathrm{Tm}$} \\
\hline $\mathrm{Yb}$ & 0.049 & 0.012 & 39.9 & 1.473 & 8.38 & 527 & & & 0.017 & 23.9 \\
\hline $\mathrm{Lu}$ & 0.046 & 0.006 & 29.6 & 1.617 & 5.5 & 641.5 & 10 & & 0.014 & 20.2 \\
\hline
\end{tabular}

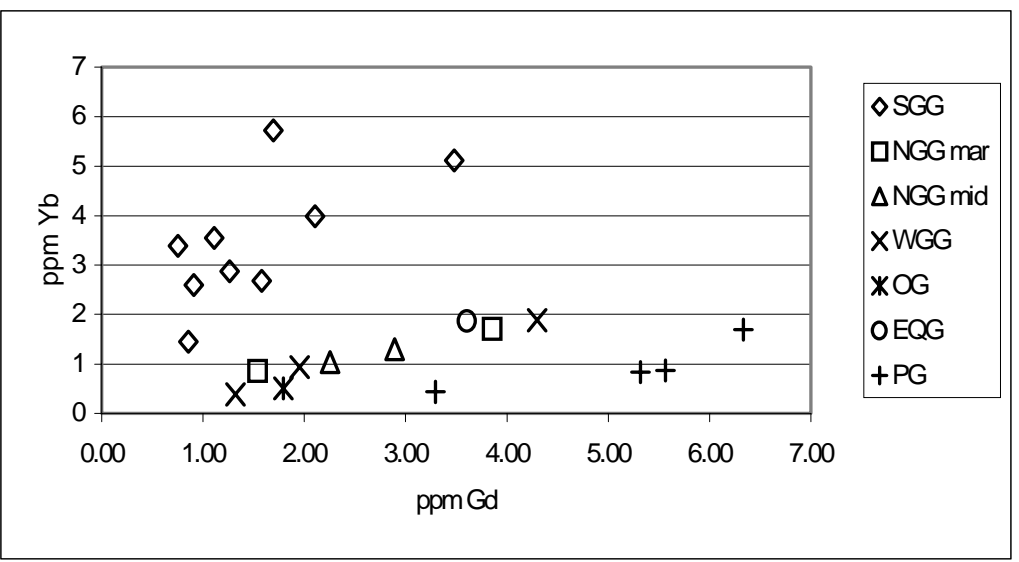

Fig. 3.6: Ratio of $\mathrm{Yb} / \mathrm{Gd}$ (in ppm) showing a linear relationship of the gneisses except for the southern gneisses that have an elevated content in $\mathrm{Yb}$ due to the frequent occurrence of garnet. 
According to MacCaskie (1984) covariance plots are useful indicators to identify different petrogenetic processes in the formation of related magmas. Feng \& Kerrich (1992) effectively use covariance plots of $\mathrm{Rb} / \mathrm{Sr}$ versus $\mathrm{Rb} / \mathrm{Ba}$ to distinguish between different fractionation processes and AFCs (assimilation of wall rocks during fractional crystallization) in the genetic process of evolving Archean TTG's. As can be seen from Fig. 3.7 the analyzed samples of the Chinamora Batholith clearly define a linear trend indicating a close petrogenetic relationship in the evolution of the gneissic- and porphyritic granites. The samples from the porphyritic granite reflect the evolved nature of the magma and therefore show higher $\mathrm{Rb} / \mathrm{Sr}$ and $\mathrm{Rb} / \mathrm{Ba}$ ratios than the gneissic granites.

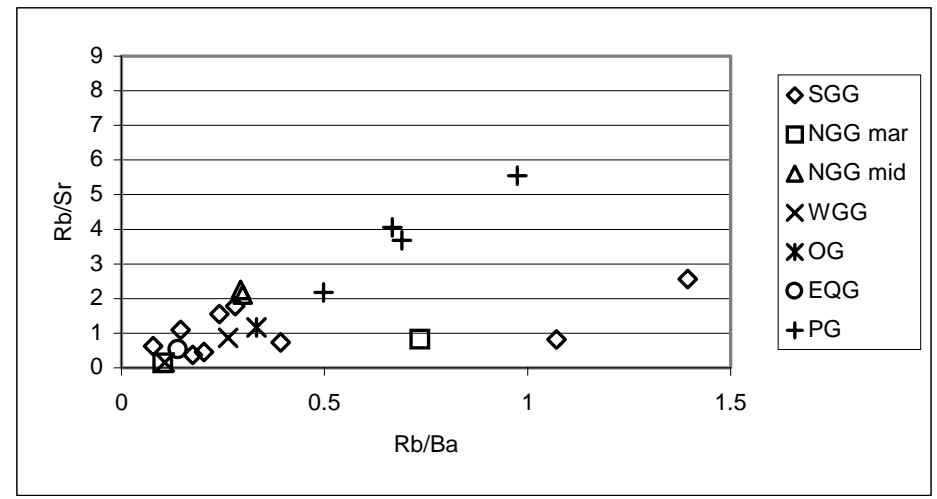

Fig. 3.7: $\mathrm{Rb} / \mathrm{Sr}$ versus $\mathrm{Rb} / \mathrm{Ba}$

The frequently observed hiatus between the trace element content of the gneissic granites and the porphyritic granite does not necessarily point to a different source for these two units. The linear relationship of major as well as trace elements can be achieved if K-feldspar is concentrated in the remaining melt. In addition, to account for the high $\mathrm{U}, \mathrm{Th}, \mathrm{Hf}$ and $\mathrm{Pb}$ content of the porphyritic granite an accessory mineral must be present that shows high $K_{D}$ 's for these elements without significantly changing the major element composition.

\subsubsection{Normalized diagrams (Spider plots)}

Despite the processes that may have changed the element distribution in the analyzed rock samples, element abundance diagrams are useful to demonstrate trends in large databases and may be used to compare the source and evolution of rocks. In Fig. 3.8 the MORB (Mid-Ocean Ridge Basalts)-normalized trace elements of the respective units are plotted. It can be seen that the different gneisses show comparable trends, only the element abundance differs to a wider extend. 

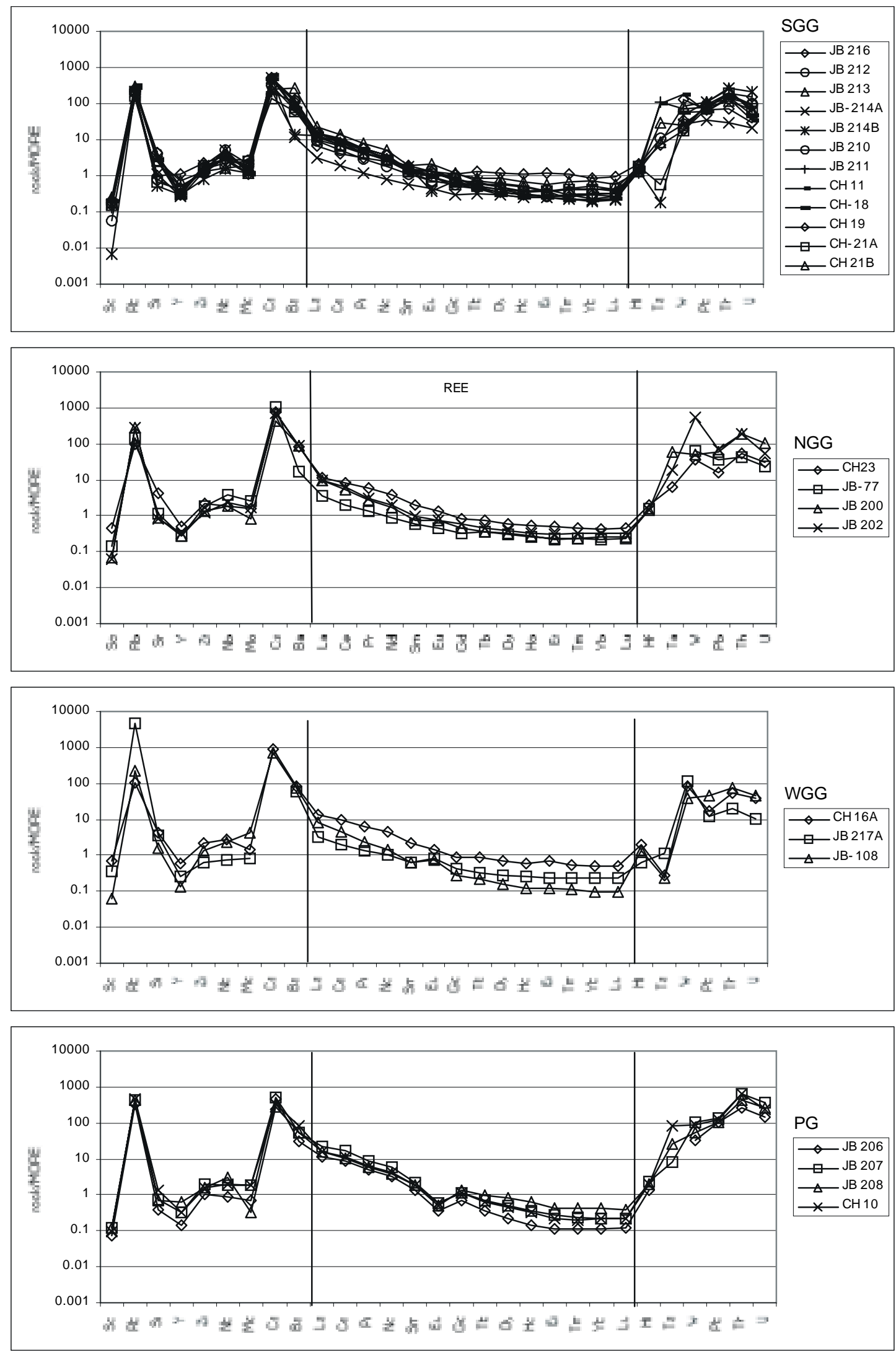

Fig. 3.8: Spider plots of trace elements normed to MORB (mid ocean ridge basalt).

All are highly enriched in most ( $\mathrm{Rb}, \mathrm{Cs}, \mathrm{Ba}, \mathrm{Pb}$ ) of the large ion lithophile elements (LILE), the light REE are only slightly enriched while the heavy REE are slightly depleted. 
Furthermore, they are highly enriched in Th and $U$. In general, the gneissic granites are enriched in incompatible elements.

According to Hall (1993), during partial melting the initial melts will be enriched in these trace elements due to their low distribution coefficient for the solid phase of the source material. The porphyritic granite shows much higher abundances for some light REE ( $\mathrm{La}, \mathrm{Ce}, \mathrm{Pr}, \mathrm{Nd}$ and $\mathrm{Sm}$ ) than the gneisses with a marked negative Eu-anomaly. $\mathrm{Hf}, \mathrm{Ta}, \mathrm{W}, \mathrm{Pb}, \mathrm{Th}$ and $\mathrm{U}$ are enriched in the porphyritic granite, especially $T h$ and $U$ have much higher concentrations in the porphyritic granite than in the gneissic granites.

\subsection{Conclusions}

Two modes of origin are applicable for the TGGM series with this type of major and trace element signature: either melting of a granitic or an amphibolitic source (Feng \& Kerrich, 1992; Arth \& Hanson, 1975M; Condie, $1981+1986$ or Drummond \& Defant, 1990). Due to the high $\mathrm{SiO}_{2}$-content of the analyzed samples the latter seems to be questionable. The origin of the porphyritic granite is ambiguous, according to Goodwin (1991) the late tectonic series may have originated from partial melting of the residuum left from the TGGM series.

The pronounced linear relationship of the gneissic granites and the porphyritic granite seems to point to a close petrogenetic relationship of the syntectonic and the late tectonic series with the late tectonic series originating from fractional crystallization of $\mathrm{k}$-feldspar and an accessory mineral with a high $\mathrm{K}_{\mathrm{d}}$ for the elements $\mathrm{Hf}, \mathrm{Ta}, \mathrm{W}, \mathrm{Pb}$, Th and $\mathrm{U}$ without changing the major element content of the melt significantly. This is confirmed by Fig. 3.9 where normative An-Ab-Or is plotted in a trivariant diagram according to O'Connor (1965). 


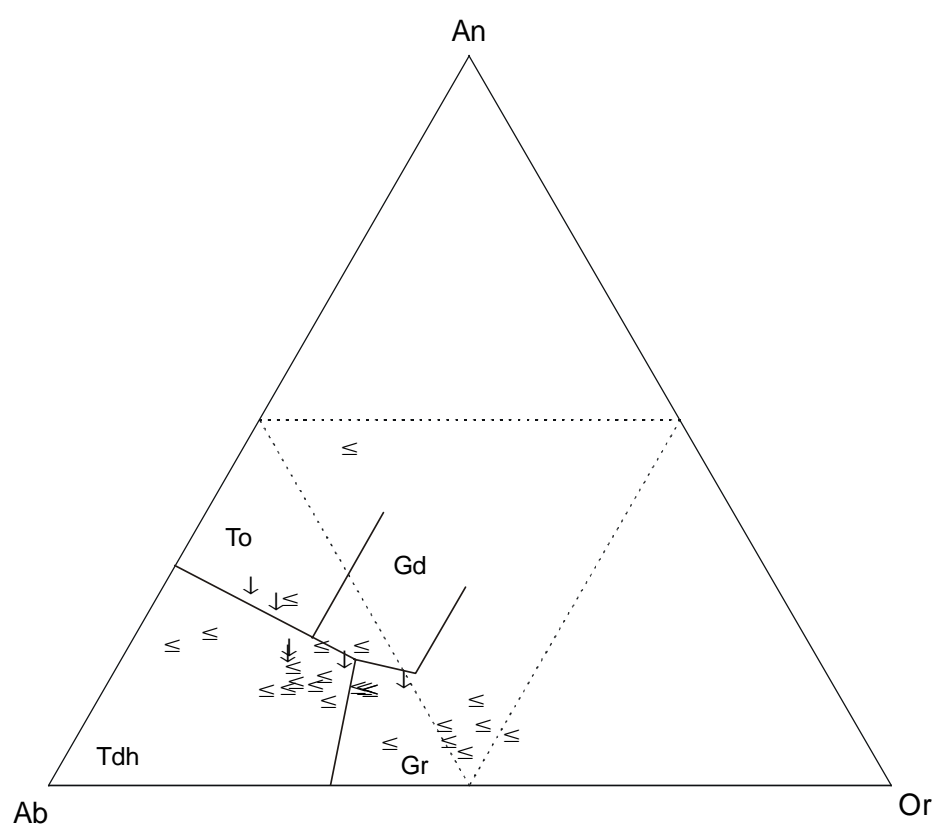

Fig. 3.9: Normative An-Ab-Or diagram according to O'Connor (1965). Circles are data from this work, squares are from Snowden (1976) and diamonds are from Jelsma (1993). Gr = granite; Tdh $=$ trondhjemite $; \mathrm{Gd}=$ granodiorite and To = tonalite.

The samples define a trend from largely undifferentiated granite to more differentiated tonalite which is typical for a fractionation of the melt (pers. com. Foley, 2000). Based on this it seems most likely that the lithologies originated from the same granitic source and were fractionated during the process of (batch?) melting. 


\section{Petrography and fabrics of the Chinamora Batholith}

After evaluating the possible sources and origin of the different lithologies a thorough analyzes of their field appearance and microstructures is performed to gain insight in the age coherence, timing of deformation (e.g. magmatic, submagmatic and solid state) and possibly the deformation mechanism itself. The different lithologies have been grouped into the gneissic granites (include the possible basement gneisses, see below), the equigranular granites and the porphyritic granite, their field appearance, modal composition and microstructures are described below.

\subsection{Field observations and petrography}

\subsubsection{Gneissic granites}

The gneissic granites in the marginal areas and the erosional windows of the Chinamora Batholith may be differentiated according to their amount of deformation into the southern, northern and western gneissic granites. They all show different intensities of their internal deformations and are hence described separately.

\subsubsection{Southern gneissic granites}

Field observations of the southern gneissic granites revealed numerous small scale shear zones (Plate 1D). The shear zones often cut xenoliths with offsets of a few centimeters (Plate 1A). Kinematic indicators in these small scale shear zones show sinistral as well as dextral movements and therefore probably originated from emplacement mechanisms rather than by movement along the Umwindsi Shear Zone (Jelsma pers. communication; Ramsay, 1989) that parallels the southern margin of the batholith. Strongly elongated xenoliths are abundant in the southern gneisses. Usually only 2D views of the xenoliths are available. Where a $3 \mathrm{D}$ view is possible they show strongly oblate forms and are flattened in the foliation plane (Plate 1B). Foliation is usually defined by small biotite flakes that form only weakly or unconnected layers and sometimes anastomose around 
feldspars (Plate 2 and 3). Feldspar megacrysts usually show a strong preferred alignment (Plate $3 \mathrm{~A}$ ), folded pegmatites are abundant and are frequently refolded (Plate1C).

Hand specimen all show a very high content of hornblendes and biotites giving the rocks a dark grey appearance. The well developed foliation plane (Plate 2) in most of the samples is defined by biotites and/or hornblendes. Feldspars are oriented in the foliation plane and sometimes appear to define augen gneisses, however, this texture is only weakly developed. Biotites of the southern gneisses are much smaller than biotites in the other suites, they hardly exceed $\sim 0.5 \mathrm{~cm}$ in diameter. Shear zones can be observed in some of the samples indicating a sinistral as well as dextral sense of shear. These shear zones sometimes crosscut large feldspars (Plate $3 \mathrm{~A}$ ) and hence must have been active after crystallization of the melt. Lineations in the southern gneisses are defined by weakly aligned feldspars.

The southern gneissic contain quartz, plagioclase, K-feldspar, hornblendes and biotite as their main constituencies (see Table 4.1 for modal analyzes) and magnetite, titanite, zircon, apatite and garnet as accessories. The Streckeisendiagram is shown in Fig. 4.1. Most of the samples plot in the granodiorite-field, still some of the samples plot as monzogranites or tonalites. Baldock (1991) found the same modal composition in his study.

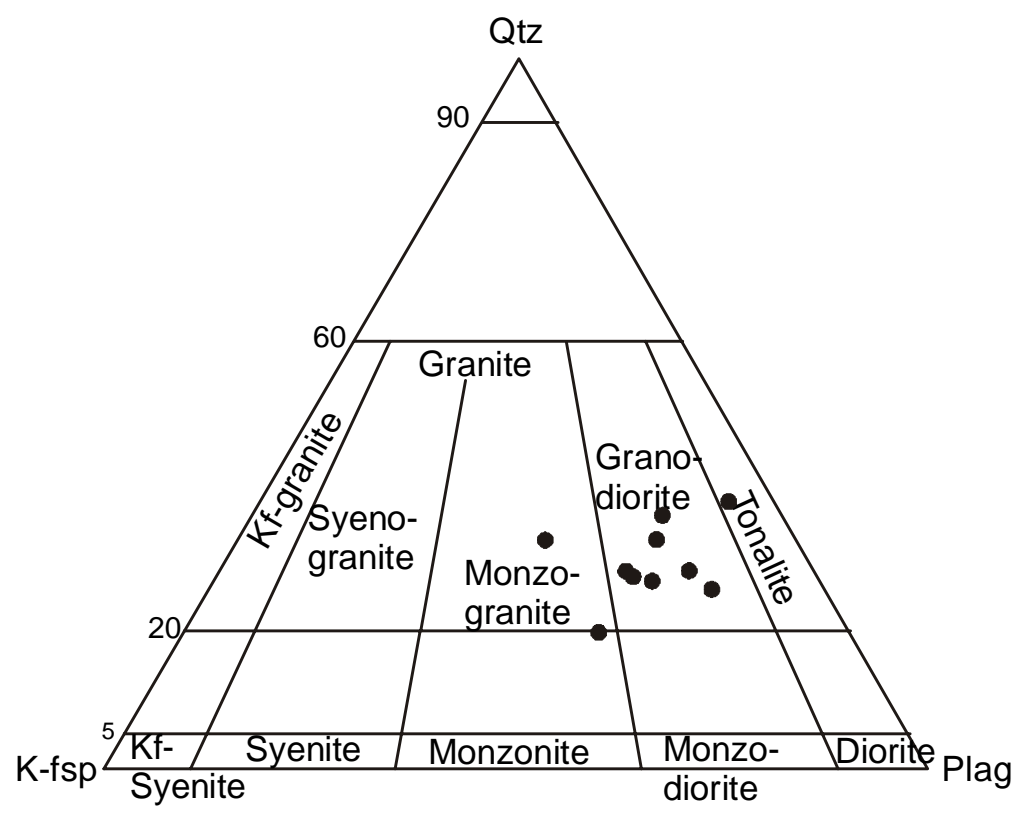

Fig. 4.1: Streckeisen diagram of the samples in the southern gneissic granites. 
Table 4.1: Modal composition calculated from geochemical analyses for the southern gneissic granites.

\begin{tabular}{|l|r|r|r|r|r|r|}
\hline & CH 11 & CH 18 & CH 19 & CH 21A & CH 21B & JB 210 \\
\hline quartz (\%) & 23 & 21 & 15 & 23 & 28 & 23 \\
\hline K-feldspar (\%) & 13 & 11 & 0 & 19 & 26 & 17 \\
\hline plagioclase (\%) & 45 & 48 & 40 & 43 & 32 & 45 \\
\hline hornblende (\%) & 9 & 11 & 28 & 6 & 0 & 3 \\
\hline biotite (\%) & 10 & 10 & 18 & 9 & 14 & 12 \\
\hline & & & & & & \\
\hline & & & & & & \\
\hline & JB 211 & JB 212 & JB 213 & JB 214A & JB 214B & JB 216 \\
\hline quartz (\%) & 24 & 33 & 15 & 33 & 29 & 28 \\
\hline K-feldspar (\%) & 20 & 13 & 22 & 5 & 18 & 14 \\
\hline plagioclase (\%) & 43 & 45 & 37 & 50 & 49 & 44 \\
\hline hornblende (\%) & 3 & 0 & 19 & 0 & 2 & 0 \\
\hline biotite (\%) & 10 & 12 & 7 & 12 & 2 & 14 \\
\hline
\end{tabular}

\subsubsection{Western gneissic granites}

In the western gneissic granites internal fabric mainly is defined by large biotite flakes $(\sim 2 \mathrm{~cm})$ that define a well developed foliation (Plate 4). Feldspars are small and oriented in the foliation plane. In some samples hornblendes seem to define a weak SC-fabric indicating a dextral sense of shear. Generally, grain size is much coarser than in most of the southern gneissic granites. The massive occurrence of feldspars gives these rocks a light grey to white color, some ore minerals are embedded in the rocks that are easily recognized due to their small, brownish corona that probably originated during weathering (Plate 4A).

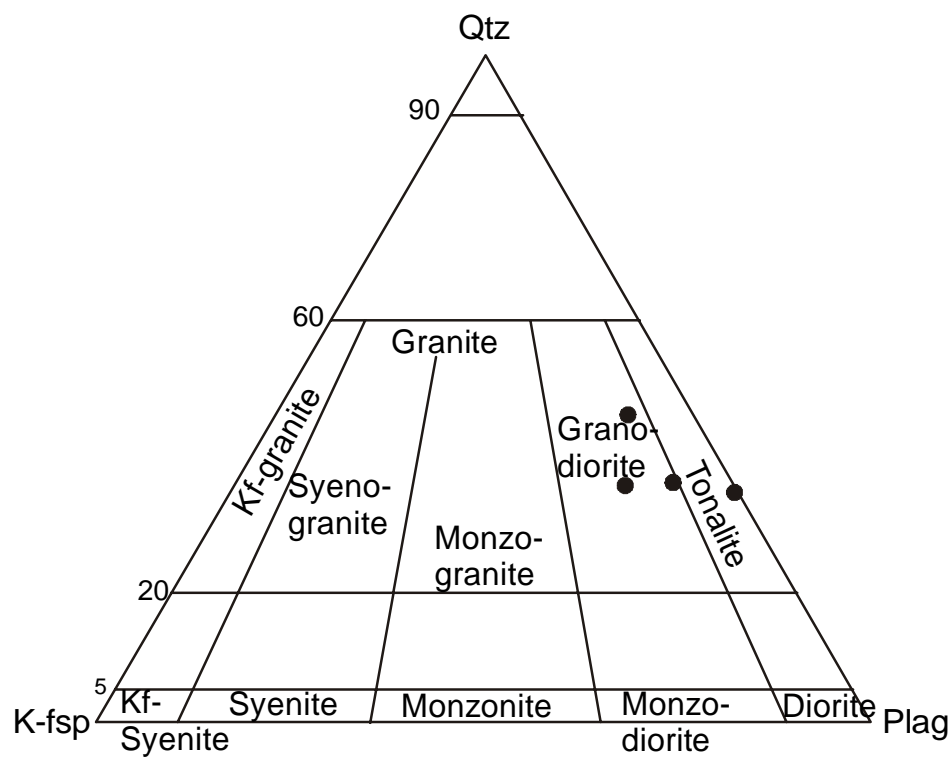

Fig. 4.2: Streckeisen diagram for the samples in the western gneissic granites. 
The western gneissic granites contain quartz, plagioclase, K-feldspar and biotite as the main constituencies. In most of the samples the hornblende content is fairly high and must be seen as a major phase as well. Accessories are magnetite, apatite and zircons. The modal content of the samples differs widely depending on the lithology (see Table 4.2 and Fig. 4.2), in the Streckeisen-diagram the samples plot in the granodiorite and tonalite field (see Fig. 4.2).

Table 4.2: Modal composition calculated from the geochemical measurements.

\begin{tabular}{|l|r|r|r|r|}
\hline & CH 16A & JB 217B & JB 108 & JB 217A \\
\hline quartz (\%) & 37 & 18 & 29 & 21 \\
\hline K-feldspar (\%) & 8 & 0 & 14 & 5 \\
\hline plagioclase (\%) & 41 & 40 & 48 & 37 \\
\hline hornblende (\%) & 0 & 20 & 2 & 11 \\
\hline biotite (\%) & 14 & 22 & 8 & 25 \\
\hline
\end{tabular}

\subsubsection{Northern gneissic granites}

The northern gneissic granites can be divided into the central granodiorite (Musana Communal Land, see Fig. 4.3) and the marginal gneissic granodiorite and granite. The central granodiorite shows a weak foliation defined by small biotite flakes (Plate 5) while other samples in the same area are isotropic and do not show any macroscopically visible internal fabric. These samples are comparable to samples from the porphyritic granite but they lack the common occurrence of large feldspar phenocrysts. Ore minerals can frequently be recognized due to their brownish corona (Plate $5 A+B$ ). Grain size usually is small although some large quartz grains can be observed.

Outcrops in the marginal northern gneissic granites usually show small grains of feldspars and biotites defining a strong foliation. Folding of pegmatites is common but in contrast to the southern gneisses refolding of veins can only rarely be observed. These two subunits (sample JB200 and JB202 are from the Musana Communal Land) in the northern gneissic granites can not be distinguished according to their modal content (see Table 4.3, Fig. 4.4).

Table 4.3: Modal composition calculated from geochemical analyses.

\begin{tabular}{|l|r|r|r|r|r|}
\hline & CH 23 & JB 77 & JB 200 & JB 202 & JB 215 \\
\hline quartz (\%) & 36 & 37 & 34 & 33 & 31 \\
\hline K-feldspar (\%) & 0 & 3 & 18 & 18 & 15 \\
\hline plagioclase (\%) & 52 & 48 & 41 & 41 & 44 \\
\hline hornblende (\%) & 1 & 3 & 0 & 1 & 1 \\
\hline biotite (\%) & 11 & 10 & 7 & 8 & 9 \\
\hline
\end{tabular}




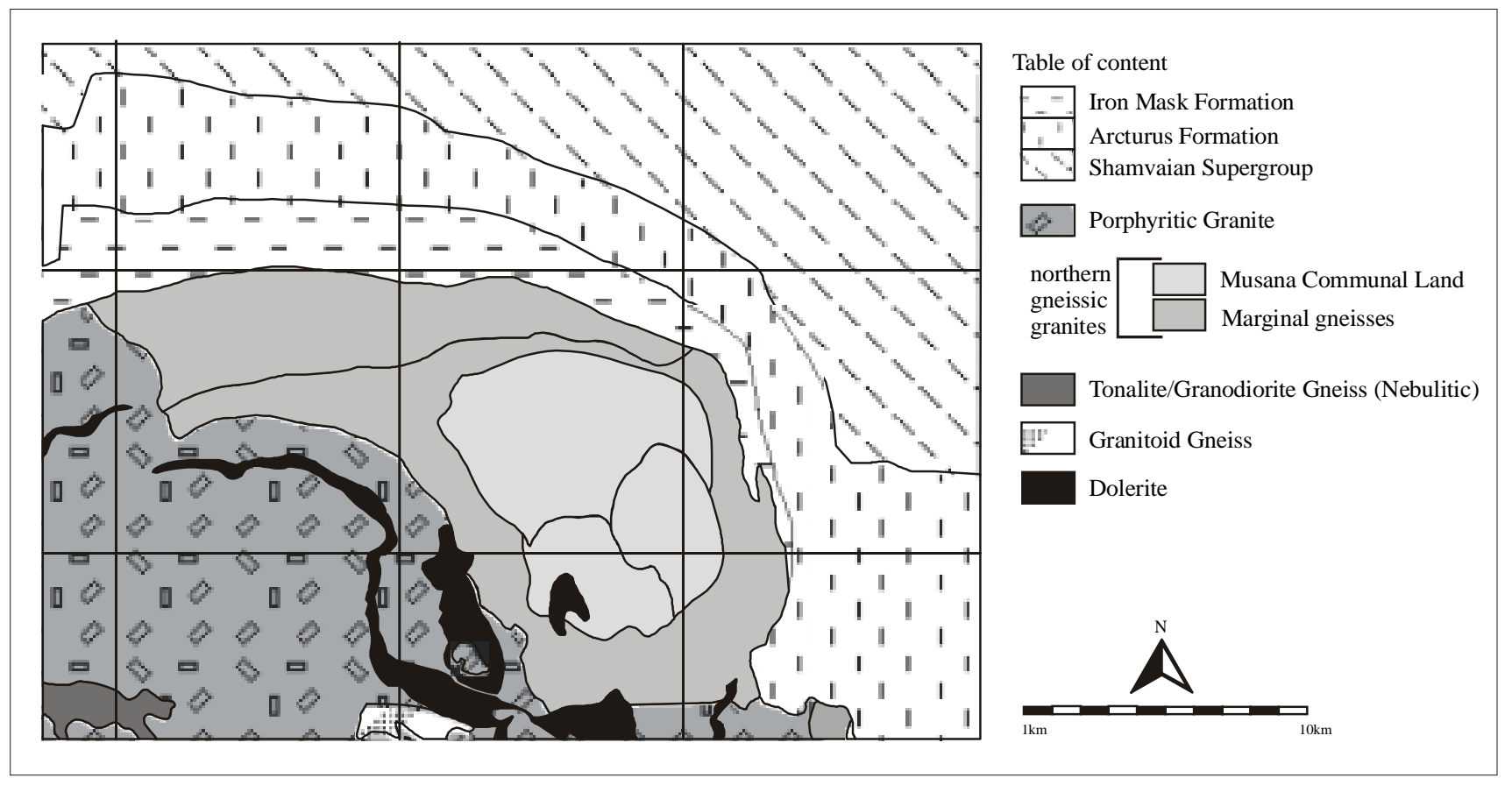

Fig. 4.3: Location of the Musana Communal Land area

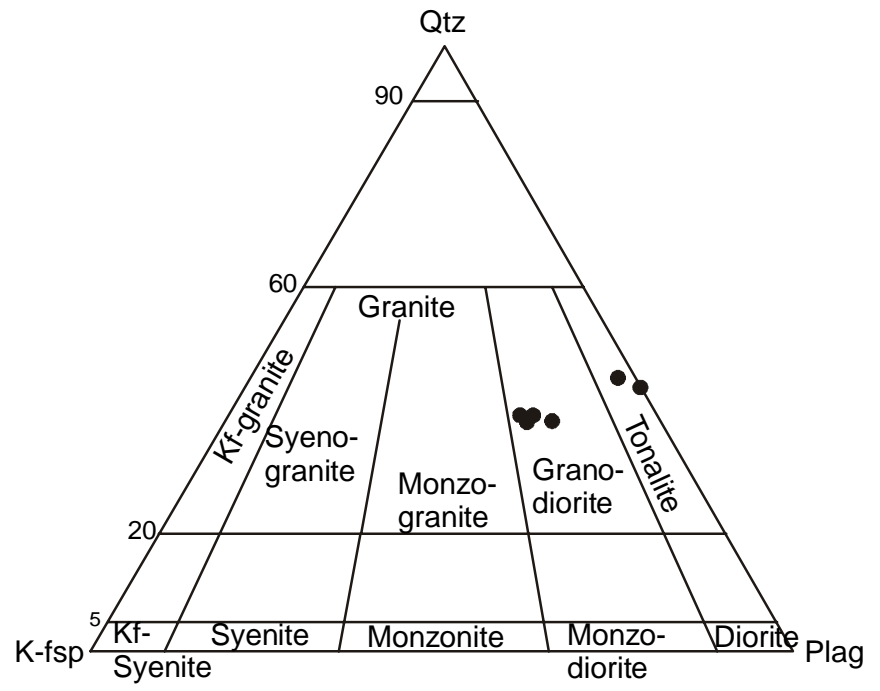

Fig. 4.4: Streckeisen diagram of the samples in the northern gneissic granites.

Their main constituencies are quartz, K-feldspar (although some samples show a very low K-feldspar content), plagioclase, biotite and minor hornblende, accessories include magnetite, haematite, zircon, apatite, titanite and sphene.

\subsubsection{Equigranular granites}

The equigranular granites in the western portion of the Chinamora Batholith range in composition from tonalite/trondhjemite to monzogranite, the majority of the 
samples can be described as quartz-rich granodiorites (Snowden \& Snowden, 1979). They contain less than $5 \%$ of mafic minerals and do not show any feldspar megacrysts. The poor outcrop situation in this area complicates a precise analyzes of the rocks, outcrops in the equigranular granites are usually highly altered and fresh samples were scarce. The equigranular granites can be subdivided into a fine grained (Valeria/Surtic) and a coarse grained (Mazowe granodiorite) unit (e.g. Baldock, 1991). Both contain 29\% quartz, 11\% K-feldspar, 44\% plagioclase, $2 \%$ hornblendes and $14 \%$ biotite as their main constituencies (Snowden \& Snowden, 1979). Only one sample has been analyzed geochemically, it plots in the field of granodiorites in the Streckeisen diagram.

\subsubsection{Porphyritic granite}

The porphyritic granite in the center of the batholith (see Fig. 2.4) has an areal extend of approx. $600 \mathrm{~km}^{2}$ and represents the largest unit in the Chinamora Batholith. Outcrops usually occur as nearly horizontal surfaces (see Plate 6A), however, the porphyritic granite includes the typical whaleback-domes that can be observed in most of the area and includes the Ngomakurira which, with its elevation of $1655 \mathrm{~m}$, is the highest hill in the area (see Plate 6D). The porphyritic granite can only be observed above an elevation of $\sim 1200 \mathrm{~m}$. This suggests that the porphyritic granite has a convex form being at a higher elevation in the center than at the margins. In the various outcrops the most prominent characteristic of the porphyritic granite is the large size of feldspar phenocrysts. They reach $5 \mathrm{~cm}$ in length, sometimes more, and are usually well aligned (Plate $6 B+C)$. Grain size of the other minerals is diverge, usually quartz and biotites are very small. Small scale shear zones in the porphyritic granite are rare and can only be observed near the southern margin where the porphyritic granite abuts on the gneissic granites (Plate $6 \mathrm{C}$ ). The shear zones probably were formed during crystallization since feldspar grains are dragged into the shear zone, although they could have developed in the solid state as well when the rocks behaved plastically. The shear zones indicate a sinistral or dextral sense of shear. Recognition of foliations or lineations in the outcrops can be difficult due to the lack of suitable surfaces (Plate $6 \mathrm{~A})$. The hand specimen show the well alignment of feldspar megacrysts throughout the porphyritic granite (Plate 7). The central porphyritic granite mainly 
contains quartz (27\%), plagioclase (34\%), K-feldspar (31\%) and biotite (5\%), in some samples a hornblende content of up to $2 \%$ has been calculated from geochemical analyzes (see Table 4.4). In the Streckeisen diagram the samples all plot in the field of monzogranites (see Fig. 4.5).

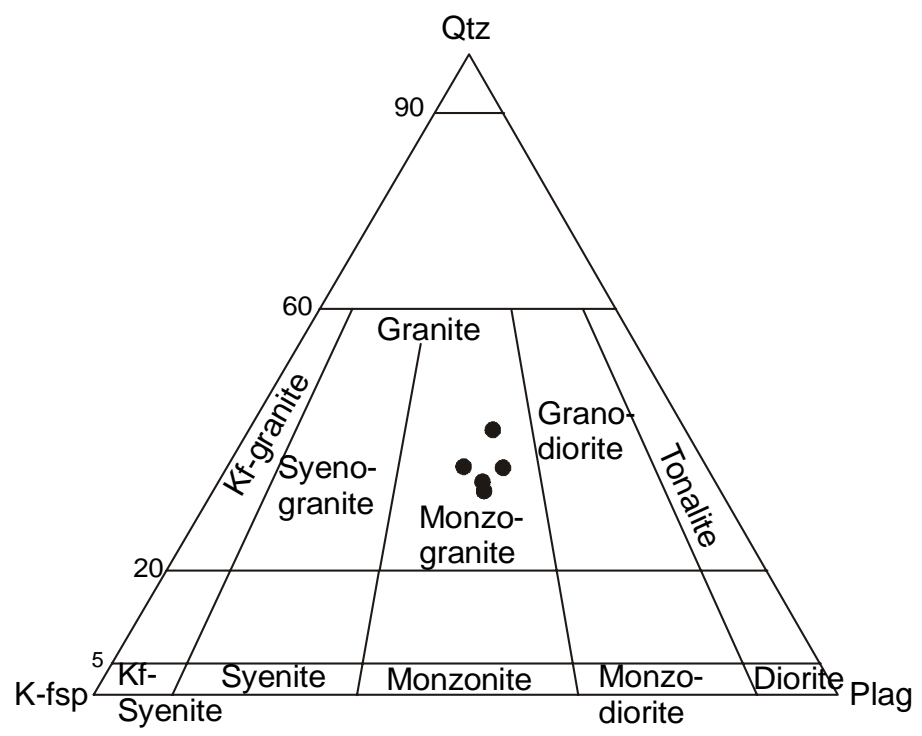

Fig. 4.5: Streckeisen diagram of the samples in the porphyritic granite.

Table 4.4: Modal composition of the porphyritic granite calculated from geochemical analyses.

\begin{tabular}{|l|r|r|r|r|r|}
\hline & CH 10 & JB 206 & JB 207 & JB 208 & JB 209 \\
\hline quartz (\%) & 27 & 30 & 27 & 35 & 30 \\
\hline K-feldspar (\%) & 31 & 32 & 32 & 26 & 27 \\
\hline plagioclase (\%) & 34 & 31 & 35 & 32 & 36 \\
\hline hornblende (\%) & 2 & 0 & 0 & 1 & 0 \\
\hline biotite (\%) & 5 & 6 & 7 & 7 & 6 \\
\hline
\end{tabular}



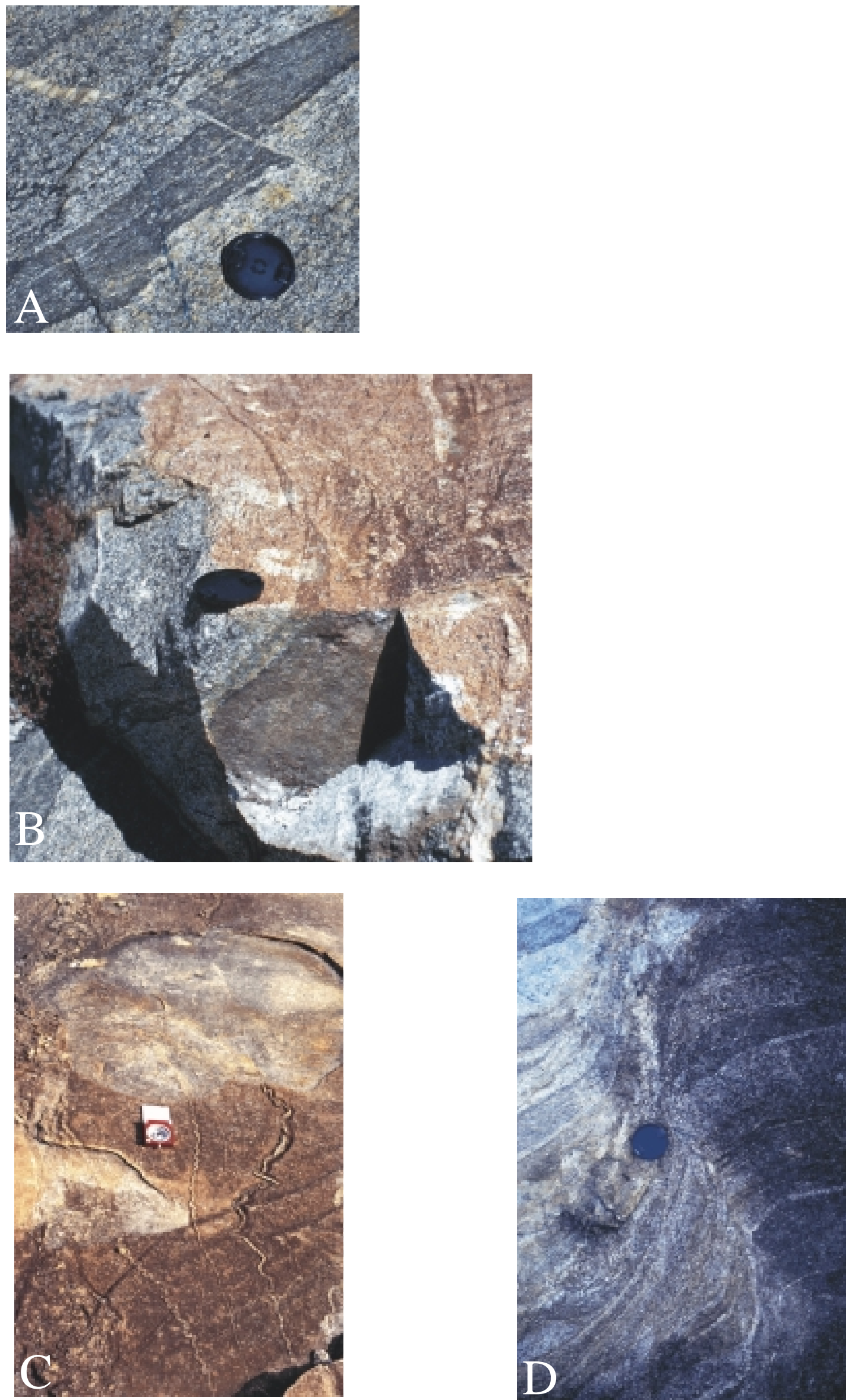

Plate 1: A - Xenolith crosscut and offset by a small shear zone. B - Flattened xenoliths in the southern gneissic granites are oriented in the foliation plane. C - Small, refolded pegmatite veins in the southern gneissic granites. D - Small scale shear zone in the southern gneissic granites. Xenoliths are cross cut and offset along these shear zones. 

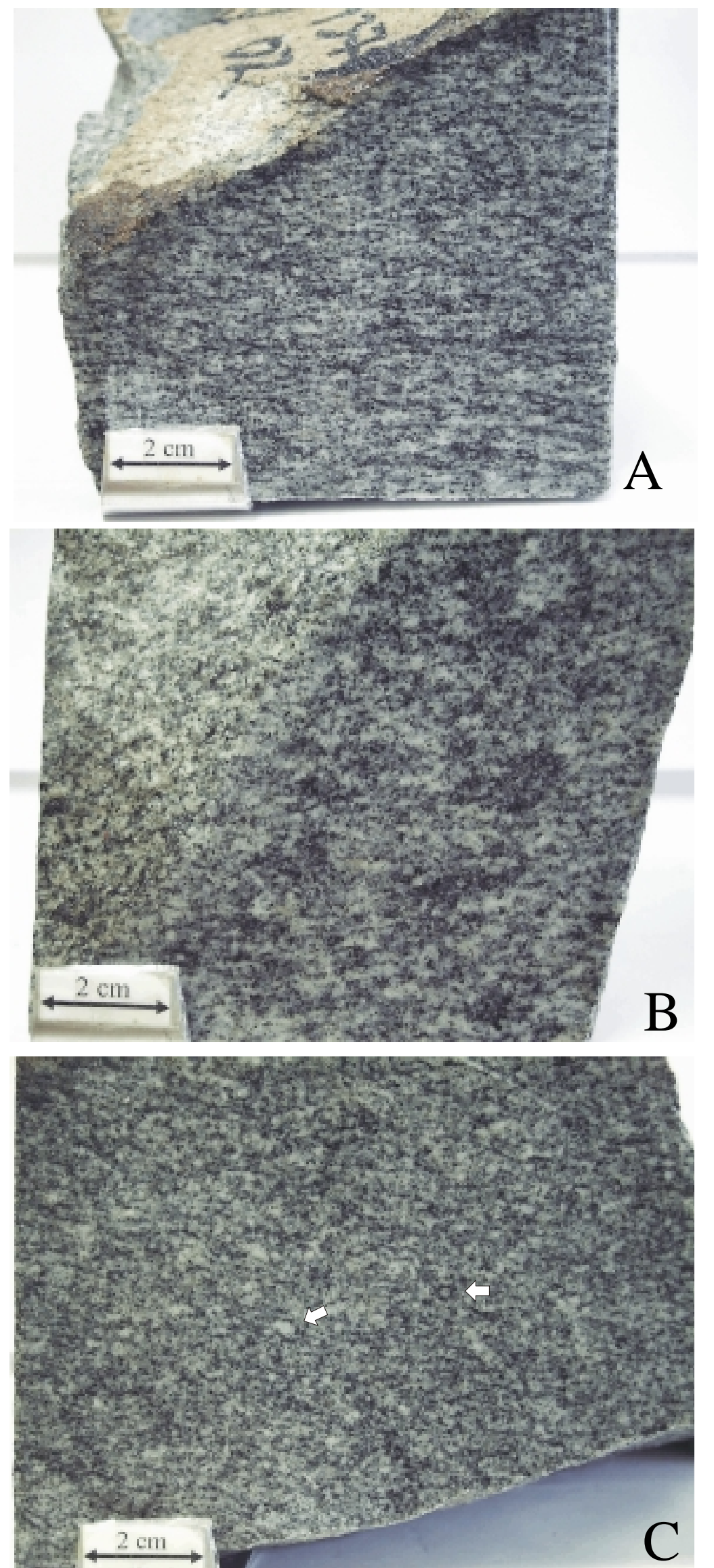

Plate 2: Hand specimen of sample JB309 (southern gneissic granites) showing strong alignment of biotites. A - Cut parallel to lineation and perpendicular to foliation. B -Cut parallel to foliation and lineation. C - Cut perpendicular to foliation and lineation. Note the osciallation of biotites around feldspars (arrows in C). 

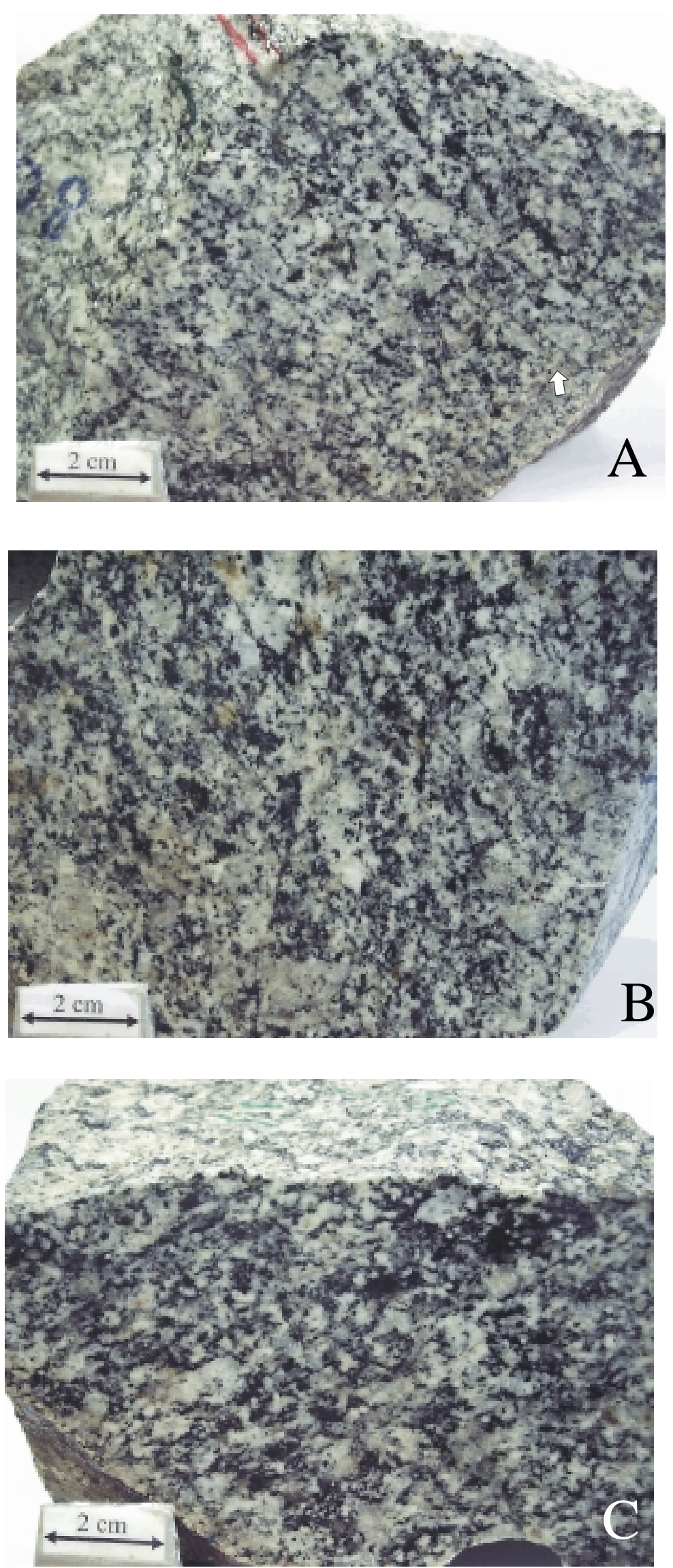

Plate 3: Hand specimen of sample JB308 (southern gneissic granites). A - Plane cut parallel to lineation, perpendicular to foliation. Arrow points to offset of feldspar at a small shear zone. B - Plane cut parallel to foliation and lineation. $\mathrm{C}$ - Cut perpendicular to foliation and lineation. 

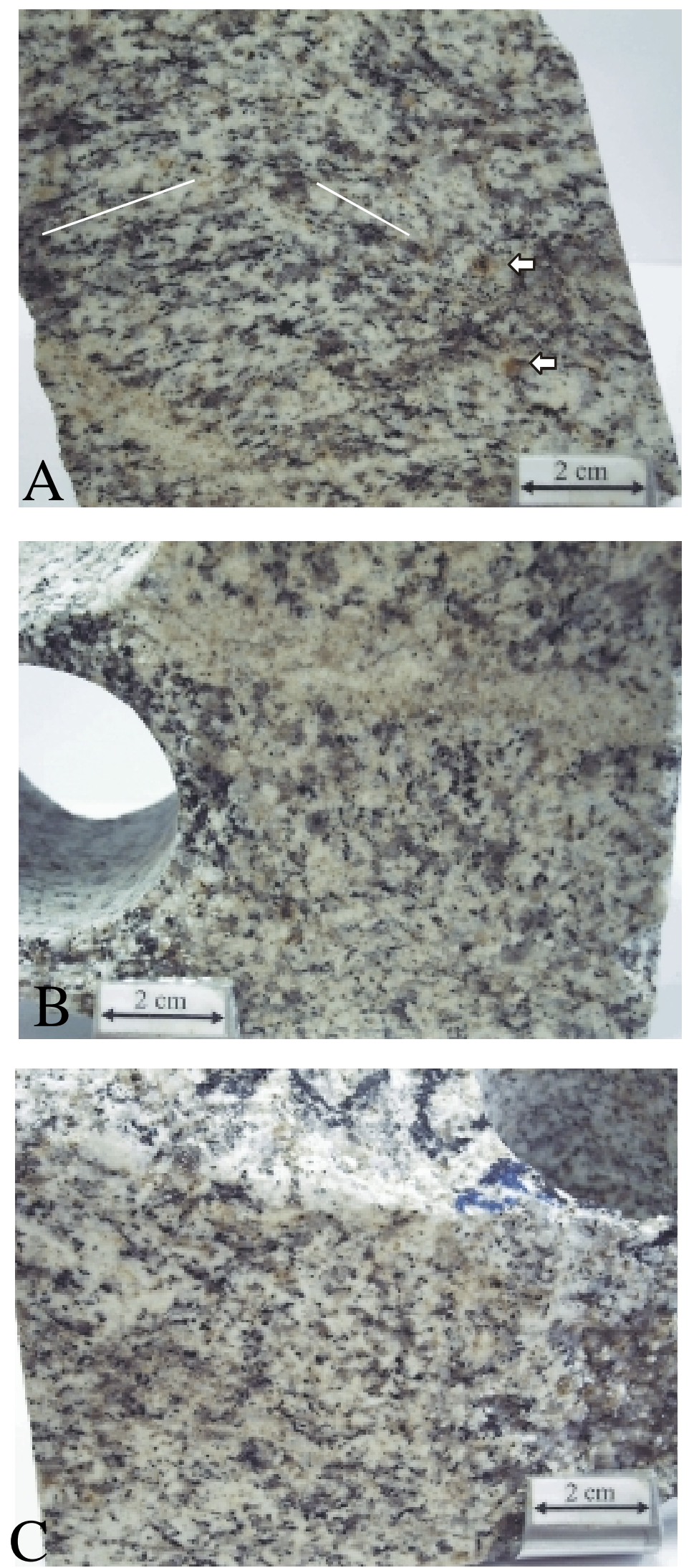

Plate 4: Sample JB296 of the western gneissic granites. A - Plane cut parallel to lineation and perpendicular to foliation. Note the change in the orientation of foliation (solid white lines). Ore minerals are easily recognizable due to their brownish corona (white arrows). B - Cut parallel to foliation and lineation. $\mathrm{C}$ - Cut perpendicular to foliation and lineation. 

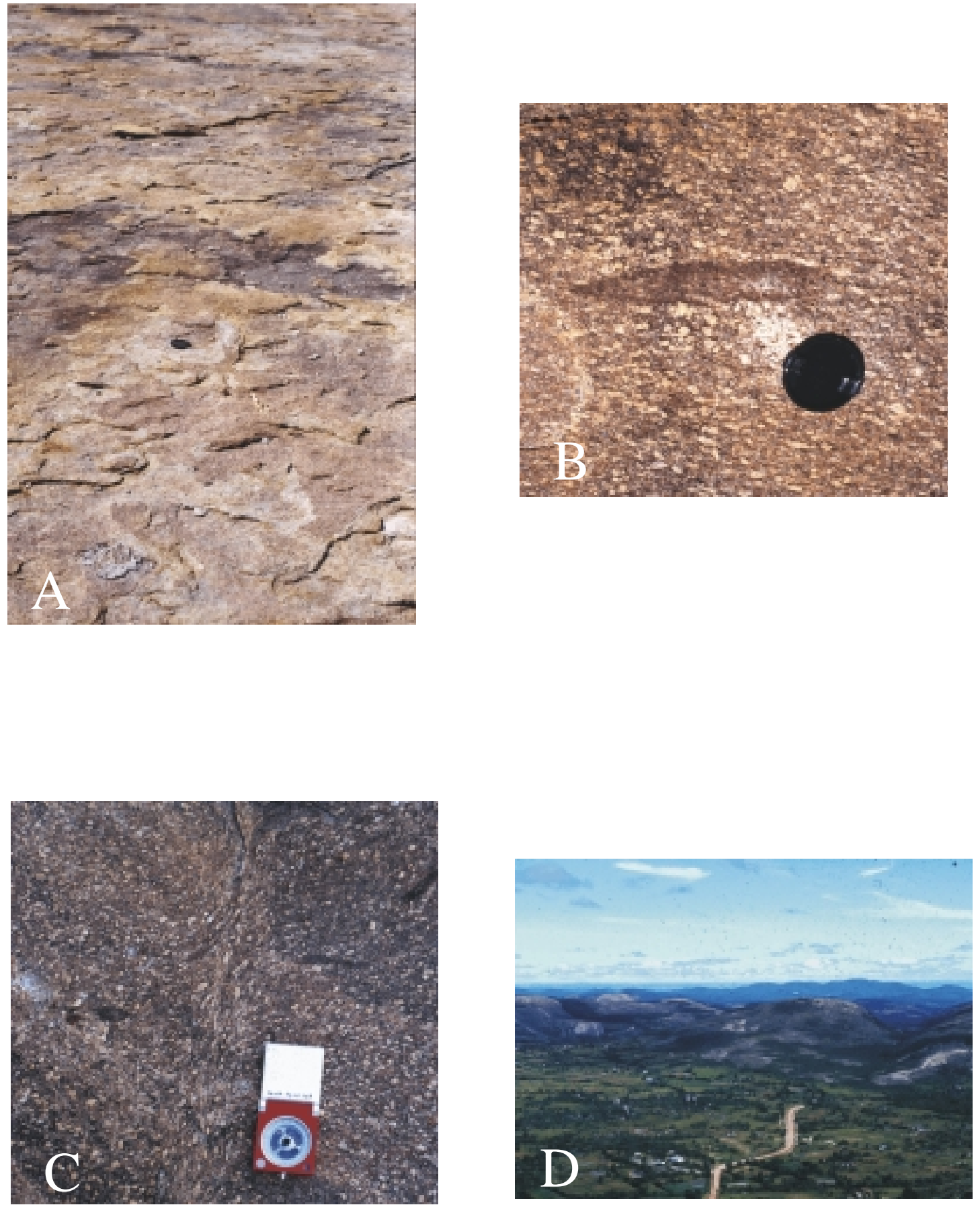

Plate 5: A - Typical outcrop situation in the Chinamora Batholith (here porphyritic granite). Outcrops usually occur as flat lying plates. B - Well aligned feldspar phenocrysts in the porhyritic granite. Xenoliths are oriented in the foliation plane. C - Small scale shear zone in the porphyritic granite near the margin to the southern gneissic granites. D - Whaleback domes in the porphyritic granite, front of the photo shows part of the southern gneissic granites. 


\subsection{Microstructures}

Microscopic analyzes have been performed on two sets of thin sections, one was cut according to the sample coordinates of the magnetic measurements while the other thin sections were cut parallel or perpendicular to the macroscopic foliation.

\subsubsection{Gneissic granites}

The division of the gneissic granites into the southern, western and northern gneissic granites is used for the microscopic analyzes as well, these three units are hence described separately.

\subsubsection{Southern gneissic granites}

Quartz in the southern gneissic granites usually occurs as small grains with highly irregular grain boundaries representing a consertal texture and frequently shows strong undulose extinction or even chessboard patterns (Plate 8E). Bulging of quartz at quartz/quartz or quartz/feldspar boundaries is common.

Plagioclase usually occurs as large grains with euhedral to subhedral shapes. Twin lamellas of the frequent polysynthetic twinning are sometimes slightly bend or offset at intracrystalline fractures (Plate $8 F+D)$. Deformation lamellas, fractures and cracks healed with quartz or feldspar are abundant.

K-feldspar in the southern gneissic granites occurs as euhedral to subhedral grains that frequently show exsolution lamellas of albite (microcline with microperthitic texture, Plate $8 \mathrm{~A}$ ). Zoning in feldspars is common, where grains are sericitized the sericitization reflects the zoning. Myrmekites can frequently be observed around feldspars.

The abundant sub- to euhedral biotites in the southern gneissic granites occur in a wide variety of grain sizes and resemble the typical birds-eye structures.

Hornblendes occur as cluster of small, euhedral grains that do not show any signs of twinning or as larger, euhedral to subhedral grains. The larger hornblendes frequently show the typical central, lamellar twinning parallel [001] (Plate 9A).

The accessory minerals such as magnetite, titanite, zircon, apatite or garnet are common throughout the southern gneissic granites. Subhedral magnetite usually 
occurs in association with biotites and probably derived due to martitization (Plate 9E). Titanites, zircons and apatite are scarce and can be observed as isolated, euhedral to subhedral grains. Garnet grains have anhedral, rounded shapes and usually are cracked or broken up into smaller fragments (Plate $8 \mathrm{C}$ ).

Analyzes of the microstructures revealed numerous structures pointing to a solidstate overprint of the magmatic fabric. The microperthitic texture observed in microclines and their weak alignment is frequently used as an indicator for deformation in the magmatic state (e.g. Roig \& Faure, 1998, Paterson et al. 1989). However, the transition between magmatic to submagmatic or solid-state fabrics is dependent on the amount of melt. If the melt percentage falls below a certain level crystals are no longer able to rotate without interacting with each other which increases the viscosity of magma rapidly by several orders of magnitudes. Estimates for this critical melt percentage usually range between 10-30\% (McBirney \& Murase, 1984; van der Molen \& Paterson, 1978). If this critical melt percentage is exceeded, strain is completely accommodated by movement of the melt and rafting of crystals in suspension (magmatic flow; Hibbard, 1987). The frequent occurrences of microcracks in feldspars healed with quartz therefore point to a submagmatic origin (Bouchez et al., 1992) since these cracks must have developed from grain interaction. Sometimes exsolution lamellae (e.g. albite) in feldspars are offset along these microcracks which is indicative for a later solidstate origin of the cracks. The high internal strain frequently observed in feldspars indicated by offsets of twin lamellae along intercrystalline cracks and deformation twins confirms the solid-state overprint. The genesis of myrmekites is ambiguous since they may crystallize directly from $\mathrm{H}_{2} \mathrm{O}$-rich melts or may develop by solidstate deformation or even metamorphism (Godin, 1994; Paterson et al. 1989). The chessboard patterns in quartz and their elongated subgrains parallel to the chessboard patterns point to a deformation in the submagmatic state (Lonka et al., 1998). These subgrains have developed due to grain boundary migration. This process occurs when dislocations are free to climb from one lattice plane to another and when dislocations are continuously added to subgrain boundaries (Passchier \& Trouw, 1996). Some quartz grains show grain boundary migration recrystallization which was observed by Means \& Park (1994) at any melt fraction as long as an interface of two grains of the same phase is present. The process of grain boundary migration leads to a reduction of dislocation density of grains in 
deformed crystals (Passchier \& Trouw, 1996). The local displacement of atoms to fit the lattice of a neighbouring crystal with a lower dislocation density counterparts processes that cause distortion of the crystal lattice and depends on relative parameters of deformation such as temperature and strain (Passchier \& Trouw, 1996). However, it is unlikely that a crystal shows internal dislocations of atoms without some kind of interaction with a stress field during crystallization. This may be a regional stress field as well as a local stress field from interaction with other crystals. The process of shifting of grain boundaries due to dislocation climb (bulging) can frequently be observed at quartz/quartz contacts, sometimes bulging of quartz into feldspar grains occurs. Some shear zones are developed where quartz shows dynamic recrystallization of grains in the shear zone while grains outside the shear zone do only show weak solid-state fabrics such as bending of twin lamellae in feldspars or deformation lamellae in feldspars (Miller \& Paterson, 1994). Biotites and hornblendes usually form a weak foliation plane in the rocks. Only in some samples a strong biotite foliation is developed. Samples taken near the Umwindsi shear zone show weak SC-fabrics indicating a sinistral sense of shear with hornblendes defining the C-plane (Plate 10). SC-fabrics in magmatic rocks may be assigned to a deformation in the submagmatic as well as in the solid-state (Paterson et al., 1989). However, the observed structures seem to display a transition from magmatic flow fabrics (alignment of feldspars) that have been overprinted in the submagmatic (?myrmekites?, chessboard-patterns in quartz, elongated subgrains in quartz parallel to chessboard patterns) and solidstate (shear zones with dynamic recrystallization, offset of twin lamellas, exsolution of albite in feldspars, occurrence of microcline, bent twin lamellae in plagioclase, deformation lamellae in plagioclase). Furthermore it is obvious from the hand specimen as well as from thin sections and field observations that the amount of deformation seems to decrease towards the batholith center. This has been observed by Jelsma (1993) as well.

\subsubsection{Western gneissic granites}

Quartz in the western gneissic granites occurs as subhedral to anhedral, small, elongated grains showing only weak undulose extinction but no signs of subgrain formation or chessboard patterns. Only in samples with a low hornblende content 
quartz may form larger grains with strong undulose extinction, subgrain boundaries and chessboard patterns.

Plagioclases are abundant and show the typical polysynthetic twinning. Twin lamellas are sometimes offset along intracrystalline cracks, deformation twins are scarce.

K-feldspars usually show a patchy, irregular zoning (Plate 9B). Fractures and cracks in feldspars are commonly healed with quartz or feldspar (Plate 9C).

Hornblende usually occurs as both, very small well aligned, untwinned grains and as large, twinned grains. The large hornblendes sometimes have a rough arrow form with a trail of smaller hornblendes starting at the tip of the hornblende grain (Plate 11).

The microstructures in the western gneissic granites point to a magmatic (alignment of zoned feldspars) to submagmatic (chessboard pattern, microcracks) development of the fabric with minor solid-state overprint (offset of twin lamellae, deformation twins). No shear zones have been observed and the observed solidstate deformations mainly affected large feldspar grains. The division between magmatic, submagmatic and solid-state deformation is usually drawn according to the amount of melt present (see chapter 4.2.1.1). In terms of temperature the division between magmatic and submagmatic state for leucogranites is only a temperature difference of $4^{\circ} \mathrm{C}$ while for tonalites it is in the range of $63^{\circ} \mathrm{C}$ (Bouchez et al., 1992). For other granitoid rocks this division lies in between these two end members. These small temperature differences may be passed very fast by the cooling magma, therefore submagmatic fabrics may be hard to distinguish from high temperature solid-state deformational fabrics.

\subsubsection{Northern gneissic granites}

Microscopical analyzes in the marginal areas of the northern gneissic granites revealed chessboard patterns in quartz, bulging at quartz/quartz or quartz/feldspar boundaries is common. Strongly elongate quartz grains defining a lineation can be observed in some of the samples (Plate 12).

The anhedral to subhedral K-feldspar grains show undulose extinction, plagioclase resembles bend twin lamellas (Plate $8 \mathrm{~B}$ ) and deformation twins, their grain size is large and they usually are anhedral to subhedral. 
In the central part of the northern gneissic granites (Musana Communal Land area) quartz grains are much smaller. Inclusions in feldspars are scarce and microcline appears as very small sized grains with highly irregular grain boundaries.

Hornblende in the northern gneissic granites is scarce, biotites are abundant and much larger than in the southern gneissic granites. Small muscovite grains can frequently be observed neighboring biotites.

The observed microstructures in the marginal areas of the northern gneissic granites revealed indications for submagmatic deformation (chessboard patterns in quartz) and indicators for a solid-state overprint of the fabric (feldspar grains showing undulose extinction, bending of twin lamellae and deformation twins). Especially the undulose extinction in feldspars is indicative for a high internal strain and can only occur during solid-state deformation (Paterson et al. 1989). In the central part of the northern gneissic granites (Musana Communal Land area) no solid-state deformation can be observed.

The microscopic fabric in the outer parts of the northern gneisses shows the same deformational features as the southern gneisses, only the inner part (Musana Communal Land) appears to be less deformed (Plate 13), hand specimen are nearly isotropic.

\subsubsection{Equigranular granites}

In the equigranular granites, quartz usually shows undulose extinction and subgrains are frequently developed. Inclusions in quartz are small rutile-needles (no preferred orientation), K-feldspars and less common biotites also occur. The quartz grain boundaries show strong bulging with smaller lobes at quartz/quartz boundaries than at quartz/feldspar boundaries.

Plagioclases are nearly always serictized (Plate 14). The typical, polysynthetic twinning of plagioclase is well developed, lamellas are only slightly bend and no deformation lamellas can be observed.

Orthoclases make up the largest grains in the granodiorites (Plate 14B) resembling narrow albite lamellas forming a braided pattern in the orthoclase host. Poikilitic inclusions in orthoclase can frequently be observed, usually k-feldspars or 
plagioclases are included. Microcracks in feldspars, usually filled with quartz, and tiling of feldspars can be observed, zonation of feldspars is scarce.

Biotite occurs as cumulates of numerous single grains and possibly represent early crystallizations in the melt. Larger biotite grains are scarce, usually strongly altered and are frequently replaced by secondary magnetite.

The fine grained variety of the equigranular granites (Valeria/Surtic) is strongly altered (massive occurrence of epidote in anhedral feldspars). Some wide cracks filled with epidote and hornblendes point to a deformation in the solid state (Plate 14). Feldspars next to the cracks usually show slight deformational patterns such as bend twin-lamellas. Next to the differing grain size the two varieties may be distinguished according to the frequent occurrence of microcline and the low content of orthoclases and biotites in the fine grained granodiorite.

From their internal fabric the equigranular granites can be compared to the western gneissic granites, most microscopic fabric elements are indicative of a transition between submagmatic (microcracks, subgrains in quartz, tiling of feldspars) origin to a solid-state overprint (bend twin lamellae, cracks, exsolution in feldspars) of the fabric. However, the frequent occurrence of shear zones in the equigranular granites clearly points to a later solid-stage deformation of the granitoids.

\subsubsection{Porphyritic granite}

Quartz in the porphyritic granite shows beginning of subgrain development, the typical chessboard patterns are scarce. Grain boundaries are lobate indicating bulging, especially at quartz/quartz boundaries. Exsolution of quartz in feldspars is abundant.

Microcracks in feldspars are usually healed with quartz or feldspars showing a preferred elongated shape towards the center of the crack (Plate 9D). Distinguishing between quartz and feldspars in the cracks with microscopic analyzes only is difficult, most of the cracks are probably healed with feldspar due to solution of the host grain. Feldspar grains usually show a strong preferred alignment (see Plate 15), some of the feldspars show poikilitic inclusions (Plate $15 \mathrm{~A})$. Biotites usually are replaced by magnetites to a degree that only in the marginal part of the grain biotite may be identified. 
Melt segregation is a common phenomenon, especially in the north of the porphyritic granite at intergranular cracks in the phenocrysts. In zones with increased melt segregation no deformation patterns can be observed in the phenocrysts (except for microcracks in feldspars) as well as in the surrounding matrix. The porphyritic granite shows no signs of a solid-state overprint of the fabric. The observed microscopic fabric seems to be due to magmatic flow (alignment of phenocrysts) or interaction of rotating grains in the submagmatic state (chessboard patterns, healed microcracks, ?myrmekites?). 

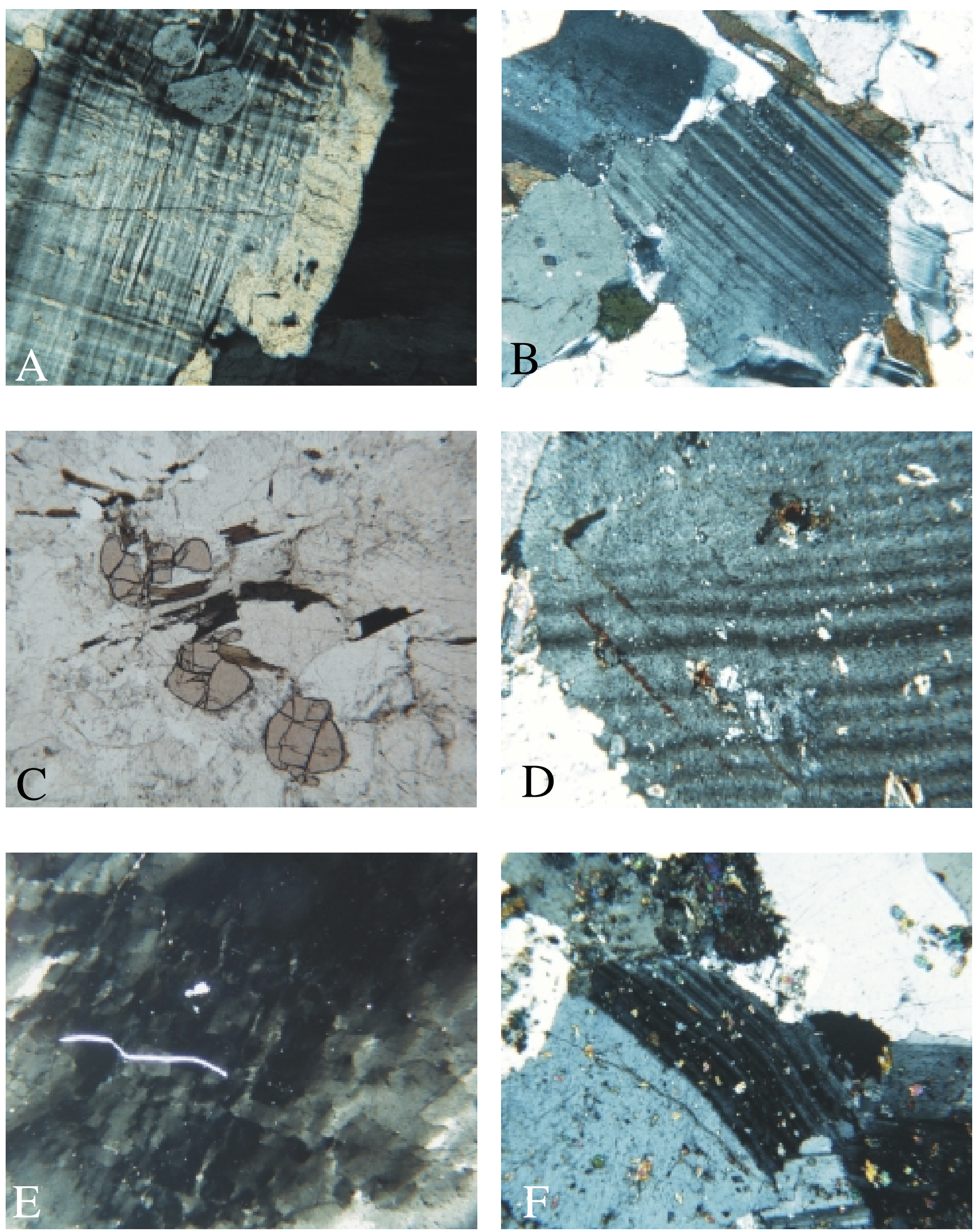

Plate 6: A - Exsolution of albite in microcline (southern gneissic granites, Foto is $0.06 \mathrm{~mm}$ wide). B Slightly bend twin lamellae in plagioclase of the northern gneissic granites (photo is $0.15 \mathrm{~mm}$ wide). $\mathrm{C}$ - Rounded, cracked garnet grains in the southern gneissic granites (photo is $0.4 \mathrm{~mm}$ wide). D Offset of twin lamellae at intragranular cracks in plagioclase (southern gneissic granites, photo is $0.04 \mathrm{~mm}$ wide). E - Large quartz grain showing typical chessboard patterns (southern gneissic granites, photo is $0.04 \mathrm{~mm}$ wide). F - Strong bend twin lamellae in plagioclase (southern gneissic granites, Foto is $0.15 \mathrm{~mm}$ wide). 

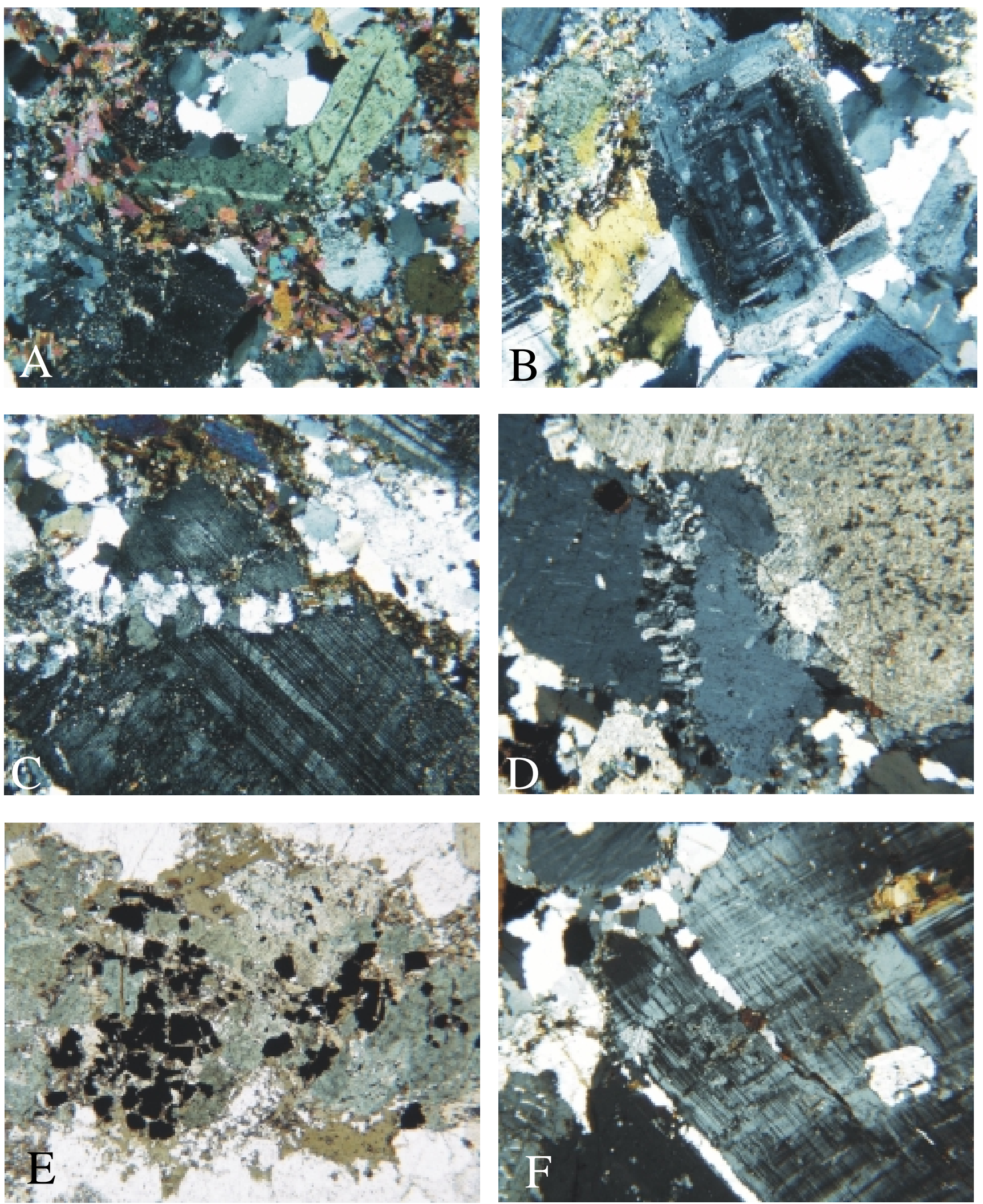

Plate 7: A- Hornblende grains in the western gneissic granites, large grains show typical twinning, smaller grains appear as untwinned cluster (photo is $0.15 \mathrm{~mm}$ wide). B - Irregular, patchy zoning of feldspar in the northern gneissic granites (photo is $0.06 \mathrm{~mm}$ wide). $\mathrm{C}$ - Microcracks in feldfspar healed with quartz (western gneissic granites, photo is $0.15 \mathrm{~mm}$ wide). D - Microcrack in feldspar, filling shows oriented growth (porphyritic granite, Foto is $0.4 \mathrm{~mm}$ wide). E - Replacement of biotite (southern gneissic granites) by magnetite. Magnetite grains are in contact to each other provoking an interaction of their magnetic properties (photo is $0.4 \mathrm{~mm}$ wide). $\mathrm{F}$ - Microcrack in microcline in the northern gneissic granites (photo is $0.15 \mathrm{~mm}$ wide). 

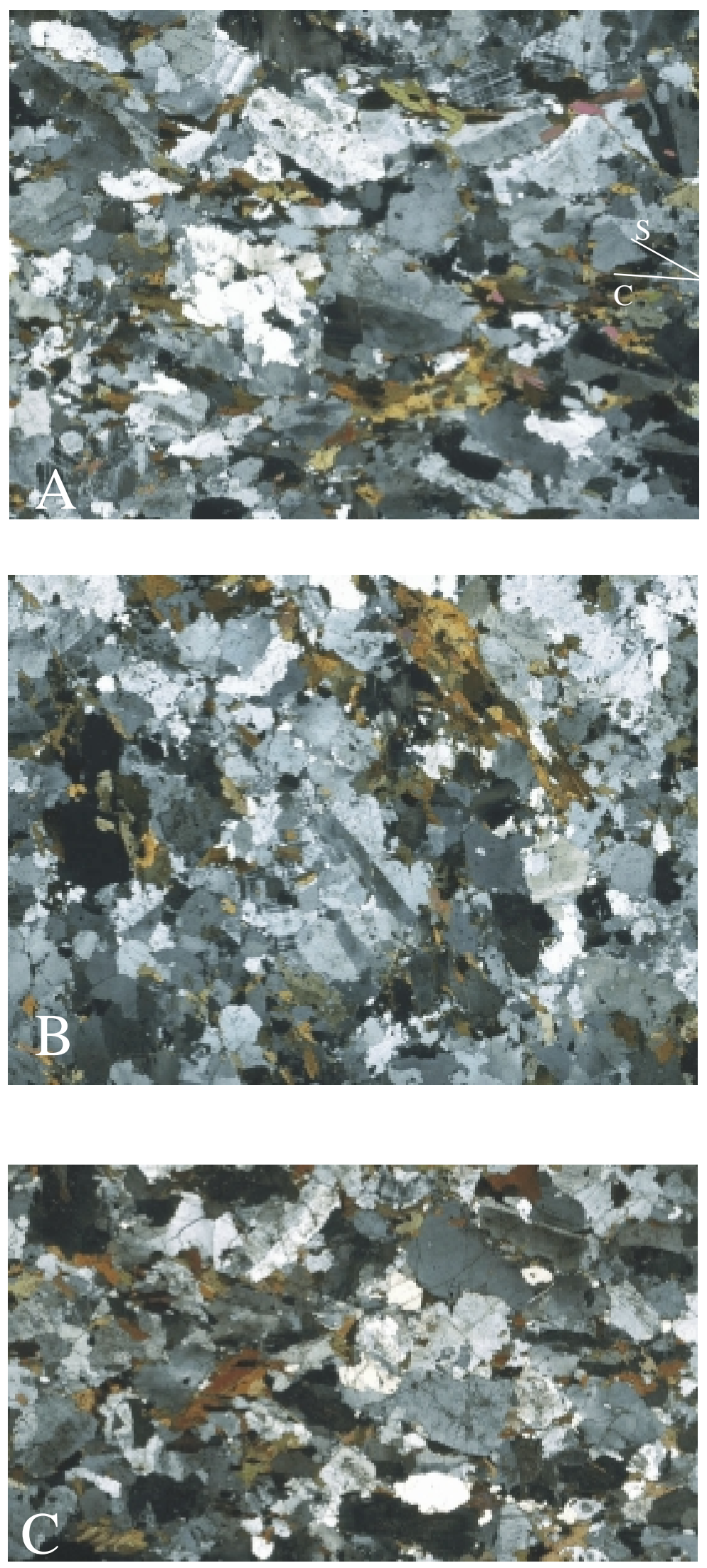

Plate 8: Sample JB305 from the southern gneissic granites (photos are $1.7 \mathrm{~cm}$ wide). A - Cut parallel to lineation and perpendicular to foliation, a weak SCfabric is developed with hornblende defining the C-plane. B - Cut parallel to foliation and lineation. $\mathrm{C}$ - Cut perpendicular to foliation and lineation. 

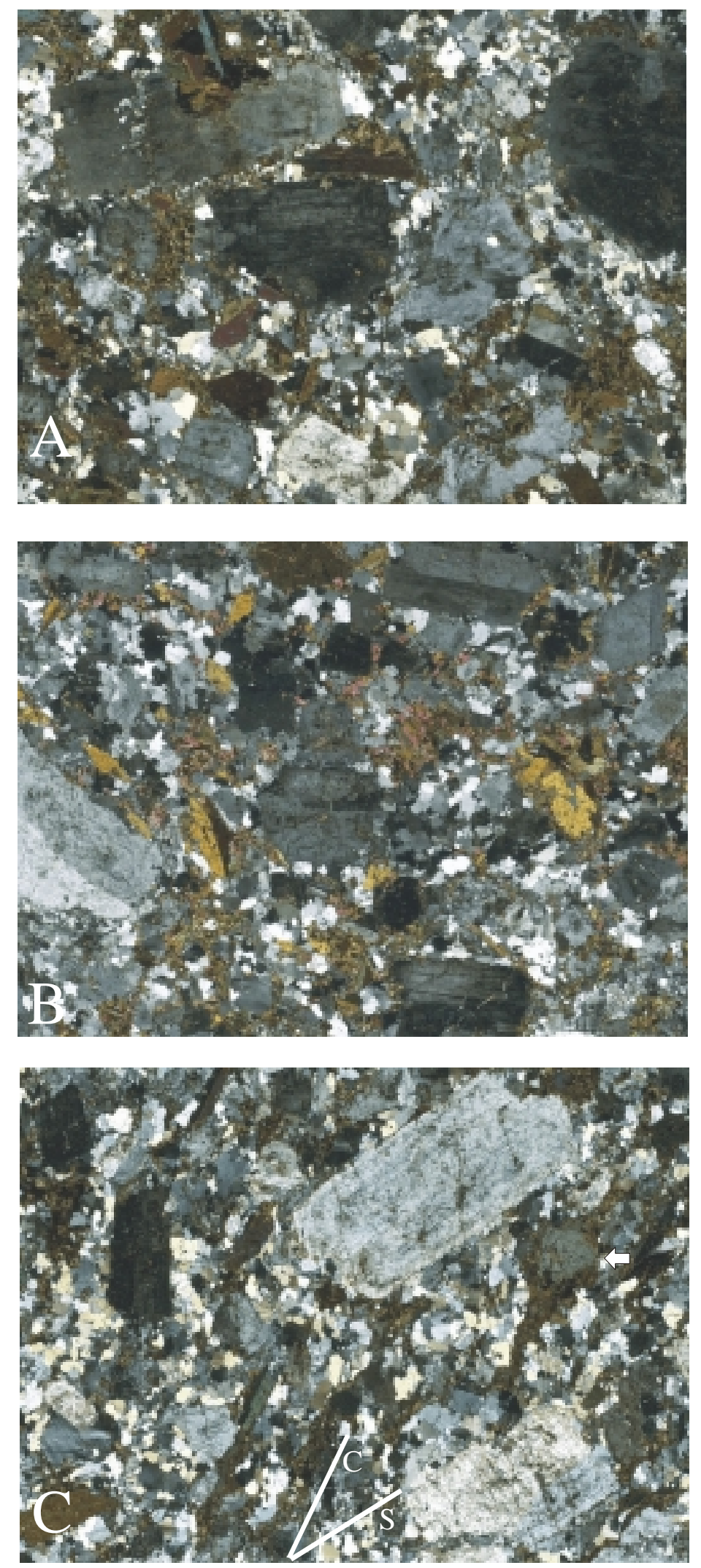

Plate 9: Sample from the western gneissic granites (JB134). A SC-fabric is developed, large plagioclase phenocrysts and hornblendes are oriented in a matrix consiting of mainly quartz and small hornblende grains. Thin sections were cut according to the magnetic fabric. A - Cut parallel to magnetic foliation. B - Cut perpendicular to magnetic lineation and magnetic foliation. C - Cut parallel to magnetic lineation. White arrow points to possible mantled porphyroclust.Photos are $1.7 \mathrm{~cm}$ wide. 

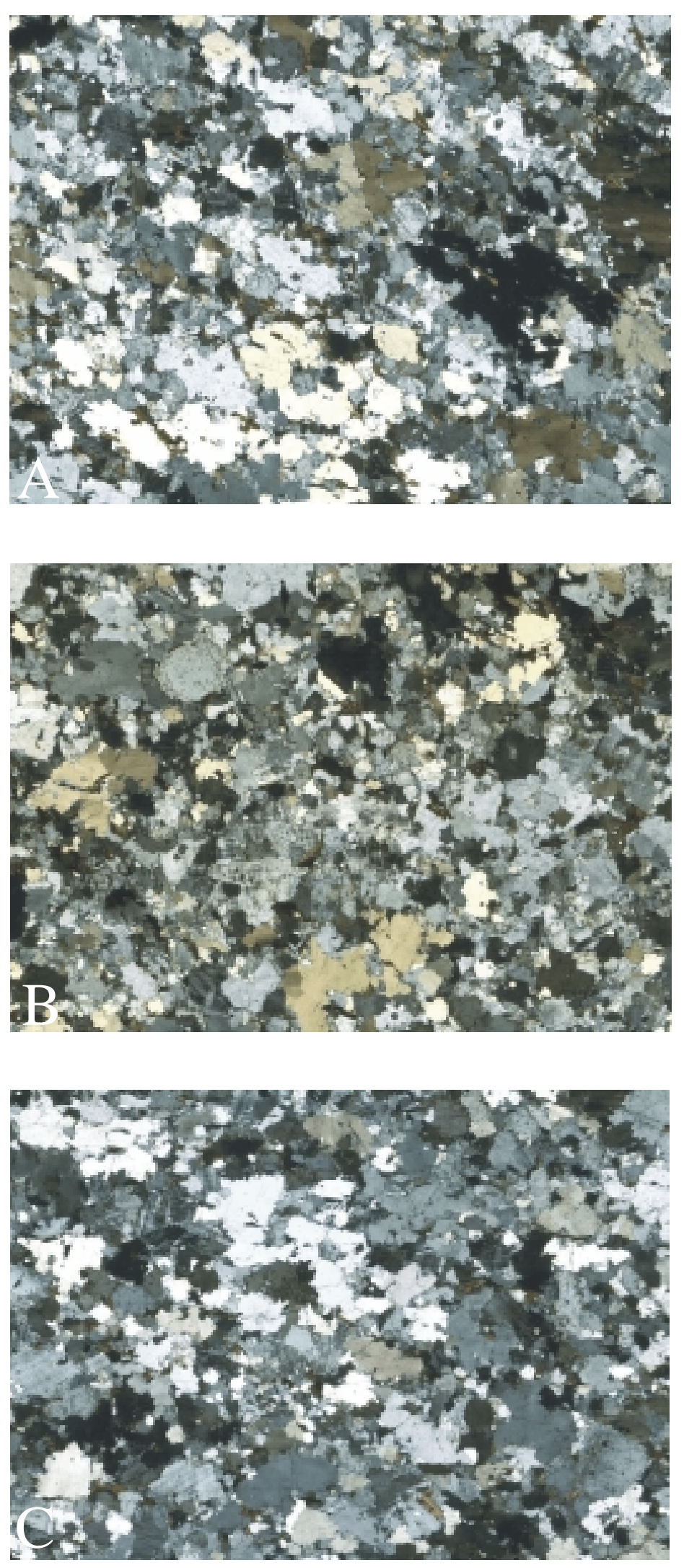

Plate 10: Sample JB71 from the marginal northern gneissic granites (photos are $1.7 \mathrm{~cm}$ wide). A - Cut parallel to lineation, perpendicular to foliation. Strongly elongate quartz grains define the lineation (compare Fig. 4.11, quartz textures of the sample). B - Cut perpendicular to lineation and foliation. $\mathrm{C}$ - Cut parallel to foliation and lineation. 

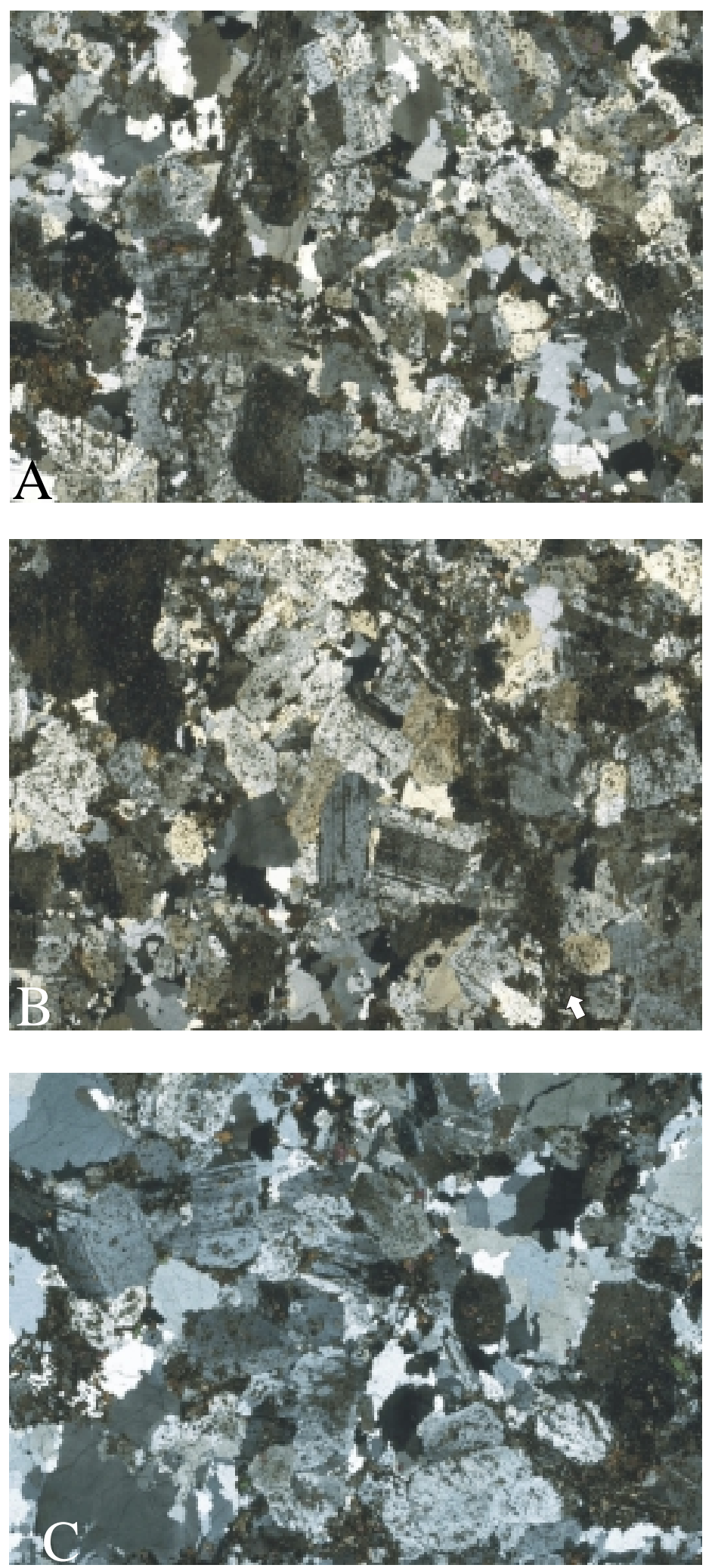

Plate 11: Typical sample from the equigranular granites (JB146).

Feldspars are strongly sericitized, small shear zones can be observed. A - Cut parallel to lineation, perpendicular to foliation. B - Cut parallel to foliation, perpendicular to lineation. White arrow points in direction of crack. C - Cut perpendicular to lineation and foliation.

Photos are $1.7 \mathrm{~cm}$ wide. 

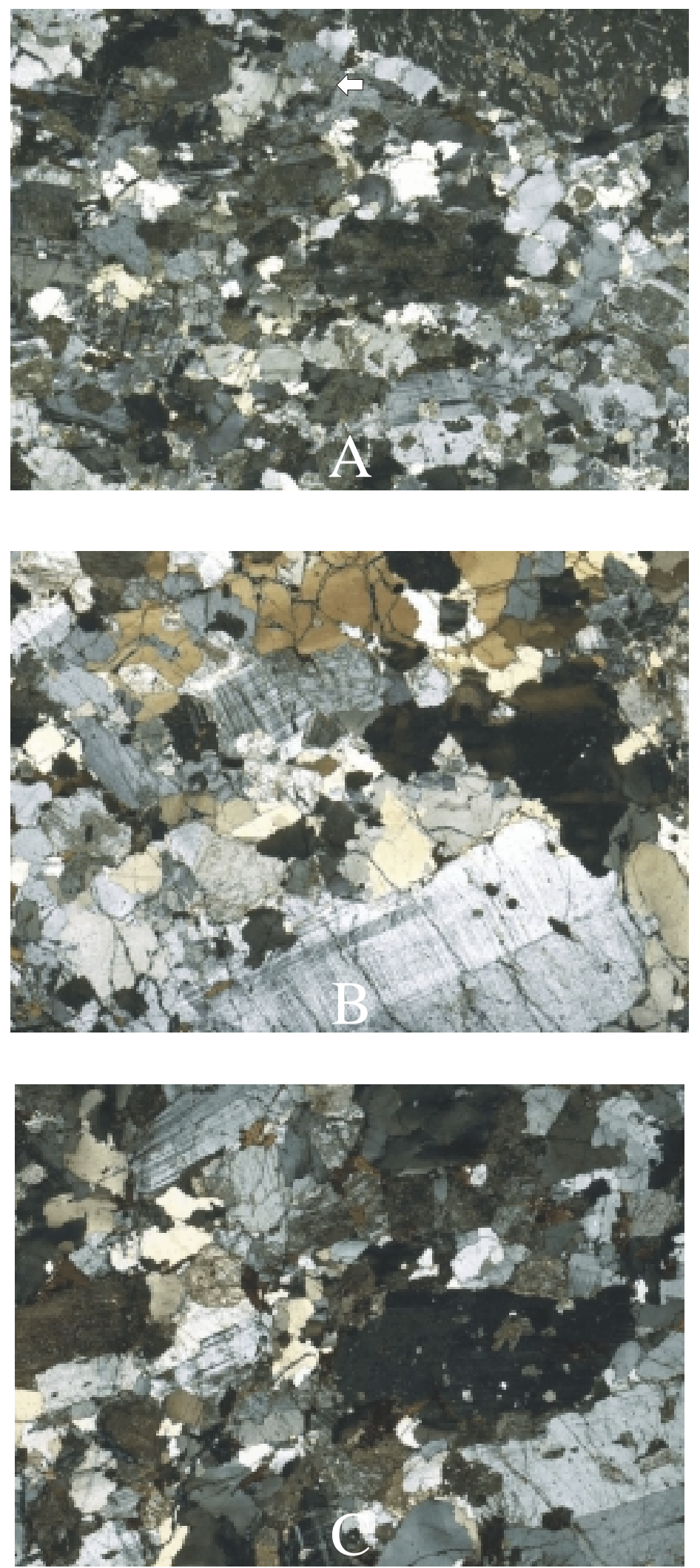

Plate 12: Three different samples from the porphyritic granite (A - JB273, B - JB220, C - JB218). All show a weak alignment of feldspar phenocrysts, solid state deformations are scarce. Photos are $1.7 \mathrm{~cm}$ wide. 


\subsection{Macroscopic rock fabric}

The macroscopic foliation has been measured in the field where possible, lineations were not detected in the field. The macroscopic foliation of the gneissic granites shows a stable trend to parallel the outer margins of the pluton. Internal lithological boundaries are frequently crosscut. The dip is moderate, ranging between $40^{\circ}$ and $60^{\circ}$ dipping away from the batholith center (see Fig. 4.6 and Fig. 4.7). Only in the northern gneissic granites in the Musana Communal Land area foliation seems to be randomly oriented. Foliation planes outside the Musana Communal Land area are parallel to the outer margin of the batholith and the inner lithological contact.

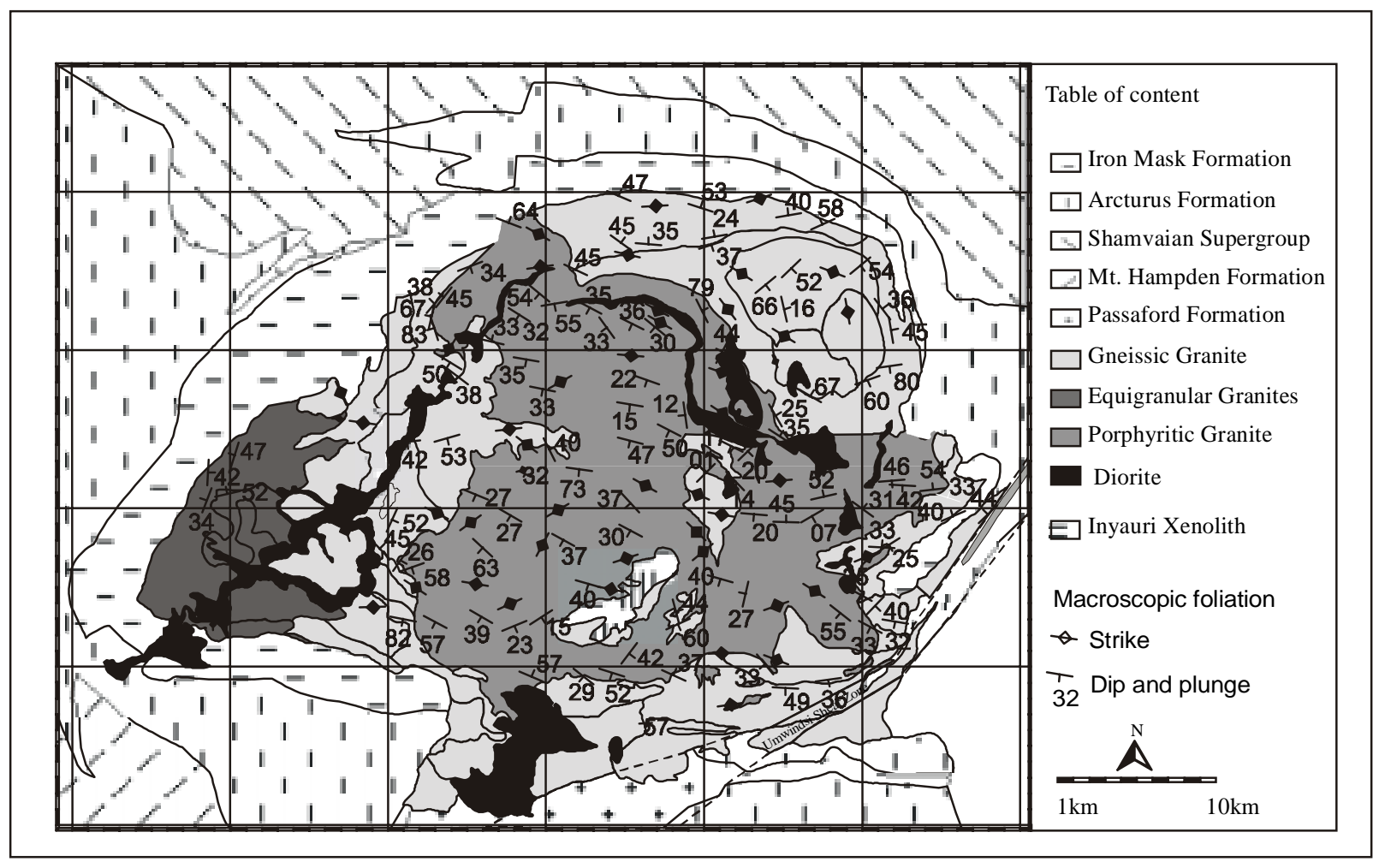

Fig. 4.6: Macroscopic foliation in the Chinamora Batholith.

In the equigranular granites in the west of the Chinamora Batholith only few outcrops were found where a measurement of the macroscopic foliation was possible. Still, the few measurements showed a tendency to parallel the outer margin of the pluton with dips ranging from $30^{\circ}$ to $50^{\circ}$ away from the batholith center (see Fig. 4.6). Foliation planes in the porphyritic granite trend WNW-ESE 
with a preferred dip to the SW. Only in some areas near the contact with other lithologies the strike is margin parallel.
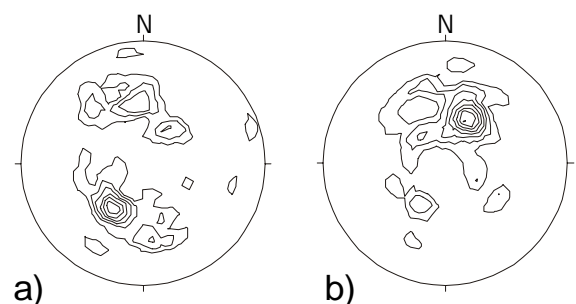

Fig. 4.8: Schmidt net projection (lower hemisphere) of the macroscopic foliation of the a) gneissic granites $(n=41)$ and b) porphyritic granite $(n=71)$.

The angle of dip is usually moderate, ranging between $30^{\circ}$ and $50^{\circ}$ (see Fig. 4.6 and Fig. 4.7). Only at the northern margin of the porphyritic granite the foliation dips to the NE. The preferred WNW-ESE orientation of the foliation provokes that contacts to the gneissic granites as well as the erosional windows in the porphyritic granite are cross cut. Foliation planes near the Inyauri Xenolith in the porphyritic granite cross cut the xenolith and seem not to be deflected.

\subsection{Texture analyzes}

Texture analyzes have been performed using a U-stage on biotites, hornblendes and quartz of the different lithologies in the Chinamora Batholith. The resulting measurements were rotated into the geographical orientations and are presented as pole figure plots (Schmidt net, lower hemisphere). Density plots were calculated using the algorithm of Adam (1989).

\subsubsection{Biotite textures}

Biotite (001)-poles have been measured in samples of the different lithologies in the Chinamora Batholith. In total 14 samples have been measured for the gneissic granites, one for the equigranular granites and five for the porphyritic granite (see Fig. 4.8). The orientation of the maximum densities of (001)-poles depends on the sampling location, all the measured samples of the gneissic granites showed a roughly margin parallel orientation of the basal planes of biotites. The orientation patterns of the mica (001)-poles usually reflect point maxima or show the tendency to form partial girdles indicative for a rotation of biotite flakes around a preferred 
axis. The calculated densities of the mica (001)-poles reflects the different intensities of deformation observed in the microstructural analyzes.

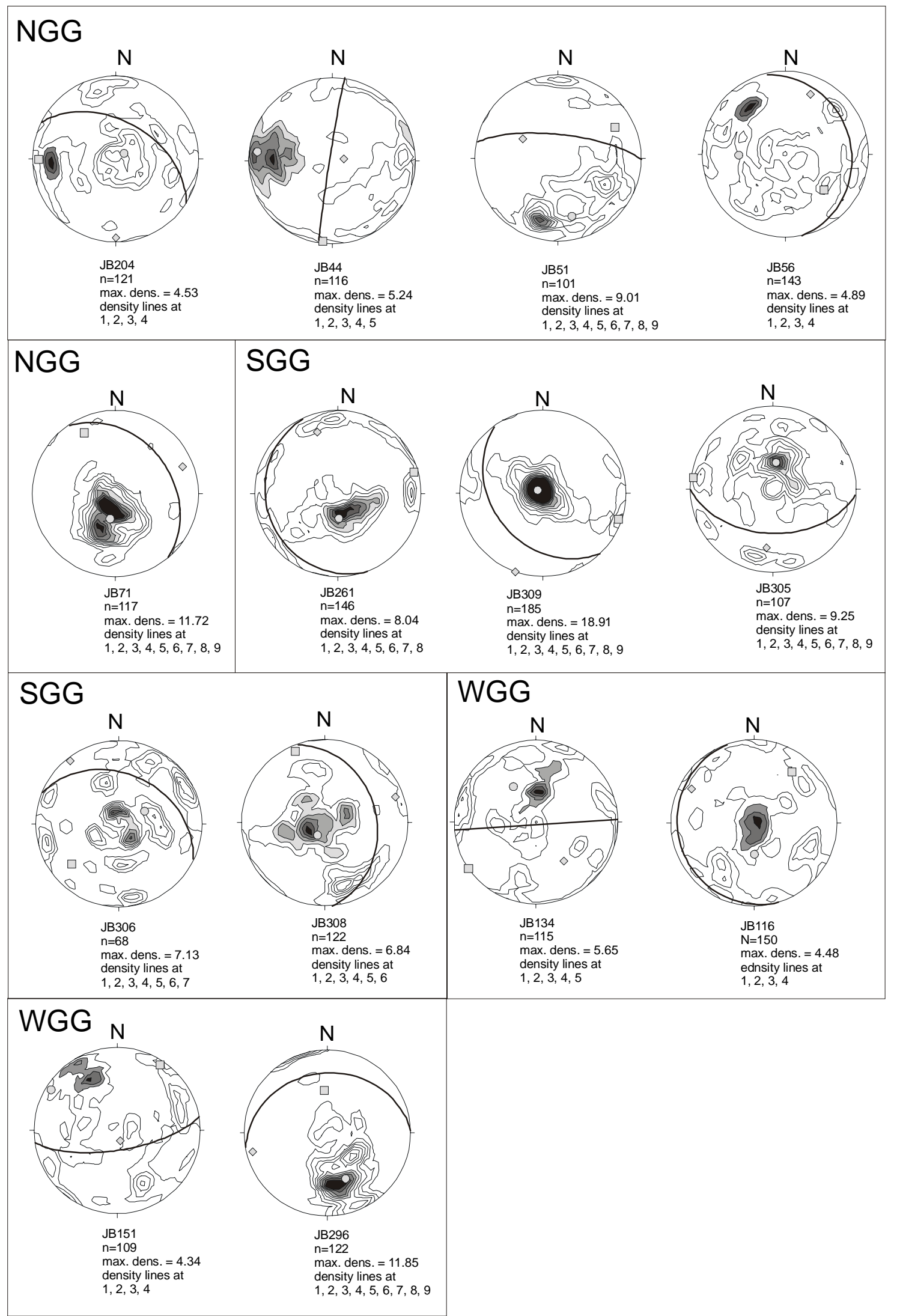

Fig. 4.8: Textures from biotite U-stage measurements. Solid line represents macroscopic foliation, grey shading indicates highest calculated density, grey symbols represent orientation of Eigenvectors (square $=e_{1}$, diamond $=e_{2}$, circle $=e_{3}$ ). 

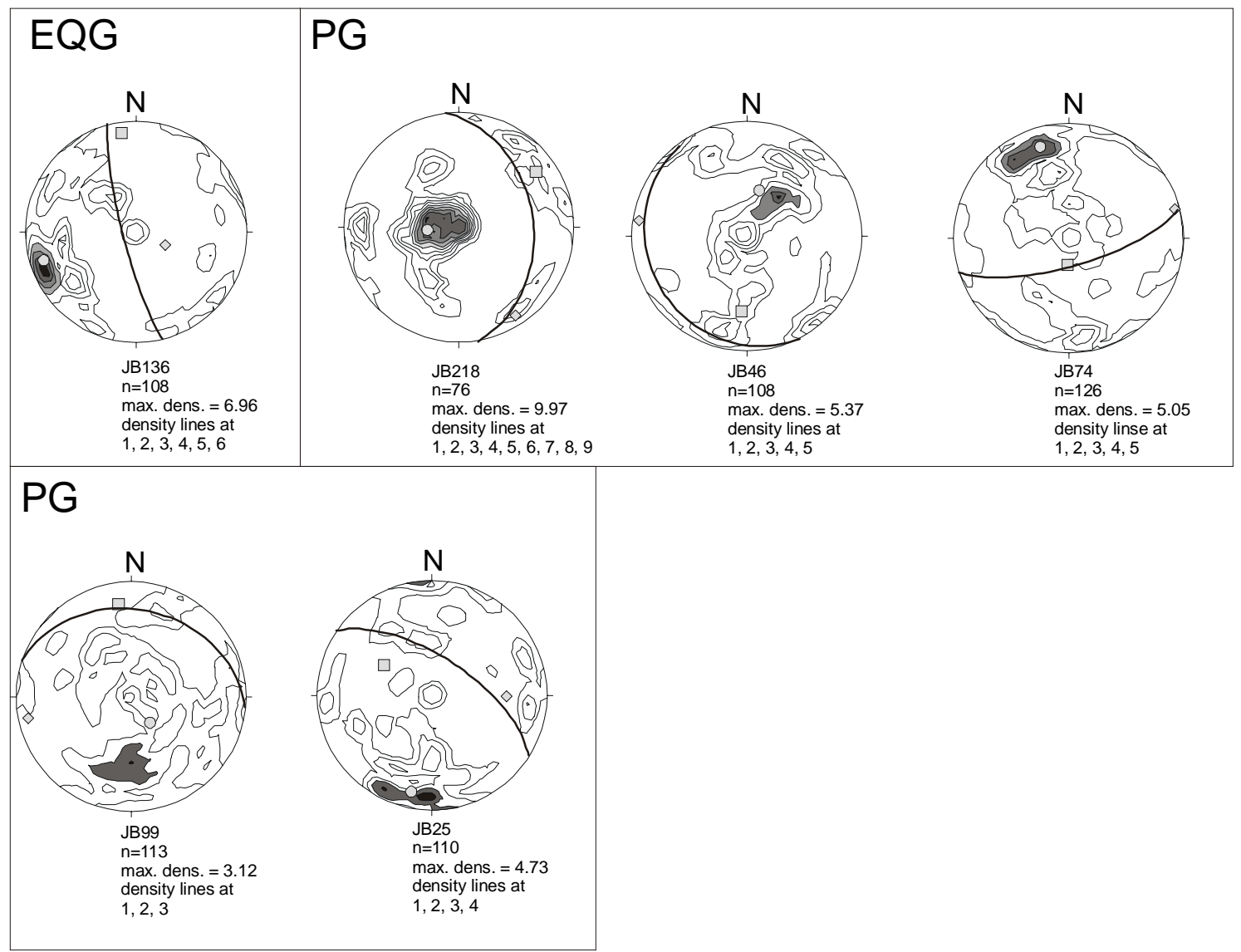

Fig. 4.8: continued

The distinctness of the mica orientation is highest in the southern gneissic granites while most of the western gneissic granites show less distinct orientation patterns. In the northern gneissic granites two different sets can be distinguished, one in the Musana Communal Land area where the orientation pattern is less distinct (JB204 and JB56, see Fig. 4.8) and one in the marginal areas of the northern gneissic granites where the distinctness of the orientation patterns is high (sample JB44, JB51 and JB71, see Fig. 4.8).

In the equigranular granites only one sample was measured, the resulting pole figure is presented in Fig. 4.8. The distribution of mica (001) poles roughly reflects margin parallel orientation of the macroscopic foliation of this sample.

U-stage measurements in the central porphyritic granite revealed weak point maxima for most of the samples with a tendency to form partial girdles. Samples in the center of the batholith do not show consistency with any stable trend (some 
are margin parallel, some show a preferred subhorizontal E-W trend of biotite orientations). The Eigenvectors and Eigenvalues can be used to describe the bestfit ellipsoid for the respective biotite measurements. The Eigenvalues can be used to calculate a shape parameter $\left(T_{\text {tex }}\right)$ of the texture (see e.g. Jelinek, 1981; Ullemeyer, 1992). For samples with a weak texture neutral or even prolate shapes were calculated from the texture measurements (e.g. JB204, $T_{\text {tex }}=-0.236$; JB116, $T_{\text {tex }}=0.027, J B 99, T_{\text {tex }}=0.045$ ) while calculations for samples with a distinct texture resulted in oblate shapes (e.g. JB309, $T_{\text {tex }}=0.572$, JB71, $T_{\text {tex }}=0.651$ ). The prolate shapes have as well been observed by Siegesmund et al. (1995) in samples where biotites were randomly oriented or oscillated around a preferred axis.

\subsubsection{Hornblende textures}

From two samples the orientation pattern of hornblendes were determined, mainly for the theoretical calculations of the AMS tensor (see chapter 9). The measurements were performed using the algorithm described e.g. by Cumbest (1990). This method uses the principal axes of the optical indicatrix and a fiducal marker such as cleavage to determine the orientation of the crystallographic axes. Only two indicatrix axes and the cleavage must be measured, the third optical and hence crystallographic axis can be calculated.

Both measured hornblende textures resemble typical textures in magmatic or metamorphic rocks (Berger, 1995) with a point maximum or weak girdle distribution of [100] normal to the foliation. As expected the sample from the southern gneissic granite resembles a more distinct texture of the different axes and hence a more distinct orientation pattern of hornblendes than the measurements of the western gneissic granites (see Fig. 4.9). 


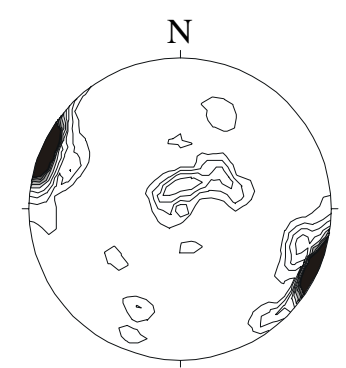

305

a-axis, $\mathrm{n}=57$

max. dens. $=18.82$ density lines at

$1,2,3,4,5,6,7,8,9$

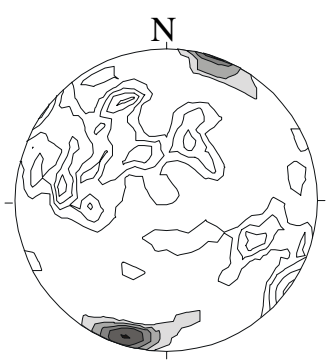

134

a-axis, $\mathrm{n}=66$

max. dens. $=5.12$

density lines at

$1,2,3,4,5$

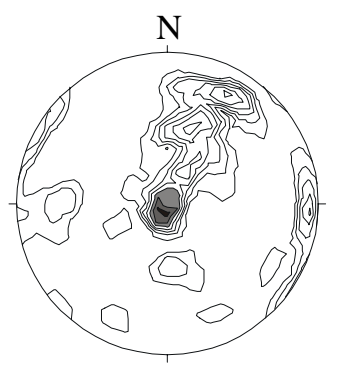

b-axis, $n=57$ max. dens. $=7.62$ desnity lines at 1, 2, 3, 4, 5, 6,7

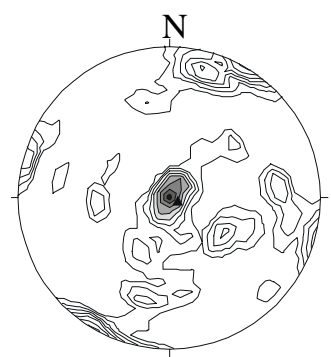

b-axis, $n=66$ max. dens. $=8.58$ density lines at $1,2,3,4,5,6,7,8$

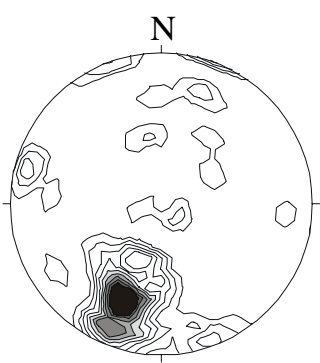

c-axis, $\mathrm{n}=57$

max. dens. $=12.03$

density lines at

$1,2,3,4,5,6,7,8,9$

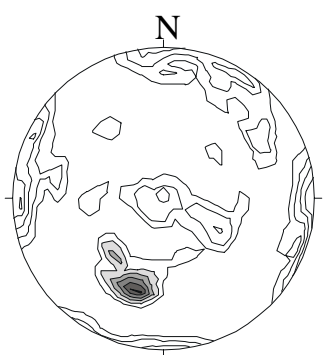

c-axis, $\mathrm{n}=69$

max. dens. $=5.94$

density lines at

$1,2,3,4,5$

Fig. 4.9: Hornblende textures from U-stage measurements. Sample 305 is from the southern gneissic granites, sample 134 from the western gneissic granites.

\subsubsection{Quartz textures}

In total five different samples have been measured, one for each of the different units within the Chinamora Batholith (see Fig. 4.10). From the northern gneissic granites a sample from outside the Musana Communal Land area has been chosen (sample JB71, see Fig. 4.10) since the samples from the Musana Communal Land are isotropic or nearly isotropic. Sample JB71 shows a very strong orientation pattern of the quartz c-axis with a subhorizontal N-S orientation which is parallel to the outer margin of the batholith and the inner boundary of the Musana Communal Land area. The quartz texture from the southern gneissic granites (sample JB305) shows a double maxima, a typical feature for quartz deformed in or nearby shear zones at higher temperatures (Riekels \& Baker, 1977; Ramsay \& Graham, 1970). 

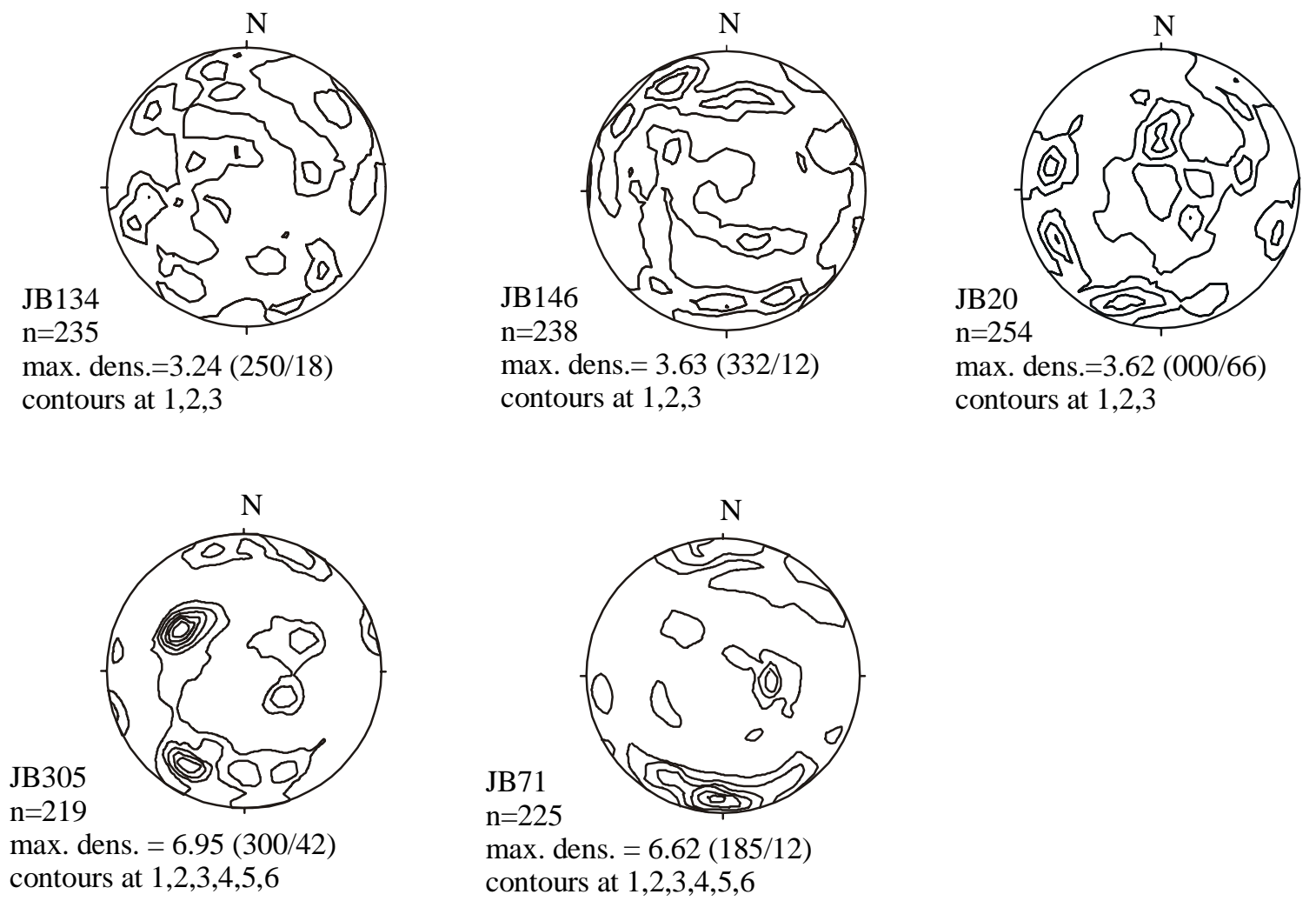

Fig. 4.11: Pole figures of quartz textures obtained from U-stage measurements.

The measurements of the western gneissic granites (sample JB134) and the equigranular granites (sample JB146) only exhibit a random distribution of the crystallographic c-axes.

Measurements of the orientation patterns of quartz c-axes of the porphyritic granite (sample JB20) revealed a very weak, irregularly occupied crossed girdle. This has been assigned by Tullis et al. (1973) to a preferred basal glide at higher temperatures. However, since the fabric is only very weakly developed its interpretation is ambiguous.

\subsection{Conclusions}

The microscopic analyzes showed that a division of the different units of the Chinamora Batholith according to their amount of deformation can be drawn. The southern gneissic granites show the highest deformational features in the solid state while the other gneissic granites only show a weak overprint of magmatic to submagmatic features in the solid state. The microstructures observed in the 
equigranular granites are comparable to those of the western gneissic granites. The northern gneissic granites shows two distinct units, the central Musana Communal Land area resembles isotropic or nearly isotropic rocks while the marginal areas of the northern gneissic granites shows a moderately to strongly developed fabric. This can be explained by two pulses of magma with the magma pulse now forming the Musana Communal Land being slightly younger than the marginal northern gneisses. The second magma pulse pushed the first pulse outwards producing the observed fabric. The central porphyritic granite shows no solid state overprint of the magmatic or submagmatic fabric. The macroscopic foliation in the granitoid rocks of the Chinamora Batholith is margin parallel in the gneissic granites and, except for the Musana Communal Land area, cross cuts internal lithological boundaries. This indicates an at least nearly coeval emplacement of the different lithologies in the different gneissic granites. Macroscopic fabric in the porphyritic granite shows a stable trend that can not solely be related to the emplacement mechanism. The orientations of the whaleback domes in the porphyritic granite has been mapped using a SPOT (Système Pour l'Observation de la Terre) satellite image, they preferably are orientated in a WNW-ESE direction and probably eroded controlled by the orientation of the fracture network. This preferred orientation is subparallel to the macroscopic foliation. Some major fault zones can be recognized very well, they usually are pathways for rivers draining the area. Their strike is very consistent, either NNW-SSE or WNW-ESE. No other linear features are recognizable in the SPOT-image due to the extensive use of the area for farming. Only the northern gneissic granites and the porphyritic granite can be distinguished from the other units.

The biotite texture analyzes performed on samples from the southern gneisses showed that they all display a strong preferred alignment of biotite 001-poles. In the western and northern gneissic granites deformation was less distinct and hence the developed fabrics show a less distinct orientation pattern. Only some samples in the marginal areas of the northern gneissic granites exhibited a welldefined fabric which can be drawn back to the later intrusion of the granitoids in the Musana area. The orientation of biotite fabric in the analyzed samples does not reflect any common emplacement mechanism. Biotite foliation is not always parallel to the outer margin of the batholith or to internal lithological boundaries. 
Given the observed structural patterns in the different gneissic granites it seems obvious that the different lithologies resemble different plutons that intruded during a distinct tectonic setting over a more or less longer period of time. During the time span of intrusions either the orientation of the regional stress-field has changed slightly or the different lithologies behaved different due to rheological differences and/or a changing amount of coupling between stress-field and intrusions (e.g. intruding into the "shadow" of earlier intrusions) giving rise to the observed different fabrics. The southern gneisses have obviously suffered additional deformation as can be concluded from the more pronounced solid-state deformation, the subhorizontal orientations of biotites and the double maxima of the measured quartz texture. Orientations of the biotites in the porphyritic granite indicate a different textural genesis. 


\section{Methodology of magnetic measurements}

From the drill cores taken in the field measurement cylinders have been prepared for the measurement of different magnetic properties. This includes the measurement of the Anisotropy of the Magnetic Susceptibility (AMS), High Field Analyses (HFA) as well as measurements with the Curie-balance. The basic background of the magnetic rock properties and their origin is described below before analyzing the measurement results.

\subsection{Magnetic properties and their origin}

Since the magnetic properties derive in part from the spin of electrons around the nucleus of atoms any substance has magnetic properties (if temperature $T>0 \mathrm{~K}$ ), no matter how weak they are. If an external magnetic field is applied to a substance a magnetization is produced which characterizes the magnetic properties of the substance. If the magnetization is directed into the opposite direction compared to the applied field the substance has diamagnetic properties (Tarling \& Hrouda, 1993; see Fig. 5.1). The magnetization in the opposite direction is lost as soon as the external field is removed. Most common rock forming minerals with diamagnetic properties are quartz and feldspars. The susceptibility of diamagnetic substances is by definition negative due to their opposite orientation of magnetization vectors with respect to the externally applied field. Since the bulk susceptibility of diamagnetic minerals is very low they usually are neglected in magnetic measurements if paramagnetic and/or (anti)ferri(o)magnetic minerals are present. All other natural substances are paramagnetic, the magnetization has the same direction as the applied external field (Tarling \& Hrouda, 1993; see Fig. 5.1). Most common rock-forming paramagnetic minerals are biotite and hornblendes. A few substances have a very strong magnetization and may not loose their magnetization after the external field is removed. These substances are called ferrimagnetic. Ferrimagnetic substances are subdivided into ferromagnetic, antiferromagnetic and ferrimagnetic (senso stricto) substances (Tarling \& Hrouda, 1993). This division of ferrimagnetic properties depends on the coupling of electron spins. Ferrimagnetism is superimposed on paramagnetic behavior, if the coupling of electron spins is destroyed by e.g. heating above a specific temperature (called Curie-temperature for ferri(o)magnetic substances or 
Néel-temperature for antiferromagnetic substances) ferrimagnetic substances behave paramagnetic (Tarling \& Hrouda, 1993). If the alignment of electron spins forces all magnetic vectors to point into the same direction the resulting magnetism is called ferromagnetism (see Fig. 5.1). If the electron spins of two or more neighboring atoms are coupled they form so called lattices which have a specific direction of magnetization. If two neighboring lattices show opposite directions of magnetization the substance is called antiferromagnetic (see Fig. 5.1). If the lattices show opposing directions of magnetization but not of the same strength the substance is called ferrimagnetic (s.s.; Tarling \& Hrouda, 1993; see Fig. 5.1).

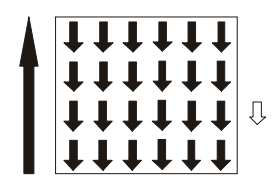

a) Diamagnetic

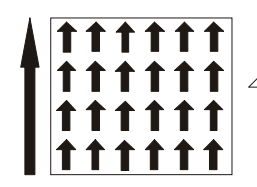

b) Paramagnetic

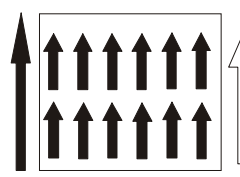

c) Ferromagnetic

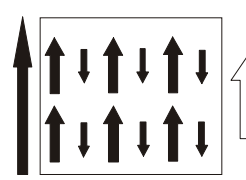

d) Ferrimagnetic

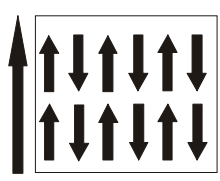

e) Antiferromagnetic

Fig. 5.1: Magnetic properties in external fields (black arrow outside boxes). Light arrow at the side of the boxes indicates orientation and strength of the resulting magnetic field induced by the measured sample (modified from Tarling \& Hrouda, 1993).

\subsection{Magnetic properties of minerals}

Since the alignment of atoms in the crystal structure of euhedral minerals is not uniform in all directions minerals display a more or less pronounced anisotropic magnetic behavior. This is expressed in the three principal axes $k_{1}, k_{2}$ and $k_{3}$ where $k_{1}$ is the axis with the strongest magnetization and $k_{3}$ with the weakest magnetization while $k_{2}$ represents an intermediate magnetization (Tarling \& Hrouda, 1993). These three axes are perpendicular to each other and represent the so called magnetic ellipsoid which frequently is used to demonstrate the magnetic anisotropy of minerals (and rocks, see chapter 5.3). The orientation of the different magnetic axes of diamagnetic and paramagnetic minerals is controlled by the orientation of the respective crystallographic axes of the minerals (crystal anisotropy; Tarling \& Hrouda, 1993). Since diamagnetic minerals usually are neglected in the interpretation of magnetic data of granitoid rocks they will not be discussed any further. The most important paramagnetic minerals in granitic rocks concerning the magnetic behavior are biotites and hornblendes. In biotite $\mathrm{k}_{3}$ is oriented parallel to the crystallographic c-axis (normal to basal plane of biotite) 
while $\mathrm{k}_{1}$ and $\mathrm{k}_{2}$ are oriented in the basal plane (Zapletal, 1990; Ballet \& Coey, 1982, see Fig. 5.2).

In hornblende, $k_{1}$ is oriented parallel to the crystallographic b-axis while $k_{2}$ and $k_{3}$ are oriented parallel to the crystallographic $\mathrm{c}$ - and $\mathrm{a}^{*}$-axis respectively (Friedrich, 1994; see Fig. 5.2).

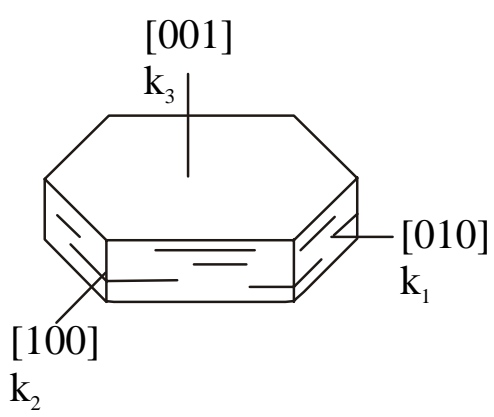

Biotite

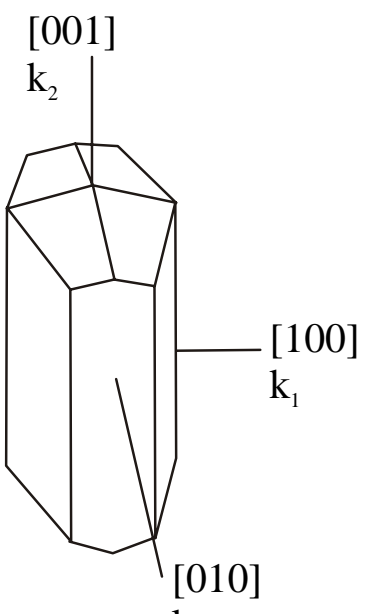

Hornblende ${ }^{\mathrm{k}}$

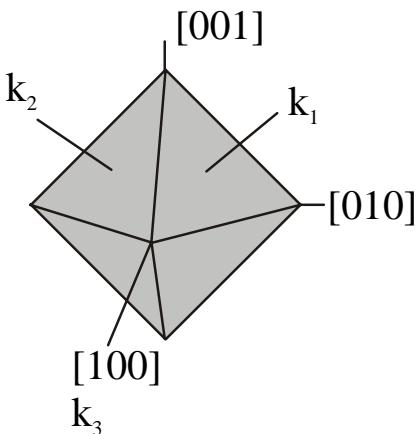

Magnetite

Fig. 5.2: Orientation of the main magnetic axes and the respective crystallographic axes in the most important minerals of granitoid rocks. While biotite and hornblende show a crystal anisotropic behavior of the magnetic properties, magnetite has a shape anisotropic behavior. Therefore, the orientation of the respective magnetic axes may change according to its grain shape.

In case of cubic minerals (mainly ore minerals) the magnetic mineral anisotropy is controlled by the grain shape (Tarling \& Hrouda, 1993). $k_{1}$ is oriented parallel to the axes of the longest grain diameter, $k_{2}$ to the intermediate and $k_{3}$ to the axis with the shortest diameter (Archanjo et al., 1995). One prominent example for this is the ferrimagnetic (s.s.) magnetite (see Fig. 5.2) which frequently is observed in granitoid rocks. The shape anisotropy only occurs in minerals of the titanomagnetite series (magnetite, haematite, rutile etc.; Damm, 1980; Tarling \& Hrouda, 1993).

\subsection{Magnetic rock properties}

Most magnetic measurement methods give the magnetic properties for the whole rock and not for the contended minerals. The rock magnetization is the summed contribution of all minerals in the rock. The bulk susceptibility of this summed contribution can be calculated using equation [1]. 
$K_{\text {bulk }}=V d{ }^{*} K d+V p * K d+V f{ }^{*} K f$

where $K_{\text {bulk }}$ is the bulk susceptibility, $V(d, p, f)$ is the volume (percentage) of diamagnetic, paramagnetic and (anti)ferri(o)magnetic minerals and $K(d, p, f)$ is the bulk susceptibility of the specific minerals (Hrouda, 1982).

The magnetic anisotropy of a rock depends on the orientation of the mineral anisotropy in the rock. If the mineral anisotropies are oriented in a way that the different magnetic axes are constructive (e.g. strong alignment of minerals) the rock sample will show an anisotropic magnetic behavior as well. If the mineral anisotropies are oriented destructive (e.g. minerals are randomly distributed) the rock will be magnetically isotropic. For an interpretation of the observed magnetic anisotropy it is therefore important to analyze the minerals contributing to the magnetic properties of the rock. The magnetic anisotropy of a whole rock sample is characterized in the same way as the anisotropy of minerals using $k_{1}, k_{2}$ and $k_{3}$. If, for example, next to diamagnetic minerals only paramagnetic biotite contributes to the magnetic properties of the whole rock the summed contribution of all biotites is measured. Therefore, the orientation of the magnetic axes $k_{1}, k_{2}$ and $k_{3}$ reflect the summed orientation of the biotites.

If more than one paramagnetic phase contributes to the whole rock magnetic anisotropy the resulting orientation of $k_{1}, k_{2}$ and $k_{3}$ is a mixture of all contributing phases. Even if only small amounts of ferri(o)magnetic minerals are presented in the analyzed rock sample the ferri(o)magnetic properties usually control the magnetic anisotropy of the whole rock sample. In this case the obtained orientations of $k_{1}, k_{2}$ and $k_{3}$ of the whole rock sample represent a mixture of every contributing paramagnetic phase and every contributing ferri(o)magnetic phase in the rock. Due to the complex origin these orientations are not yet interpretable but have to be separated into their contributing paramagnetic and ferri(o)magnetic properties (see chapter 5.4.2 for details).

\subsection{Measurements of magnetic fabric}

The measurement of magnetic fabric of rocks is a frequently used method to obtain structural data on rocks which appear to be macroscopically isotropic. As for most measurement methods, the actual measurement is simple but to be able 
to interpret the results from the measurement, understanding of the actual measured values is crucial. Therefore the following chapters will describe the used methods and the obtained values, their calculation and their meaning shortly.

\subsubsection{Measurement of the AMS}

The AMS measurement is based on the induced change of an applied magnetic field $(\vec{H})$ through the magnetic properties of the sample. The strength of the induced magnetization $(\vec{M})$ can be correlated with the applied field $(\vec{H})$ by the susceptibility $(\overline{\bar{k}})$ which is a constant of proportionality (e.g. Tarling \& Hrouda, 1993). The equation to calculate the magnetic properties can be simplified to:

$\overline{\mathrm{k}}=\frac{\overrightarrow{\mathrm{M}}}{\overrightarrow{\mathrm{H}}}$

with the susceptibility $\overline{\overline{\mathrm{k}}}$ (dimensionless, in $\mathrm{SI}$ units), $\overrightarrow{\mathrm{M}}$ is the magnetic dipole moment per unit volume (in $\mathrm{Am}^{-1}$ ) and $\overrightarrow{\mathrm{H}}$ the applied magnetic field strength (in $\left.A m^{-1}\right)$. $\overline{\mathrm{k}}$, a second rank tensor, can be visualized as an ellipsoid (see Fig. 5.3) where the three orthogonal main axes of the ellipsoid are calculated from the eigenvalues and eigenvectors of the tensor matrix with the susceptibilities $k_{11}, k_{22}$ and $\mathrm{k}_{33}$.

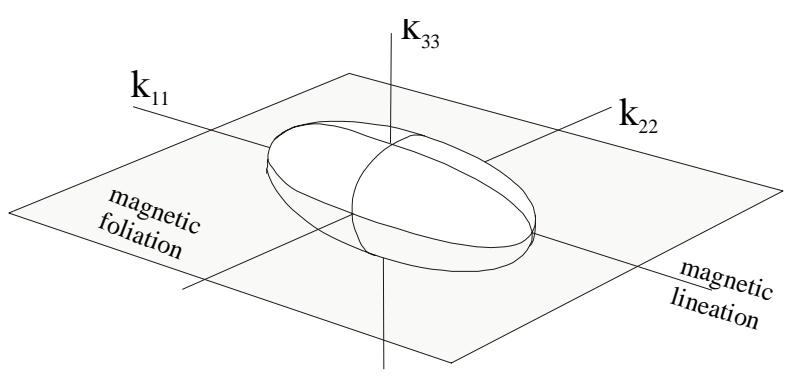

Fig. 5.3: Tensor from AMS measurements visualized by an ellipsoid with the eigenvalues $\left(\mathrm{k}_{11}, \mathrm{k}_{22}\right.$ and $\left.\mathrm{k}_{33}\right)$ of the tensor matrix as the main ellipsoid axes (modified from Siegesmund et al., 1995).

From these susceptibilities, other parameters can be calculated to characterize the magnetic rock properties. Frequently used are the bulk susceptibility ( $k_{\text {bulk }}$ ), the corrected degree of anisotropy ( $\left.\mathrm{P}^{\prime}\right)$, the shape $(\mathrm{T})$ of the magnetic ellipsoid, the linear degree of anisotropy $(\mathrm{L})$ and the planar degree of anisotropy $(\mathrm{F})$. 
The degree or magnitude of anisotropy (P') reflects the ratio of $k_{1}\left(k_{11}\right)$ to $k_{3}\left(k_{33}\right)$ (see equation [3]). A value of 1 for $P$ ' is calculated when $k_{1}=k_{2}=k_{3}$, the magnetic ellipsoid is represented by a sphere. The higher the differences of the susceptibility of the respective magnetic axes, the higher the degree of anisotropy (Jelinek, 1981).

$P^{\prime}=\exp \sqrt{2\left(\operatorname{lnk}_{1}-\operatorname{lnk}\right) 2+2\left(\operatorname{lnk}_{2}-\operatorname{lnk}\right) 2+2\left(\operatorname{lnk}_{3}-\operatorname{lnk}\right) 2}$

with $\mathrm{k}=\frac{\ln k_{1}+\ln k_{2}+\ln k_{3}}{3}$

The shape-factor $(T)$ of the magnetic ellipsoid ranges between -1 and 1. In case of $\mathrm{T}=-1$ the resulting magnetic ellipsoid has a perfect prolate shape (cigar shaped) and $k_{1}>>k_{2} \geq k_{3}$. If $T=1$ the magnetic ellipsoid has a perfect oblate shape (pan cake shape) and $k_{1} \geq k_{2}>>k_{3}$. For $-0.05<T<0.05$ the samples show a neutral (spherical) magnetic ellipsoid. T is calculated according to equation [5] (Hrouda, 1982).

$\mathrm{T}=\left[\frac{2 \ln \left(\mathrm{k}_{1} / \mathrm{k}_{3}\right)}{\ln \left(\mathrm{k}_{1} / \mathrm{k}_{3}\right)}\right]-1$

The linear degree of anisotropy (L, Balsley \& Buddington, 1960) as well as the planar degree of anisotropy ( $F$, Stacey et al., 1960) are ratios of the main ellipsoidal axes.

$\mathrm{L}=\frac{\mathrm{k}_{1}}{\mathrm{k}_{2}}$ (linear anisotropy)

and

$\mathrm{F}=\frac{\mathrm{k}_{2}}{\mathrm{k}_{3}}$ (planar anisotropy)

The degree of linear and planar anisotropy are calculated according to equations [6] and [7] respectively and are used to demonstrate the distinctness of a preferred shape ( $T$ ) of the magnetic ellipsoid. If a sample shows a high degree of planar anisotropy the degree of linear anisotropy is low and the shape of the magnetic ellipsoid $(\mathrm{T})$ exhibits positive (oblate) values. In case of a high degree of linear 
anisotropy the degree of planar anisotropy is low and the shape of the magnetic ellipsoid ( $T$ ) exhibits negative values (compare Fig. 5.4).

Another shape parameter $(U)$ is used here to compare the AMS measurements with the HFA. $U$ ranges between -1 and 1 and is indirectly comparable to $T$ since both parameters characterize the shape of the magnetic ellipsoid and hence its eccentricity. However, $T$ is calculated from the second rank tensor while $U$ is calculated using the deviatoric part of the second rank tensor, therefore the actual values of $T$ and $U$ are not comparable (Jelinek, 1977). $U$ can be calculated using equation [8] (from Jelinek, 1977):

$\mathrm{U}=\frac{2 \mathrm{k}_{2}-\mathrm{k}_{1}-\mathrm{k}_{3}}{k_{1}-k_{3}}$

All the parameters described above are calculated from ratios of the different main magnetic axes and can therefore be correlated with each other (see Fig. 5.4).

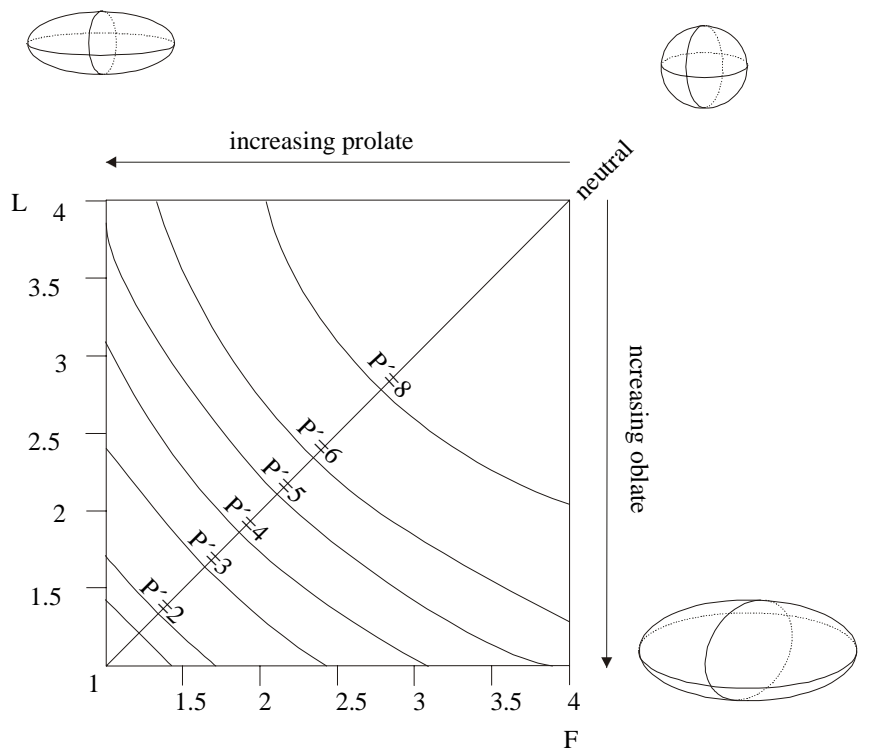

Fig. 5.4: Correlation between the different magnetic parameters of the AMS measurements. For example a strongly oblate magnetic ellipsoid induces high degrees of anisotropy $\left(\mathrm{P}^{\prime}\right)$, high planar anisotropies $(\mathrm{F})$ and low degrees of linear anisotropies (L) (modified from Jelinek, 1981 and Borradaile \& Craig, 1987).

From Fig. 5.4 it becomes clear that increasing ratios of $L$ and $F$ (or vice versa) cause increasing values of $P^{\prime}$ and increasing $T\left(\begin{array}{ll}0 & \text { to }\end{array}\right)$ in case of $F>L$ or decreasing $T(0$ to -1$)$ in case of $L>F$.

A perfect spherical rock sample would be needed to obtain exact measurements of the anisotropic magnetic rock properties. Since the production of these spheres is complicated, cylinders with a defined ratio of diameter to height are used (diameter/height $=1 / 0.87$ ) which approximate the attributes of a sphere best 
(Scriba \& Heller, 1978). Cylinders with diameters of $25 \mathrm{~mm}$ and $40 \mathrm{~mm}$ are commonly used and can be measured with the standard AMS equipment. For this work a KappaBridge KLY 2 was used. A so called pick-up unit generates the external magnetic field $\left(300 \mathrm{Am}^{-1}, \sim 0.4 \mathrm{mT}\right)$ that is disturbed by the rock sample. By comparing the disturbed magnetic field in the pick-up unit with an undisturbed reference coil in the KappaBridge the change of the magnetic field can be measured. For the complete analyses of the AMS tensor 15 orientations must be measured (see Fig. 5.5; Jelinek, 1977). The KappaBridge has a high accuracy (about $4^{*} 10^{-8} \mathrm{SI}$ ), measurement errors are low because of the double determination of most of the measurement directions (the tensor matrix consist of only 9 elements). The overdefinition of the tensor gives way to a calculation of errors for each measurement that allows a first control of the measured values from a mathematical point of view.

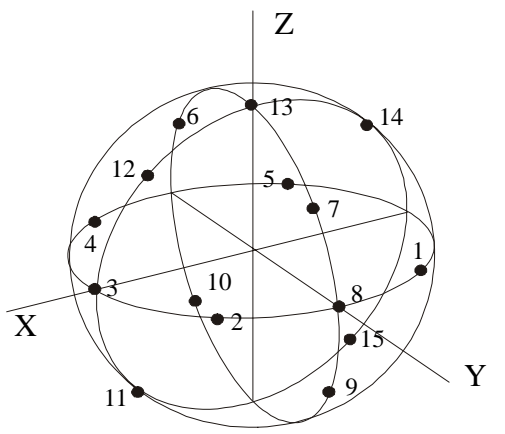

Fig. 5.5: Measurement directions and orientation of the sample cylinder.

$\begin{array}{lll}\text { 1. }-X / Y & \text { 6. }-Y / Z & \text { 11. } X /-Z\end{array}$

$\begin{array}{lll}\text { 2. } X / Y & \text { 7. } Y / Z & \text { 12. } X / Z\end{array}$

$\begin{array}{lll}\text { 3. } X & \text { 8. } Y & \text { 13. } Z\end{array}$

4. $X /-Y \quad$ 9. $Y /-Z \quad$ 14. $-X / Z$

5. $-\mathrm{X} / \mathrm{-} \mathrm{Y} \quad$ 10. $-\mathrm{Y} / \mathrm{-Z} \quad$ 15. $-\mathrm{X} / \mathrm{-Z}$

(modified from Juckenack, 1990)

\subsubsection{HFA}

The biggest disadvantage of the AMS measurements is that the results do not distinguish between paramagnetic and ferrimagnetic minerals. If high bulk susceptibilities and/or high degrees of anisotropies point to a high amount of oreminerals in the rock sample it is important to know the orientation of both phases separately. This separation can be performed using a torque magnetometer. A sample is exposed to a high magnetic field (usually magnetic fields of $0.5 \mathrm{~T}$ up to 1.8 T are used, see Bergmüller et al., 1994 and Bergmüller \& Heller, 1995) and the torque that is induced in the sample due to the applied external field is measured. If a purely paramagnetic sample is measured the transferred torque increases linearly with the increasing magnetic field (see Fig. 5.6, curve a; Lowrie, 1989). The torque of a purely ferrimagnetic sample would increase very fast up to the 
saturation magnetization after which it shows no further increase of the transferred torque (see Fig. 5.6, curve b; Lowrie, 1989). If a sample with a mixture of both is measured the measurements will show a combination of paramagnetic and ferrimagnetic properties (see Fig. 5.6 Curve $a+b$; Lowrie, 1989). If the torque of a sample is measured above the saturation magnetization at two fields the difference between the torque in these two fields can be directly correlated to the magnetic properties of the paramagnetic phase in the sample. The allotment of paramagnetic and ferrimagnetic properties to the torque of the sample can be calculated using the AMS tensor and the ratio of paramagnetic and ferrimagnetic properties at high magnetic fields (Hrouda \& Jelinek, 1990).

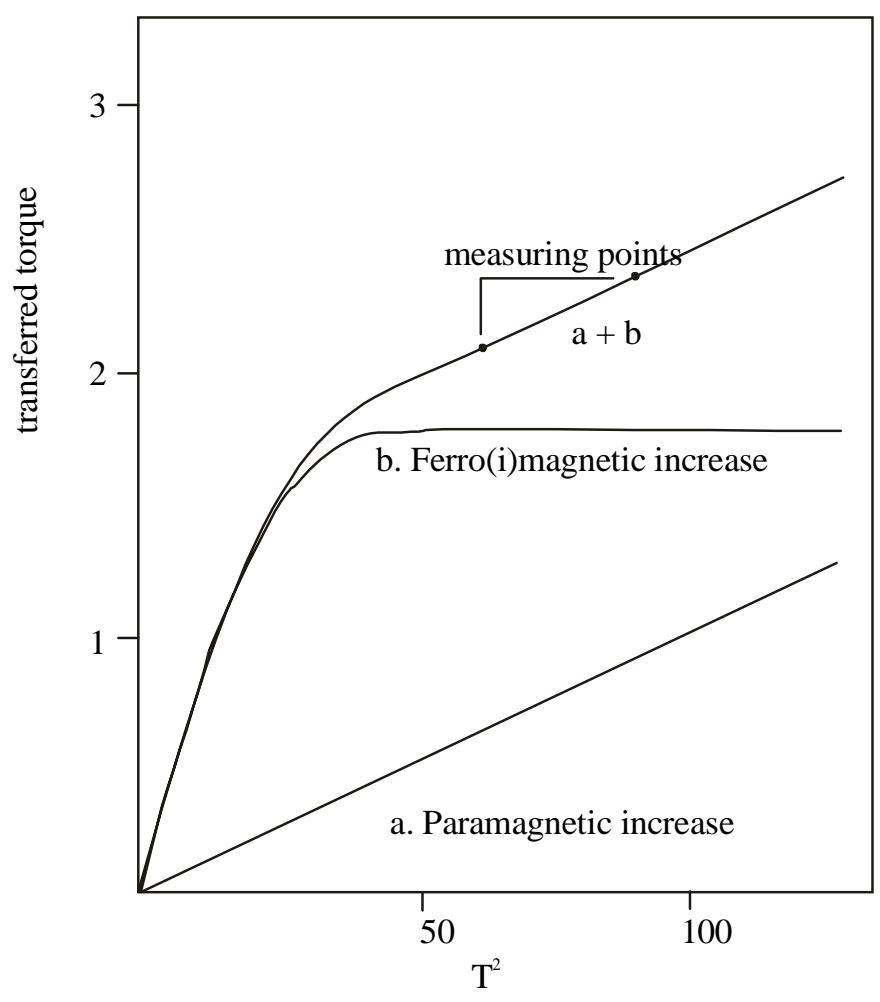

Fig. 5.6: Measurement of the HFA. Curve a: linear increase of transferred torque of the paramagnetic minerals. Curve b: fast increase of transferred torque up to the saturation magnetization of ferrimagnetic minerals, higher magnetic fields do not influence the transferred torque. Curve $a+b$ is $a$ mixture of both curves, because of the observed parallelism of $\mathrm{a}+\mathrm{b}$ and $\mathrm{a}$ in high magnetic fields the separation of ferrimagnetic and paramagnetic properties can be performed (modified from Lowrie, 1989).

The separation of the different magnetic properties of a sample was performed using the SEPANG-program written by Jelinek and Hrouda (AGICO Inc., Brno; Hrouda \& Jelinek, 1990). This program uses the results from two measurements with different applied external fields and the normed tensor components of the AMS measurements. From these parameters different factors and orientations of the separated properties are calculated.

Most important results are the orientation of the main axes of the magnetic ellipsoid of the paramagnetic and ferrimagnetic properties of the rock. In addition, the form of the different magnetic ellipsoids $(U)$ is calculated from the deviatoric 
parts of the measured tensor. Next to these parameters three factors are given that specify the ratios of different axes of the measured properties (Hrouda \& Jelinek, 1990). These ratios are:

$$
\begin{aligned}
& \mathrm{l}=\frac{\left(\mathrm{k}_{1 \mathrm{p}}-\mathrm{k}_{2 \mathrm{p}}\right)}{\left(\mathrm{k}_{1 \mathrm{f}}-\mathrm{k}_{2 \mathrm{f}}\right)} \\
& \mathrm{f}=\frac{\left(\mathrm{k}_{2 \mathrm{p}}-\mathrm{k}_{3 \mathrm{p}}\right)}{\left(\mathrm{k}_{2 \mathrm{f}}-\mathrm{k}_{3 \mathrm{f}}\right)} \\
& \mathrm{p}=\frac{\left(\mathrm{k}_{1 \mathrm{p}}-\mathrm{k}_{3 \mathrm{p}}\right)}{\left(\mathrm{k}_{1 \mathrm{f}}-\mathrm{k}_{3 \mathrm{f}}\right)}
\end{aligned}
$$

with $k_{1 p(f)}$ being the longest axes of the paramagnetic (ferrimagnetic) ellipsoid, $k_{2 p(f)}$ being the intermediate axes of the paramagnetic (ferrimagnetic) ellipsoid and $k_{3 p(f)}$ being the shortest axes of the paramagnetic (ferrimagnetic) ellipsoid. Values $>1$ in equation [9]-[11] point to a more pronounced fabric of the paramagnetic properties with respect to the ferrimagnetic properties. Values $<1$ point to a more pronounced ferrimagnetic fabric with respect to the paramagnetic fabric. Very high or low values of I or $f$ do not necessarily reflect a strong mineral fabric. If, for example, the ferrimagnetic minerals are euhedral and not aligned in a way that their magnetic properties interact, they do not show any fabric at all $\left(\mathrm{k}_{1} \approx \mathrm{k}_{2} \approx \mathrm{k}_{3}\right)$ and calculated values for the divisor reaches values close to 0 . In this case, even if the paramagnetic minerals show only slight linear or planar fabrics ratios of I or $f$ may reach very high values. Furthermore, neither $I, f$ nor $p$ is suitable for a verification of a domination of one property over the other. This has to be verified through a comparison of measured HFA values with measured AMS values of the sample (Hrouda \& Jelinek, 1990).

\subsubsection{Curie-balance}

The Curie-balance can be used for a qualitative characterization of the ferrimagnetic ore content of the samples. Small quantities of the rock are powdered, only $\sim 150 \mathrm{mg}$ are needed for the measurement. The powder is heated in an applied external magnetic field of $0.55 \mathrm{~T}$ in temperatures up to $700^{\circ} \mathrm{C}$. 
Temperature is raised stepwise by $20^{\circ} \mathrm{Cmin}^{-1}$. The induced magnetic field is measured (mass magnetization $\left[\mathrm{Am}^{2} \mathrm{~kg}^{-1}\right]$ ) with respect to the temperature. Above a specific temperature (Curie- or Néel-temperature) the ore-minerals loose their ferrimagnetic properties, at this point the induced magnetic field is close to zero. After a temperature of $700^{\circ} \mathrm{C}$ is reached the sample is cooled to room temperature in steps of $20^{\circ} \mathrm{Cmin}^{-1}$. During the cooling the sample regains its ferrimagnetic properties, both, heating and cooling traces of the curve are important for the recognition of the ore content. According to the trace of the curve and the temperature at the point of the lowest induced magnetic field the contained ore minerals can be determined (e.g. Orlicky, 1990; Dekkers, 1988). In the case that more than one ore mineral is present in the sample the curve will show a mixture of the specific mineral curves (see Fig. 5.7 for examples of specific minerals). If only very low amounts of ore minerals are present in the sample a linear dependence of temperature to magnetization is measured and no information can be gained on the ore content of the sample.
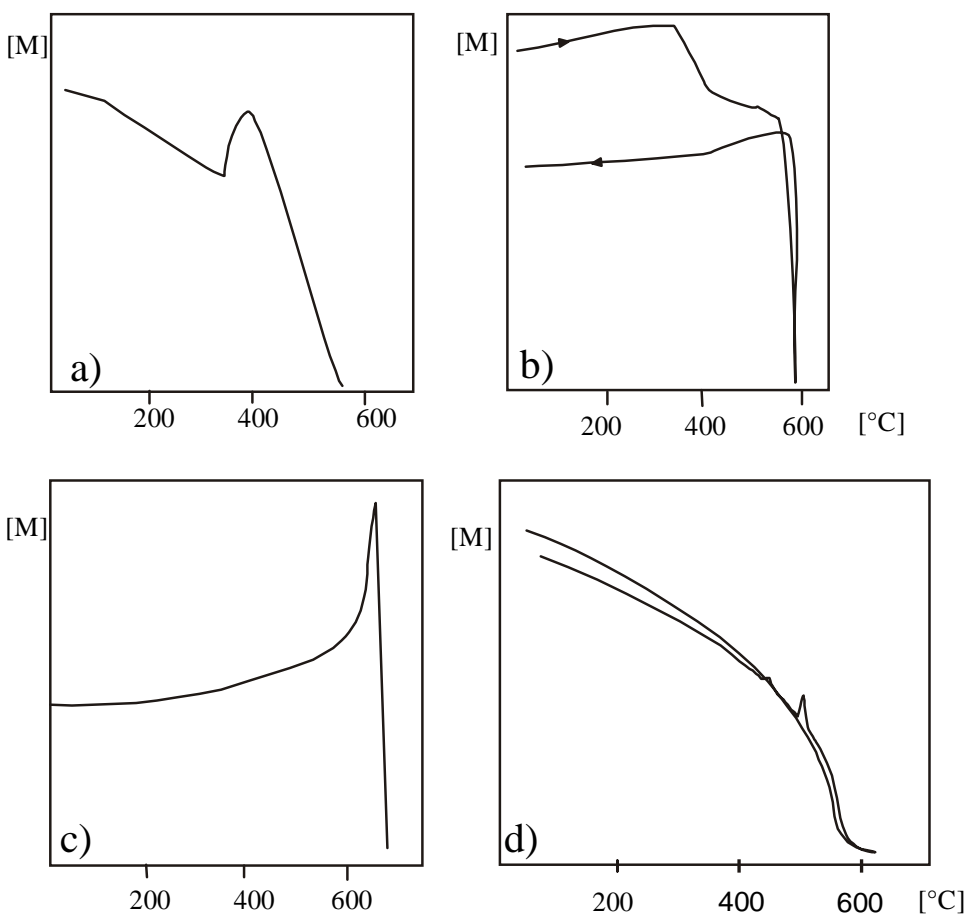

Fig. 5.7: a) Thermomagnetic curves for a) mixture of monokline and hexagonal pyrrothite (Dekkers, 1988), b) magnetite (Orlicky, 1990), c) haematite (Orlicky, 1990) and d) mixture of all three curves. 


\section{Low field magnetic measurements (AMS and Curie-balance)}

The AMS measurement results of the different rock groups are described below. As stated earlier the possible basement (according to Snowden, 1976) has been included with the gneissic granites.

\subsection{Gneissic granites}

The gneissic granites near the margins of the batholith and in the erosional windows of the porphyritic granite show bulk susceptibilities ranging between $18^{*} 10^{-6} \mathrm{SI}$ and $8500^{*} 10^{-6} \mathrm{SI}$ averaging at $1670^{*} 10^{-6} \mathrm{SI}$ (see Fig. 6.1). Only a weak correlation between the location of the investigated samples and the bulk susceptibility can be drawn. The bulk susceptibility of the northern and western gneisses averages at $2099^{*} 10^{-6} \mathrm{SI}$ and $1375^{*} 10^{-6} \mathrm{SI}$, respectively, while the southern gneisses show bulk susceptibilities of $1893^{*} 10^{-6} \mathrm{SI}$. The degree of anisotropy of the gneissic granites ranges between 1.011 and 2 averaging at 1.12 (see Fig. 6.1). According to Rochette (1987) and Hrouda (1982) the height of the degree of anisotropy does not point to a domination of ferrimagnetic minerals over the paramagnetic minerals, still the high bulk susceptibilities imply at least for some samples a domination of ferrimagnetic over paramagnetic properties. The degree of anisotropy is higher at the southern margin near the Umwindsi Shear Zone (averaging at 1.2) than in the north (averaging at 1.15) or west (averaging at 1.1) of the batholith (see Fig. 6.1). The shape of the magnetic ellipsoids (T) of the respective measurements is highly irregular, however, the southern gneissic granites seem to cluster in the weak oblate and prolate field while the northern and western gneissic granites show clusters in the oblate field (see Fig. 6.1). The degree of linear and planar anisotropy in the samples follows the degree of anisotropy and the shape of the magnetic ellipsoids. In the southern gneisses the degree of linear anisotropy $(\mathrm{L}=1.094)$ is slightly higher than the corresponding degree of planar anisotropy $(F=1.089)$ while in the northern $(L=1.068, F=1.084)$ and western $(L=1.045, F=1.047)$ gneisses the degree of planar anisotropy is slightly increased with respect to the degree of linear anisotropy. Therefore, for the majority of the measured samples in the southern gneisses a preferred linear 
magnetic anisotropy must be assumed while samples in the northern and western gneisses show a preferred planar magnetic anisotropy.
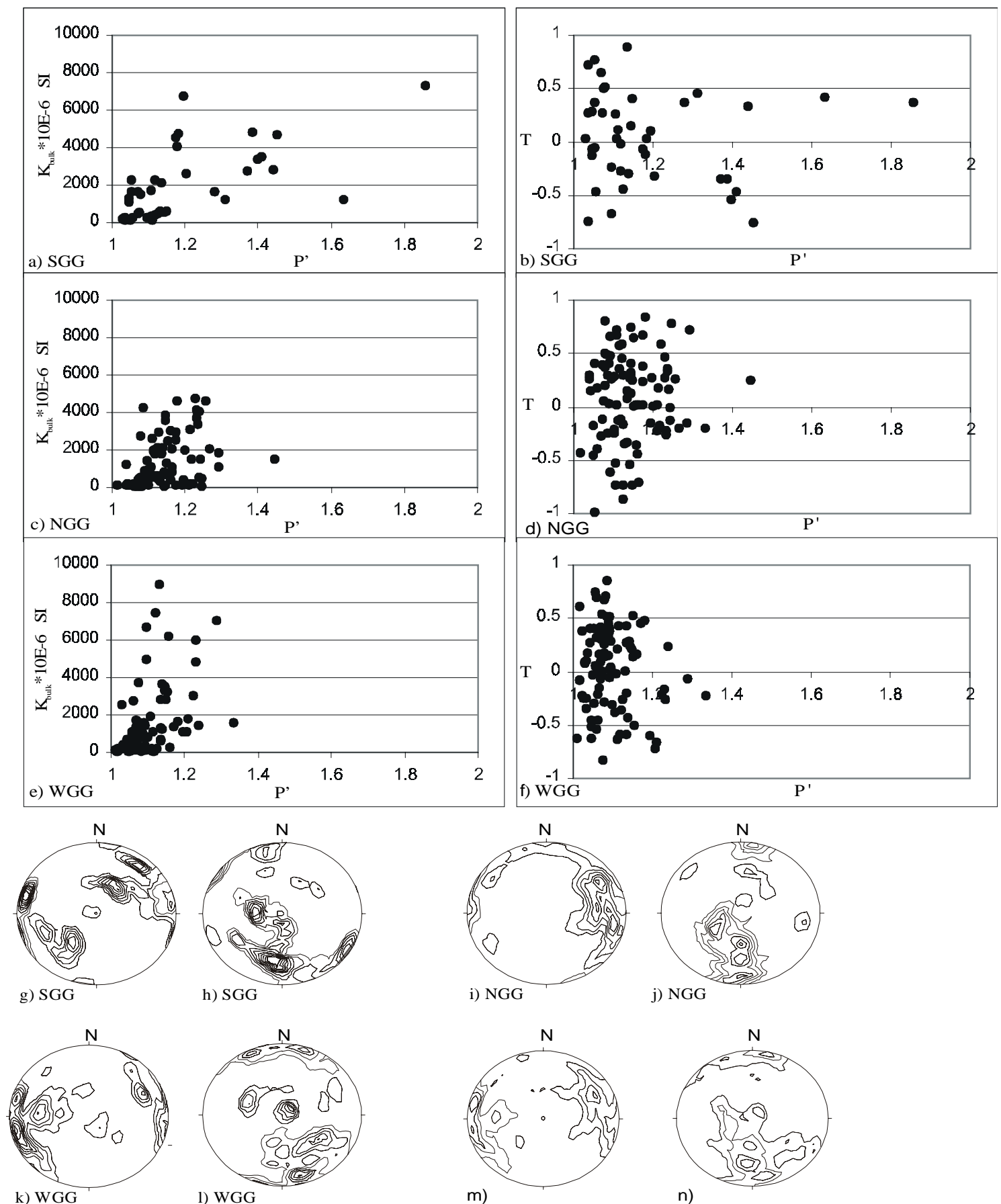

n)

Fig. 6.1: Magnetic fabric of the gneissic granites. The results of the measurements have been divided into the southern gneisses $(a-b, g-h)$, the northern gneisses $(c-d, i-j)$ and the western gneisses (e-f, $k-l)$. In $m$ and $n$ the different gneisses have been analyzed as a whole. Orientations of magnetic lineations $(\mathrm{g}, \mathrm{i}, \mathrm{k})$ and foliations $(\mathrm{h}, \mathrm{j}, \mathrm{l})$ are slightly rotated in the different gneisses, this probably is due to small changes in the tectonic environment during their emplacement. The southern gneissic granites have additionally been deformed during movement along the Umwindsi Shear Zone. 
The orientation of the magnetic lineation in the gneissic granites can be divided into a southern, northern and western domain as well. While in the southern gneissic granites the magnetic lineation parallels the Umwindsi Shear Zone, in the northern and western gneissic granites the magnetic lineation strikes E-W with preferred flat lying, east plunging magnetic lineations in the north and preferably west plunging, subhorizontal magnetic lineation in the west (see Fig. 6.1 and 6.3). The magnetic foliation of the gneissic granites does not show a comparable pronounced division. The northern gneissic granites show steeply inclined magnetic foliations plunging away from the batholith center. In the area of the Musana Communal Land the magnetic foliation near the eastern margin parallels internal boundaries while in the center and the western margin the magnetic foliation is margin parallel cross cutting internal boundaries with shallow to moderate dips. The western gneisses show steeply to moderately inclined, margin parallel magnetic foliations. The southern gneissic granites show nearly horizontal to nearly vertical inclined magnetic foliations with a roughly E-W strike (see Fig. 6.2 ), some of the samples show a margin parallel foliation.

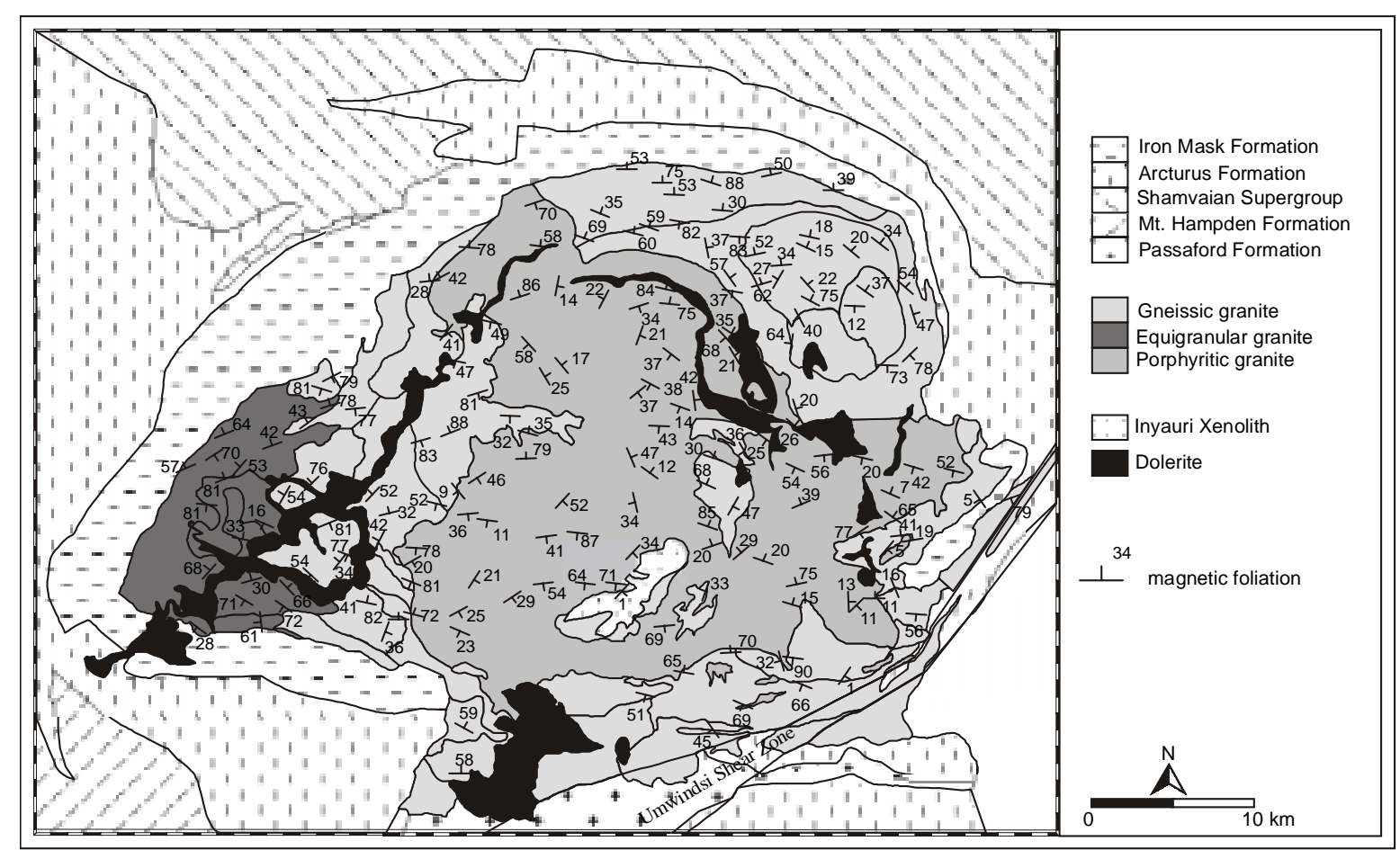

Fig. 6.2: Magnetic foliation in the Chinamora batholith. The gneissic granites and the equigranular granites show a preferred margin parallel strike of the magnetic foliation, internal lithological boundaries are crosscut. The porphyritic granite shows a preferred SE-NW strike.

The map view of the magnetic lineations (see Fig. 6.3) reveals a tendency to crosscut lithological boundaries in the gneissic granites. The northern gneissic 
granites exhibit a radial magnetic lineation around the granodiorite core (Musana Communal Land) in the tonalitic to granodioritic gneisses. This is evidence for the diapiric emplacement of the Musana Communal Land area into the host rocks. In the other northern gneisses the magnetic lineation has a preferred E-W strike and roughly parallels the outer margin of the batholith. Internal boundaries are crosscut which is common in the western gneisses as well. The magnetic lineations in this area show the same E-W strike. The southern portion of the gneissic granites shows a magnetic lineation subparallel to the Umwindsi Shear Zone (see Fig. 6.3).

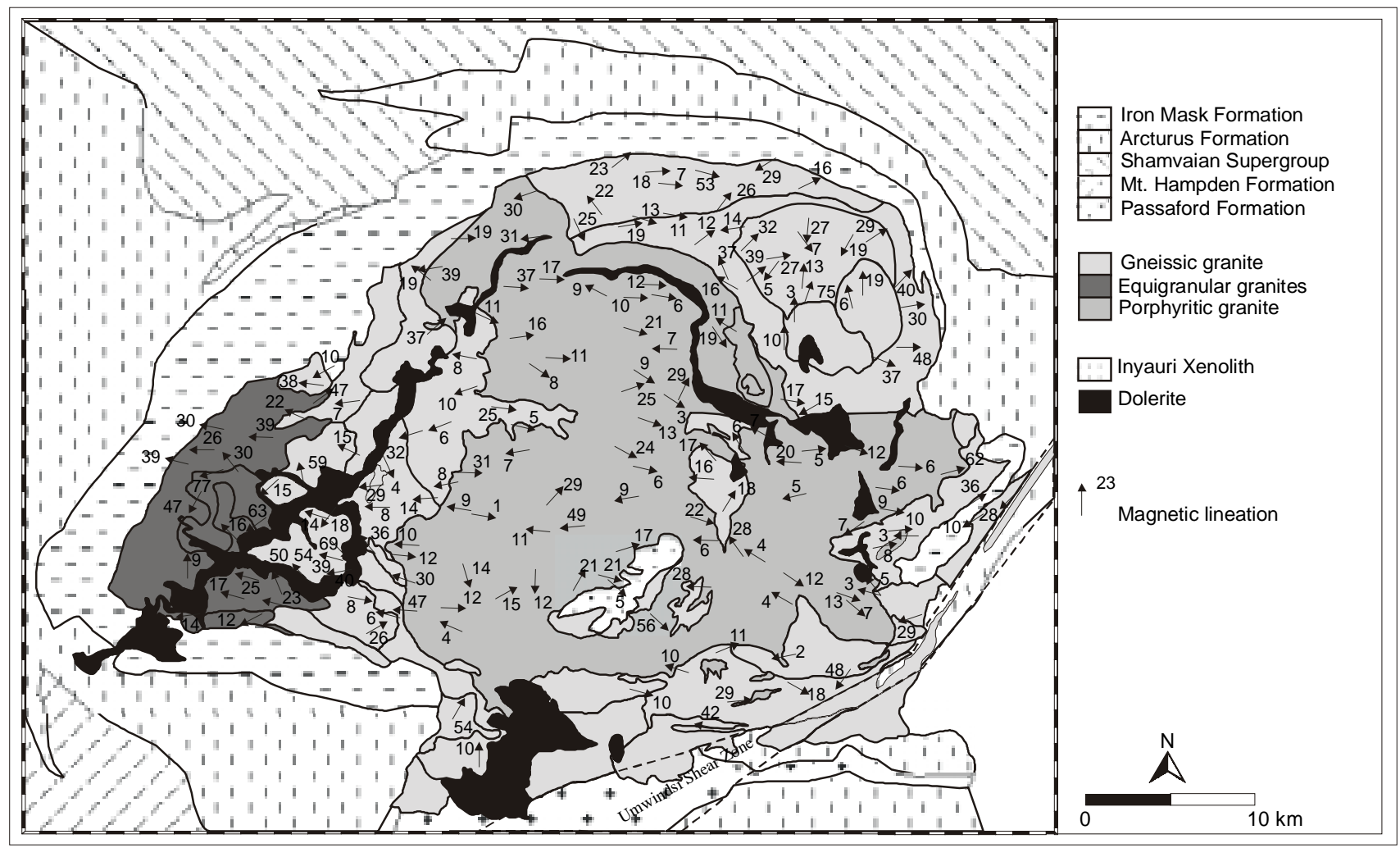

Fig. 6.3: Map of the magnetic lineations in the Chinamora Batholith. Lineations trend EW throughout the batholith with shallowly plunging angles. Note that the plunge of the lineation in the northeastern granites is mainly to the $E$ while in the western granites magnetic lineation preferably plunge to the west. The gneissic granites in the northeast show fabrics indicative of a small diapiric pluton intruded into the gneissic granites.

\subsection{Equigranular granites}

The equigranular granites in the west of the batholith revealed bulk susceptibilities ranging from $70^{*} 10^{-6} \mathrm{SI}$ to $6000^{*} 10^{-6} \mathrm{SI}$ (see Fig. 6.4). Only three samples exceed this range of bulk susceptibilities. They average at $1550^{*} 10^{-6} \mathrm{SI}$ when the three highly susceptible samples are not taken into account. The degree of anisotropy 
averages at 1.05. No correlation can be established between the degree of anisotropy, the bulk susceptibility and the sample location in the batholith. The shape of the magnetic ellipsoids in the equigranular granites concentrates in the moderate oblate field (see Fig. 6.4). The degree of linear and planar anisotropies of the samples has a random distribution, no preferred location in the equigranular granites with oblate or prolate shapes is apparent.
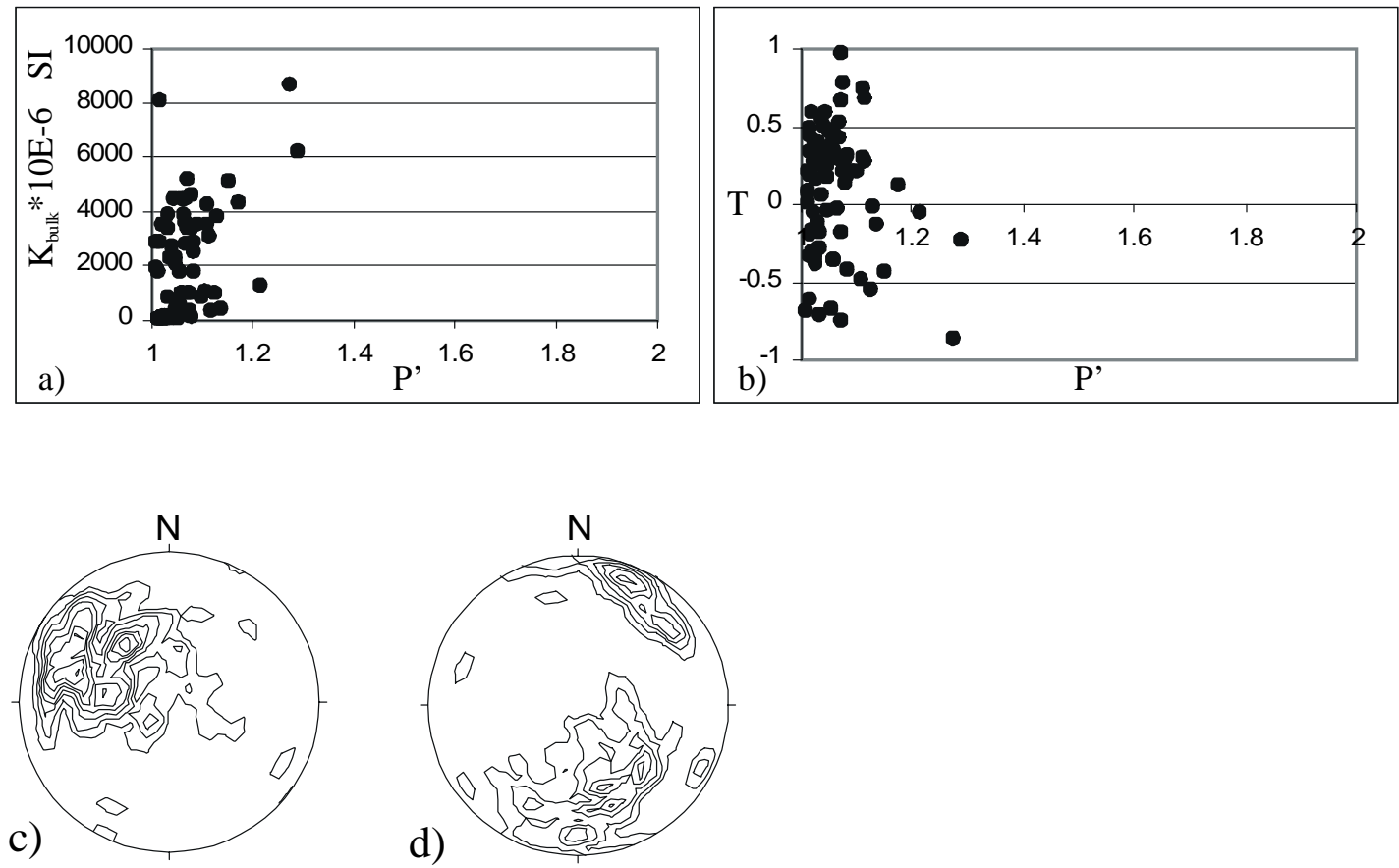

Fig. 6.4: AMS measurements for the equigranular granites. a) Samples show moderate bulk susceptibilities and low degrees of anisotropy. b) Most of the samples have moderate oblate shapes of their magnetic ellipsoids indicating a better defined magnetic foliation than magnetic lineation. c) The magnetic lineation preferably plunges to the NW at moderate angles. d) The magnetic foliation seems to build an incomplete girdle indicating a preferred margin parallel strike.

The magnetic lineation of the samples shows a broad maximum in the pole figure, they preferably plunge to the northwest and are moderately inclined (see Fig. 6.4). The magnetic foliation shows an incomplete girdle distribution in the pole figure. If sample density was higher they probably would form a complete girdle indicating a preferred margin parallel strike with dip-directions pointing away from the batholith center (see Fig. 6.4 and 6.2). Crosscutting of internal lithological boundaries is common in the equigranular granites, magnetic lineations tend to lie perpendicular to the outer margin of the batholith and hence follow the preferred E-W strike (compare Fig. 6.3). 


\subsection{Porphyritic granite}

The bulk susceptibility of the samples differs to a greater extent with values as low as $16^{*} 10^{-6} \mathrm{SI}$ up to $8303^{*} 10^{-6} \mathrm{SI}$ (see Fig. 6.5). The average of the samples lies at $2754^{*} 10^{-6} \mathrm{SI}$. Therefore, most of the samples show a domination of ferrimagnetic properties over the paramagnetic properties of the samples (Rochette, 1987). The distribution of the samples with low or high bulk susceptibilities does not show any regular zoning or distribution pattern in the porphyritic granite. The degree of anisotropy for the samples ranges between 1.008 and 1.6 throughout the porphyritic granite averaging at 1.14 (see Fig. 6.5). According to this the degree of anisotropy for most of the samples is well defined pointing to a distinct magnetic fabric of the samples.
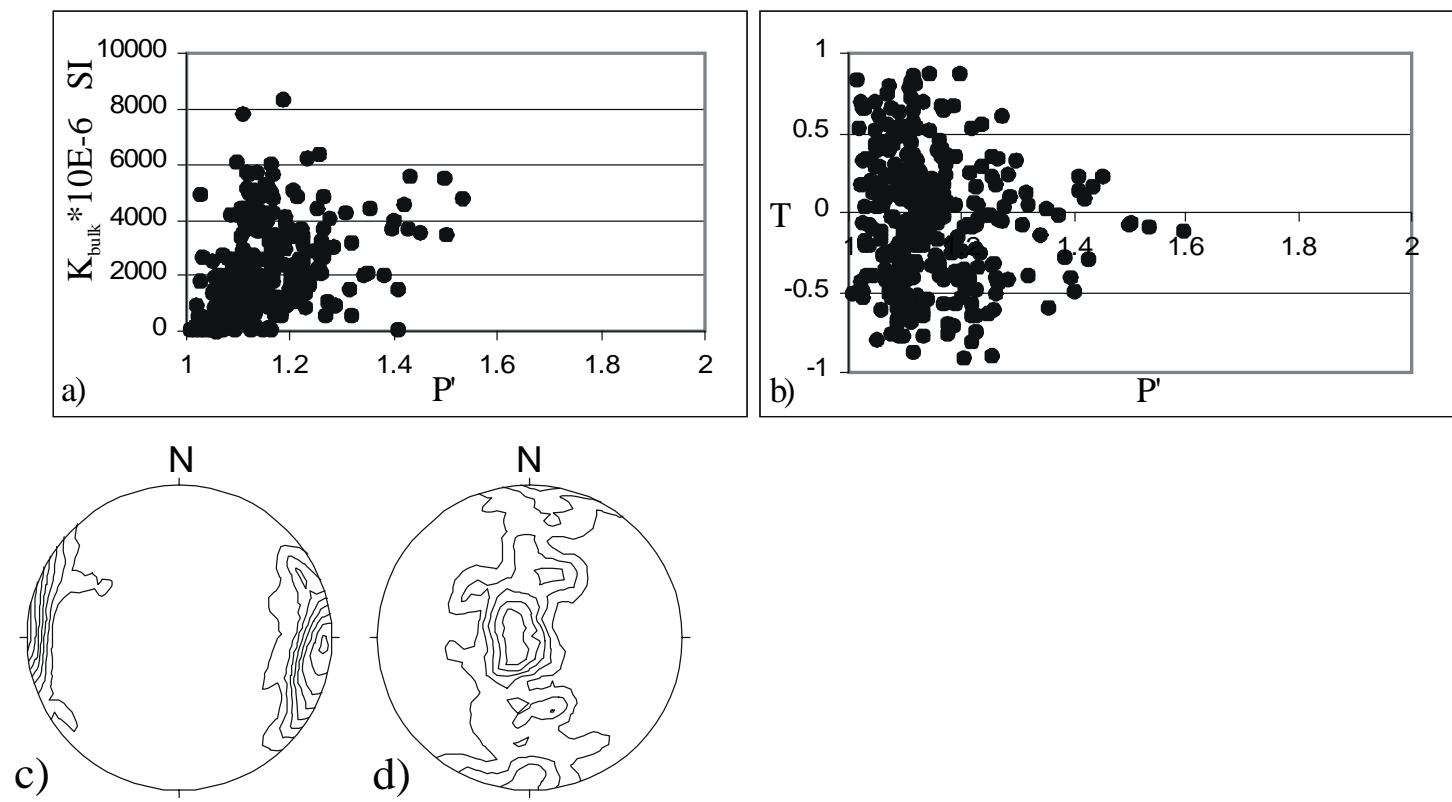

Fig. 6.5: Magnetic fabric of the porphyritic granite. a) The bulk susceptibility as a function of the degree of anisotropy is widely scattered. Only a weak trend of increasing degrees of anisotropies with increasing bulk susceptibility is apparent. The shape of the magnetic ellipsoid (b) is also inconsistent. c) The magnetic lineation in the porphyritic granite has a narrow point maximum indicating flat lying (subhorizontal) magnetic lineations with an ENE-WSW strike. d) The poles to the magnetic foliation define a girdle in the pole figure, however, the majority of the foliation planes are nearly horizontal.

The degree of anisotropy tends to be higher near the Umwindsi Shear Zone in the south. The observed values again point to a domination of ferrimagnetic properties over the paramagnetic properties of the samples (Rochette, 1987; Hrouda, 1982). The shape of the magnetic ellipsoids of the samples again shows great differences in their values. They range from nearly perfectly oblate to nearly perfectly prolate, 
still the majority of the samples exhibits values that concentrate in the field of neutral to moderately oblate or prolate samples $(-0.5<T<0.5)$. Again no clear correlation of the shapes of the magnetic ellipsoids according to their position in the porphyritic granite can be established. The degree of linear and planar anisotropy seems to have a random distribution throughout the porphyritic granite. The distinctness of linear and planar fabrics changes from locality to locality and sometimes even within the same locality in different measured cylinders of the same core. This must be ascribed to the influence of the ferrimagnetic properties of the ore minerals rather than to a different orientation of the paramagnetic properties. Possibly this can be assigned to the interaction of ferrimagnetic minerals (magnetite). Gregoire et al. (1995) observed a change in the orientation of the magnetic properties when the spacing between two grains of magnetite is less than twice the grain diameter. The bulk susceptibility of the measured samples was raised $8 \%$ while the degree of anisotropy increased about $40 \%$. If the spacing was less than one grain diameter the magnetic axes $\mathrm{k}_{1}$ and $\mathrm{k}_{2}$ were exchanged leading to a change from prolate to oblate shapes of the magnetic ellipsoids in the AMS measurements.

Because of the observed influence of ferrimagnetic properties over the paramagnetic properties of the samples the most important magnetic values are the orientations of the main axes of the magnetic ellipsoid. While the other parameters are definitely influenced by the ore minerals it will be shown in chapter 7 (High Field Analyses) that the orientation of the paramagnetic and ferrimagnetic properties is comparable.

The magnetic lineation of the porphyritic granite shows a very stable ENE-WSWtrend while the magnetic foliation shows a weak, N-S oriented girdle distribution of the sample (see Fig. 6.3). From Fig. 6.3 it can be seen that the magnetic lineation of the samples in the porphyritic granite has a very stable trend in the northern part of the porphyritic granite while in the southwest strike-directions are vague but seem to follow a general ENE-WSW trend. No deflection of the linear fabric at the gneissic inlayers or the Inyauri Xenolith is apparent emphasizing that in fact the porphyritic granite is overlying the gneissic granites rather than being emplaced into it. Furthermore, the magnetic lineation does not show any signs of bending into concordance with the Umwindsi Shear Zone in the south. 


\subsection{Curie-balance results}

Measurement results of different samples from the Chinamora Batholith all showed magnetite as the main ore content. This is indicated by a temperature of $578^{\circ} \mathrm{C}$ at the lowest point of magnetization in the curves (see Fig. 6.6). The horizontal deflection to $\sim 630^{\circ} \mathrm{C}$ indicates minor amounts of hematite in the samples. Only in sample JB89 small amounts of pyrrothite were measured as indicated by the slight increase of the induced magnetic field at temperatures of $430^{\circ} \mathrm{C}$ and $500^{\circ} \mathrm{C}$.

The results described above show that mainly magnetite and to a smaller extent haematite is responsible for the high bulk susceptibilities of the analyzed samples. Minor amounts of other ore minerals are present but their content is to small to be measured (compare chapter 4).

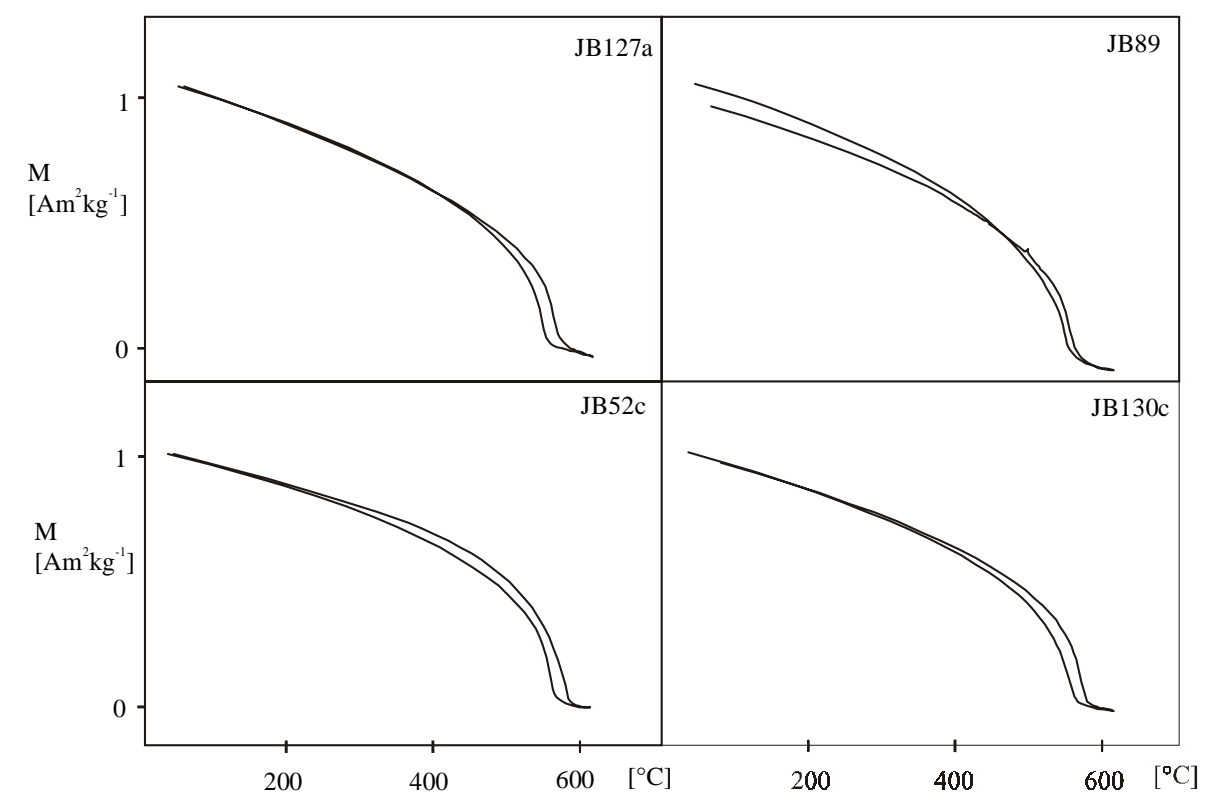

Fig. 6.6: Curie balance results for some selected samples. Most of the samples showed magnetite as the main ore mineral with minor amounts of haematite included. Only sample JB89 showed very low amounts of pyrrothite in addition.

\subsection{Results}

The magnetic fabric of the different lithologies of the Chinamora Batholith shows highly irregular degrees of anisotropy and shapes of the magnetic ellipsoids. Only a weakly pronounced clustering of prolate ellipsoids in the southern gneissic granites and of oblate ellipsoids in the northern and western gneissic granites is apparent. While the equigranular granites show preferred, moderately oblate 
magnetic ellipsoids the porphyritic granite does not show any preferred shape of the magnetic ellipsoids. The bulk susceptibility of the samples ranges between values as low as $10^{*} 10^{-6} \mathrm{SI}$ units to values well above $5000^{*} 10^{-6} \mathrm{SI}$. High bulk susceptibilities are correlated with increased degrees of anisotropies, this must be assigned to the ferrimagnetic content of the samples. According to Gregoire et al. (1995) the degree of anisotropy is increased about $40 \%$ when interacting magnetite grains are present in the sample. The measured parameters are randomly distributed throughout the batholith, none of the analyzed lithologies shows areas of a preferred shape of the magnetic ellipsoid, degree of anisotropy or bulk susceptibility. Even measurement cylinders cut from the same core sometimes show completely different magnetic properties. This can not be explained in terms of a different tectonic or cooling history but rather must be assigned to the ferrimagnetic content of the samples. However, the orientation of the magnetic foliation and lineation is consistent in the different lithologies. The southern gneissic granites revealed magnetic lineations subparallel to the Umwindsi Shear zone and hence probably are related to a progressive movement of the shear zone. The orientation of the magnetic lineation in the western and northern gneissic granites uniformly trends $\mathrm{E}-\mathrm{W}$ with a preferred easterly plunge in the northern gneisses and a preferred westerly plunge in the western gneissic granites, the equigranular granites and the porphyritic granite show preferred ENE or ENE-WSW plunging magnetic lineations respectively. This orientation of lineations was also found in the greenstone belts throughout the northern parts of the Zimbabwe Craton (Shamva, Dindi, Makaha; see Jelsma 1993; Dirks \& Jelsma 1998a; Jelsma \& Dirks 2000 or Becker et al. 2000). According to Jelsma \& Dirks (2000) this direction represents the direction of transport during the $D_{1}$ deformational event. In the northern gneissic granites in the Musana Communal Land area magnetic lineations point radially outwards of the granitic to granodioritic core. This must be related to a diapiric rise of the core into the host rock (compare Fig. 1.1). This is confirmed by the magnetic foliation that parallels the internal boundaries of the granitic core. Magnetic foliation in the other gneissic granites, outside the Musana Communal Land area and in the equigranular granites generally tends to parallel the batholith margin and seems to crosscut lithological boundaries. Magnetic foliation tends to dip away from the batholith center with moderate inclinations. The porphyritic granite revealed moderately inclined foliations that crosscut internal boundaries to the Inyauri Xenolith and the erosional windows to the gneissic granites. 


\section{High field analyzes (HFA)}

26 samples from different locations within the batholith have been chosen for the HFA. The samples all represent a broad range of bulk susceptibilities with values between $100^{*} 10^{-6}$ and $7500^{*} 10^{-6} \mathrm{SI}$. The presented values of $\mathrm{I}, \mathrm{f}$ and $\mathrm{p}$ (see chapter 5.4.2) are NOT capable to differentiate the dominant magnetic properties but rather state the domination of paramagnetic or ferrimagnetic anisotropy in the sample.

\subsection{Energy density}

The energy density of the samples is calculated from the HFA measurements and indicates the dominant magnetic property in the rock. In Fig. 7.1 the logarithmic ratio of the energy density of paramagnetic and ferrimagnetic minerals is plotted versus the bulk susceptibility of the samples. The resulting curve shows a correlation between the dominant magnetic property versus the bulk susceptibility obtained from the AMS measurements. From Fig. 7.1 it is obvious that the higher the bulk susceptibility, the more pronounced is the domination of ferrimagnetic minerals. Samples with bulk susceptibilities below $1000^{*} 10^{-6} \mathrm{SI}$ usually have ratios of para- over ferrimagnetic energy densities higher than 1 although some exceptions do occur. Samples with bulk susceptibilities $>1000^{*} 10^{-6} \mathrm{SI}$ are controlled by the ferrimagnetic minerals and show ratios lower than 1 . With higher bulk susceptibilities the ratio seems to vary within the range of $0.1-0.3$.

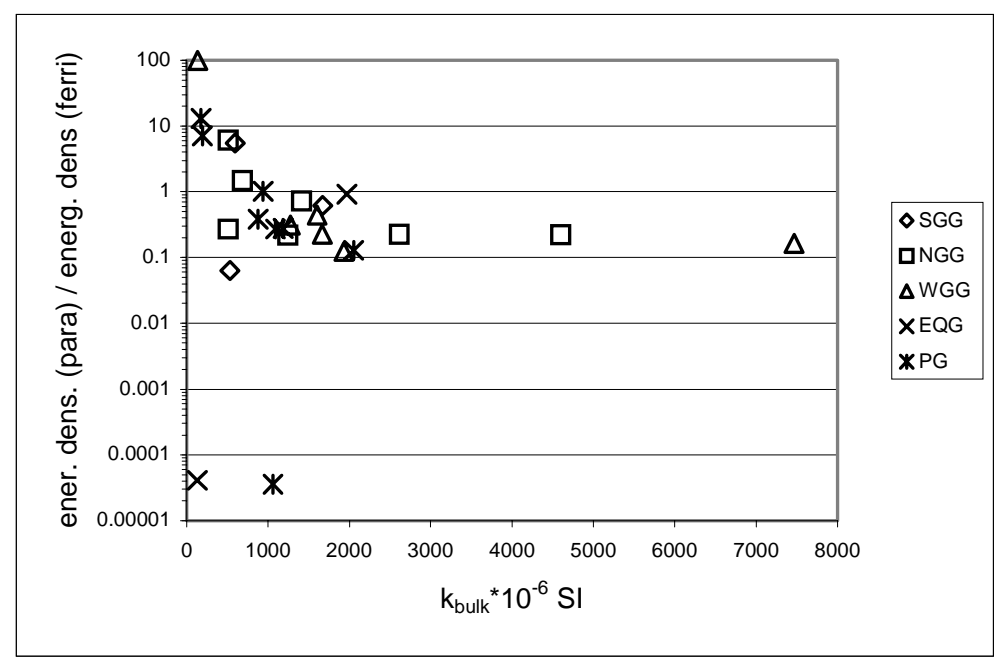

Fig. 7.1: Energy density (log) versus bulk susceptibility of the HFA samples. Except for two samples a strong trend is obvious with an increasing domination of ferrimagnetic minerals with increasing bulk susceptibility. Samples from the different lithological units can not be differentiated according to their amount of ferrimagnetic minerals. 


\subsection{Southern gneissic granites}

For the southern gneissic granites, samples $42 \mathrm{a}, \mathrm{x} 1$ and $128 \mathrm{bll}$ were chosen for the measurements. The samples show bulk susceptibilities of 530-, 595- and $1670^{*} 10^{-6} \mathrm{SI}$ units, respectively. The AMS measurements revealed a weakly oblate magnetic ellipsoid $(T=0.15 ; \mathrm{U}=0.117)$ and a high degree of anisotropy ( $P^{\prime}=$ 1.144) for sample $42 a$, a moderately oblate magnetic ellipsoid ( $T=0.409 ; \mathrm{U}=0.38$ ) and a high degree of anisotropy $\left(P^{\prime}=1.148\right)$ for sample $x 1$ and a weakly oblate magnetic ellipsoid ( $T=0.274 ; \mathrm{U}=0.258)$ and a low degree of anisotropy $\left(P^{\prime}=1.072\right)$ for sample 128bll (see Fig. 7.2). The orientation of the main magnetic axes from the different magnetic measurements is shown in Fig. 7.3.

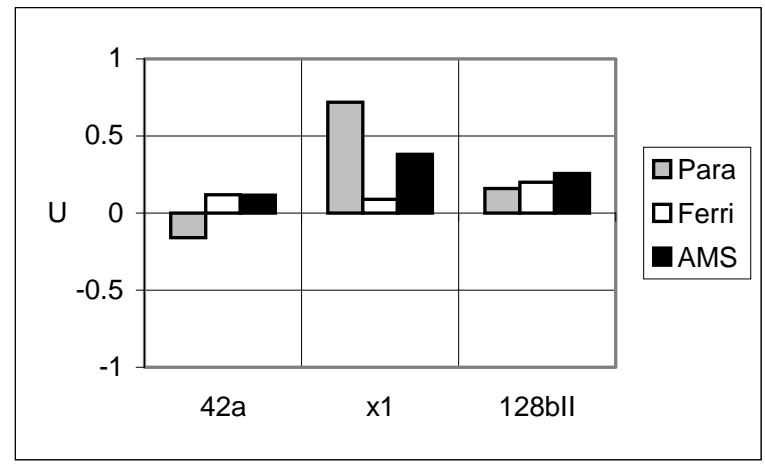

Fig. 7.2: Comparison of the form-parameters $U$ of the different measurements (AMS and HFA).

The different samples show a different behavior concerning the interaction of paramagnetic and ferrimagnetic properties.

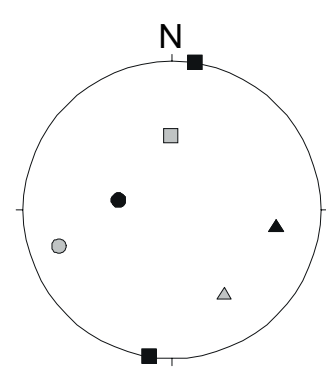

$42 \mathrm{a}$

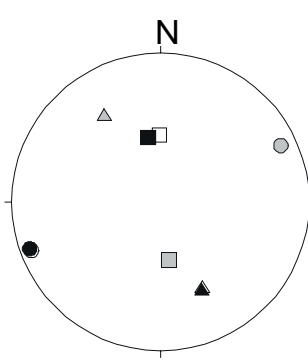

$128 b$

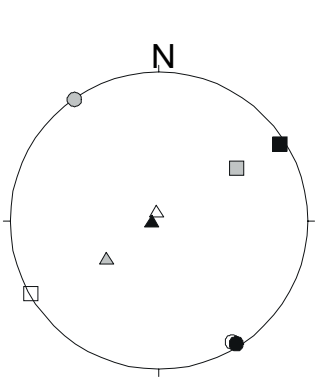

$\mathrm{X} 1$

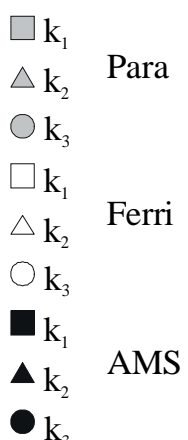

AMS

Fig. 7.3: Comparison of the orientation of the different axes of the magnetic ellipsoid from different measurements of magnetic properties. The orientation of the ferrimagnetic axes usually shows a perfect correlation with the axes of the AMS measurement indicating a domination of the ferrimagnetic properties. The orientation of the paramagnetic axes seems to be rotated with respect to the AMS measurement. 
In sample $42 a$ the magnetic properties of the rocks seems to be controlled by the ferrimagnetic properties since the shape of the magnetic ellipsoid of the AMS measurements and the ferrimagnetic properties exhibit the same values (see Fig. 7.2). In sample $x 1$ the different properties seem to be interacting slightly destructive while in sample 128bll the interaction of the magnetic properties seems to be constructive (see Fig. 7.2). This observation, however, is not confirmed by the orientation of the main axes of the respective magnetic ellipsoids (see Fig. 7.3), where a destructive orientation of the paramagnetic axes to the nearly perfectly matching AMS and ferrimagnetic axes can be observed. In sample $42 a$ the axes of the ferrimagnetic ellipsoid perfectly match those of the AMS ellipsoid while the axes of the paramagnetic ellipsoid are rotated. In sample $\mathrm{x} 1$ small differences in the orientation of the ferrimagnetic and AMS axes and the rotation of paramagnetic axes contribute to the bulk magnetic properties of the rock sample. In samples $42 \mathrm{a}$ and $128 \mathrm{~b}$ ll the ferrimagnetic fabric is much better defined than the paramagnetic fabric. In sample $x 1$ the paramagnetic fabric is much better defined than the ferrimagnetic fabric (see Fig. 7.4).

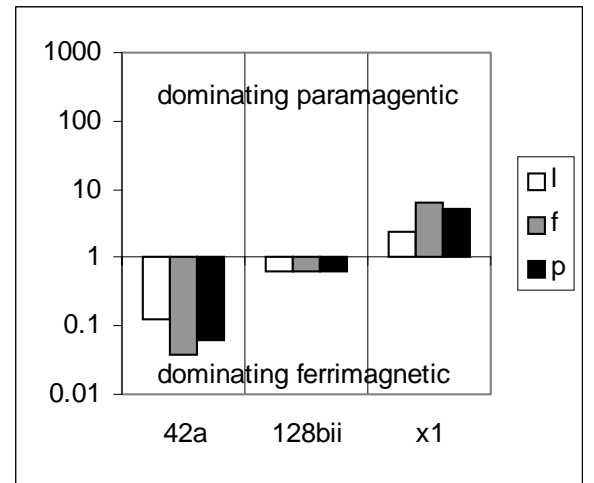

Fig. 7.4: Diagram of the $I, f$ and $p$ parameters of the respective samples. While in sample $42 a$ the ferrimagnetic fabric is much better developed than the paramagnetic fabric, for sample 128bll only a slightly more pronounced ferrimagnetic than paramagnetic fabric was calculated. In sample $\mathrm{x} 1$ the paramagnetic fabric is better developed than the ferrimagnetic fabric. However, the samples do show a pronounced planar fabric which is confirmed by the measured form of the respective ellipsoids.

This is confirmed by the pronounced oblate shape of the paramagnetic ellipsoid and the accompanying high value of $P^{\prime}$. Furthermore, $f$ (see equation [10], chapter 5.4.2) reflects the oblate magnetic ellipsoid as well while I (see equation [9], chapter 5.4.2) is smaller by a factor of $\sim 2.6(f=6.355, l=2.46$, see Fig. 7.4$)$.

\subsection{Northern gneissic granites}

Seven samples have been chosen from the northern gneissic granites ranging in their bulk susceptibilities from 500 to $4600^{*} 10^{-6} \mathrm{SI}$. While the AMS measurements 
revealed uniformly high $T$ values for most of the samples ( $T=0.3-0.8)$, sample 63d $(T=0.051)$ and 48c ( $T=-0.073)$ show neutral or nearly neutral values (see Fig. 7.5). The orientation of the respective magnetic axes exhibits a parallelism of the axes for most of the samples, only in samples 56all and 44a there is no perfect alignment of the respective magnetic axes (see Fig. 7.6). In sample 63d the paramagnetic axes are slightly shifted with respect to the other axes.

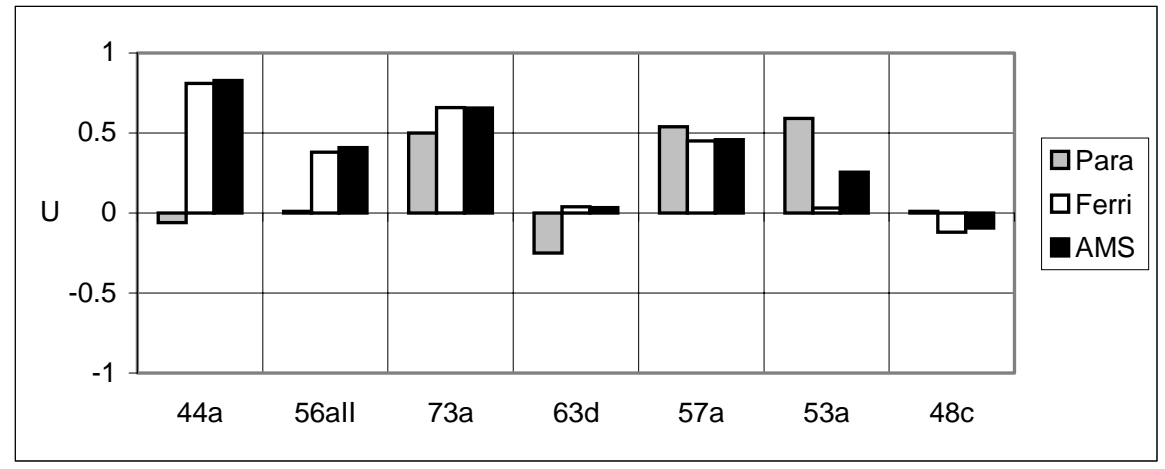

Fig. 7.5: Comparison of the form-parameter $\mathrm{U}$ of the northern gneissic granites.

The ferrimagnetic and AMS-axes of sample 63d show a good concordance in $\mathrm{k}_{1}$ and $k_{2}$, only $k_{3}$ of the measurement shows small differences in its orientation. Since the axes of the same measurements have to be perpendicular with respect to each other this probably reflects a measurement error. In samples 56all and 44a the ferrimagnetic and AMS axes are perfectly aligned, the paramagnetic axes $k_{1}$ and $k_{2}$ seem to have interchanged in comparison to the ferrimagnetic or AMS axes.
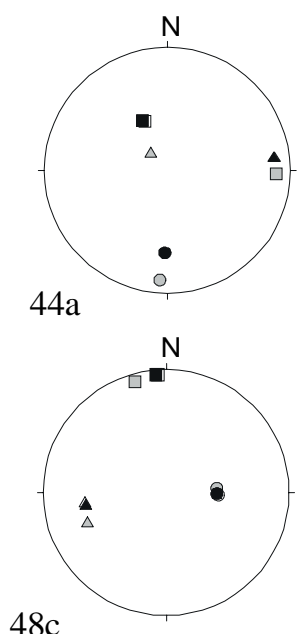

$48 \mathrm{c}$

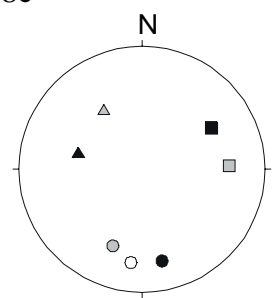

$53 a$
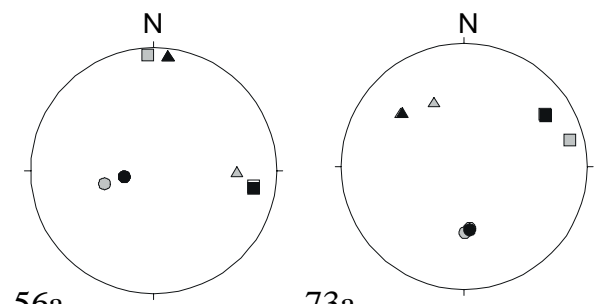

$56 a$

$73 a$
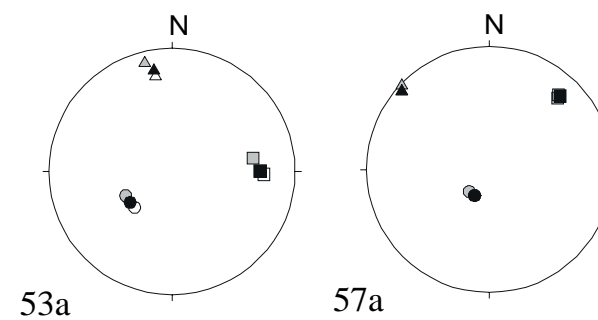

$\square \mathrm{k}_{1} \triangle \mathrm{k}_{2} \bigcirc \mathrm{k}_{3}$

Para

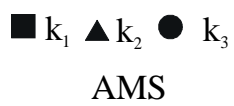

$\square \mathrm{k}_{1} \triangle \mathrm{k}_{2} \bigcirc \mathrm{k}_{3}$

Ferri
Fig. 7.6: Comparison of the orientation of the different main magnetic axes of the different measurement methods. It is confirmed by the respective orientations that in most of the measured samples the ferrimagnetic minerals do not necessarily dominate the orientation of the magnetic ellipsoid. For example sample $53 a$ points to a contribution of both, paramagnetic and ferrimagnetic properties to the orientation of the AMS ellipsoid. 
Sample 53a shows a domination of paramagnetic properties over the bulk magnetic properties of the sample (see Fig. 7.5). This is also indicated by the orientation of the AMS axes between the respective paramagnetic and ferrimagnetic axes. Furthermore, the magnetic properties show a more distinct paramagnetic fabric than ferrimagnetic fabric $(l=3.144, f=7.517$, see Fig. 7.7). This is confirmed by the highly oblate form of the paramagnetic ellipsoid $\left(U_{\text {para }}=0.59\right.$, $\left.U_{\text {ferri }}=0.03\right)$. The same holds true for sample 48c, still, as can be deduced from the shape of the respective magnetic ellipsoids, the ferrimagnetic properties dominate the paramagnetic properties.

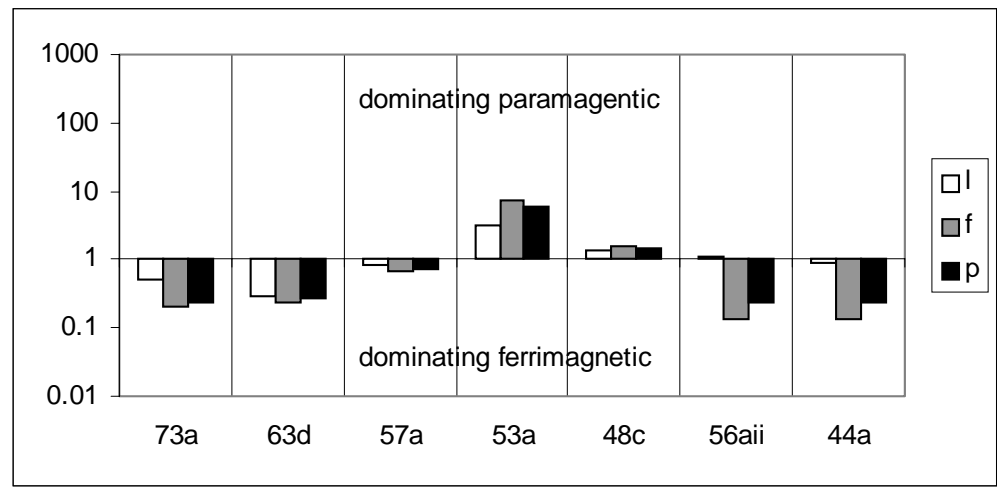

Fig. 7.7: $\mathrm{I}, \mathrm{f}$ and $\mathrm{p}$ parameters of the samples. In most samples the ferrimagnetic anisotropies are better developed, only sample $53 a$ shows a more distinct paramagnetic fabric. Samples $57 \mathrm{a}$ and $48 \mathrm{c}$ show nearly equally developed fabric anisotropies.

\subsection{Western gneissic granites}

The six selected samples for the western gneissic granites (140al, 133d, 116bl, 108bll, 125all and 123b) show oblate (140al, 116bl and 125all) as well as prolate (133d, 108bll and 123b) magnetic ellipsoids (see Fig. 7.8).

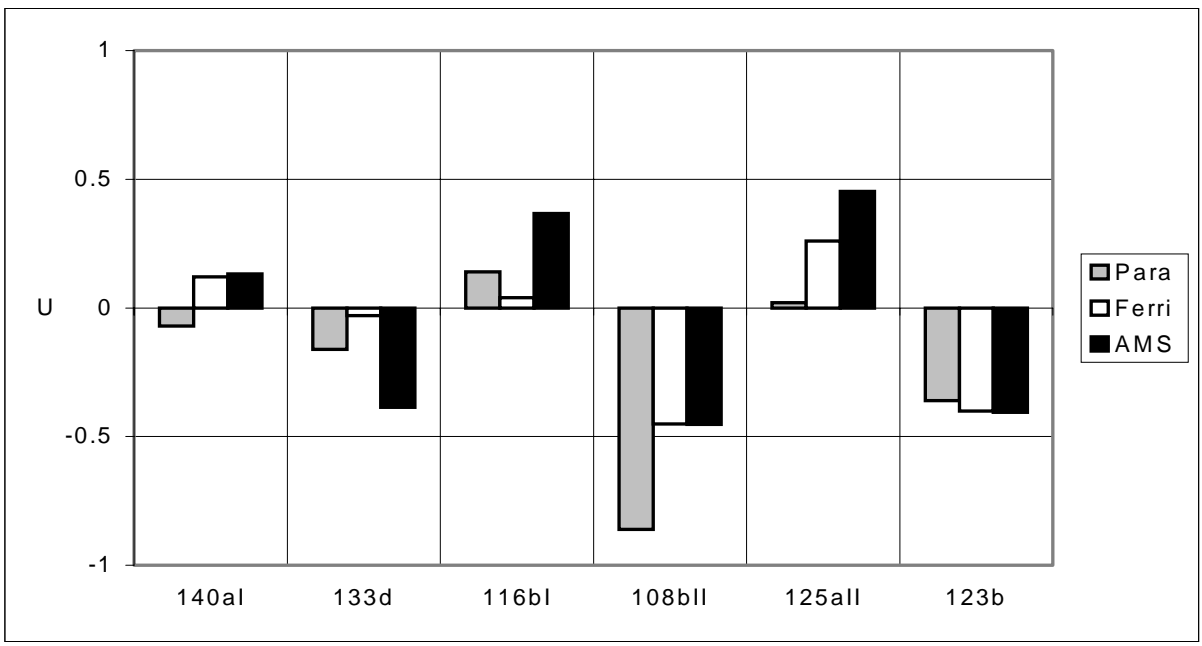

Fig. 7.8: Comparison of the U-parameters for the western gneissic granites. Again only a weak correlation between the AMS measurements and the paramagnetic properties of the HFA measurements is obvious pointing to a domination of the ferrimagnetic properties over the paramagnetic properties for most of the samples. 
The distinctness of the ellipsoids is moderate with U-values in the range of -0.4 and 0.4 . The orientations of the respective axes of the different measurements do not show a pronounced concordance of axes, but rather seem to be only loosely connected to each other (see Fig. 7.9). Sample 116bl shows a marked alignment of the paramagnetic axes with the AMS axes indicating a domination of paramagnetic properties of the sample. The other samples either show a correlation between the ferrimagnetic axes and the AMS axes (125all, 133d and $108 \mathrm{~b})$ or the axes are rotated or interchanged (140al, 125a and 123b).
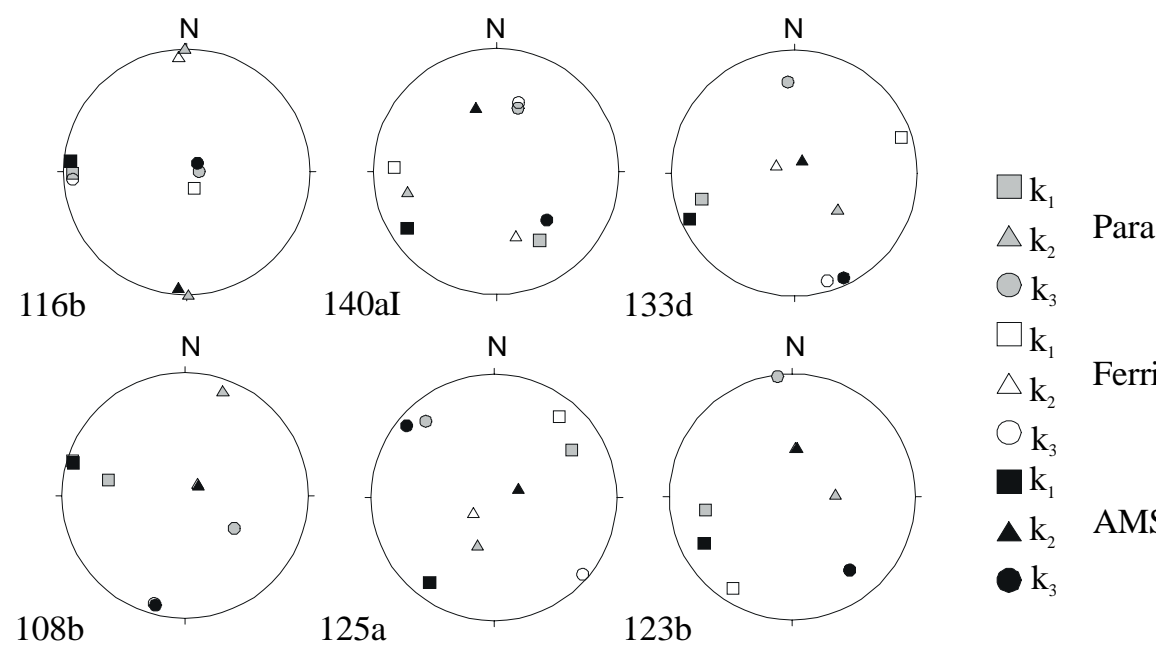

$\square \mathrm{k}_{1}$

$\triangle \mathrm{k}_{2} \quad$ Ferri

$\mathrm{k}_{3}$

$\mathrm{k}_{1}$

$\Delta \mathrm{k}_{2} \quad \mathrm{AMS}$

$125 \mathrm{a}$

$123 b$

Fig. 7.9: The correlation of the orientation of the magnetic axes for most of the samples is weak. A mixture of ferrimagnetic and paramagnetic properties is responsible for the orientation of the AMS ellipsoid. Only sample 108bll shows a pronounced domination of the ferrimagnetic properties over the paramagnetic properties indicated by the perfect alignment of the respective magnetic axes.

The ratios of $I$ and $f$ reflect the above stated observations (see Fig. 7.10). For sample $116 \mathrm{bl}$ unusually high values were calculated $(l=124, f=87$, see Fig. 7.10). Together with the low bulk susceptibility and the orientation of the respective magnetic axes only very small amounts of ferrimagnetic minerals seem to be present in the sample. This is confirmed by the low degree of bulk susceptibility $\left(133^{*} 10^{-6} \mathrm{SI}\right)$. The other samples of the western gneissic granites with their destructive and constructive alignment of magnetic axes are characterized by a more distinct fabric of the ferrimagnetic minerals present than that of the paramagnetic minerals. 


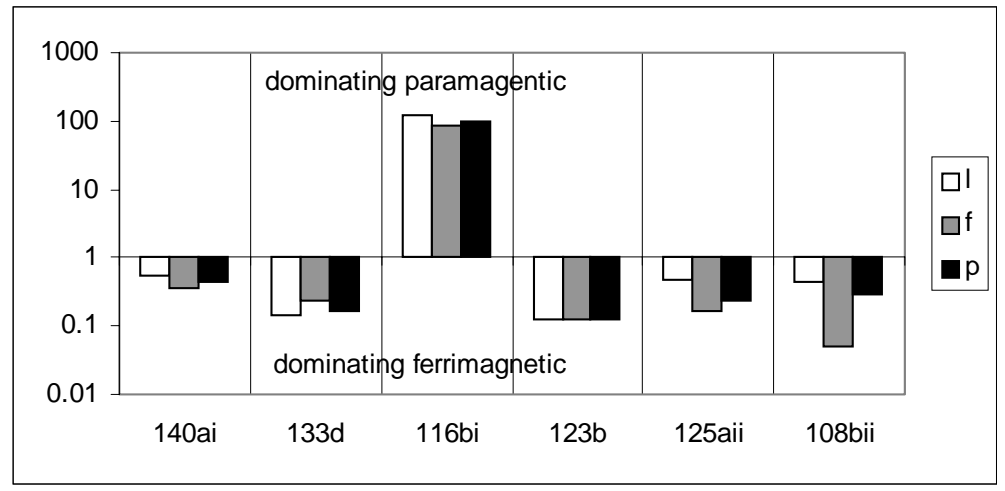

Fig. 7.10: I, f and p parameters of the samples. Only in sample $116 \mathrm{bl}$ the paramagnetic anisotropy is more pronounced than the ferrimagnetic anisotropy.

\subsection{Equigranular granite}

Only two samples were used from the granitoids of the equigranular granites (146all and 136c). Sample $136 \mathrm{c}$ has a bulk susceptibility of $133^{*} 10^{-6} \mathrm{SI}$ while sample 146 all has a bulk susceptibility of $\sim 2000^{*} 10^{-6} \mathrm{SI}$. For sample $136 \mathrm{c}$, the low susceptibility points to a control of the paramagnetic properties over the bulk rock properties. The magnetic ellipsoid shows a neutral shape of the paramagnetic ellipsoid and a pronounced prolate shape of the ferrimagnetic ellipsoid. However, the AMS measurements revealed a moderately oblate magnetic ellipsoid (see Fig. 7.11).

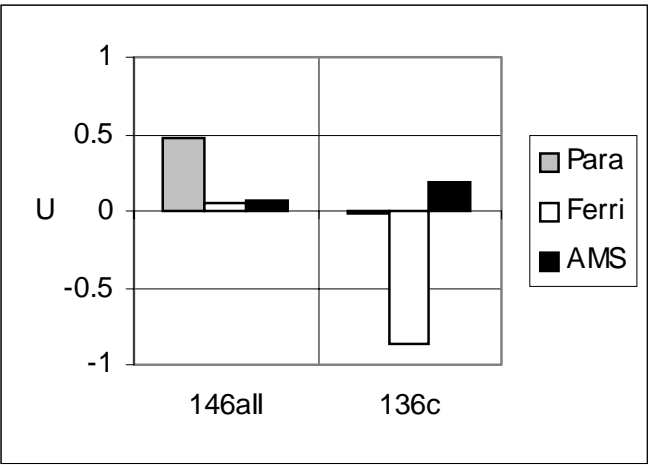

Fig. 7.11: U-parameters for the samples of the equigranular granites.

The orientation of the different axes show a concordance between the paramagnetic and the ferrimagnetic axes for sample 136c, still the AMS axes are rotated (see Fig. 7.12). This might reflect the occurrence of other ore minerals in the sample whose magnetic properties control the orientation of the AMS that can not be measured during the separation process due to its ferromagnetic or antiferromagnetic behavior. This is confirmed by the contrasting values of the respective shapes of the magnetic ellipsoids. Sample 146all again shows a good concordance between the ferrimagnetic and AMS axes (see Fig. 7.12), and a 
constructive connection of the paramagnetic and ferrimagnetic properties (see Fig. 7.11).

The magnetic fabric of sample 146all has I- and f-values of $\sim 1$ (see Fig. 7.13). The shape of the magnetic ellipsoid from the AMS measurements suggests a domination of the ferrimagnetic over the paramagnetic properties of the sample. Sample $136 \mathrm{c}$ shows equally evolved planar fabrics $(f=0.868)$, the linear fabric of the ferrimagnetic minerals seems to be far better defined (see Fig. 7.13) which is reflected in the shape-parameters $\left(\bigcup_{\text {para }}=-0.02, \bigcup_{\text {ferri }}=-0.87\right)$.

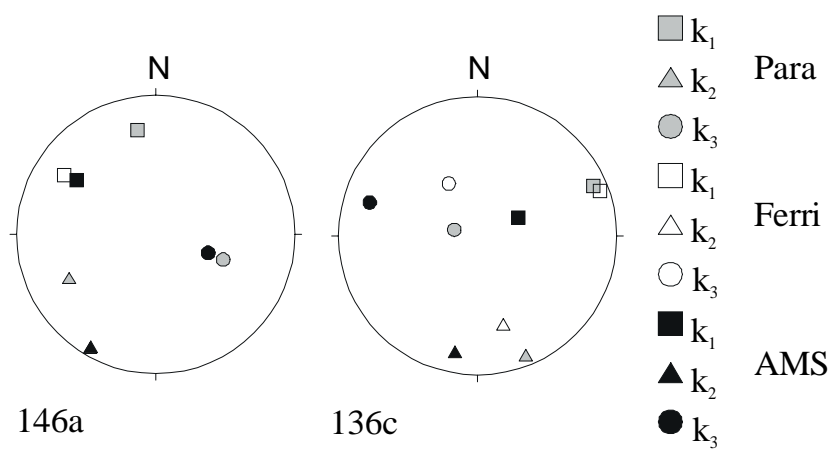

Fig. 7.12: Orientations of the main magnetic axes for the equigranular granites. Sample 146a shows a good correlation of the ferrimagnetic axes with the AMS ellipsoid while sample $136 \mathrm{c}$ only shows a weak correlation.

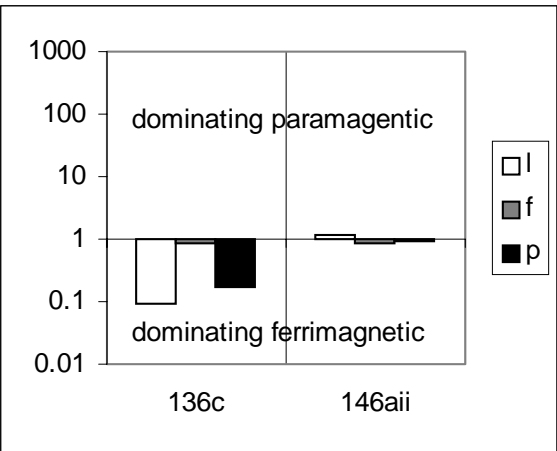

Fig. 7.13: I, $f$ and $p$ parameters of the different samples. In sample 146all the para- and ferrimagnetic anisotropies are equally developed while in sample $136 \mathrm{c}$ the ferrimagnetic linear anisotropy is much better developed than the paramagnetic anisotropy.

\subsection{Porphyritic granite}

Seven samples were chosen for the separation using the HFA with bulk susceptibilities ranging between $175^{*} 10^{-6} \mathrm{SI}$ and $2055^{*} 10^{-6} \mathrm{SI}$, the shape of the respective magnetic ellipsoids ranges between oblate and prolate, no neutral samples were separated. Most of the samples show a domination of the ferrimagnetic properties over the paramagnetic properties. From the $U$-values a constructive superposition of the para- and ferrimagnetic axes can be inferred for 
sample 74c (see Fig. 7.14). The orientation of the axes points to an addition of properties since the AMS-axes are oriented as a geometric mean between the ferrimagnetic and paramagnetic axes (see Fig. 7.15). The other samples show all kinds of interaction (constructive or destructive) and the axes are rotated or interchanged (see Fig. 7.15).

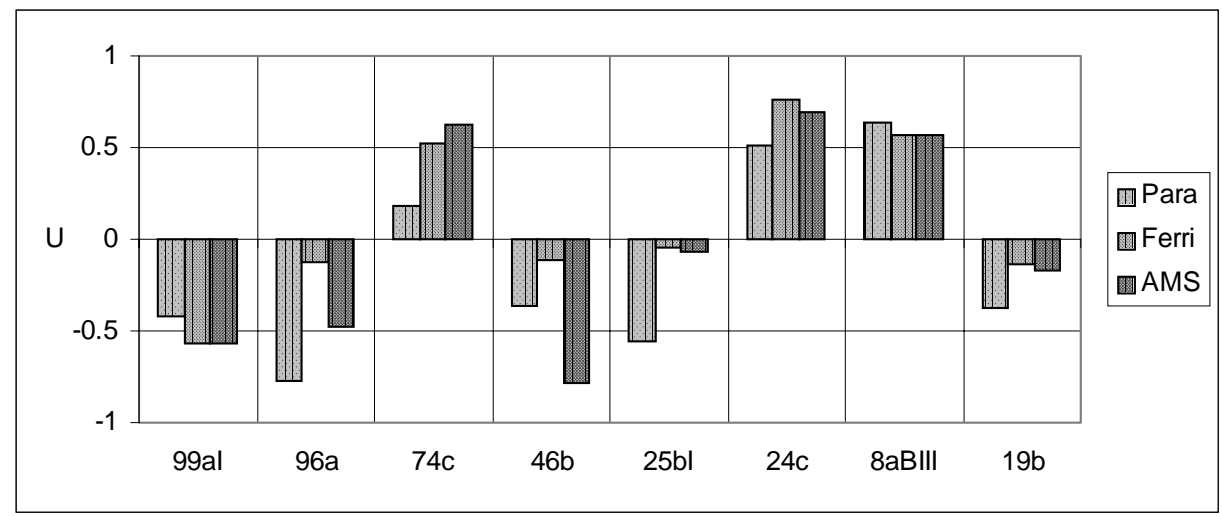

Fig. 7.14: U-parameters of the different samples.

Most of the samples show a domination of the ferrimagnetic over the paramagnetic properties which is confirmed by the moderate to high bulk susceptibilities of the samples.

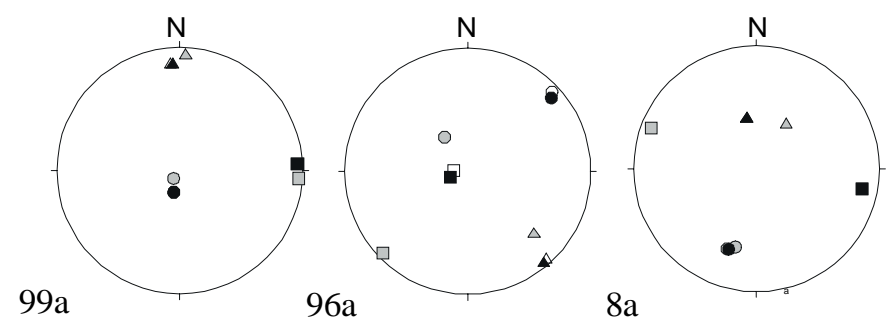

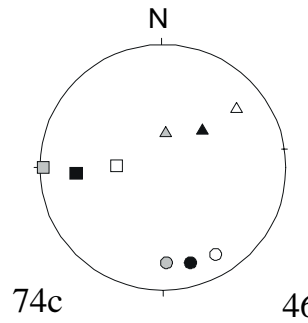

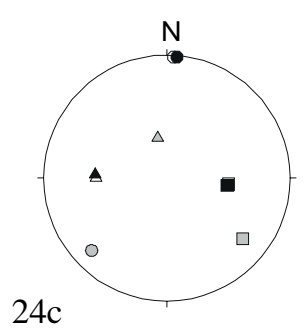

$46 \mathrm{~b}$
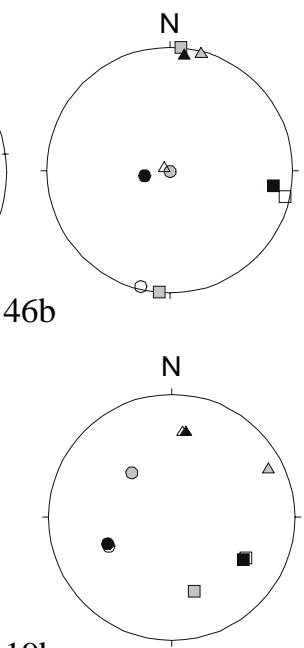

$19 b$

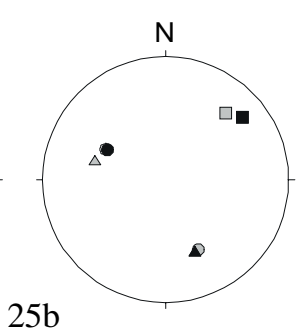

$\square \mathrm{k}_{1}$

$\triangle \mathrm{k}_{2} \quad$ Para

$\mathrm{k}_{3}$

$\square \mathrm{k}_{1}$

$\triangle \mathrm{k}_{2} \quad$ Ferri

$\bigcirc \mathrm{k}_{3}$

$\mathrm{k}_{1}$

$\mathrm{k}_{2}$ AMS
Fig. 7.15: Orientation of the main magnetic axes. Usually a good correlation between the ferrimagnetic ellipsoids and the AMS ellipsoids is found. Sample $74 \mathrm{c}$ shows an interaction of paramagnetic and ferrimagnetic axes leading to the measured AMS ellipsoid. 


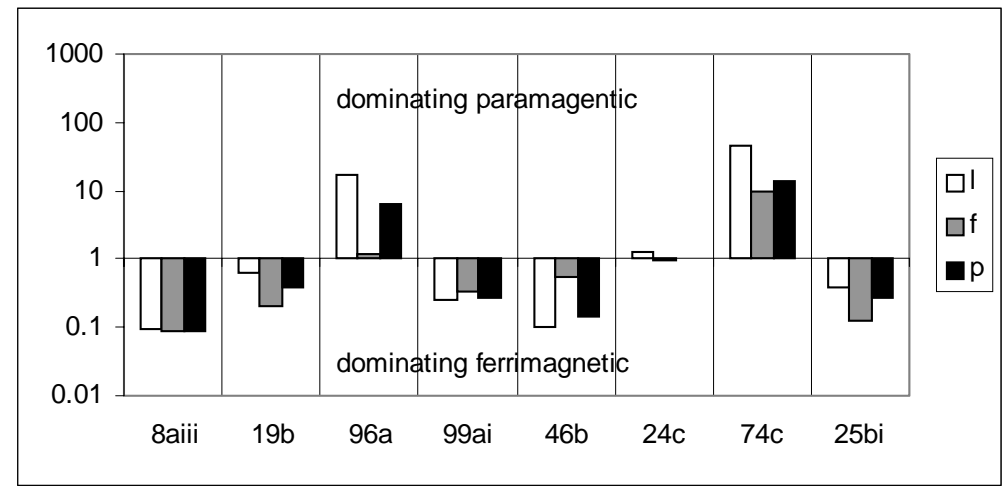

Fig. 7.16: I, $f$ and $p$ parameters of the samples.

From their I-, f- and p-ratios most of the samples show more pronounced ferrimagnetic fabrics than paramagnetic fabrics (see Fig. 7.16). Only samples 96a and $74 \mathrm{c}$ have dominating paramagnetic linear anisotropies, in sample $24 \mathrm{c}$ ( $\mathrm{p}$ is exactly 1) both anisotropies from both contributing phases are equally developed.

\subsection{Implications of HF-analyzes}

The magnetic properties of the majority of the samples are controlled by ferrimagnetic minerals, sample 136c of the equigranular granites is controlled by another mineral (probably (anti)ferromagnetic) that can not be separated using the applied calculations. However, even if the bulk magnetic properties of the samples are controlled by the ferrimagnetic fraction of the sample the paramagnetic properties usually are parallel or subparallel to the ferrimagnetic properties. Some of the samples with high bulk susceptibilities show a destructive correlation between the respective main magnetic axes (paramagnetic axes are interchanged or rotated with respect to the ferrimagnetic axes). They are controlled solely by the ferrimagnetic minerals and their orientation of AMS-ellipsoid axes reflects the orientation of the main magnetic axes derived from ferrimagnetic minerals. Nevertheless, the parameters calculated (U-parameter) for the ferrimagnetic and paramagnetic ellipsoids are comparable. The question arises how this difference between samples with high bulk susceptibilities may be explained. This phenomenon is not restricted to specific lithological units, grain sizes or ages which rejects the explanation through different origin or emplacement history of the units. Furthermore, the distribution of these samples is not restricted to certain areas in the batholith or in the different units in the batholith so no different tectonic modification of the samples can be assumed. Whether the different magnetic axes 
correlate constructively, destructively or are rotated with respect to other axes seems to depend on the distribution of ferrimagnetic minerals in the samples. Where ferrimagnetic minerals are aligned in such a way that their magnetic properties may interact, a disturbed distribution of the ferrimagnetic axes is an explanation (Gregoire et al., 1995). The orientation of the magnetic ellipsoids obtained from AMS measurements depends on whether the samples are dominated by ferrimagnetic minerals (then the AMS-axes correlate with the ferrimagnetic ellipsoid) or whether they are controlled by the paramagnetic minerals in the sample (then the AMS-axes correlate with the paramagnetic ellipsoid). This is confirmed by the ratio of energy densities. Samples with a ratio $>1$ (controlled by paramagnetic minerals) always show a subparallel distribution of magnetic axes while samples with interchanged or rotated magnetic axes all show ratios $<1$. The inverted conclusion that all samples with ratios of energy densities $<1$ show rotated or interchanged axes does not hold true as it depends on the distribution of ferrimagnetic minerals in the samples.

Since the rotation of axes is restricted to samples with high bulk susceptibilities it may be a calculation error during the separation of the ferri- and paramagnetic properties. When only small amounts of paramagnetic minerals are present in the rock (e.g. in the porphyritic granite) that furthermore are nearly isotropic $\left(k_{1} \sim k_{2} \sim k_{3}\right)$ it may be possible that axes with comparable susceptibilities (e.g. in biotites with $\left.\mathrm{k}_{1} \sim \mathrm{k}_{2}>\mathrm{k}_{3}\right)$ are swapped. This would as well explain the observed exchange in orientations of paramagnetic axes with respect to the AMS measurements and the ferrimagnetic axes. This is confirmed by the observation that in samples where the shape of the paramagnetic ellipsoid is prolate, the paramagnetic $\mathrm{k}_{1}$-axis matches with $k_{1}$ of the AMS measurements while $k_{2}$ and $k_{3}$ (paramagnetic) may be exchanged. In samples where the paramagnetic ellipsoid shows an oblate shape of the magnetic ellipsoid $k_{3}$ (paramagnetic) and $k_{3}$ (AMS) are subparallel to each other while $k_{1}$ and $k_{2}$ (paramagnetic) may be exchanged with respect to the AMS measurements. Finally, samples where the shape of the paramagnetic ellipsoid is neutral all three paramagnetic axes $\left(k_{1}, k_{2}\right.$ and $\left.k_{3}\right)$ may be exchanged or even rotated with respect to the AMS axes. According to this the orientation of the different paramagnetic axes are correlated with the respective AMS axes even if the magnetic rock properties are dominated by the ferrimagnetic properties. If only low amounts of paramagnetic minerals are present in the sample at least the axis 
corresponding to the preferred shape of the magnetic ellipsoid $\left(\mathrm{k}_{1}\right.$ if $-1<\mathrm{U}<0$ or $\mathrm{k}_{3}$ if $0<U<1)$ are subparallel. It may be possible that in this case the exchanged axes ( $k_{2}$ and $k_{3}$ or $k_{1}$ and $k_{2}$ respectively) are subparallel to the corresponding AMS axes even if they are calculated otherwise.

However, from the I, $f$ and $p$ values of the samples it appears that in samples that show a domination of ferrimagnetic over paramagnetic properties, the degrees of linear and planar anisotropy as well as the magnitude of anisotropy are controlled by the ferrimagnetic minerals. Hence these values from the AMS measurements do not reflect the distinctness and degree of the magnetic fabric of the biotites and/or hornblendes and should therefore not be used for the interpretation of the paramagnetic mineral fabric. 


\section{Calculating theoretical bulk susceptibilities}

Two different methods were used to calculate a theoretical bulk susceptibility of the samples. In one set of calculations the modal content of the samples was used while in the second set the $\mathrm{FeO}, \mathrm{Fe}_{2} \mathrm{O}_{3}$ and $\mathrm{MnO}$ content was used.

\subsection{Calculations using the modal content of the samples}

Calculations of theoretical bulk susceptibilities can be performed using the modal content of the samples by simply adding the different mineral susceptibilities according to their percentage content (see equation [1], chapter 5.3). Since no ferrimagnetic minerals were calculated from the geochemical analyzes the calculated susceptibility only matches the measured susceptibility if no ferrimagnetic minerals are present in the sample. It has been shown by Siegesmund \& Becker (2000) that in case of a difference between the calculated and measured susceptibility the difference must be assigned to the ferrimagnetic minerals. For samples with a reasonable hornblende content two different susceptibilities were used for the calculation (see Table 8.1 for mineral susceptibilities), one set with a highly and one with a less susceptible hornblende.

Table 8.1: Mineral susceptibilities and anisotropy values of the different main magnetic axes used for the calculations. Data for magnetite grains was calculated (Angenheister \& Soffel, 1972) from metamorphic and granitic rocks, since the susceptibility of magnetite is shape preferred only the bulk susceptibility should be used. Data from (1) Borradaile et al. (1987); (2) Friedrich (1994); (3) Angenheister \& Soffel (1972); (4) Hrouda (1986)

\begin{tabular}{|c|c|c|c|c|c|c|c|}
\hline & Ref. & $k_{\text {bulk }}\left({ }^{*} 10^{-6} \mathrm{SI}\right)$ & $k_{1}$ & $k_{2}$ & $k_{3}$ & $\mathrm{P}$ & $\begin{array}{l}\text { Remark } \\
\mathrm{s}\end{array}$ \\
\hline Biotite & 1 & 1180 & 1.098 & 1.095 & 0.832 & 1.32 & $\begin{array}{|lr|}k_{x} & <c> \\
k_{y} & <c> \\
k_{z} & <c>\end{array}$ \\
\hline $\begin{array}{l}\text { Hornblende } \\
\text { (high hbl) }\end{array}$ & 2 & 1306 & 1.037 & 1.023 & 0.94 & 1.1 & \begin{tabular}{|l|l|}
$\mathrm{k}_{\mathrm{x}}$ & $\|<\mathrm{b}>$ \\
$\mathrm{k}_{\mathrm{y}} \|<\mathrm{c}>$ \\
$\mathrm{k}_{\mathrm{z}} \|<\mathrm{a}>$ \\
\end{tabular} \\
\hline $\begin{array}{l}\text { Hornblende } \\
\text { (low hbl) }\end{array}$ & 2 & 425 & 1.066 & 1.036 & 0.898 & 1.19 & \begin{tabular}{|l|l|l|}
$k_{x}$ & $<b>$ \\
$k_{y} \|<c>$ \\
$k_{z} \|<a>$
\end{tabular} \\
\hline Magnetite & 3 & $\sim 600000$ & 1.108 & 0.964 & 0.936 & 1.18 & mean \\
\hline Quartz & 4 & -13.4 & & & & & isotropic \\
\hline Plagioclase & 1 & -2.7 & & & & & isotropic \\
\hline K-feldspar & 4 & -12 & & & & & isotropic \\
\hline
\end{tabular}

Results of the calculations are presented in Table 8.2. Calculations resulted for nearly all of the samples in bulk susceptibilities that are too low, an influence of 
ferrimagnetic minerals must be assumed for most of the samples. The influence of ferrimagnetic minerals on the bulk susceptibility is confirmed by the marked difference in the actually measured values. While the arithmetic mean of the bulk susceptibilities of the different units was calculated to values well above $1000^{*} 10^{-6}$ $\mathrm{SI}$, the lowest measurement of samples is usually well below $100^{*} 10^{-6} \mathrm{SI}$. If a specific magnetite content is added to the calculated values to match the arithmetic mean of actually measured values, the magnetite content of the different units is calculated to $0.27 \%$ for the southern gneissic granites, $0.33 \%$ for the northern gneissic granites and $0.18 \%$ for the western gneissic granites. Calculations for the equigranular granites resulted in $0.24 \%$ of magnetite while the porphyritic granite should contain $0.45 \%$. These amounts were calculated using a magnetite with a bulk susceptibility of $600000^{*} 10^{-6} \mathrm{SI}$ (see Table 8.1).

Table 8.2: Results of the calculations of the theoretical bulk susceptibility based on the average mineral content of the samples. Since more than one measurement core has been measured the arithmetic mean and the lowest measurement value obtained during AMS measurements is given.

\begin{tabular}{|c|c|c|c|c|}
\hline & $\begin{array}{l}\text { high hbl } \\
k_{\text {bulk }}\end{array}$ & $\begin{array}{l}\text { low hbl } \\
k_{\text {bulk }}\end{array}$ & $\begin{array}{l}\text { AMS (calculated } \\
\text { average) } k_{\text {bulk }}\end{array}$ & $\begin{array}{l}\text { AMS (lowest } \\
\text { measuremen } \\
\text { t) } k_{\text {bulk }}\end{array}$ \\
\hline VGS & $\begin{array}{r}200.482^{*} 10^{-6} \\
\mathrm{SI}\end{array}$ & $\begin{array}{r}147.622^{*} 10^{-6} \\
\mathrm{SI}\end{array}$ & $1839^{*} 10^{-6} \mathrm{SI}$ & $134^{*} 10^{-6} \mathrm{SI}$ \\
\hline VGW & $\begin{array}{r}298.348^{*} 10^{-6} \\
\mathrm{SI}\end{array}$ & $\begin{array}{r}236.678^{*} 10^{-6} \\
\mathrm{SI}\end{array}$ & $1375^{*} 10^{-6} \mathrm{SI}$ & $47^{*} 10^{-6} \mathrm{SI}$ \\
\hline VGN & $\begin{array}{r}110.895 * 10^{-6} \\
\mathrm{SI}\end{array}$ & & $2098^{*} 10^{-6} \mathrm{SI}$ & $66^{*} 10^{-6} \mathrm{SI}$ \\
\hline EQG & $\begin{array}{r}184.926^{*} 10^{-6} \\
\mathrm{SI}\end{array}$ & $\begin{array}{r}167.306^{*} 10^{-6} \\
\mathrm{SI}\end{array}$ & $1656^{*} 10^{-6} \mathrm{SI}$ & $70^{*} 10^{-6} \mathrm{SI}$ \\
\hline$P G$ & $74.089 * 10^{-6} \mathrm{SI}$ & & $2753^{*} 10^{-6} \mathrm{SI}$ & $16^{*} 10^{-6} \mathrm{SI}$ \\
\hline
\end{tabular}

\subsection{Calculations using the $\mathrm{FeO}, \mathrm{Fe}_{2} \mathrm{O}_{3}$ and $\mathrm{MnO}$ content of the sampels}

Calculation of a theoretical bulk susceptibility can be performed using geochemical analyzes (Gleizes et al., 1993). If the weight percentage of $\mathrm{FeO}, \mathrm{Fe}_{2} \mathrm{O}_{3}$ and $\mathrm{MnO}$ are added according to equation [12] (from Gleizes et al., 1993), the results should match the measured bulk susceptibility of the sample obtained from AMS.

$\mathrm{K}_{\mathrm{Ic}}=\mathrm{k}_{\text {dia }}+\mathrm{k}_{\text {para }}+\mathrm{K}_{\mathrm{af}}$

with

$k_{\text {para }}=d\left(2.52 t+3.34 t^{\prime}+3.38 t^{\prime \prime}\right)(T / T-P T)$ 
$\mathrm{t}, \mathrm{t}$ ' and t" are the weight percentages of $\mathrm{Fe}^{2+}, \mathrm{Fe}^{3+}$ and $\mathrm{Mn}^{2+}$ respectively, $\mathrm{d}$ is the density of the rock and T (in Kelvin) temperature. PT (in Kelvin) is the Curietemperature of the paramagnetic minerals and has been assumed to be $15 \mathrm{~K}$ (Gleizes et al., 1993). $\mathrm{K}_{\text {dia }}$ is assigned a value of $-1.4^{*} 10^{-5} \mathrm{SI}$ which is the diamagnetic susceptibility of quartz, $k_{a f}$, the ferrimagnetic content of the samples, is assumed to be zero.

If the calculated bulk susceptibility is higher than the measured ones the difference must completely be assigned to the occurrence of ferri(o)magnetic minerals since these minerals are not used in the calculations (Gleizes et al., 1993; Rochette et al., 1992).

For eight samples the theoretical bulk susceptibility has been calculated, a $(\log / \log )$ comparison of the calculations with the measured values is presented in Fig. 8.1.

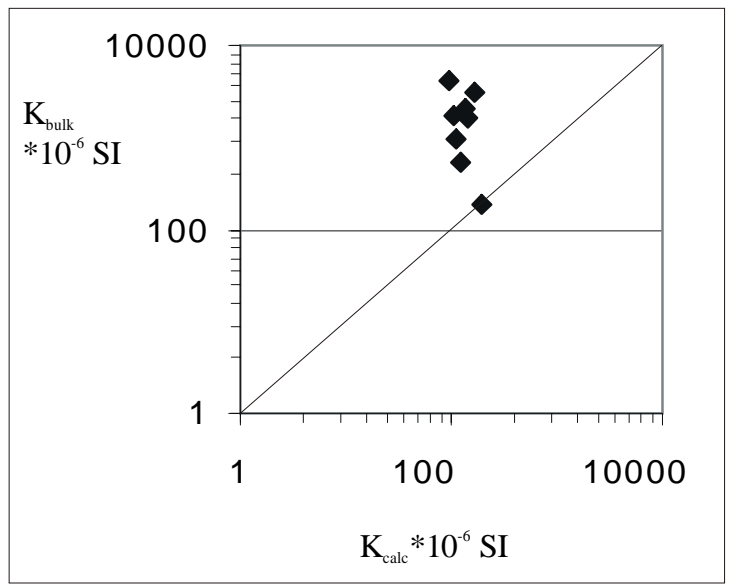

Fig. 8.1: Comparison between calculated and measured bulk susceptibilities. Most of the calculations resulted in far lower bulk susceptibilities than were measured for the sample. $\mathrm{k}_{\text {calc }}$ are the calculated values and $\mathrm{k}_{\text {bulk }}$ are the actual AMS measurements.

Most of the samples showed much higher measured bulk susceptibilities than calculated ones, an influence of ferri(o)magnetic minerals is obvious. Only for one sample a ratio of $\sim 1$ was calculated indicating that only paramagnetic and diamagnetic minerals are present in the sample. 


\section{Modeling of magnetic fabric}

The U-stage data from biotites and hornblendes (see chapter 4.4) was used to calculate a theoretical AMS tensor. From this tensor some fundamental ratios can be calculated concerning the magnetic properties of the specimen and are compared to the actual measured ones obtained from AMS measurements. In case that the AMS is solely controlled by paramagnetic minerals the calculated values should exactly match the measured values. If differences occur other, probably ferrimagnetic minerals must contribute to the magnetic properties of the specimen as well. The modeling takes into account the textures of biotites and hornblendes, other major rock forming minerals such as quartz or feldspars were included in the calculation but due to their diamagnetic properties only have very low magnetic properties and hence have been treated as isotropic constituencies. For the anisotropic minerals biotite and hornblende the tensor was calculated by calculating texture coefficients from the measured pole figures. A detailed description on the theoretical background is given in Siegesmund et al. (1995). The usefullness to test the significance of the AMS measurements with this method has been shown by Siegesmund \& Becker (2000), they demonstrated an increasing ferrimagnetic content towards the marginal areas in the Ardara pluton (northern Ireland).

The orientation of the main magnetic axes in biotite is well known, $k_{3}$ parallels the crystallographic c-axis, $k_{1}$ and $k_{2}$ are oriented in the basal plane (see Fig. 5.2, chapter 5.2), the resulting magnetic ellipsoid has a nearly perfect oblate shape (Zapletal, 1990). The anisotropy of biotites in the basal plane is low $\left(k_{1} / k_{2}=1.097\right.$, Borradaile et al. 1987), the degree of anisotropy for a single crystal reaches values of $P=1.3$. Hornblendes show a somewhat unexpected behavior concerning the orientation of the magnetic axes, $k_{1}$ is oriented parallel to the crystallographic $b$ axis (010), $k_{2}$ parallels the crystallographic c-axis (001) and $k_{3}$ parallels the crystallographic $a^{*}$-axis (100) (Friedrich, 1994; see Fig. 5.2). Therefore, if a preferred mineral orientation of hornblendes is measured in AMS measurements the resulting orientation of $\mathrm{k}_{1}$ is orthogonal to the crystallographic mineral lineation. However, the resulting magnetic ellipsoid of a single crystal measurement shows an oblate ellipsoid as well (Friedrich, 1994). Hornblendes show a wide range of magnetic properties according to their Fe-content. This has been taken into account by using a very low and a very high susceptible hornblende for the 
calculations (see Table 8.1 for values). The mineral content of the different lithologies has been calculated from geochemical measurements without distributing $\mathrm{Fe}^{2+}$ and $\mathrm{Fe}^{3+}$ into minerals like magnetite, sphene or apatite which have ferrimagnetic properties. Due to the shape anisotropy of theses minerals no general parameters with respect to their axial ratios can be used for the calculations. This disregard leads to a slightly raised biotite and hornblende content in the modal composition of the rocks. In Fig. 9.1 it is exemplary shown for sample JB305 how the different textures were used to calculate a theoretical rock texture.

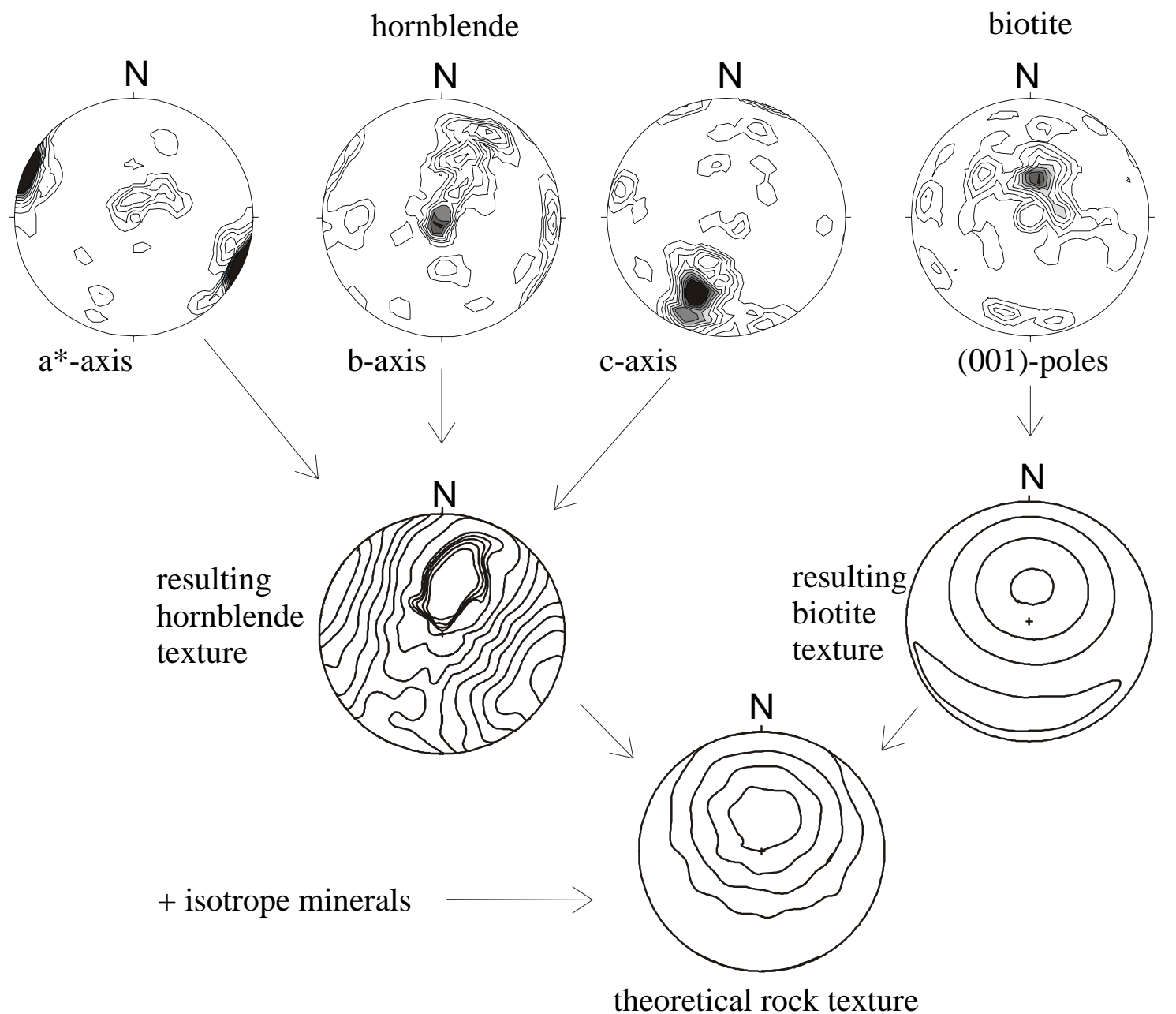

Fig. 9.1: Calculation of the theoretical rock texture using textures obtained from U-stage measurements. The hornblende textures of the different crystallographic axes are used to calculate a resulting texture, biotite is treated alike. From these resulting textures and the mineral content of the isotropic minerals in the rock a theoretical rock texture is calculated from which the theoretical AMS-tensor can be obtained. The resulting theoretical rock texture matches the biotite texture since the hornblende content of the sample is lower than the biotite content. 


\subsection{Southern gneissic granites}

The modal composition of the southern gneissic granites was estimated, using geochemical data, to $24 \%$ quartz, $15 \%$ K-feldspar, $44 \%$ plagioclase, $11 \%$ biotite and $6 \%$ hornblende. Only one hornblende texture was measured from thin sections (sample JB305), this texture was rotated in a way to match the orientation of the basal plane of biotites and the magnetic orientations of $k_{1}$ and $k_{3}$ for the calculations with the other samples of the southern gneissic granite suite. For the calculations with a high and a low susceptible hornblende the same textures with different susceptibilities were used. None of the calculations produced matching values for P' and T and the AMS values (see Fig. 9.2). However, this was not expected due to the high bulk susceptibility of the samples. While the highly susceptible samples (JB309, 2564* $10^{-6} \mathrm{SI}$ and JB261, 2885*10-6 SI) show great differences in the shape of the ellipsoids $(T)$ and the degree of anisotropy, the less susceptible samples (JB305, $540^{*} 10^{-6} \mathrm{SI}$ and JB308, 280*10-6 $\mathrm{SI}$ ) only show smaller differences (see Fig. 9.2) when compared to the AMS measurements.
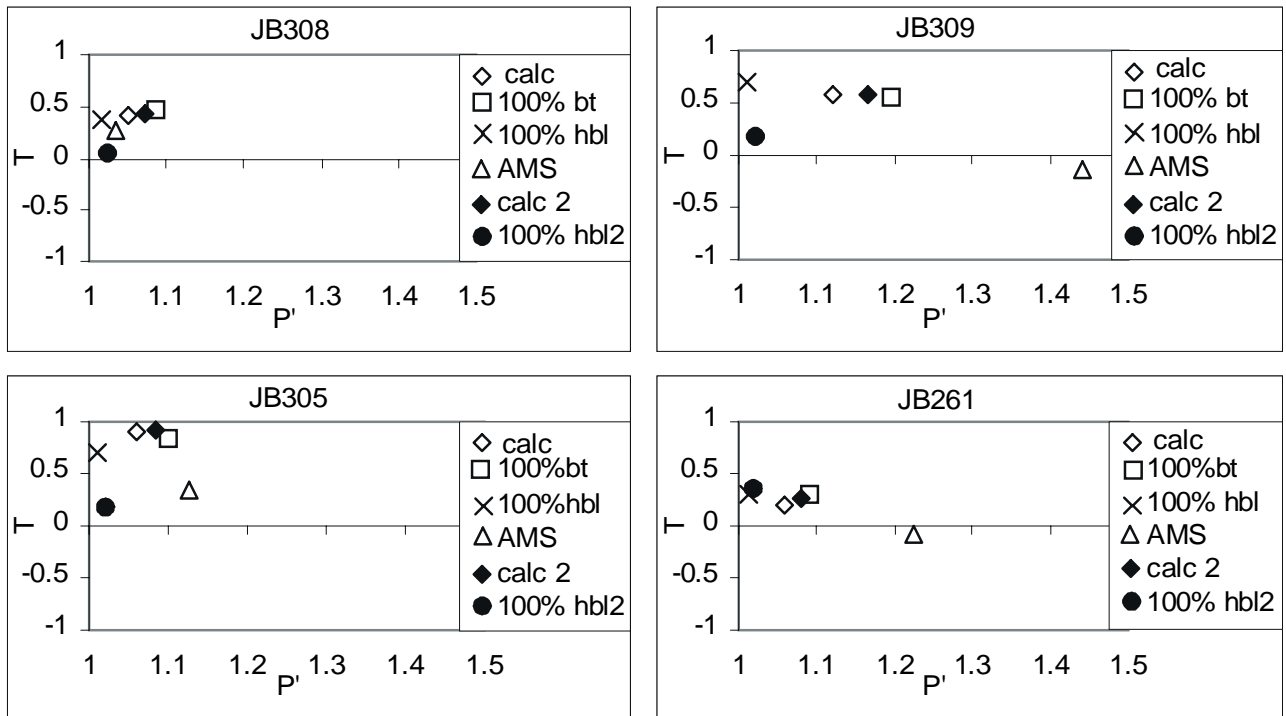

Fig. 9.2: Calculated and measured values for the degree of anisotropy ( $\left.P^{\prime}\right)$ and the shape of the magnetic ellipsoids $(T)$. While sample JB308 shows a good correlation between the measured and calculated values the other samples show greater differences related to their amount of ferrimagnetic minerals (which was not used in the calculations). calc $=$ calculated whole rock properties with highly susceptible hornblende, $100 \%$ bt $=$ hypothetical rock containing $100 \%$ biotite only, $100 \% \mathrm{hbl}=$ hypothetical rock containing $100 \%$ hornblende with a high mineral susceptibility, AMS = actually measured values obtained from the AMS, calc2 $=$ calculated whole rock properties with less susceptible hornblende, $100 \%$ hbl 2 = hypothetical rock containing $100 \%$ hornblende with a low mineral susceptibility only. 
The calculations with the less susceptible hornblende resulted in a higher degree of anisotropy than the whole rock calculation. This must be assigned to the well developed texture of the respective biotite measurements that, due to their higher susceptibility, dominate the paramagnetic properties of the samples in case of a less susceptible hornblende. The shape of the calculated magnetic ellipsoid does not change due to the susceptibility of the hornblende which either points to a subparallel orientation of the respective magnetic axes of hornblende and biotite or to a domination of the biotite texture over the shape of the calculated magnetic ellipsoids in both calculations. Nevertheless, from these calculations it is obvious that a ferrimagnetic phase is responsible for the measured degree of anisotropy and the shape of the magnetic ellipsoids in the AMS measurements.

\subsection{Northern gneissic granites}

The modal mineral content of the northern gneissic granites was calculated to $35 \%$ quartz, 10\% K-feldspar, 45\% plagioclase and 10\% biotite. Four samples have been chosen for the calculations, three samples are located near the outer margin (JB71, JB51, JB44) and one sample (JB204) was taken in the center of the northern gneisses. The AMS measurements showed that sample JB71 has a very low bulk susceptibility of $\sim 85^{*} 10^{-6} \mathrm{SI}$, the calculations show a good concordance with the measured values (see Fig. 9.3).
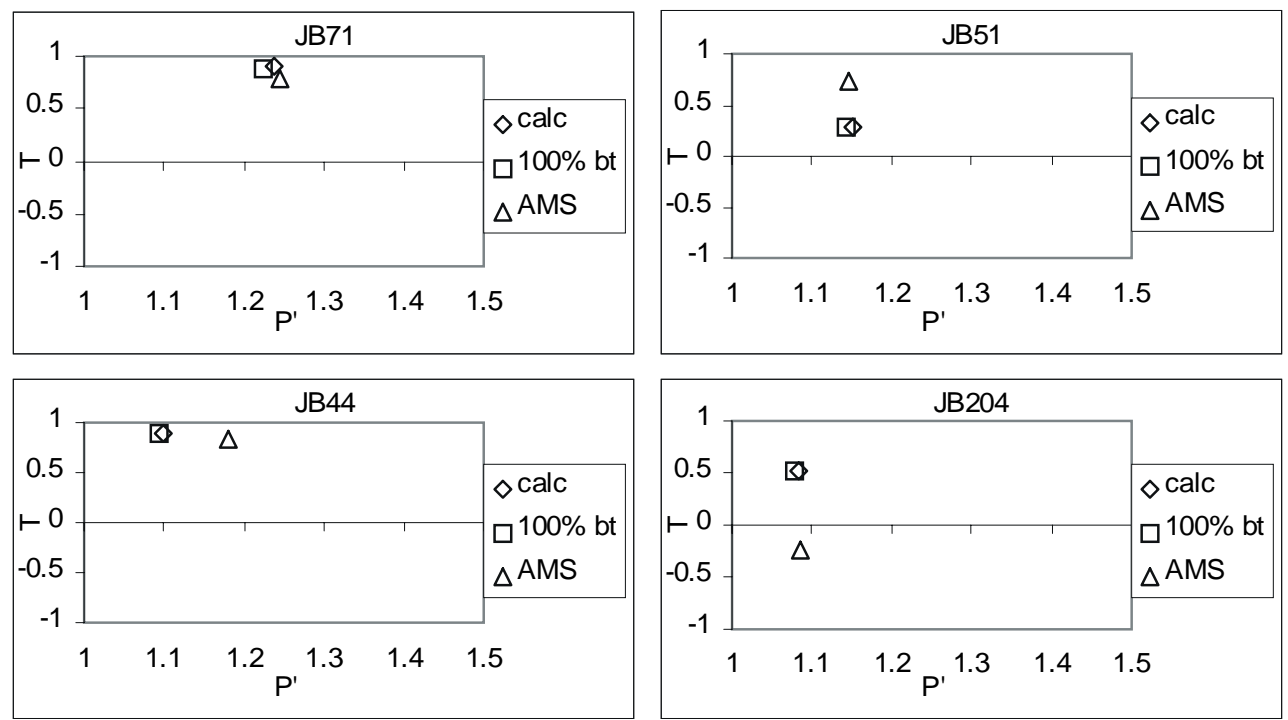

Fig. 9.3: Calculated degree of anisotropy and shape of the magnetic ellipsoid for the northern gneissic granites. Only sample JB71 shows a good correlation of the calculated and measured values. calc $=$ calculated whole rock, $100 \%$ bt $=$ hypothetical rock containing $100 \%$ biotite only, AMS $=$ actually measured values obtained from the AMS. 


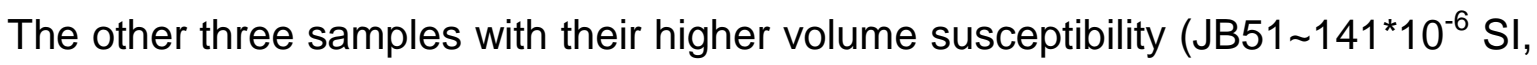

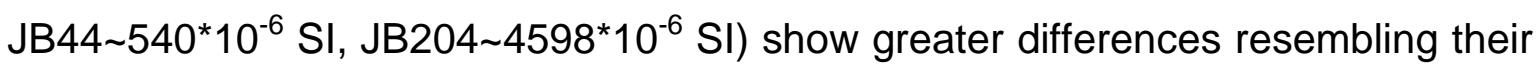
higher content of ferrimagnetic minerals.

Again the highly susceptible sample JB204 shows a great difference in the degree of anisotropy, the difference in the shape of the magnetic ellipsoid seems not to be related to the height of the bulk susceptibility and hence on the amount of ferrimagnetic minerals.

\subsection{Western gneissic granites}

The modal content of the western gneisses was estimated to $27 \%$ quartz, $6 \% \mathrm{~K}$ feldspar, $42 \%$ plagioclase, $18 \%$ biotite and $7 \%$ hornblende. Calculation of the two specimen was performed using one rotated hornblende texture (originally measured from sample JB134). Both samples (JB134 264*10-6 $\mathrm{SI}$ and JB296 $780^{*} 10^{-6} \mathrm{SI}$ ) show a good concordance of the calculated and the measured values (see Fig. 9.4). The degree of anisotropy of sample JB296 is again controlled by the biotite content, a less susceptible hornblende results in a higher degree of anisotropy.
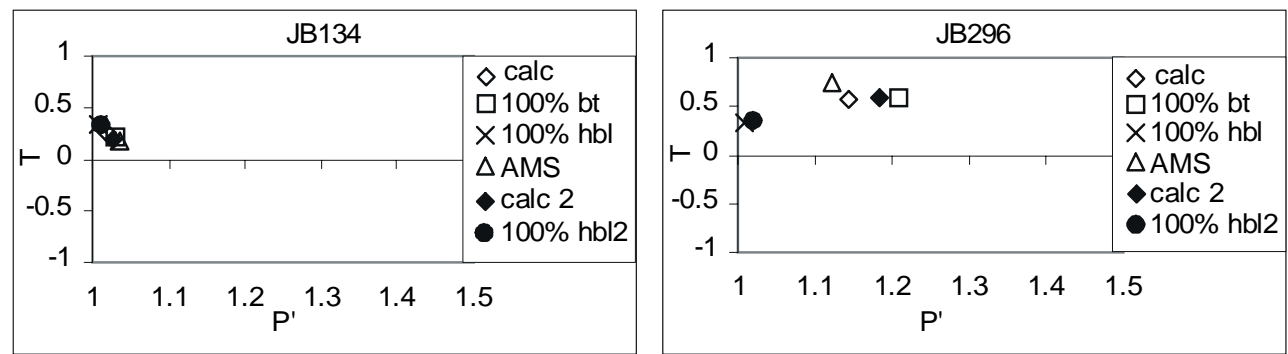

Fig. 9.4: Calculated values for the western gneissic granites. Both samples show a good concordance with the AMS measurements. calc = calculated whole rock properties with highly susceptible hornblende, $100 \%$ bt $=$ hypothetical rock containing $100 \%$ biotite only, $100 \% \mathrm{hbl}=$ hypothetical rock containing $100 \%$ hornblende with a high mineral susceptibility, AMS = actually measured values obtained from the AMS, calc2 = calculated whole rock properties with less susceptible hornblende, $100 \%$ hbl2 = hypothetical rock containing $100 \%$ hornblende with a low mineral susceptibility only.

\subsection{Porphyritic granite}

The (modal) mineral content of the porphyritic granite was calculated to $30 \%$ quartz, 30\% K-feldspar, 33\% plagioclase and 7\% biotite. Five samples have been selected for the calculations from different locations inside the porphyritic granite. None of the samples shows a correlation between the calculated values and the 
corresponding AMS measurements resembling the high content in ferrimagnetic minerals (see. Fig. 9.5). The calculated whole rock values are in good concordance with the calculated values for a hypothetical rock containing $100 \%$ biotite which is not surprising since biotite was the only anisotropic phase used for the calculations. Most of the AMS-measurements show only slightly higher degrees of anisotropy ( $P$ ') but a completely different shape of the magnetic ellipsoid $(\mathrm{T})$. Usually an oblate magnetic ellipsoid is calculated contrasting the preferred prolate ellipsoid of the AMS measurements. Only sample JB46 shows a prolate ellipsoid for the calculated values indicating a random orientation of biotites (Siegesmund et al. 1995). For sample JB261 the degree of anisotropy was calculated to 1.102 and 1.091 for the whole rock and the $100 \%$ biotite calculation, respectively, while the AMS measurements revealed a degree of anisotropy of 1.495. The high value of the AMS probably must be assigned to the interaction of ferrimagnetic minerals indicating a high content of ferrimagnetic minerals in the sample.
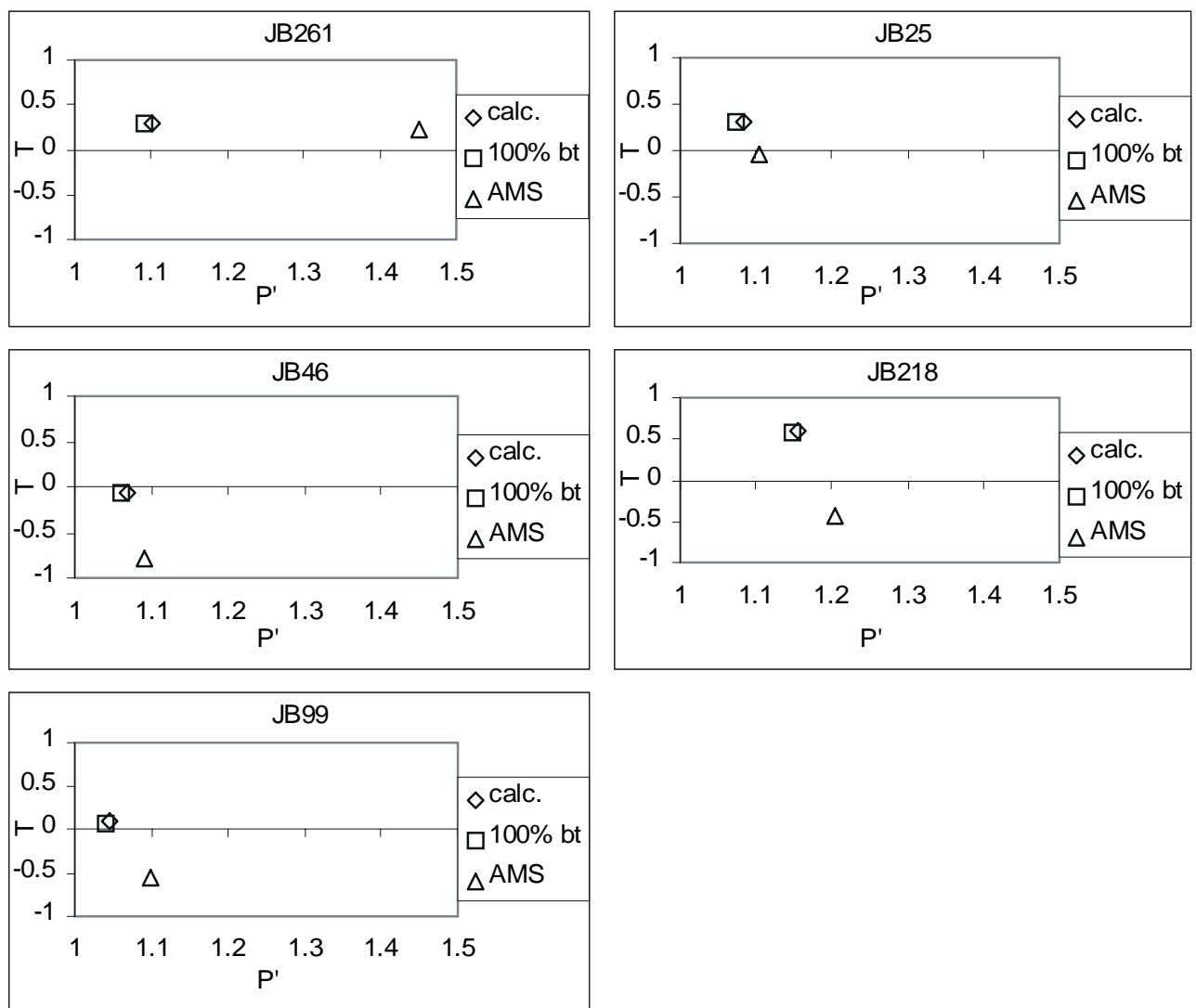

Fig. 9.5: Comparison of the calculated with the actually measured values. The samples show no correlation with the AMS measurements when only the paramagnetic minerals are taken into account for the calculations. calc $=$ calculated whole rock properties, $100 \% \mathrm{bt}=$ hypothetical rock containing $100 \%$ biotite only, AMS = actual values obtained from AMS measurements. 


\subsection{Results}

While the orientation of the main magnetic axes can not be calculated using the above described procedure the basic parameters $\mathrm{P}^{\prime}$ and $\mathrm{T}$ may be modeled and compared to the actual AMS measurements. Calculation of these parameters revealed that it is not only the samples with a very high susceptibility that have a reasonable content of ferrimagnetic minerals that contribute to their overall magnetic properties, but that less susceptible samples can, but must not necessarily have, a contribution of the ferrimagnetic minerals to the AMS measurements as well. The hornblende content only plays a minor role in the overall magnetic properties. Calculations with a highly susceptible hornblende showed lesser degrees of anisotropy than calculations with a less susceptible hornblende. This must solely be attributed to the interplay of biotite and hornblende since no other anisotropic minerals have been calculated. Siegesmund \& Becker (2000) have observed a comparable change of the degree of anisotropy with varying hornblende and biotite contents in the sample. Moreover, they observed a switch from prolate to oblate magnetic ellipsoids during the calculation when biotites are only weakly or randomly distributed while the hornblende texture resembles a typical granitic distribution according to Berger (1995).

Based on these calculations and on the separation of para- and ferrimagnetic properties of the samples (see chapter 7) it is obvious, that the anisotropy parameters measured during the AMS measurements (e.g. degree of anisotropy, shape of the magnetic ellipsoid) are clearly controlled by the ferrimagnetic minerals in case of ferrimagnetic properties dominating paramagnetic properties. Therefore, the anisotropy parameters of the AMS measurements should be used with caution. Nevertheless it has been shown in chapter 7 that the orientation of the respective magnetic axes of the paramagnetic minerals in most cases are subparallel to the ferrimagnetic axes even if the ferrimagnetic properties dominate the magnetic properties of the sample. 


\section{Geological significance of structure, magnetic- and rock fabric}

The different methods used to resolve the internal fabric of the different lithologies of the Chinamora Batholith all resulted in the same constrains, the gneissic granites and the equigranular granites both suffered solid-state deformation. The gneissic granites show different intensities of deformation, the southern gneissic granites show the strongest deformation while the western and northern gneissic granites are less deformed. The porphyritic granite in the center of the batholith only shows a weak solid-state overprint of the fabric, it basically resembles structures pointing to a magmatic flow fabric. This is confirmed by the microscopic analyzes as well as by the measured intensities of quartz, biotite and hornblende textures. The parameters obtained from AMS measurements, that reflect the anisotropy of the magnetic fabric and hence should give evidence on the distinctness of the magnetic fabric have been shown to be controlled by the ore content of the samples and therefore do not reflect the distinctness of the orientation of paramagnetic minerals like biotite or hornblendes. This is confirmed by the calculations of theoretic bulk susceptibilities where the calculated values (without the ferrimagnetic fraction) always showed lower values of the bulk susceptibility than the actually measured bulk susceptibilities. However, the separation of the paramagnetic and ferrimagnetic anisotropies showed that, for most samples, the orientation of the paramagnetic axes mimics the orientation of the ferrimagnetic axes, orientation distributions obtained from AMS measurements can hence be used as an indicator for the orientation of the magnetic lineation and foliation which is subparallel to the measured macroscopic foliation obtained from field measurements. The gneissic and equigranular granites and the porphyritic granite show differences in these orientations. While the gneissic granites and equigranular granite show a margin parallel foliation that cross cut internal lithologies the magnetic and macroscopic foliation planes in the porphyritic granite have a very stable WNW-ESE trend. The different intensities of deformation and the different orientation of foliations and lineations calls for a two stage development of the Chinamora Batholith, first the intrusion of the gneissic granites and after a yet unconstrained time span the intrusion of the porphyritic granite. The equigranular granites either emplaced nearly coeval with or shortly after the gneissic granites but at any rate before the porphyritic granite. Otherwise its 
internal fabric should be comparable to the porphyritic granite and not to the fabric in the gneissic granites. The remaining question is the timing of the different intrusions.

\subsection{Age data}

The temporal relationship between the different intrusions of the Chinamora Batholith and the surrounding greenstone belt can not be deciphered on the basis of structural observations alone. Therefore, different age dating techniques have been used on different minerals to get reliable age data for the different rock types. For this purpose, zircons, apatites and hornblendes were separates from $2 \mathrm{~kg}$ samples using successive density and magnetic separation techniques. The resulting rock powder was improved by hand picking of minerals.

Zircons and apatites were analyzed using a U-Pb multizircon TIMS (thermal ionization solid source mass spectrometry). The ratio of $U$ to its daughter isotope $\mathrm{Pb}$ is a measure of the age of the sample but caution must be applied in interpreting $\mathrm{U} / \mathrm{Pb}$ ratios since most $\mathrm{U}$-bearing minerals contain small amounts of $\mathrm{Pb}$ when they first crystallize. Discrimination between naturally included $\mathrm{Pb}$ and the daughter isotope $\mathrm{Pb}$ is easily done since natural lead also contains the isotope ${ }^{204} \mathrm{~Pb}$ which is not radiogenic. This can be used as a measure for the original lead contamination (Hall, 1993). The measurement results are plotted as conventional ${ }^{206} \mathrm{~Pb} /{ }^{238} \mathrm{U}$ and ${ }^{207} \mathrm{~Pb} /{ }^{235} \mathrm{U}$ concordia diagrams that help to interpret discordant ages. According to Ludwig \& Stuckless (1978), when applied to granites the upper concordia intersection corresponds to the time of zircon growth (emplacement and crystallization of the granitoid body) while the lower concordia intersection is interpreted as an episode of recrystallization. However, samples may represent much older ages than estimated for emplacement from other methods. This maybe due to the frequently observed preservation of old zircons carried up by the magma from its source contaminating the samples (e.g. Bickford et al., 1981). Methods of loss of $\mathrm{Pb}$ during thermal events in zircons include metamorphism, weathering and other processes, however, zircon is quite robust concerning the complete resetting at high temperatures and usually keeps at least a partial record of all thermal events (Mezger \& Krogstad, 1997; Aleinikoff et al., 1989). 
The ${ }^{40} \mathrm{Ar} /{ }^{39} \mathrm{Ar}$ dating of hornblendes was performed using a mass spectrometer $\left(\mathrm{VG}-3600^{\circ}\right)$. The preparation of the hornblendes was done following the technique described by York et al. (1981) and Layer et al. (1987). The Ar/Ar age dating method is a refinement of the $\mathrm{K} / \mathrm{Ar}$ dating method. The sample is subjected to a neutron flux which converts ${ }^{39} \mathrm{~K}$ into ${ }^{39} \mathrm{Ar}$, the ratio of ${ }^{40} \mathrm{Ar} /{ }^{39} \mathrm{Ar}$ is then measured by mass spectrometry with ${ }^{39} \mathrm{Ar}$ being the measure of the amount of undecayed potassium (Hall, 1993). This method is frequently used to specify the duration and frequency of magmatic events because the step-wise heating of the samples, while constantly measuring the ${ }^{39} \mathrm{Ar} /{ }^{40} \mathrm{Ar}$ ratio, gives valuable information on argon held in the crystal structures with different retentivity and thus gives more information on the thermal history of the samples than could be obtained from the bulk ${ }^{40} \mathrm{~K} /{ }^{39} \mathrm{Ar}$ ratio alone (Hall, 1993). According to Philpotts (1990) access argon is fused during the first steps of heating giving these heating steps a younger age than the actual calculated age while loss of argon results in older ages for the first steps of heating. Only if the calculated age of a few heating steps remains constant, the age can be considered reliable.

\subsubsection{U-Pb dating of Zircons}

\subsubsection{Sample description}

The sample description (this chapter and chapter 10.1.2.1) was adopted from Siegesmund et al. (in prep.).

$\mathrm{CH} 3$

This sample was taken from the western gneissic granites from a massive, homogeneous leucogranodiorite. Main constituents are quartz, alkali feldspars and plagioclase with accessory biotite, apatite, magnetite and hypidiomorphic, red to colorless zircons. The zircons are partly well rounded and exhibit etched, deeply corroded crystal surfaces under the REM. Magmatic oscillatory zoning with widely spaced zones can frequently be observed with metamict, rounded cores. 
$\mathrm{CH} 4$

$\mathrm{CH} 4$ also was taken from the western gneissic granites and resembles a granodioritic lithology. Quartz, plagioclase, microcline and perthite as well as minor hornblendes, biotite, muscovite and sericite are the main phases next to accessory epidote, allanite, zircon, apatite and titanite. The whitish to reddish zircons are metamict, their shape varies greatly from prismatic to short prismatic and ideomorphic to well rounded. Again REM analyzes showed deeply corroded crystal surfaces with cracks radial and parallel to zones of growth. Oscillatory zoning is weakly developed and widely spaced documenting the rapid growth during crystallization.

\section{$\mathrm{CH} 13 \mathrm{~b}$}

This sample was taken from a layer-parallel, boudinaged pegmatite within a hornblende schist from the eastern margin of the Chinamora Batholith (Umwindsi Shear Zone). The pegmatite contains quartz, microcline perthite and plagioclase as well as minor biotite and hornblende. Secondary chlorite, sericite and accessory apatite, zircon and magnetite occur. Four size fractions of apatite have been analyzed with the transparent colorless grains varying from rounded xenomorphic crystals to long prismatic, needle shaped specimen. No inclusions or zoning was apparent.

\subsubsection{Results}

The dating of two zircon samples $(\mathrm{CH} 3, \mathrm{CH} 4)$ and the apatites of sample $\mathrm{CH} 13 \mathrm{~b}$ resulted in three differing lines on the concordia diagram (see Fig. 10.1) with discordant ages for every sample. 


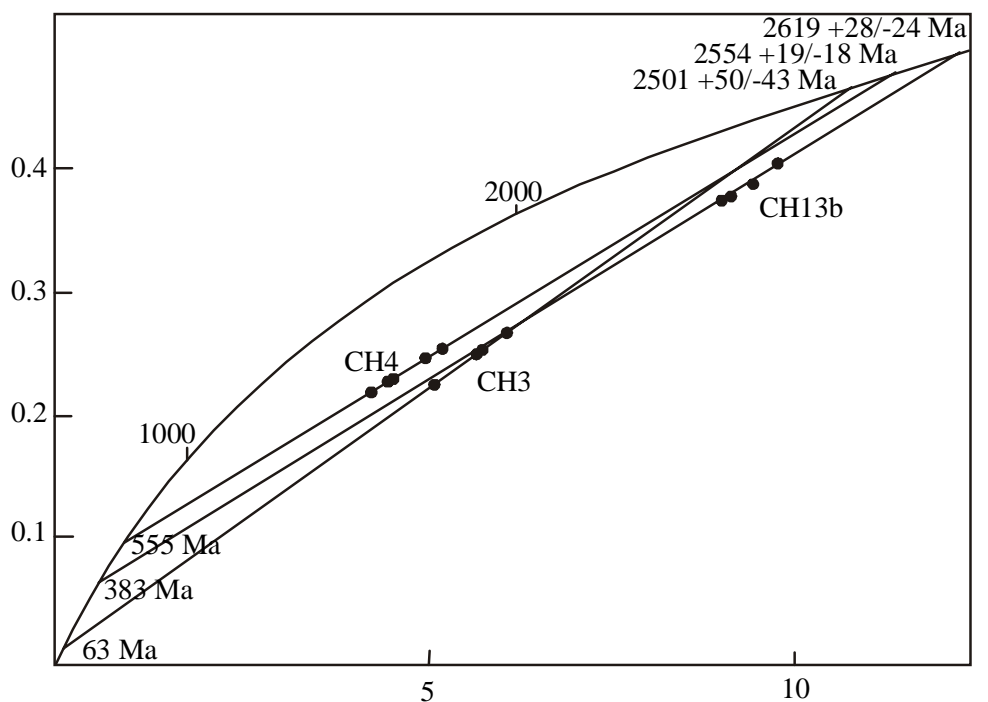

Fig. 10.1: Discordant age data obtained from zircon $(\mathrm{CH} 3$ and $\mathrm{CH} 4)$ and apatite $(\mathrm{CH} 13 \mathrm{~b})$. Lower intercept ages do not point to a meaningful geological event, upper intercept ages are influenced by lead loss probably due to metamorphic overprint $(\mathrm{CH} 3$ and $\mathrm{CH} 4$ ). Apatite seems to resemble a more undisturbed age as indicated by clustering of points at the upper interception with concordia. (Fig. from Siegesmund et al., in prep.)

Age data for the three samples is in the range of $2619+28 /-24 \mathrm{Ma}$ and $2501+50$ $43 \mathrm{Ma}$, a time span of more than $100 \mathrm{Ma}$ is measured between the samples for the upper age while the lower intersection is between 63 and 555 Ma enclosing a time span of nearly $500 \mathrm{Ma}$.

The lower intercept ages seem not to be related to any reasonable geological event. The great variation in obtained ages points to one or more thermal events during which the zircons lost more $\mathrm{Pb}$ than $\mathrm{U}$ (Mezger \& Krogstad, 1997). Tilton (1960) compared U-Pb zircon data from different archean cratons and observed that they defined lower intercepts with concordia of $\sim 600 \mathrm{Ma}$. Since there is no world wide event affecting all Archean cratons at this time Tilton (1960) suggested constant, temperature independent $\mathrm{Pb}$ loss for this discordance pattern. Based on similar observations Goldich \& Mudrey (1972) suggested exhumation as a result of a decreased confining pressure for the constant lead loss which would imply a geological significance for the lower intercept age. However, it has been shown by other authors (e.g. Corfu et al., 1985; Dunning et al., 1990 or Mortensen, 1993) that zircons from magmatic rocks that have not been affected by later thermal events lose $\mathrm{Pb}$ more readily than other minerals in the same sample (e.g. titanite or monazite). This observation supports the idea that $\mathrm{Pb}$ loss must not necessarily be related to a geological event hence giving meaningless ages for the lower intercept age.

In igneous rocks with a simple history, zircons generally plot close to the upper intercept with concordia while zircons influenced by metamorphism show a 
characteristic array near the lower intercept with the concordia (Mezger \& Krogstad, 1997). Metamict zircons that recrystallized during medium to high grade metamorphism usually show strong discordances and plot near the middle of the calculated discordia (see Fig. 10.2).
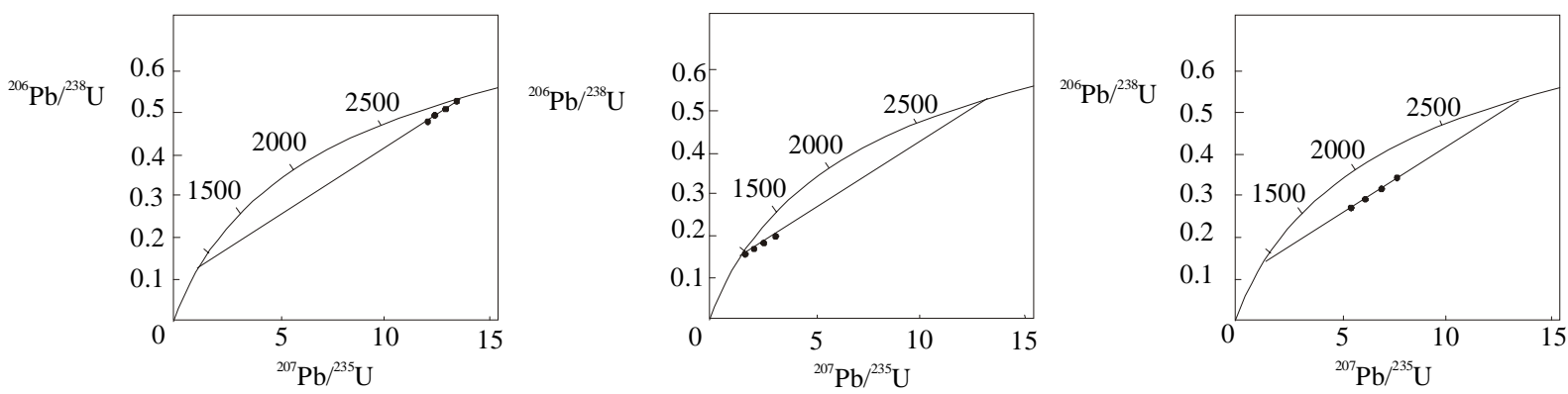

Fig. 10.2: Clustering of points and their position to interceptions with concordia can be used to infer the reliability of measurements (Mezger \& Krogstad, 1997).

According to this the measured samples form the Chinamora Batholith show a meaningless lower intercept age due to constant, temperature independent lead loss. Sample $\mathrm{CH} 13 \mathrm{~b}$ may represent a less disturbed sample plotting near the upper intercept with the concordia while samples $\mathrm{CH} 3$ and $\mathrm{CH} 4$ represent metamict samples that suffered lead loss. The measured high $U$ concentrations (see chapter 3 ) in some of the samples probably has speeded up lead loss by damaging the crystal lattice through radioactive decay.

\subsubsection{Ar/Ar dating of hornblendes}

\subsubsection{Sample description}

Several samples have been collected for age dating in a hornblende schist from the Inyauri remnant within the Chinamora Batholith $(\mathrm{CH} 8 \mathrm{~b}, \mathrm{CH} 9 \mathrm{~b}, \mathrm{CH} 10 \mathrm{~b})$ and a sample $(\mathrm{CH} 13 \mathrm{a})$ from the Umwindsi area.

\section{$\mathrm{CH} 8 \mathrm{~b}$}

$\mathrm{CH} 8 \mathrm{~b}$ was taken in an amphibole xenolith from the central part of the porphyritic granite with a very high hornblende content (40\%) and minor brown biotite (10\%). 
Plagioclase and accessory titanite, epidote, quartz and zircon are also regular components.

$\mathrm{CH} 9 \mathrm{~b}, \mathrm{CH} 10 \mathrm{~b}$

These samples were taken from a hornblende-biotite schist in the central part of the porphyritic granite (Inyauri remnant). CH9b contains 20\% hornblende, 20\% green biotite, plagioclase, clinozoisite and accessory quartz and titanite. $\mathrm{CH} 10 \mathrm{~b}$ is similar but shows lower amounts of biotite (10\%) and hornblende (5\%).

\section{$\mathrm{CH} 13 \mathrm{a}$}

This sample was taken near the Umwindsi Shear Zone and contains high amounts of hornblende (55\%), saussuritized plagioclase and accessory biotite, apatite, epidote and opaques. Some biotites show retrogradation to chlorite and hornblendes sometimes show marginal replacement to actinolite.

\subsubsection{Results}

The $\mathrm{Ar}-\mathrm{Ar}$ data are shown as cumulative ${ }^{39} \mathrm{Ar}$ emission spectra against age (Fig. 10.3). A composite plateau age for sample $\mathrm{CH} 8 \mathrm{~b}$ (multi grain) is $2523 \pm 11 \mathrm{Ma}$, individual ages of the different runs are $2507 \pm 11 \mathrm{Ma}, 2516 \pm 10 \mathrm{Ma}$ and $2543 \pm$ $10 \mathrm{Ma}$ while one run showed a less well defined plateau giving younger ages than the other runs, indicating an alteration of the sample. Single grain dating for sample $\mathrm{CH} 9 \mathrm{~b}$ revealed an age of $2564 \pm 16$ Ma while multi-grain runs showed a stairstep-up spectrum from $1000 \mathrm{Ma}$ up to the single grain hornblende age. The weak plateau giving an age of 2240 Ma probably indicates a mixture of different ages. Two single grain runs for sample $\mathrm{CH} 10 \mathrm{~b}$ have been carried out giving well defined flat age spectra and plateaus of $2538 \pm 10 \mathrm{Ma}$ and $2546 \pm 12 \mathrm{Ma}$, respectively. A third sample showed evidence of alteration resulting in a lower age of $1350 \mathrm{Ma}$ and an upper age of $2240 \mathrm{Ma}$. Sample $\mathrm{CH} 13 \mathrm{a}$ shows well defined plateaus giving an age of $2481 \pm 11 \mathrm{Ma}, 2513 \pm 64 \mathrm{Ma}$ and $2514 \pm 11 \mathrm{Ma}$, respectively, for the three runs (single grain). 
The time span covered by the ${ }^{40} \mathrm{Ar} /{ }^{39} \mathrm{Ar}$ ages of $41 \mathrm{Ma}$ from hornblendes in the central porphyritic granite may be explained by the thermal resetting and slow cooling below the closure temperature of hornblendes after the intrusion of the porphyritic granite at $2601 \mathrm{Ma}$ (age from Jelsma et al., 1996).
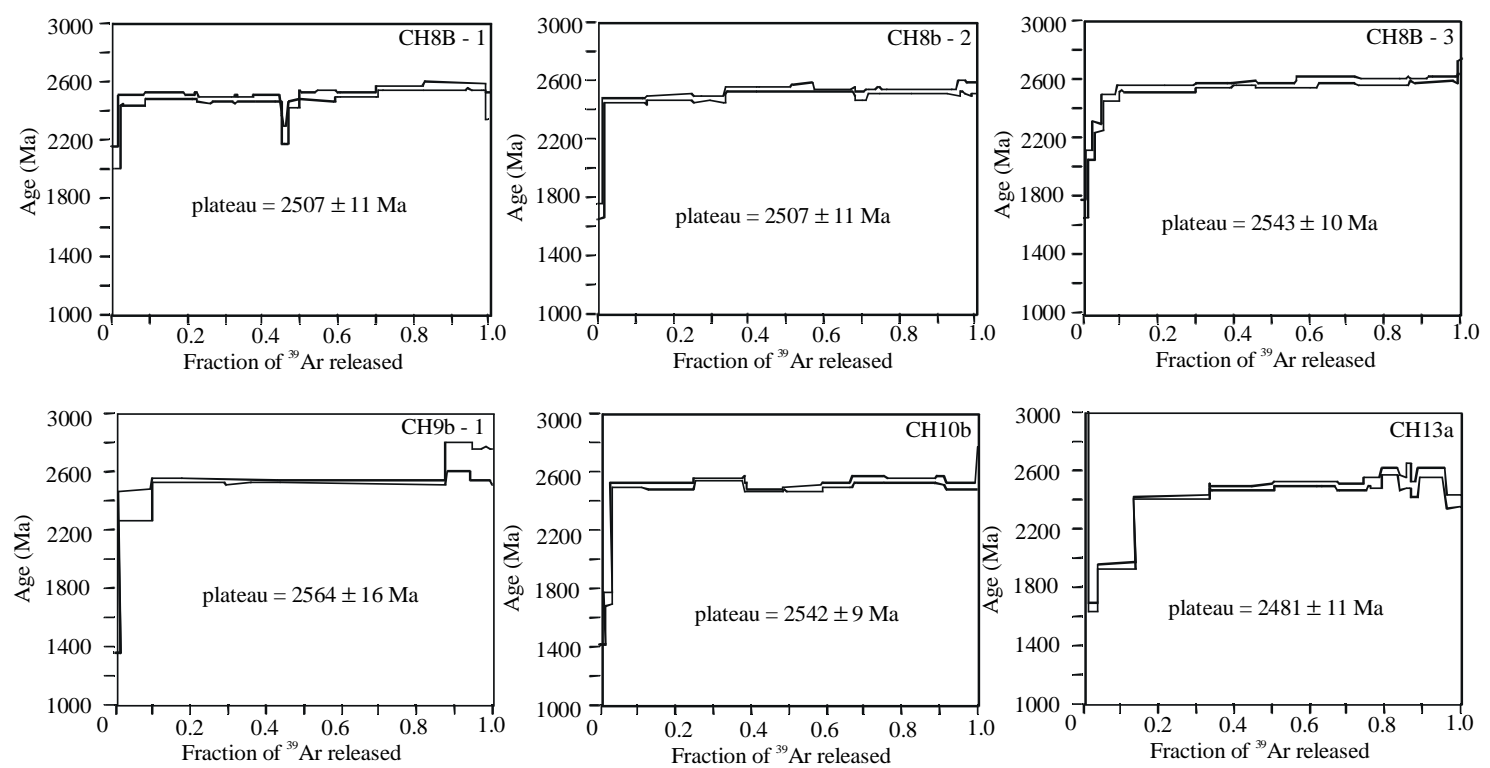

Fig. 10.3: Age data for ${ }^{40} \mathrm{Ar} /{ }^{39} \mathrm{Ar}$ age determination of hornblendes (Fig. from Siegesmund et al., in prep.).

\subsection{Thermal constraints from isotope geochemistry}

The methods used for age dating all give valuable information on the thermal conditions of the minerals at the measured time. Generally, hornblendes have a closing temperature of approx. $580^{\circ} \mathrm{C}-480^{\circ} \mathrm{C}$ which depends on the cooling rate (Harrison, 1981). For the U-Pb system closing temperatures for apatites were estimated at $580^{\circ} \mathrm{C}-540^{\circ} \mathrm{C}$ (vonBlanckenburg, 1992; Cherniack et al., 1991), the closing temperature for zircons is estimated at $450^{\circ} \mathrm{C}$, however, for pristine zircons the closure temperature is estimated much higher in the range of $700-900^{\circ}$ C (Mezger \& Krogstad, 1997). Even temperatures of $950^{\circ} \mathrm{C}$ were shown not to be sufficient to reset the zircons completely (e.g. Williams, 1992). According to the great gap in the closing temperature of zircons and the observed discordant data of zircon U-Pb measurements it seems not too reliable to use the obtained data. The apatite data suggest that a maximum temperature of $580^{\circ} \mathrm{C}$ was reached at $2619+28 /-24 \mathrm{Ma}$ in the western gneissic granites. Hornblende data suggests that temperatures of $580^{\circ} \mathrm{C}-480^{\circ} \mathrm{C}$ were reached between 2523 and $2564 \mathrm{Ma}$ in the 
porphyritic granite. This indicates that the metamorphic temperatures reached in the gneissic granites during the intrusion of the porphyritic granite at $2601 \mathrm{Ma}$ (age from Jelsma et al., 1996) was not enough to reset the apatite U-Pb system but may have sufficiently reset the U-Pb system of hornblende from samples $\mathrm{CH} 8 \mathrm{~b}$, $\mathrm{CH} 9 \mathrm{~b}$ and $\mathrm{CH} 10 \mathrm{~b}$.

The obtained ages give a time span of $\sim 60$ Ma between the cooling of the gneissic granites below $\sim 580^{\circ} \mathrm{C}$ and the cooling of the porphyritic granite below $580^{\circ} \mathrm{C}$. This temperature is usually seen as indicative for a remaining melt fraction below 10\% (Bouchez et al., 1992).

The obtained ages for the porphyritic granite point to an intrusion at $2601 \mathrm{Ma}$ (age from Jelsma et al., 1996) and a crystallization at $2523-2564 \mathrm{Ma}$, leaving a time span of approx. $50 \mathrm{Ma}$ for the intrusion and crystallization of the porphyritic granite.

\subsection{Thermodynamic modeling}

The thermal modeling of different geometries has been performed to compare the maximum reached temperatures in the contact area of the intrusion with calculated temperatures from metamorphic mineral assemblages. Only if the temperatures of a modeled geometry are sufficient to produce the calculated metamorphic temperatures in the host rocks the geometry may be a reasonable model of the shape of the intrusion. Furthermore, it may be tested whether the estimated time of cooling below specific temperatures obtained from age dating is adhered to during modeling.

The modeling was performed using the program SHEMAT from the BGR (Hanover). The program can be used to model thermodynamic processes as well as fluid-flow under different chemical conditions for a given time period. Little is known about fluids and their chemical content in the Archean, a model including these variables would be rather complex and most of the variables would at best be a good approximation, most of the parameters would have been poorly constrained. Therefore, only the thermodynamic modeling over a given period of time without any influence derived from fluid flow was performed. The thermodynamic variables in the Archean like temperature gradient at depth, basal heat flow and radiogenic heat production have been analyzed by different authors (e.g. Pollack, 1997; Goodwin, 1991; Rudnick et al., 1998). Variables like thermal 
capacity of minerals or rocks have not changed during time so "state of the art“ values may be used. Five different geometries have been modeled that maybe assigned, according to the used geometry, to different emplacement mechanism (ballooning, diapirism, intrusion as a comparatively thin body and the emplacement of the gneisses as a few smaller intrusions independent from each other or as a pulsed intrusion). The values used for the displayed models are given in table 10.1 .

Table 10.1: Values used for the thermal modeling of the Chinamora batholith

\begin{tabular}{|c|c|}
\hline \multirow{2}{*}{\multicolumn{2}{|c|}{$\begin{array}{l}\text { Thermal matrix properties: } \\
\text { Density }[\mathrm{kg} / \mathrm{m} 3]\end{array}$}} \\
\hline & \\
\hline Heat capacity $[\mathrm{J} / \mathrm{kgK}]$ & 1000 \\
\hline Thermal conductivity [W/mK] & 2.5 \\
\hline $\begin{array}{l}\text { Radiogenic heat production } \\
{\left[\mathrm{W} / \mathrm{m}^{3}\right]}\end{array}$ & $0.9 \mathrm{E}^{-6}$ \\
\hline Initial temperature $\left[{ }^{\circ} \mathrm{C}\right]$ & Temp. gradient \\
\hline Thickness of crust [km] & 40 \\
\hline \multirow{2}{*}{\multicolumn{2}{|c|}{$\begin{array}{l}\text { Thermal properties of } \\
\text { greenstones: }\end{array}$}} \\
\hline \multirow{2}{*}{\multicolumn{2}{|c|}{$\begin{array}{l}\text { Density }\left[\mathrm{kg} / \mathrm{m}^{3}\right] \\
\text { Heat capacity }[\mathrm{J} / \mathrm{kgK}]\end{array}$}} \\
\hline & \\
\hline Thermal conductivity [W/mK] & 2.85 \\
\hline $\begin{array}{l}\text { Radiogenic heat production } \\
{[\mathrm{W} / \mathrm{m} 3]}\end{array}$ & $0.3 E-6$ \\
\hline Initial temperature $\left[{ }^{\circ} \mathrm{C}\right]$ & Temp. gradient \\
\hline \multicolumn{2}{|l|}{ Thermal properties of granitoids: } \\
\hline \multicolumn{2}{|l|}{ Density [kg/m3] } \\
\hline Heat capacity $[\mathrm{J} / \mathrm{kgK}]$ & 1000 \\
\hline Thermal conductivity [W/mK] & 2.5 \\
\hline $\begin{array}{l}\text { Radiogenic heat production } \\
{[\mathrm{W} / \mathrm{m} 3]}\end{array}$ & $2.2 \mathrm{E}-6$ \\
\hline Initial temperature $\left[{ }^{\circ} \mathrm{C}\right]$ & 750 \\
\hline
\end{tabular}

\subsubsection{Radiogenic heat production}

The radiogenic heat production was estimated according to the half-lives of the most abundant heat producing isotopes ${ }^{40} \mathrm{~K},{ }^{238} \mathrm{U},{ }^{235} \mathrm{U}$ and ${ }^{232} \mathrm{Th}$. The estimates range from as high as 6 times the present day heat production rate at the beginning of the Archean to values of 1.6 times the present day value at the end of the Archean time interval (Pollack, 1997). The used value of $0.9^{*} 10^{-6} \mathrm{Wm}^{-3}$ is approx. two times the present day value and takes into account the dominating Na-rich tonalite-trondhjemite-suites in the area of the Chinamora Batholith with their comparatively low contents of $\mathrm{K}, \mathrm{U}$ and $\mathrm{Th}$. The greenstone belts were 
assigned a value of about $0.3^{*} 10^{-6} \mathrm{Wm}^{-3}$. The chosen values therefore should be good estimations of the archean radiogenic heat production rate in the modeled area. One of the restrictions of the program SHEMAT is that the higher radiogenic heat production in the magma chamber compared to the surrounding basement does not decrease with ongoing time. This has the effect that in simulations, until a steady state is reached, the initial form of the batholith with its increased radiogenic heat production is preserved which results in an elevated geothermal gradient below and above the site of intrusion.

\subsubsection{Thickness of the crust and geothermal gradients}

The thickness of the Archean crust was estimated, amongst others, by Goodwin (1991) according to evidences from metamorphic and experimental studies at about $40 \mathrm{~km}$ after $3 \mathrm{Ga}$. The eruption of high-magnesian komatiites restricted to the Archean implies mantle temperatures greater than $1650^{\circ} \mathrm{C}$ (which is the estimated eruption temperature of these komatiites, see Richter, 1985). Given the present day radiogenic heat production and the present day mantle temperature a secular cooling in the order of $100^{\circ} \mathrm{C} / \mathrm{Ga}$ is required to reach present day mantle temperatures (Richter, 1985). From these bounding parameters the geothermal gradients can be calculated (see Richter (1985) for details) leading to a temperature of $600-800^{\circ} \mathrm{C}$ at $40 \mathrm{~km}$ depth. Similar values can be observed today in active orogenic areas (Boak \& Dymek, 1982). According to Philpotts (1990) the geothermal gradient decreases non-linearly with depth. This decrease of the thermal gradient can not be simulated, a nearly linear thermal gradient must be used in the program SHEMAT resulting in somewhat lower temperatures in the initial temperature field in the upper crust than the actual values during the Archean.

A set of models has been calculated to obtain reasonable temperature gradients for the background temperature (geothermal gradient) of the models. For this reason a steady-state simulation has been performed where only the framing variables have been set. These include basal heat flow, radiogenic heat production, thermal capacity and a fixed temperature for the upper boundary. The program SHEMAT calculated the thermal gradients produced by these framing variables (see Fig. 10.4). The resulting geothermal gradients are in good 
concordance with values obtained from the literature (see e.g. Guillou et al., 1994; Sclater et al., 1981 or Richter, 1985). These temperature gradients were used for the actual modeling of the different geometries. As stated earlier the program used is capable to calculate very complex models, that is, if parameters for different rock properties are available.

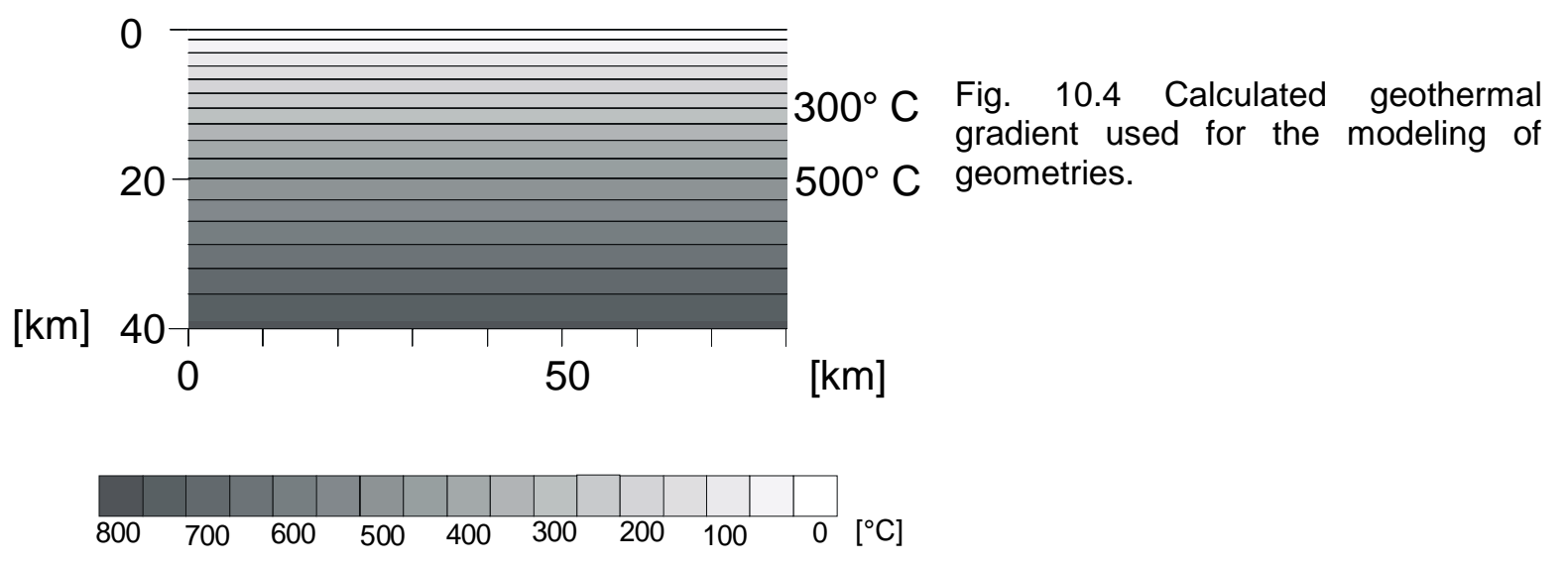

Furthermore, the influence of thermally sealing (isolatory) layers (like komatiites) in the greenstone belts was not taken into account. It may be possible that e.g. komatiites with their reduced thermal capacity induce temperature reflections and hence may provoke elevated temperatures below. In the presented models only basic thermal criteria have been used to keep the models as simple as possible. This means for example that the thermal conductivity of rock samples was estimated as a "bulk" thermal conductivity without taking into account its anisotropy depending on the geological situation (e.g. layering of greenstone belts, foliated internal granitoids etc.).

\subsubsection{Basal heat flow}

The heat flux of the upper boundary layer during the Archean (mean surface heat flow) was estimated around $41 \mathrm{mWm}^{-2}$ (Rudnick et al., 1998). The thickness of the crust, the mean surface heat production rate and the basal heat flow can be correlated according to equation [14] (Lachenbruch, 1968; Saltus \& Lachenbruch, 1991)

$\mathrm{q} 0=\mathrm{qr}+\mathrm{A} 0^{*} \mathrm{D}$ 
with q0 as the upper heat flux, qr as the reduced heat flow (basal heat flow), A0 as the mean surface heat production rate and $D$ as the depth of $\mathrm{gr}$ (in this case the thickness of the crust).

Different values for $\mathrm{q} 0$ and $\mathrm{A} 0$ have been used, the basal heat flow was averaged at $0.025 \mathrm{Wm}^{-2}$, this value was recorded by Guillou et al. (1994), Sclater et al. (1981) or Richter (1985) for a reduced average heat flow for the boundary between the continental crust and the upper mantle as well.

\subsubsection{Metamorphic conditions around the Chinamora Batholith}

The thermal modeling of the intrusion of the Chinamora Batholith has the aim to compare modeled thermal isograds with actually observed isograds from metamorphic conditions in the field. The metamorphic conditions in Archean granite-greenstone environments typically show a low pressure - high temperature metamorphic pattern. The Harare-Shamva area has been analyzed by Jelsma (1993) on the basis of mineralogical and petrological data. He divided the greenstone belts into three metamorphic zones: (i) low grade metamorphic zones of greenschist-facies conditions, (ii) medium-grade metamorphic zones of low- to medium grade amphibolit-facies and (iii) a high grade metamorphic zone of upper amphibolite-facies. The low grade metamorphic zone is characterized by the occurrence of white mica and chlorite in the metasedimentary and felsic metavolcanic rocks. The medium-grade metamorphic zone is bound by the biotite and garnet isograds and are characterized by the presence of white mica, biotite, andalusite, chloritoid, staurolite, cordierite and garnet. The high-grade metamorphic rocks contain in addition to other metamorphic minerals sillimanite, andalusite, hornblende, clinopyroxene and garnet. The highest metamorphic zones are found in the contact-area with the granitoid rocks of the Chinamora Batholith, with increasing distance from the intrusion margin the maximum temperatures during metamorphism decrease (Jelsma, 1993). The average reached temperatures were calculated by Jelsma (1993) to lie around $450-500^{\circ} \mathrm{C}$ for rocks in the low-metamorphic zones (approx. $5 \mathrm{~km}$ distance from contact area) increasing to $550 \pm 25^{\circ} \mathrm{C}$ in the medium metamorphic zones (1-5 km distance from the contact) reaching up to $600 \pm 25^{\circ} \mathrm{C}$ in the contact area of the greenstone belt with the granitoid rocks of the Chinamora Batholith. The depths of the different 
zones was estimated to 1.5-2 kbar for the low-, $2.7 \pm 0.5 \mathrm{kbar}$ for the medium and $3.3 \pm 1 \mathrm{kbar}$ for the high grade metamorphic zone which corresponds to depths of 5-7 km, 9-11 km and 12-15 km, respectively. These depths, at least for the medium- and high-grade metamorphic zones, are greater than the estimated stratigraphic thickness of the greenstone belt of approx. $10 \mathrm{~km}$. This discrepancy can be explained by the observed snyclinal/anticlinal shape of the greenstone belts adjacent to the intrusion. As stated earlier the greenstone belts have a synformal shape around the batholith.

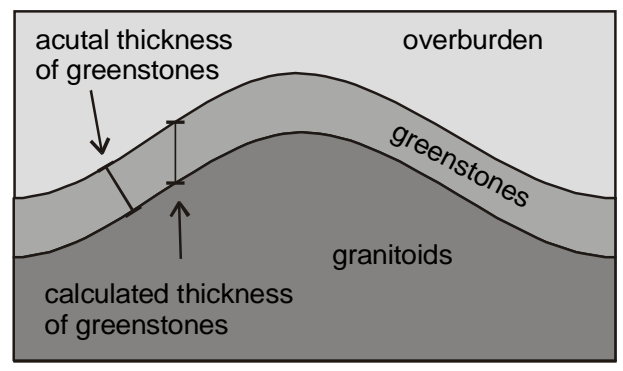

Fig. 10.5: Difference between actual and calculated thickness of greenstone pile.

From Fig. 10.5 it is apparent that the estimated thickness from the stratigraphic succession of the greenstone belt does not necessarily reflect the actual vertical extent of the greenstones in the crust and hence the depth of intrusion but rather gives a minimum depth of intrusion of the Chinamora Batholith. The estimated pressure of the different metamorphic zones largely reflects the different thicknesses of the successions of the greenstone pile.

Besides the general analyzes of the thermal environment of the different modeled geometries the maximum reached temperatures in the models near the intrusions are compared to the calculated metamorphic zones in the field.

A common feature of the different geometries is the relatively flat top of the intrusions which is based on field evidence. The porphyritic granite is a thin sheet on top of the gneissic granites with an elevation of $+300 \mathrm{~m}$ compared to the gneissic granites. Since the porphyritic granite (Chilimanzi-type) is much younger than the gneisses the top of the gneisses must have been extremely flat before the emplacement of the porphyritic granite. 


\subsubsection{Thick geometry}

From simple geometric analyzes it is apparent that if a balloon is the final geometry of the Chinamora Batholith it would have expanded to a depth of $40 \mathrm{~km}$ or more. Furthermore, the present day erosional level of the batholith must be somewhere near the top of the intrusion since the surrounding greenstone belts overlap the marginal areas of the batholith. Therefore the actual outcrop area of the batholith is not its largest diameter. Depending on this the resulting spherical intrusion would have definitely reached the upper mantle. This is highly unlikely because it would have opened a source of nearly infinite new magma, taken into account the cooling rate of such large magmatic bodies that would possibly result in a complete melting of the crust.

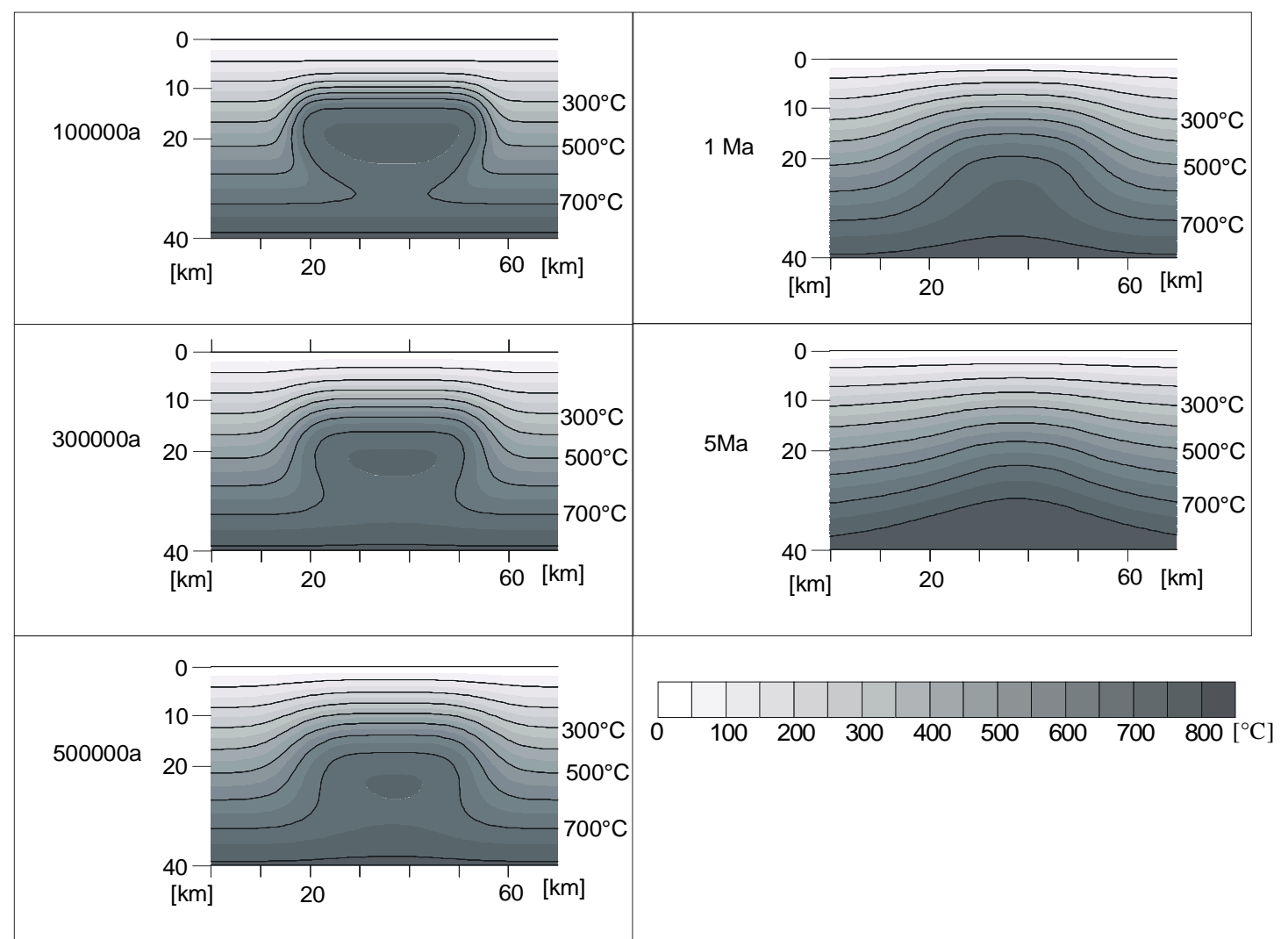

Fig. 10.6: Thermal modeling of a thick magma body that may be associated with ballooning. See text for explanations.

Therefore, the shape of the balloon probably would have been more or less lensshaped with an unknown thickness. The modeled geometry that may correspond to the final shape of a ballooning or diapiric emplacement has a horizontal diameter of $35 \mathrm{~km}$ and a vertical extent of $20 \mathrm{~km}$. The total cooling time (time until 
a steady-state situation is reached) of this geometry was estimated to be about $\sim 7$ $8 \mathrm{Ma}$ which is far less than stated by other authors (e.g. Dirks \& Jelsma (1998a) still have temperatures of $570^{\circ} \mathrm{C}$ at a distance of $3 \mathrm{~km}$ from the contact area after $15 \mathrm{Ma}$ when the surrounding country rock had initial temperatures of $400^{\circ} \mathrm{C}$ ). Temperature gradients at the top of the intrusion are very steep and lie in the range of $100^{\circ} \mathrm{C} / 1.5 \mathrm{~km}$ (in vertical direction). Fig. 10.6 shows that after $0.1 \mathrm{Ma}$ of cooling temperatures in the contact area (at $10 \mathrm{~km}$ depth) range between 500 $600^{\circ} \mathrm{C}$ while at a horizontal distance of $3 \mathrm{~km}$ temperatures are as low as $300^{\circ} \mathrm{C}$. Ongoing cooling of the main intrusive body affects the isotherms in a way that they become more and more domal shaped with lower temperatures on top of the intrusion as during the first time span but higher temperatures in the horizontal distance. After $0.5 \mathrm{Ma}$ of cooling temperatures in the contact area of the intrusion (again at $10 \mathrm{~km}$ depth) have dropped to approx. $400^{\circ} \mathrm{C}$ while at a distance of $3 \mathrm{~km}$ temperatures have risen to $\sim 400^{\circ} \mathrm{C}$. After $1 \mathrm{Ma}$ of cooling the domal shaped isotherms lower and the temperatures at the top of the intrusion as well as in the horizontal distances decrease. Still, even after $1 \mathrm{Ma}$ of cooling temperatures at 40 $\mathrm{km}$ depth are increased above $800^{\circ} \mathrm{C}$ which would probably result in the generation of new melt and a constant replenishing of the magma chamber (Wyllie et al., 1997).

\subsubsection{Domal shaped geometry}

A diapiric emplacement of the Chinamora Batholith includes a very large magmatic body ascending through the crust to the site of final emplacement. This ascent of a comparatively hot body through the crust will probably result in elevated temperatures below the final site of emplacement. The actual ascent of the body can not be simulated since the program SHEMAT is not capable to simulate an upward moving body, therefore the elevated temperatures below the geometry used for the modeling were included in the initial temperature field. The diameter of the domal shaped geometry is set to approx. $35 \mathrm{~km}$, the vertical extent is simulated to $16 \mathrm{~km}$. The difference to the thick geometry is (i) the thickness of the

modeled geometry and (ii) the elevated temperatures below the intrusive body. The thickness of the modeled geometry seems to play a minor role concerning the 
cooling history if elevated temperatures in comparison to the thick geometry are assumed. The cooling history of both geometries are comparable.

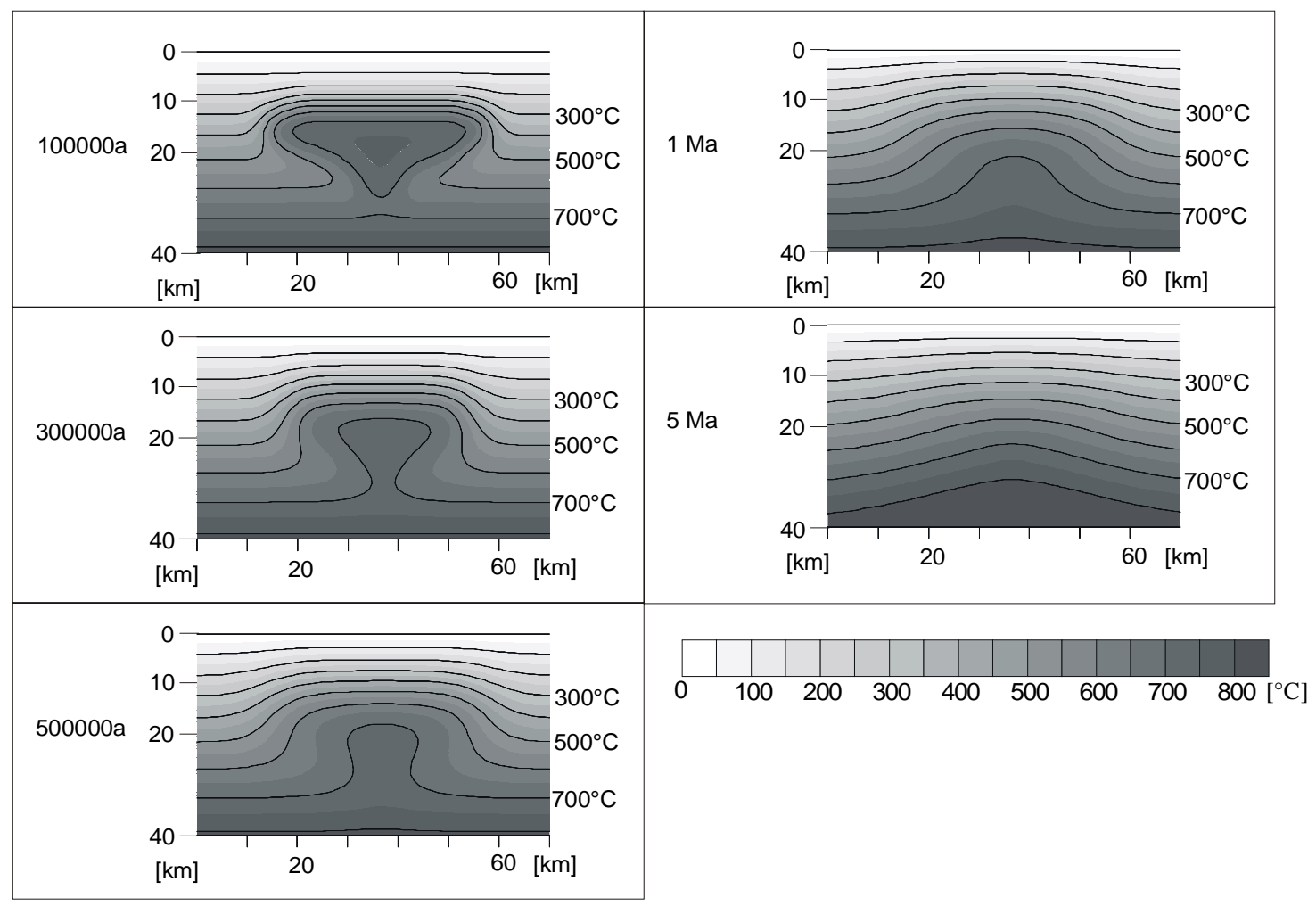

Fig. 10.7: Model of a domal shaped geometry with elevated temperatures below the intrusion. See text for explanations.

If beneath the domal shaped geometry a "normal" temperature is assumed the cooling is faster than with elevated temperatures leading to smaller thermal gradients and hence to lower temperatures in horizontal distances to the contact area. The elevated temperatures below the intrusion lead to higher temperatures of up to $750-800^{\circ} \mathrm{C}$ at depths of $35-40 \mathrm{~km}$ after $0.5 \mathrm{Ma}$ of cooling (see Fig. 10.7). Even temperatures above $800^{\circ} \mathrm{C}$ are reached at depths of $35-37 \mathrm{~km}$ after $0.75 \mathrm{Ma}$ which again may result in the formation of new melt (Wyllie et al., 1997).

\subsubsection{Thin sheet geometry}

Another geometry has been simulated with a diameter of the comparatively thin sheet of $35 \mathrm{~km}$ and a thickness of $10 \mathrm{~km}$ only. This geometry may correspond to the shape of a blistering diapir but a magma chamber reflecting this shape may as well be fed by dyke-like conduits. The reduced thickness seems to be necessary to prevent the $800^{\circ} \mathrm{C}$ isotherm from being raised significantly which would result in 
temperatures capable of producing new magma at a depths of $40 \mathrm{~km}(\sim 11 \mathrm{~kb})$. Peak temperatures in a (horizontal) distance from the contact area of $5 \mathrm{~km}$ at a depth of $10 \mathrm{~km}$ reach $\sim 350^{\circ}-400^{\circ} \mathrm{C}$ after $0.5 \mathrm{Ma}$ of cooling, at $3 \mathrm{~km}$ distance they reach approx. $450^{\circ}-500^{\circ} \mathrm{C}$.

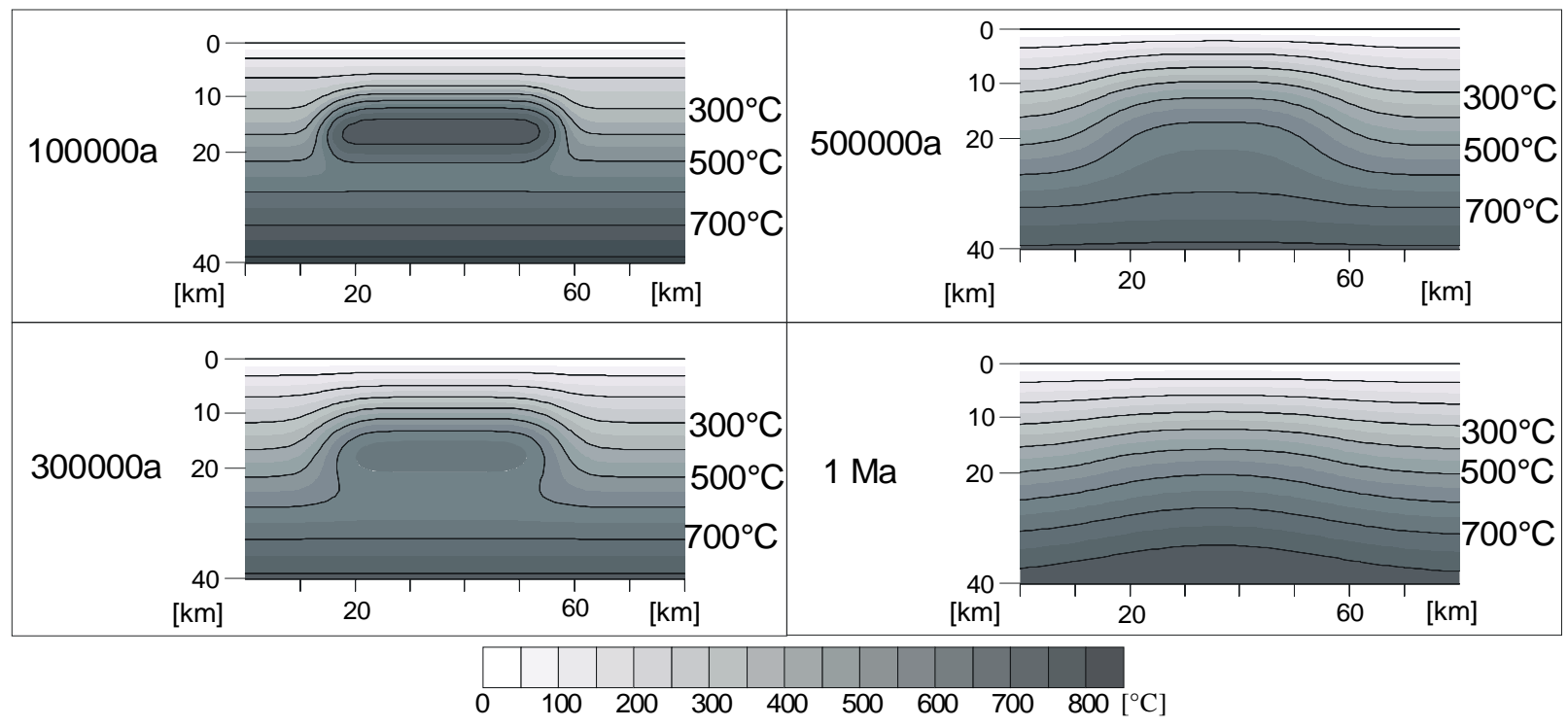

Fig. 10.8: Modeling of a thin sheet, see text for explanation.

Temperatures in the contact area reach 550 to $600^{\circ} \mathrm{C}$ at the beginning of the simulation but temperatures in this area decrease below $500^{\circ} \mathrm{C}$ relatively early (see Fig. 10.8). This matches the temperatures obtained from the thick and the domal shaped geometries. The temperatures below the intrusion at a depth of 30 $\mathrm{km}$ or more are only slightly changed, the $700^{\circ} \mathrm{C}$ and $800^{\circ} \mathrm{C}$ isotherms are raised slightly.

\subsubsection{Small scale intrusion geometry}

Another possibility for the final emplacement of the Chinamora Batholith is the ascent of more than one magmatic body. These magmatic bodies would have thicknesses far less than the modeled thick or domal shaped geometries and might even ascend during a longer time span. Modeled here are five equidimensional intrusions, each with a diameter of $7 \mathrm{~km}$ and a depth of approx. 5 $\mathrm{km}$. To keep the model simple they all intrude during a very close time span of a few hundred years. The resulting isotherms differ from the other models. 
The $500^{\circ} \mathrm{C}$ isotherm is not affected until cooling of $0.15 \mathrm{Ma}$ where it is slightly raised, however the $600^{\circ} \mathrm{C}$ isotherm does not show any influence from the intrusions (see Fig. 10.9). The overall temperatures at a horizontal distance of 3 $\mathrm{km}$ away from the contact area after $0.5 \mathrm{Ma}$ is in the range of $300^{\circ} \mathrm{C}$ while $5 \mathrm{~km}$ away from the contact area (both in $10 \mathrm{~km}$ depth) they do not exceed $250^{\circ} \mathrm{C}$. Directly in the contact area temperatures still may reach $600^{\circ} \mathrm{C}$ but only for a very short time span at the beginning of the emplacement.

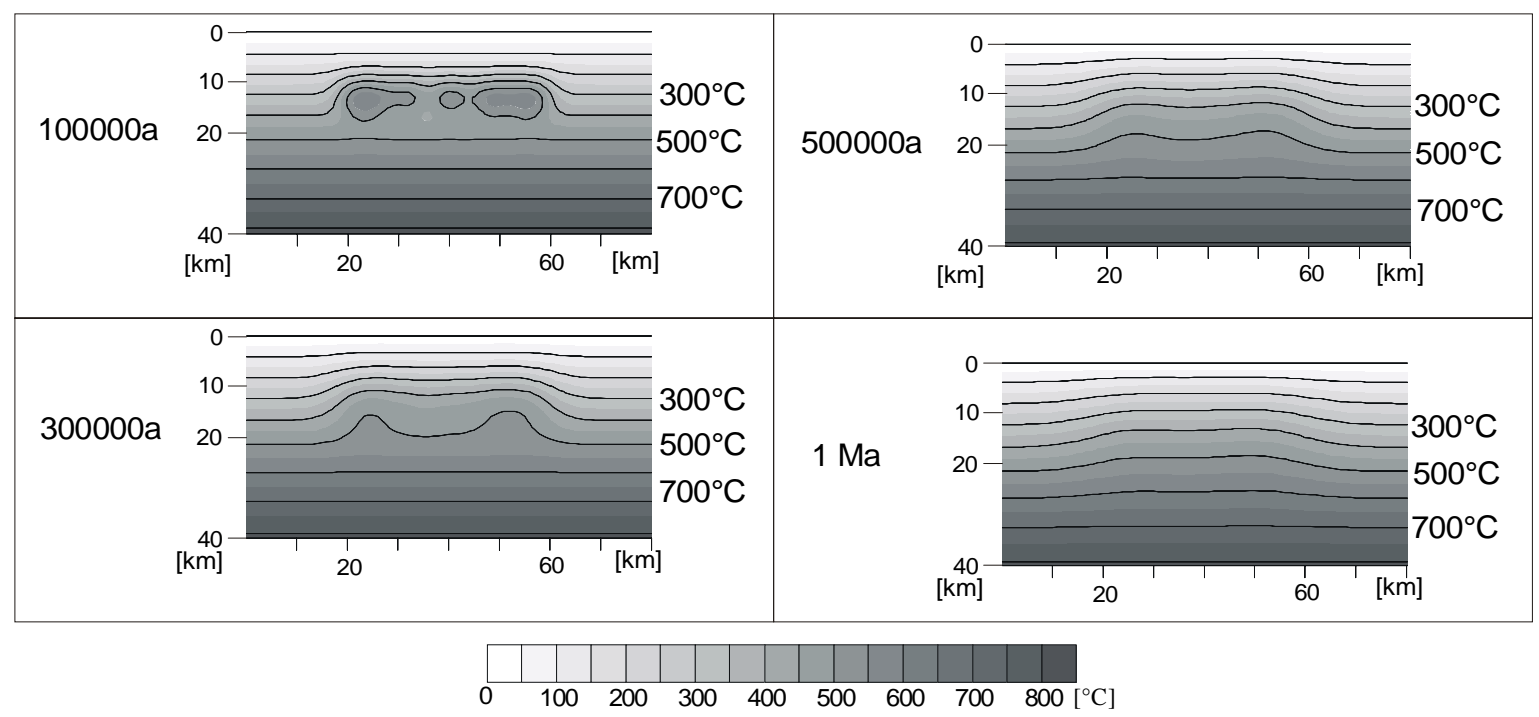

Fig. 10.9: Modeling of the small scale intrusions. See text for explanations.

Another possibility for small scale intrusions is a pulsed intrusion where the different pulses do not intrude coeval. The modeling includes three different pulses, the first pulse intrudes in the center, the second pulse to the right of the first and the third pulse to the left of the first magma body. Between each pulse 0.1 Ma of cooling was modeled. Since no evidence exists about the timing of the different intrusions of the gneissic granites the time between the different pulses was taken randomly. The modeling showed that this type of intrusion is not sufficient to produce the observed temperatures in the surrounding host rock (see Fig. 10.10), however, modeling resulted in a completely different cooling history than did the coeval intrusions. Cooling is much slower and even after $5 \mathrm{Ma}$ significantly raised isotherms exist at depth. 


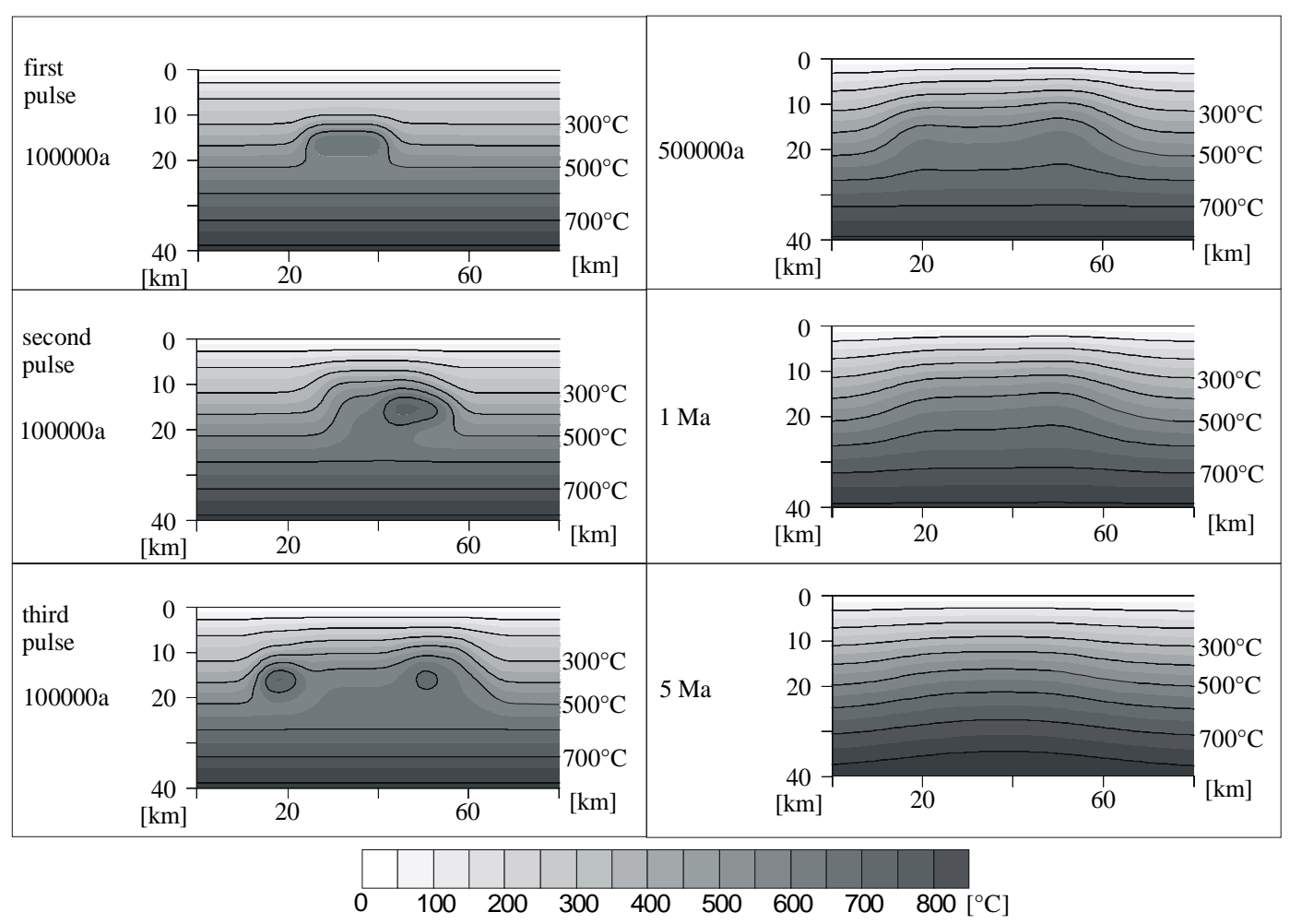

Fig. 10.10: Modeling of a pulsed intrusion

\subsubsection{Conclusions from thermal modeling}

The different modeled geometries show, that any emplacement mechanism resulting in a thick geometry is unlikely since the isotherms at $40 \mathrm{~km}$ depth would be high enough to produce new melt which would lead to constant replenishing of the magma chamber. Since the thick and the domal shaped geometries only differ from each other in their shape and temperature at depth this applies to both modeled geometries and hence to both associated emplacement mechanisms. From the simulated geometries it can be deduced that the isotherms in the upper part of the intrusion are not significantly changed until the intrusion reaches a thickness between 9 and $5 \mathrm{~km}$. If the intrusion thickness is $>=10 \mathrm{~km}$ the isotherms in the upper part are comparable, only in the lower parts of the intrusion between 20 and $40 \mathrm{~km}$ the thickness of the intrusion is of importance. The thicker the intrusive body, the higher are the isotherms of $800^{\circ}$ and even $900^{\circ} \mathrm{C}$. At a thickness of the intrusion of $20 \mathrm{~km}$ the $800^{\circ} \mathrm{C}$ isotherm reaches depths of approx. $35 \mathrm{~km}$. Given the fact that the estimated crustal thickness during the Archean may have been well below the modeled $40 \mathrm{~km}$ the $800^{\circ}$ or even the $900^{\circ} \mathrm{C}$ isotherm 
would have reached depths of only $25-20 \mathrm{~km}$ which definitely would have resulted in the formation of new magma.

The small intrusive bodies modeled (pulsed intrusion of small scale geometries) were not able to produce the observed temperatures deduced from metamorphic mineral assemblages. Their peak temperatures at a distance of $3 \mathrm{~km}$ away from the contact only reached $300^{\circ}-400^{\circ} \mathrm{C}$. The simulation that best fits the field observations without raising the high-temperature isotherms unrealistically is the model of the thin sheet that may be associated with the emplacement of the body through dyking or to a blistering diapir. The temperatures reached with this geometry during the simulations are in good concordance to the observed metamorphic temperatures.

\subsection{Constrains from age dating and thermodynamic modeling}

The age dating of the granitoid rocks of the Chinamora Batholith has shown that the estimated time span of intrusion of the porphyritic granite is approx. $50 \mathrm{Ma}$. From field observations (e.g. erosional windows, orientation of foliation) and the performed measurements (magnetic foliation and lineation) the estimated shape of the porphyritic granite is that of a thin sheet. From the performed thermodynamic modeling it is obvious, that the time span of intrusion of $50 \mathrm{Ma}$ is more than long enough for the porphyritic granite to intrude, emplace and cool down to temperatures of approx. $500^{\circ} \mathrm{C}$. If even the modeled thin sheet with a thickness of $10 \mathrm{~km}$ cools down to temperatures of $500^{\circ} \mathrm{C}$ after $5 \mathrm{Ma}$ the porphyritic granite, which probably was even thinner, needs even less time to cool. For the gneissic granites and the equigranular granites no data is available for the time of intrusion and hence no comparison of the cooling history with the modeled geometries is possible. 


\section{Summary and discussion}

Based on the fabric, age coherence and structural relationships the different lithologies have been based into i) the gneissic granites, ii) the equigranular granites and iii) the porphyritic granite (where $\mathrm{i}$ is the oldest and iii the youngest unit respectively). The erosional windows in the porphyritic granite that have been assigned by Snowden (1976), Snowden \& Bickle (1976) and Snowden \& Snowden $(1979,1981)$ to the possible basement have been assigned in this work to the gneissic granites as well. They do show the same macroscopic, microscopic and magnetic fabric as the gneissic granites, their lithology is comparable to the gneissic granites. The only occurrence of possible basement is near the batholith margin in the Umwindsi Shear Zone in the south-west of the batholith.

The gneissic granites in the marginal areas of the Chinamora Batholith can be divided into the southern, northern and western gneissic granites. These units show differences concerning their microscopic and magnetic fabric. While the southern gneissic granites revealed a strong solid-state overprint of the magmatic fabric that must be assigned to movement along the Umwindsi Shear Zone the northern and western gneissic granites do not show such a strong overprint of their magmatic fabric. Moreover, the magnetic fabric in the southern gneisses shows preferred sub-horizontal dip of the respective magnetic lineation while the magnetic foliation in this area generally has a steep to even vertical plunge. The magnetic lineation is oriented subparallel to the Umwindsi Shear Zone. Away from the Umwindsi Shear zone towards the contact area of the southern gneisses with the porphyritic granite the macroscopic as well as magnetic foliation parallels the outer margin of the pluton. In the western and the northern gneissic granites the macroscopic as well as magnetic fabric usually parallels the outer contact area, microscopic fabric only revealed a small amount of solid-state deformation. An exception to the margin parallel trend occurs in the northern gneissic granites in the Musana Communal Land area. This area showed nearly isotropic rocks with a very weak macroscopic foliation trending $\mathrm{E}-\mathrm{W}$ while the magnetic lineation has a preferred radial orientation pointing away from the center of this area. Outside the Musana Communal Land the magnetic and macroscopic foliation parallels this inner boundary while the magnetic lineation points towards the outer margin of the batholith. 
Geochemical analyzations of the gneissic granites showed a variable content of both, major and trace elements in the different lithologies. However, a linear relationship of the analyzed rocks from the lesser evolved southern gneissic granites to the more evolved western and northern gneisses is obvious.

The determined age data of the gneissic granites is diverse, dating of zircons resulted in three discordant ages ranging between 2.5 and $2.62 \mathrm{Ga}$. According to Tilton (1960) the lower intercept age ranging between 63 and 555 Ma can not be related to any world wide event and must be related to a constant, temperature independent $\mathrm{Pb}$-loss during time. This has been confirmed by Mezger \& Krogstad (1997). Ar/Ar dating of hornblende gave plateau ages of $\sim 2.5 \mathrm{Ga}$ for the gneissic granites. Moreover, the dated hornblendes and zircons revealed different ages for the different lithologies.

Finally, the modeling of the different intrusion geometries of the gneissic granites gave evidence that the isotherms in the crust are raised significantly when modeling a large magmatic body associated with a diapir or balloon. During modeling of a set of small magmatic bodies (coeval emplacement or pulsed intrusion) the metamorphic temperatures calculated from Jelsma (1993) were not reached and hence this model as well is unlikely. The geometry that matches the metamorphic temperatures without raising the lower isotherms unrealistically is that of a relatively thin body $(<15 \mathrm{~km})$ extending in horizontal direction.

The above described results of the different measurements seem to reject a ballooning emplacement mechanism as was proposed by Ramsay (1989) for the Chinamora Batholith. In addition, from a simply geometric point of view a balloon usually is described as a roughly spherical body, transferred to the Chinamora Batholith with its diameter of approx. $30 \mathrm{~km}$ and its estimated depth of emplacement (10 - $12 \mathrm{~km}$; Jelsma et al., 1993) a depth of at least $40 \mathrm{~km}$ would be reached which is more than the estimated thickness of the archean Zimbabwean crust (30 - $35 \mathrm{~km}$; Blenkinsop et al., 1997) and therefore this geometry is highly unlikely. Only a flattened shape of the balloon (or diapir) could be used as an estimation of the final shape of emplacement. Jelsma (1993) measured strain ellipses in the surrounding greenstone belt host rocks and found finite strain ellipsoids that must be assigned to triaxial flatting strain which is not likely during a ballooning batholith. Furthermore, the observed geometry of the greenstone belt as described by Dirks \& Jelsma (1998, a + b), Jelsma (1993), Jelsma et al. (1993) 
and Jelsma \& Dirks (2000) resembling a tricuspate synform seems to point to an upward deflection of the successions which is typical for a diapiric rise of magma (Clemens et al., 1997). However, this upward deflection of the greenstones may be assigned to any mechanism that either lets magma forcefully ascend to its final site of emplacement or inflates the magma chamber at its site of emplacement and hence pushes the overburden upward. Dyking may be a reasonable mechanism of emplacement for the Chinamora Batholith since it could produce the most likely geometry observed in the thermal modeling. Petford et al. (1993) or Pitcher \& Berger (1972) have shown that even very large batholiths can be constructed by dyking through continuous or intermittent feeding of the magma chamber. The latter seems to be a good model for the formation of the Chinamora Batholith. This model of emplacement could also explain the geochemical analyzes since the intermittent feeding would leave enough time for the deep seated magma chamber to evolve by fractional crystallization. Partial (?batch?) melting of the crust at depth would be another explanation that may produce the observed lithologies when magma ascends through dyking. Since more than one dyke at a time may be responsible for the magma ascend (Petford et al., 1993; Paterson, 1996; Cory, 1998) the resulting small plutons may have ascended independently from each other. It is cogitable that this simultaneous ascend and emplacement must thermally be treated in the same way such as one large yet, compared to its lateral extend, thin magmatic body. It has been shown for the Papoose Flat pluton that a translation of wall rocks in the kilometer scale is possible for the estimated overburden of $6.4-9.6 \mathrm{~km}$ (Morgan et al., 1998).

Some of the observations are not conform with the dyking model. According to Marsh (1982) due to the fast ascend velocity during dyking xenoliths should be carried up with the magma and should be visible in the field. Since the present outcrop must be in the roof area of the batholith xenoliths must not necessarily be present.

Another possible way of emplacement of the different lithologies of the Chinamora Batholith is that of a blistering diapir making up the composite batholith. This model describes the ascend of a diapir that expands outward and pushes the overburden upward (Sylvester, 1978).

Both of these models would largely explain the observed features of the gneissic granites and the surrounding host rocks of the Chinamora Batholith. The observed 
magnetic and macroscopic fabric in the gneissic granites remains to a certain degree inexplicable. While the dip and plunge of the fabric in the southern gneissic granites is related to movement of the Umwindsi Shear zone the distinct E-W trend of the magnetic lineation in the other gneissic granites can not be assigned to this movement or solely be explained by the emplacement mechanism. Interestingly, the same orientation of lineations have been found by Jelsma \& Dirks (2000) in the surrounding greenstone belts as well as in other greenstone belts in the northern Zimbabwe Craton (Dindi and Makaha). This must be taken as evidence that this orientation is not related to the emplacement of the granitoid bodies but must be related to some far-field regional tectonic stress field. Since this orientation of the fabric is consistent in the equigranular granites, the implications of this orientation will hence be discussed later in this chapter.

The equigranular granites in the west of the batholith basically resemble the same fabric as the northern and western gneissic granites. Their magnetic lineation trends E-W while their magnetic and macroscopic foliation is margin parallel in the contact area to the greenstone belts. The geochemical analyzes of this unit revealed a more evolved granitic composition than that of the gneissic granites. This is confirmed by the age of this unit since it is regarded as being younger than the gneissic granites but older than the porphyritic granite (e.g. Baldock, 1991; Jelsma, 1993 or Jelsma \& Dirks, 2000). Due to the comparable internal macroscopic and magnetic fabric to the gneissic granites it seems obvious that this setting reflects the same ascend and emplacement mechanism as the fabric in the gneissic granites.

The preferred E-W orientation of the magnetic lineation in both, the gneissic granites and the equigranular granites points to an origination due to a far field tectonic event. According to the model of Jelsma \& Dirks (2000) on the formation of the archean Zimbabwe Craton this lineation reflects the transport direction during the first deformational event $\left(D_{1}\right)$. Jelsma \& Dirks (1998b) proposed horizontal accretion of juvenile crust during $D_{1}$ which led to the stabilization of the Zimbabwe craton, the deformation associated with the emplacement of the granitoids $\left(D_{2}\right)$ may be coeval with $D_{1}$. According to their model the stacking of relatively hot, juvenile crustal fragments would have resulted in a strongly disturbed geothermal gradient. Following $D_{1}$ this crustal geothermal gradient was restored to an equilibrium leading to extensive partial melting of large parts of the 
crust and hence give a source to the observed batholiths. This model is rejected by Ridley et al. (1998) and Blenkinsop (1998) due to the proposed long time span during stacking of the crust and beginning of melting (20 - $50 \mathrm{Ma}$; Jelsma \& Dirks, 1998b). However, the observed preferred alignment of magnetic lineations in the Chinamora Batholith and the similar orientation of macroscopic lineations in the surrounding Harare-Shamva greenstone belt and other greenstone belts in northern Zimbabwe cannot be explained solely by the ascending and emplacing granitoid bodies in the northern Zimbabwe Craton but rather reflects a syn-tectonic emplacement of these units. A comparable setting was observed for the Papoose Flat pluton from Sylvester et al. (1978) who postulated a perpendicular orientation of strain to the wall rocks during the inflation of the pluton but found orientations of the fabric subparallel to regional fabric as well. They assigned this readjustment of internal fabric to an overprint during the waning stages of pluton emplacement where the internal strain is overprinted by a regional stress field.

The porphyritic granite in the center of the batholith is the youngest lithological unit in the Chinamora Batholith, Jelsma (1993) compared the porphyritic granite with the Chilimanzi type granites in the Zimbabwe Craton. The age data is confirmed by their evolved geochemical signature. The occurrence of erosional windows to the underlying gneisses in the porphyritic granite and the numerous small occurrences of porphyritic granite on the southern gneissic granites points to a thin sheet rather than a thick body extending vertically to depth (e.g. Baldock, 1991; Jelsma, 1993). Furthermore, the Inyauri Xenolith in the porphyritic granite has been interpreted as a Xenolith inside the porphyritic granite, but from field evidences it must be seen as a xenolith in the gneissic granites. This is confirmed by the magnetic and macroscopic foliation that seems not to be reflected from the Inyauri Xenolith. The magnetic lineation and foliation in the porphyritic granite tends E-W in the southern part and turns to a preferred ENE-WSW orientation in the northern part. The macroscopic foliation is subparallel to the magnetic foliation. This fabric and field relationships from the erosional windows are best explained with a laccolith-like emplacement of the porphyritic granite that has the overall form of a NNW-verging laccolith with moderate inclinations of the foliation in the south and steep inclinations in the northwest (Becker et al., 2000). The geographic extension of the porphyritic granite is consistent with experiments performed by Roman-Berdiel et al. (1995) who found a linear relationship of the thickness of the 
laccolith, the diameter of the intrusion and the thickness of the overburden. If this linear relationship is extrapolated and applied to the actual diameter of the Chinamora Batholith the estimated thickness of the overburden is approx. $12 \mathrm{~km}$ which is consistent with estimates from Jelsma et al. (1993) concerning the intrusion depth. The thickness of the laccolith should not exceed approx. $3 \mathrm{~km}$ (Roman-Berdiel et al., 1995). Recently, Blenkinsop et al. (1999) described folding of schlieren, pegmatite layers and sub-phase contacts in the porphyritic granite as a product of syn-magmatic folding with wave-lengths of several meters. The orientation of their fold-axes is subparallel to the orientations of the measured magnetic lineations. The measured magnetic as well as macroscopic foliation does not support large-scale folding because of the stable moderate inclination throughout most of the batholith but it may be quite possible that this folding represents local folding during e.g. magmatic welling. 


\section{References}

ADAM, J.F. (1989): Methoden und Algorithmen zur Verwaltung und Analyse axialer 3D Richtungsdaten und ihrer Belegungsdichten. - Göttinger Arb. Geol. Paläontol., 53: $1-100$.

ALEINIKOFF, J.N., WILLIAMS, I.S., COMPSTON, W., STUCKLESS, J.S. \& WORL, R.G. (1989): Evidence for an early archean component in the Middle to Late Archean gneisses of the Wind River Range, west-central Wyoming: conventional and ion microprobe U-Pb data. - Contrib. Min. Pet., 101: $198-206$.

ANGENHEISTER, G. \& SOFFEL, H. (1972): Gesteinsmagnetismus und Paläomagnetismus. - Gebr. Bornträger, Berlin.

ARCHANJO, C.J., LAUNEAU, P. \& BOUCHEZ, J.L. (1995): Magnetic fabric vs. magnetite and biotite shape fabrics of the magnetite bearing granite pluton of Gameleiras (Northeastern Brazil). - Phys. Earth Planet. Int., 89: 63 - 75.

ARTH, J.G. \& HANSON, G. (1975): Geochemistry and origin of the early precambrian crust of northeastern Minnesota. - Geochim. Cosmochim. Acta, 39: $325-362$.

BALDOCK, J.W. (1991): The geology of the Harare Greenstone Belt and surrounding granitic terrain. - Zim. Geol. Surv. Bul., 94.

BALDOCK, J.W. \& EVANS, J.W. (1988): Constraints on the age of the Bulawayan Group metavolcanic sequence, Harare greenstone belt, Zimbabwe. - J. Afr. Earth Sci., 7: $795-804$.

BALLET, O. \& COEY, J.M.D. (1982): Magnetic properties of sheet silicates; 2:1 layer minerals. - Phys. Chem. Min., 8: $218-229$.

BALSLEY, J.R. \& BUDDINGTON, A.F. (1960): Magnetic susceptibility, anisotropy and fabric of some Adirondack granites and orthogneisses. - Am. J. Sci., 254A: $6-20$.

BATEMAN, R. (1984): On the role of diapirism in the segregation, ascent and final emplacement of granitoid magmas. - Tectonophysics, 110(3-4): $211-231$.

BARKER, F. \& ARTH, J.G. (1976): Generation of trondhjemitic-tonalitic liquids and Archean bimodal trondhjemite-basalt suites. - Geology, 4: 596-600.

BEARD, J.S. \& LOFGREN, G.E. (1991): Dehydration melting and water-saturated melting of basaltic and andesitic greenstones and amphibolites at 1, 3 and 6.9 kbar. - J. Petrol., 32: $365-401$.

BECKER, J.K., SIEGESMUND, S. \& JELSMA, H.A. (2000): The Chinamora Batholith, Zimbabwe: structure and emplacement related magnetic rock fabric. - Int. J. Earth. Sci., in press.

BERGER, A. (1995): Magmatic and solid state flow during the syntectonic emplacement of the Bergell pluton (southeastern part):field studies and microstructural analysis. - Ph.D. thesis, Geol. Paläont. Inst. Univ. Basel, 7.

BERGMÜLLER, F., BÄRLOCHER, C., GRIEDER, M., HELLER, F. \& ZWEIFEL, P. (1994): A torque magnetometer for measurement of the high field anisotropy of rocks and crystals. - Meas. Sci. Techno., 5: $1466-1470$.

BERGMÜLLER, F. \& HELLER, F. (1995): The field dependence of magnetic anisotropy parameters derived from high-field torque measurements. Phys. Earth Planet. Int., 96: 61-76. 
BICKFORD, M.E., CHASE, R.B., NELSON, B.K., SHUSTER, R.D. \& ARRUDA, E.C. (1981): U-Pb studies of zircon cores and overgrowths, and monazite: implications for age and petrogenesis of the northeastern Idaho Batholith. J. Geol., 89: $140-150$.

BLENKINSOP, T.G., MARTIN, A., JELSMA, H.A. \& VINYU, M.L. (1997): The Zimbabwe Craton, Southern Africa.- In: DEWIT, M.J. \& ASHWAL, L.D.: Greenstone belts, Oxford University Press, 562 - 574.

BLENKINSOP, T.G. (1998): Horizontal accretion and stabilization of the Archean Zimbabwe Craton; discussion and reply. - Geology, 26(12): 1147 - 1150.

BLENKINSOP, T.G., TRELOAR, P.J. \& HANSON, R. (1999): Rheology of granite magmas during emplacement: synmagmatic folding and magmatic axial planar fabrics in the Chilimanzi granites of the Zimbabwe craton. - Abstract, meeting on deformation mechanisms and microstructures, Neustadt-amRhein.

BLUMENFELD, P. \& BOUCHEZ, J.-L. (1988): Shear criteria in granite and migmatite deformed in the magmatic and solid states. - J. Struct. Geol., 10(4): 361-372.

BOAK, J.L. \& DYMEK, R.F. (1982): Metamorphism of the 3800 Ma supracrustal rocks at Isua, West Greenland: implications for early archean crustal evolution. - Earth Planet. Sci. Let., 59: 159 - 176.

BORRADAILE, G. \& CRAIG, A. (1987): Relationship between magnetic susceptibility and strain in laboratory experiments. - Tectonotphysics, 133(19): $121-135$.

BORRADAILE, G.J., KEELER, W., ALFORD, C. \& SARVAS, P. (1987): Anisotropy of magnetic susceptibility of some metamorphic minerals. - Phys. Earth. Planet. Inter. 48: 161-166

BOUCHEZ, J.L., DELAS, C., GLEIZES, G. \& NÉDÉLEC, A. (1992): Submagmatic microfractures in granites. - Geology, 20: 35-38.

CARD, K.D. (1990): A review of the Superior Province of the Canadian Shield, a product of Archean accretion. - Precambrian Res., 63: 43 - 58.

CHERNIACK, D.J., LANFORD, W.A. \& RYERSON, F.J. (1991): Lead diffusion in apatite and zircon using ion implantation and Rutherford backscattering techniques. - Geochim. Cosmochim. Acta, 55: 1663 - 1673.

CLAY, A.N. (1978): The geology of the Mount Hampden area. - Annals Geol. Surv. Rhodesia, III: $22-34$.

CLEMENS, J.D., PETFORD, N. \& MAWER, C.K. (1997): Ascent mechanisms of granitic magmas: causes and consequences. - In: HOLNESS M.B. [ed.]: Deformation-enhanced fluid transport in the earth's crust and mantle. Chapman \& Hall, London.

CONDIE, K.C. (1981): Archean greenstone belts.- Elsevier, Amsterdam.

CONDIE, K.C. (1986): Origin and early growth rate of continents. - Precambrian Res., 32: $261-278$.

CORFU, F., KROGH, T.E. \& AYRES, L.D. (1985): U-Pb zircon and sphene geochronology of a composite archean granitoid batholith, Favourable Lake area, northwestern Ontario. - Can. J. Earth Sci., 22: 1436 - 1451.

CORY, C.E. (1998): Laccoliths; Mechanics of emplacement and growth. - Geol. Soc. Am. Spec. Pap., 220.

COX, K.G., JOHNSON, R.L., MONKMAN, L.J., STILLMAN, C.J., VAIL, J.R. \& WOOD, D.N. (1965): The geology of the Nuanetsi igneous province. - Phil. Trans. R. Soc. London, A257: $71-218$. 
COX, K.G., BELL, J.D. \& PANKHURST, R.J. (1979): The interpretation of igneous rocks. - Georg, Allan and Unwin, London.

CUMBEST, R.J. (1990): Amphax: A fortran program for calculating the lower hemisphere stereographic projections of the crystallographic axes of clinoamphibole from universal stage measurements. - Computers \& Geoscience, 16(3): $371-377$.

DAMM, V. (1980): Suszeptibilitätsanisotropien in Sedimenten und Magmatiten aus dem Gebiet der DDR und in Metamorphiten der Schirmacher Oase (Antarktika). - Zent. Phys. Erde, 95.

DECKERS, M.J. (1988): Some rockmagnetic parameters for natural geothit, pyrrothite and fine-grained haematite. - unpub. Ph.D. thesis, Uni. Uetrecht.

DEWIT, M.J. (1982): Gliding and overthrust nappe tectonics in the Barberton Greenstone belt. - J. Struct. Geol., 4: 117-136.

DIRKS, P.H.G.M. \& JELSMA, H.A. (1998a): Silicic layer-parallel shear zones in a Zimbabwean greenstone sequence: horizontal accretion preceding doming. - Gondwana Res., 1(2): 177 - 193.

DIRKS, P.H.G.M. \& JELSMA, H.A. (1998b): Horizontal accretion and stabilization Of the archean Zimbabwe Craton. - Geology, 26(1): 11 - 14.

DODSON, M.H., COMPSTON, W., WILLIAMS, I.S. \& WILSON, J.F. (1988): A search for ancient detrital zircons in Zimbabwean sediments. - J. Geol. Soc. London, 145(6): 977 - 983.

DRUMMOND, M.S. \& DEFANT, M.J. (1990): A model for trondhjemite-tonalitedacite genesis and crustal growth via slab melting: archean to modern comparisons. - J. Geophys. Res., 95B: $21503-21521$.

DUNNING, G.R., BARR, S.M., RAESIDE, R.P. \& JAMIESON, R.A. (1990): U-Pb zircon, titanite and monazite ages in the Bras d'Or and Aspy terranes of Cape Breton Island, Nova Scotia: implications for igneous and metamorphic history. Geol. Soc. Am. Bull., 102: 322 - 330.

FENG, R. \& KERRICH, R. (1992): Geochemical evolution of granitoids from the archean Abitibi southern Volcanic zone and the Pontiac subprovince, Superior Province, Canada: implications for tectonic history and source regions. - Chem. Geol., 98: 23 - 70.

FRIEDRICH, D. (1994): Gefügeuntersuchungen an Amphiboliten der böhmischen Masse unter besonderer Berücksichtigung der Anisotropie der Magentischen Suszeptibilität. - Geotekt. Forsch., 82: 1 - 118.

GLEIZES, G., NÉDÉLEC, A., BOUCHEZ, J.L., AUTRAN, A. \& ROCHETTE, P. (1993): Magnetic susceptibility of the Moint-Louis Andorra ilmenite-type granite (Pyrenees): A new tool for the petrographic characterization and regional mapping of zoned granite plutons. - J. Geophys. Res., 98(B3): $4317-4331$.

GODIN, P. (1994): Deformation within the Cannibal Creek Pluton and its aureole, Queensland, Australia: a re-evaluation of ballooning as an emplacement mechanism. - J. Struct. Geol., 16(5): 693-707.

GOLDICH, S.S. \& MUDREY, M.G. (1972): Dilatancy model for discordant U-Pb zircon ages. - In: VINOGRADOV, A.I. [ed.]: Contributions to recent geochemistry and analytical Chemistry, 415 - 418. Volume Moscow Nauka Publ. Office, Tugarinov.

GOODWIN, A.M. (1991) : Precambrian geology; the dynamic evolution of the continental crust. - Acad. Press. San Diego, CA, United States.

GREGOIRE, V., DE SAINT BLANQUAT, M., NÉDÉLEC, A. \& BOUCHEZ, J.L. 
(1995): Shape anisotropy versus magnetic interactions of magnetite grains: experiments and application to AMS in granitic rocks. - Geophys. Res. Let., 22(20): $2765-2768$.

GUILLOU, L., MARESCHAL, J.-C., JAUPART, C., GARIEPY, C., BIENFAIT, G. \& LAPOINTE, R. (1994): Heat flow, gravity and structure of the Abitibi belt, Superior Province, Canada: Implications for mantle heat flow. - Earth Planet. Sci. Let., 122: 103 - 123.

HALL, A. (1993): Igneous petrology. - Longman Scientific \& Technical.

HANMER, S.K. (1982): Microstructure and geochemistry of plagioclase and microcline in naturally deformed granite. - J. Struct. Geol, 4: $197-213$.

HARRISON, T.M. (1981): Diffusion of ${ }^{40} \mathrm{Ar}$ in hornblende. - Contrib. Mineral. Petrol., 78: $324-331$.

HIBARD, M.J. (1987): Deformation of incompletely crystallized magma system: granitic gneisses and their tectonic implications. - J. Geol., 95: 543-561.

HOLDER, M.T. (1981): Mechanics of emplacement of granite plutons. - unpub. Ph.D. thesis, University of Leeds.

HROUDA, F. (1982): Magnetic anisotropy of rocks and its application in geology and geophysics.- Geophys. Surv., 5: $37-82$.

HROUDA, F: (1986): The magnetic fabric of sedimentary rocks of the Male Karpaty Mts. and its tectonic implications. - J. Geol. Sci., 20: 155 - 167.

HROUDA, F. \& JELINEK, V. (1990): Resolution of ferrimagnetic and paramagnetic anisotropies in rocks using combined low-field and high-field measurements. - Geophys. J. Int., 103: 75 - 84.

JELINEK, V. (1977): The statistical theory of measuring anisotropy of magnetic susceptibility of rocks and its application. - Geofyzika Brno, Czech Republic.

JELINEK, V. (1981): Characterization of magnetic fabric of rocks. Tectonophysics, 79: $563-567$.

JELSMA, H. A. (1993): Granites and greenstones in northern Zimbabwe: Tectonothermal evolution and source regions. - Ph.D. thesis, Free University of Amsterdam.

JELSMA, H.A., VAN DER BEEK, P.A. \& VINYU, M.L. (1993): Tectonic evolution of the Bindura-Shamva greenstone belt (Zimbabwe): Progressive deformation around ballooning diapirs. - J. Struct. Geol., 15: 163-176.

JELSMA, H.A., VINYU, M.L., VALBRACHT, P.J., DAVIES, G.R., WIJBRANS, J.R. \& VERDUMEN, E.A.T. (1996): Constraints on archean crustal evolution of the Zimbabwe Craton: a U-Pb zircon, Sm-Nd and $\mathrm{Pb}-\mathrm{Pb}$ whole rock isotope study. - Contrib. Miner. Petrol., 124: 55-70.

JELSMA, H.A. \& DIRKS, P.H.G.M. (2000): Structural geometries of a greenstone sequence in Zimbabwe: a product of crustal amalgamation and diapirism. Tectonics, 19: $135-152$.

JOHN, B.E. \& BLUNDY, J.D. (1993): Emplacement-related deformation of granitoid magmas, southern Adamello Massif, Italy. - Geol. Soc. Am. Bull., 105: 1517-1541.

JUCKENACK, C. (1990): Beitrag der Anisotropie der magnetischen Suszeptibilität (AMS) für Struktur- und Gefügeuntersuchungen von Metamorphiten: Einzelbeispiele und regionale Anwendungen im Spessart-Kristallin. unpub. Ph.D. thesis, University of Göttingen.

KUSKY, T.M. \& KIDD, W.S.F. (1992): Remnants of an Archean oceanic plateau, Belingwe greenstone belt, Zimbabwe. - Geology, 20: 43 - 46.

LACHENBRUCH, A.H. (1968): Preliminary geothermal model of the Sierra Nevada. - J. Geophys. Res., 73: 6977-6989. 
LAYER, P.W., HALL, C.M. \& YORK, D. (1987): The derivation of ${ }^{40} \mathrm{Ar} /{ }^{39} \mathrm{Ar}$ age spectra of single grains of hornblende and biotite by laser step heating. Geophys. Res. Let., 14: 757 - 760.

LONKA, H., SCHULMANN, K. \& VENERA, Z. (1998): Ductile deformation in the Suomusjärvi shear zone, Finland.- J. Struct. Geol., 20(6): 783 - 798.

LOWRIE, W. (1989): Magnetic analysis of rock fabric. - Encyclopedia of solid earth geophysics, New York.

LUDWIG, K.R. \& STUCKLESS, J.S. (1978): Uranium-lead isotope systematics and apparent ages of zircons and other minerals in Precambrian granitic rocks, Granite Mountains, Wyoming. - C. M. P., 65: $243-254$.

MACCASKIE, D.R. (1984): Identification of petrogenetic processes using covariance plots of trace element data. - Chem. Geol., 42: $325-341$.

MACGREGOR, A.M. (1951): Some milestones in the Precambrian of Southern Rhodesia. - Proc. Geol. Soc. S. Africa, 54: 27-71.

MARSH, B.D. (1982): On the mechanics of igneous diapirism, stoping, and zone melting. - Am. J. Sci., 282(6): $808-855$.

MARTIN, H. (1987): Petrogenesis of archean trondhjemites, tonalites and granodiorites from eastern Finland. - J. Petrol., 28: 921 - 953.

MARTIN, H. (1993): The mechanisms of petrogenesis of the archean continental crust - comparison with modern processes. - Lithos, 30: $373-388$.

MARTIN, H. (1994): The archean grey gneisses and the genesis of continental crust. - In: CONDIE K.C. [ed.]: Archean crustal evolution. - Develop. Precamb. Geol., 11: $205-259$.

MASON, R. (1973): The Limpopo mobile belt - Southern Africa. - Phil. Trans. R. Soc. London, A273: 463 - 485.

MCBIRNEY, A.R. \& MURASE, T. (1984): Rheological properties of magma. - An. Rev. Earth Planet. Sci., 12: 337-357.

MEANS W.D. \& PARK, Y. (1994): New experimental approach to understanding igneous textures. - Geology, 22: $323-326$.

MEZGER, K. \& KROGSTAD, E.J. (1997): Interpretation of discordant U-Pb zircon ages: An evaluation. - J. Metam. Geol., 15: 127 - 140.

MILLER, R.B. \& PATERSON, S.R. (1994): The transition from magmatic to hightemperature solid-state deformation: implications from the Mount Stuart batholith, Washington. - J. Struct. Geol., 16(6): 853-865.

MILLER, R.B. \& PATERSON, S.R. (1999): In defense of magmatic diapirs. - J. Struct. Geol., 21: $1161-1173$.

MOLYNEUX, S.J. \& HUTTON, D.H.W. (1999): Evidence for significant granite space creation by the ballooning mechanism: The example of the Ardara pluton, Ireland. - in press.

MORGAN, S.S., RICHARD, D.L. \& NYMAN, M.W. (1998): Laccolith-like emplacement model for the Papoose Flat pluton based on porphyroblastmatrix analyses. - Geol. Soc. Am. Bull., 110(1): 96 - 110.

MORTENSEN, J.K. (1993): U-Pb geochronology of the Lapparent Massif, northeastern Abitibi belt: basement of synvolcanic pluton.- Can. J. Earth Sci., 40: $42-47$.

MUKASA, S.B., WILSON, A.H. \& CARLSON, R.W. (1998): A multielement geochronologic study of the Great Dyke, Zimbabwe; significance of the robust and reset ages. - Earth Planet. Sci. Let., 164(1-2): 353-369.

O'CONNOR, J.T. (1965): A classification for quartz-rich igneous rocks based on feldspar ratios. - U.S. Geol. Surv. Prof. Pap., 525B: 79-84.

ORLICKY, O. (1990): Detection of magnetic carriers in rocks: results of 
susceptibility changes in powdered rock samples induced by temperature. Phys. Earth Planet. Int., 63: 66 - 70.

PATERSON, S.R. (1996): Structural evolution of arcs. - Unpub. short courses notes, Giessen.

PATERSON, S.R. \& VERNON, R.H. (1995): Bursting the bubble of ballooning plutons: A return to nested diapris emplaced by multiple processes. - Geol. Soc. Am. Bul., 107(11): 1356 - 1380.

PATERSON, S.R., VERNON, R.H. \& TOBISCH, O.T. (1989): A review of criteria for the identification of magmatic and tectonic foliations in granitoids. - J. Struct. Geol., 11(3): 349 - 363.

PATERSON, S.R., KENNETH FOWLER JR., T, SCHMIDT, K.K., YOSHINOBU, A.S., YUAN, E.S. \& MILLER, R.B. (1998): Interpreting magmatic fabric patterns in plutons. - Lithos, 44: 53-82.

PASCHIER, C.W. \& TROUW, R.A.J. (1996): Microtectonics. - Springer-Verlag, Berlin.

PETFORD, N., KERR, R.C. \& LISTER, J.R. (1993): Dike transport model for transport of granitoid magmas. - Geology, 20: $845-848$.

PHILPOTTS, A.R. (1990): Principles of igneous and metamorphic petrology. Prentice Hall, New Jersey.

PITCHER, W.S. \& BERGER, A.R. (1972): The geology of Donegal, a study of granite emplacement and unroofing. - Regional Geology Series, WileyInterscience, London.

POLLACK, H.N. (1997): Thermal characteristics of the archean. - In: DEWIT, M. \& ASHWAL, L.D. [eds.]: Greenstone belts.- Oxford Science Publications, 223233.

RAMSAY, J.G. (1989): Emplacement kinematics of a granite diapir: the Chindamora batholith, Zimbabwe.- J. Struct. Geol., 11: 191-209.

RAMSAY, J.G. \& GRAHAM, R.H. (1970): Strain variation in shear belts. - Canad. J. Earth Sci., 7: $786-813$.

RAPP, R.P., WATSON, E.B. \& MILLER, C.F. (1991): Partial melting of amphibolite/eclogite and the origin of archean trondhjemites and tonalites. Precambrian Res., 51: 1- 25.

RICHTER, F.M. (1985): Models for the archean thermal regime. - Earth Planet. Sci. Let., 73: $350-360$.

RIDLEY, J.R., BALZ, S.K. \& KRAMERS, J.D. (1998): Horizontal accretion and stabilization of the Archean Zimbabwe Craton; discussion and reply. Geology, 26(12): $1147-1150$.

RIEKELS, L.M. \& BAKER, D.W. (1977): The origin of the double maximum pattern of optic axes in quarzite mylonite. - J. Geol., 85: $1-14$.

ROCHETTE, P. (1987): Magnetic susceptibility of the rock matrix related to magnetic fabric studies. - J. Struct. Geol., 9: 1015 - 1020.

ROCHETTE, P., JACKSON, M. \& AUBOURG, C. (1992): Rock magnetism and the interpretation of anisotropy of magnetic susceptibility. - Rev. Geophys., 30: $209-226$.

ROIG, J.Y. \& FAURE, M. (1998): Folding and granite emplacement inferred from structural, strain, TEM and gravimetric analyses: the case study of the Tulle antiform, SW French Massif Central. - J. Struct. Geol., 20(9/10): 1169 1189.

ROLLINSON, H.R (1993): Using geochemical data: evaluation, presentation, interpretation. Longman scientific \& technical, Longman Group, UK.

ROMAN-BERDIEL, T., GAPAIS, D. \& BRUN, J.P. (1995): Analogue models of 
laccolith formation. - J. Struct. Geol., 17(9): 1337 - 1346.

RUDNICK, R.L., MCDONOUGH, W.F. \& O'CONELL, R.J (1998): Thermal structure, thickness and composition of continental lithosphere. - Chem. Geol., 145: $395-411$.

RUSHMER, T. (1991): Partial melting of two amphibolites: contrasting experimental results under fluid-absent conditions. - Contrib. Miner. Petrol., 107: $41-59$.

SALTUS, R.W. \& LACHENBRUCH, A.H. (1991): Thermal evolution of the Sierra Nevada: tectonic implications of new heat flow density data. - Tectonics, 10: $325-344$.

SCLATER, J.G., PARSONS, B. \& JAUPART, C. (1981): Oceans and continents: similarities and differences in the mechanisms of heat loss. - J. Geophys. Res., 86: $11535-11552$.

SCRIBA, H. \& HELLER, F. (1978): Measurements of anisotropy of magnetic susceptibility using inductive magnetometers. - J. Geophys. Res., 44(4): $341-352$.

SIEGESMUND, S., ULLEMEYER, K. \& DAHMS, M. (1995): CONTROL OF MAGNETIC ROCK FABRICS BY MICA PREFERRED ORIENTATION: A QUANTITATIVE APPROACH. - J. STRUCT. GEOL., 17(11): 1601 - 1613.

SIEGESMUND, S. \& BECKER, J.K. (2000): The emplacement of the Ardara pluton (Ireland): New constraints from magnetic fabrics, rock fabrics and age dating. - Int. J. Earth Sci., in press.

SIEGESMUND, S., JELSMA, H.A., BECKER, J.K., DAVIES, G., LAYER, P., VAN DIJK, E., KATER, L. \& VINYU, M. (in prep.): Constraints on the timing of granite emplacement, deformation and metamorphism in the Shamva area, Zimbabwe.

SNOWDEN, P.A. (1976): The geology of the granitic terrain north and east of Salisbury, with particular reference to the Chinamora batholith. - Ph.D. thesis, University of Zimbabwe, Harare.

SNOWDEN, P.A. \& BICKLE, M.J. (1976): The Chinamora batholith: diapiric intrusion or interference fold?- J. Geol. Soc. London, 132: 131-137.

SNOWDEN, P.A. \& SNOWDEN, D.V. (1979): Geology of an archean batholith, the Chinamora batholith - Rhodesia. - Trans. Geol. Soc. S. Africa, 82: 7-22.

SNOWDEN, P.A. \& SNOWDEN, D.V. (1981): Petrochemistry of the late archean granites of the Chinamora batholith, Zimbabwe. - Precambrian Res., 16: $103-129$.

SNOWDEN, P.A. (1984): Non-diapiric batholiths in the north of the Zimbabwe Shield. - In: KRÖNER, A. \& GREILING, R. [eds.]: Precambrian tectonics illustrated. - Nägele und Obermiller, Stuttgart.

STACEY, F.D., JOPLIN, G. \& LINDSAY, J. (1960): Magnetic anisotropy and fabric of some foliated rocks from S.E. Austrialia. - Geophys. Pura Appl., 47: $30-$ 40.

SWANSON, S.E. (1977): Relation of nucleation and crystal-growth rate to the development of granitic textures. - Am. Min., 62: 966-978.

SYLVESTER, A.G., OERTEL, G., NELSON, C.A. \& CHRISTIE, J.M. (1978): Papoose Flat pluton: A granitic blister in the Inyo Mountains, California. Geol. Soc. Am. Bull., 89(8): $1205-1219$.

TARLING, D.H. \& HROUDA, F. (1993): The magnetic anisotropy of rocks. Chapman \& Hall.

TAYLOR, P.N., KRAMERS, J.D., MOORBATH, S., WILSON, J.F., ORPEN, J.L. \& 
MARTIN, A. (1991): $\mathrm{Pb} / \mathrm{Pb}, \mathrm{Sm}-\mathrm{Nd}$ and $\mathrm{Rb}-\mathrm{Sr}$ geochronology in the Archean Craton of Zimbabwe. - Chem. Geol., 87: 175 - 196.

TILTON, G.R. (1960): Volume diffusion as a mechanism for discordant lead ages. - J. Geophys. Res., 65: $2933-2945$.

TREOLAR, P.J. (1997): The generation, ascent and emplacement of granitic magmas: a Zimbabwean perspective. - Abstract volume of the conference "Intraplate magmatism and tectonics of southern Africa", p. 51, Harare, Zimbabwe.

TULLIS, J., CHRISTIE, J.M. \& GRIGGS, D.T. (1973): Microstructures and preferred orientations of experimentally deformed quarzites. - J. Geol., 84: $297-314$.

ULLEMEYER, K. (1992): Methodische Untersuchungen zur Röntgentexturanalyse und Gefügeuntersuchungen an Granuliten der Südlichen Böhmischen Masse. - unpub. Ph.D. thesis, University of Göttingen.

WILLIAMS, I.S. (1992): Some observations on the use of zircon U-Pb geochronology on the study of granitic rocks. - Trans. Royal Soc. Edinburgh: Earth sciences, 83: $447-458$.

WILSON, J.F. (1979): A preliminary reappraisal of the Rhodesian Basement Complex. - Geol. Soc. S. Africa Spec. Publ., 5: 1 - 23.

WILSON, J.F., NESBITT, R.W. \& FANNING, C.M. (1995): Zircon geochronology of Archaean felsic sequences in the Zimbabwe craton: a revision of greenstone stratigraphy and a model for crustal growth. - In: COWARD, M.P. \& RIES, A.C. [eds.]: Early Precambrian processes. - Geol. Soc. Spec. Pub., 95: 109-126.

WILSON, J.F., JONES, D.L. \& KRAMERS, J.D. (1987): Mafic dyke swarms in Zimbabwe. - In: Halls, H.C. \& Fahrig, W.F. [eds.]: Mafic dyke swarms. Geol. Assoc. Can. Spec. Pap., 34: 433 - 444.

WINTHER, K.T. \& NEWTON, R.C. (1991): Experimental melting of hydrous low-K tholeiite: evidence on the origin of archean cratons. - Bull. Geol. Soc. Denmark, 39: 213 - 228.

WYLLIE, P.J., WOLF, M.B. \& VAN DER LAAN, S.R. (1997): Conditions for formation of tonalites and trondhjemites: magmatic sources and products. In: DEWIT, M. \& ASHWAL, L.D. [eds.]: Greenstone Belts. - Oxford Science Publications: $256-266$.

VAN DER MOLEN, I. \& PATERSON, M.S. (1979): Experimental deformation of partially melted granite. - Contr. Miner. Petrol., 70: 299-318.

VERNON, R.H. (1989): Evidence of syndeformational contact metamorphism from porphyroblast-matrix microstructural relationships. - Tectonophysics, 158: 113-126.

VONBLANCKENBURG, F. (1990): Combined high-precision chronometry and geochemical tracing using accessory minerals: applied to the Central-Alpine Bergell intrusion (Central Europe). - Chem. Geol., 100: 19- 40.

YORK, D., HALL, C.M., YANASA, Y., HANES, J.A. \& KENYON, W.J. (1981): ${ }^{40} \mathrm{Ar} /{ }^{39} \mathrm{Ar}$ dating of terrestrial minerals with a continuous laser. - Geophys. Res. Let., 8: 1136 - 1138.

ZAPLETAL, K. (1990): Low-field susceptibility of some biotite crystals. - Phys. Earth Planet. Int., 63: $85-97$. 


\section{Appendix I}

Sample location

(Coordinates given in UTM-Grid)

\begin{tabular}{|l|l|}
\hline JB1 & $0331700-8056625$ \\
\hline JB2 & $0331559-8053335$ \\
\hline JB3 & $0328743-8053468$ \\
\hline JB4 & $0326091-8053983$ \\
\hline JB5 & $0325605-8053018$ \\
\hline JB6 & $0324709-805620$ \\
\hline JB7 & $0329639-8057290$ \\
\hline JB8 & $0331992-8058276$ \\
\hline JB9 & $0331726-8059715$ \\
\hline JB10 & $0336182-8060511$ \\
\hline JB11 & $0326070-8059566$ \\
\hline JB12 & $0325857-8061393$ \\
\hline JB13 & $0325456-8062377$ \\
\hline JB14 & $0324017-8063045$ \\
\hline JB15 & $0322172-8066462$ \\
\hline JB16 & $0319857-8065345$ \\
\hline JB17 & $0318722-8064956$ \\
\hline JB18 & $0317591-8063683$ \\
\hline JB19 & $0316015-8061932$ \\
\hline JB20 & $0316375-8058831$ \\
\hline JB21 & $0317249-8060815$ \\
\hline JB22 & $0311697-8059374$ \\
\hline JB23 & $0309567-8061865$ \\
\hline JB24 & $0312706-8057349$ \\
\hline JB25 & $0315413-8053895$ \\
\hline JB26 & $0318098-8051655$ \\
\hline JB27 & $0316046-8056040$ \\
\hline JB28 & $0320541-8053743$ \\
\hline JB29 & $0313689-8054109$ \\
\hline JB30 & $0322656-8056303$ \\
\hline JB31 & $0322471-8056207$ \\
\hline JB32 & $0322643-8062732$ \\
\hline JB33 & $0320656-8060417$ \\
\hline JB34 & $0321101-8056795$ \\
\hline JB35 & $0320425-8058078$ \\
\hline JB36 & $0305604-8052477$ \\
\hline JB37 & $0302949-8056485$ \\
\hline JB38 & $0316016-8048107$ \\
\hline JB39 & $0320215-8045844$ \\
\hline JB40 & $0322663-8047418$ \\
\hline JB41 & $0325092-8050167$ \\
\hline JB42 & $0322084-8050111$ \\
\hline JB43 & $0321194-8072006$ \\
\hline JB44 & $0321195-8073411$ \\
\hline JB45 & $0322397-8069711$ \\
\hline JB46 & $0321798-8068060$ \\
\hline JB47 & $0325713-8069136$ \\
\hline & $0326433-8070503$ \\
\hline
\end{tabular}

\begin{tabular}{|c|c|}
\hline 349 & \\
\hline 350 & $23624-8072598$ \\
\hline 51 & $3285-806855$ \\
\hline 52 & 677 \\
\hline 53 & \\
\hline 54 & 3072 \\
\hline 55 & $29101-8071208$ \\
\hline 56 & $329980-8072414$ \\
\hline 57 & $328690-8074876$ \\
\hline 58 & 322913-8074653 \\
\hline 59 & $322654-8075648$ \\
\hline 60 & $326724-8075956$ \\
\hline 60 & $318505-8078098$ \\
\hline 62 & 55 \\
\hline 63 & $324205-8079310$ \\
\hline 64 & $17839-807904 \varepsilon$ \\
\hline 65 & $284-80788$ \\
\hline 66 & $21758-8076996$ \\
\hline 67 & 0318873-8076325 \\
\hline 68 & $0317052-8075918$ \\
\hline 369 & $320697-8075129$ \\
\hline 70 & $31246-8075172$ \\
\hline 71 & $32526-8072355$ \\
\hline 72 & $29686-8062925$ \\
\hline$\overline{73}$ & $15571-8079650$ \\
\hline 74 & $10103-8077539$ \\
\hline 75 & $0306266-8074778$ \\
\hline 76 & $326270-8063795$ \\
\hline 77 & $0326963-8064311$ \\
\hline 78 & $25514-8065109$ \\
\hline 79 & $16363-8065599$ \\
\hline 80 & $17292-8065941$ \\
\hline 81 & $0304223-8073070$ \\
\hline 82 & $0465-806975$ \\
\hline 83 & $307631-8070489$ \\
\hline 84 & $09622-8071888$ \\
\hline 85 & $0310350-8074650$ \\
\hline 86 & $0311343-8072353$ \\
\hline JB87 & $0314225-8071798$ \\
\hline JB88 & $317952-8068476$ \\
\hline JB89 & $316157-8069548$ \\
\hline 390 & $18275-8071655$ \\
\hline JB91 & $0317300-8073319$ \\
\hline 92 & $316001-8070952$ \\
\hline 93 & $13754-8075492$ \\
\hline 94 & $16056-8075562$ \\
\hline 395 & $0313878-8077157$ \\
\hline 396 & $0309252-8068813$ \\
\hline
\end{tabular}




\begin{tabular}{|l|l|}
\hline JB97 & $0310713-8067082$ \\
\hline JB98 & $0311020-8067882$ \\
\hline JB99 & $0309671-8063331$ \\
\hline JB100 & $0308540-8064701$ \\
\hline JB101 & $0305385-8068212$ \\
\hline JB102 & $0304917-8065718$ \\
\hline JB103 & $0306323-8065849$ \\
\hline JB104 & $0303247-8062704$ \\
\hline JB105 & $0305034-8063368$ \\
\hline JB106 & $0306354-8060331$ \\
\hline JB107 & $0307661-8057734$ \\
\hline JB108 & $0302097-8051674$ \\
\hline JB109 & $0292500-8052900$ \\
\hline JB110 & $0293600-8051500$ \\
\hline JB111 & $0306555-8054170$ \\
\hline JB112 & $0308373-8053793$ \\
\hline JB113 & $0310705-8054116$ \\
\hline JB114 & $0310502-8056941$ \\
\hline JB115 & $0306195-8058224$ \\
\hline JB116 & $0305645-8059974$ \\
\hline JB117 & $0304290-8058968$ \\
\hline JB118 & $0302926-8055717$ \\
\hline JB119 & $0302952-8054038$ \\
\hline JB120 & $0300507-8056408$ \\
\hline JB121 & $0301441-8062176$ \\
\hline JB122 & $0300685-8060247$ \\
\hline JB123 & $0300600-8059743$ \\
\hline JB124 & $0301291-8058384$ \\
\hline JB125 & $0298039-805756$ \\
\hline JB126 & $0296636-8058854$ \\
\hline JB127 & $0305596-8051193$ \\
\hline JB128 & $0305860-8045122$ \\
\hline JB129 & $0306736-8041433$ \\
\hline JB130 & $0289735-8051710$ \\
\hline JB131 & $0297041-8066051$ \\
\hline JB132 & $0297271-8065647$ \\
\hline JB133 & $0297508-8066610$ \\
\hline JB134 & $0298722-8065295$ \\
\hline JB135 & $0289364-8061017$ \\
\hline JB136 & $0290858-8061934$ \\
\hline JB137 & $0291119-8063047$ \\
\hline JB138 & $0292713-8061300$ \\
\hline JB139 & $0296193-8060112$ \\
\hline JB140 & $0294787-8059325$ \\
\hline JB141 & $0291295-8060157$ \\
\hline JB142 & $0294533-8062448$ \\
\hline JB143 & $0296429-8063437$ \\
\hline JB146 & $0289800-8060000$ \\
\hline JB148 & $0292900-8056735$ \\
\hline & $0292855-8054558$ \\
\hline
\end{tabular}

\begin{tabular}{|c|c|}
\hline & \\
\hline 0 & \\
\hline & \\
\hline 152 & \\
\hline 153 & $70-8$ \\
\hline 154 & $19-8053696$ \\
\hline 155 & $01237-805174$ \\
\hline 6 & 5305 \\
\hline 157 & 204 \\
\hline 200 & \\
\hline 201 & \\
\hline 202 & 104 \\
\hline 203 & $26915-8064287$ \\
\hline 204 & $24877-8073857$ \\
\hline 205 & $26637-8075322$ \\
\hline 206 & $128-80567$ \\
\hline 57 & \\
\hline 208 & \\
\hline 09 & \\
\hline 210 & \\
\hline 211 & \\
\hline 212 & 1 \\
\hline 213 & 29 \\
\hline 214 & 4497 \\
\hline 215 & 059456 \\
\hline 216 & \\
\hline 217 & 01 \\
\hline 218 & \\
\hline 219 & 0 \\
\hline $219 b$ & 0 \\
\hline $220 a$ & 00 \\
\hline $220 \mathrm{~b}$ & 55 \\
\hline 221 & 064775 \\
\hline 22 & \\
\hline 223 & 14 \\
\hline 224 & 34 \\
\hline 225 & TI \\
\hline 226 & \\
\hline 227 & \\
\hline 228 & \\
\hline 229 & 04 \\
\hline & \\
\hline 3231 & 8052223 \\
\hline 3232 & -8052701 \\
\hline 233 & $5-8055707$ \\
\hline 234 & $8-8056474$ \\
\hline 235 & -805213 \\
\hline & \\
\hline & \\
\hline & \\
\hline , & 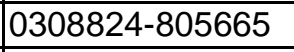 \\
\hline 3240 & $0311037-80584$ \\
\hline
\end{tabular}




\begin{tabular}{|l|l|}
\hline JB241 & $0313741-8054124$ \\
\hline JB242 & $0316721-8050413$ \\
\hline JB243 & $0319716-8052927$ \\
\hline JB244 & $0320650-8056746$ \\
\hline JB245 & $0322344-8054610$ \\
\hline JB246 & $0326106-8059548$ \\
\hline JB247 & $0324844-8063963$ \\
\hline JB248 & $0326257-8063802$ \\
\hline JB249 & $0325517-8065098$ \\
\hline JB250 & $0322419-8069692$ \\
\hline JB251 & $0322412-8062948$ \\
\hline JB308 & $03388-80593$ \\
\hline JB309 & $03249-80497$ \\
\hline JB310 & $0320952-8061937$ \\
\hline JB311 & $0316456-8059619$ \\
\hline JB312 & $0316306-805816$ \\
\hline JB252 & $0322601-8061310$ \\
\hline JB253 & $0325282-8059165$ \\
\hline JB254 & $0327682-8058806$ \\
\hline JB255 & $0331781-8059864$ \\
\hline JB256 & $0335678-8060447$ \\
\hline JB257 & $0335620-8060518$ \\
\hline JB258 & $0332347-8060761$ \\
\hline JB259 & $0332604-8057330$ \\
\hline JB260 & $0332260-8057041$ \\
\hline JB261 & $0330975-8054154$ \\
\hline JB262 & $0331713-8053497$ \\
\hline JB263 & $0332067-8052835$ \\
\hline JB264 & $0331302-8051237$ \\
\hline JB265 & $0315336-8048960$ \\
\hline JB266 & $0313678-8048389$ \\
\hline JB267 & $0310603-8052364$ \\
\hline JB268 & $0326210-8078930$ \\
\hline JB269 & $0321710-8077045$ \\
\hline JB270 & $0321542-8076397$ \\
\hline JB271 & $0315660-8079619$ \\
\hline JB272 & $0308790-8078057$ \\
\hline JB273 & $0306448-8074705$ \\
\hline JB274 & $0304263-8073123$ \\
\hline JB275 & $030567-8071793$ \\
\hline JB276 & $0307600-8070474$ \\
\hline JB277 & $0309484-8071940$ \\
\hline JB278 & $0309412-8071493$ \\
\hline JB279 & $0311409-8072253$ \\
\hline JB280 & $0313479-8075235$ \\
\hline JB281 & $0315102-8076310$ \\
\hline JB282 & $0317925-8076214$ \\
\hline JB283 & $0314084-8072241$ \\
\hline JB285 & $0314694-8071137$ \\
\hline JB287 & $0317027-8070981$ \\
\hline & $0317394-8067734$ \\
\hline
\end{tabular}

\begin{tabular}{|l|l|}
\hline JB288 & $0309390-8068829$ \\
\hline JB289 & $0310580-8067075$ \\
\hline JB290 & $0305242-8068967$ \\
\hline JB291 & $0289469-8060964$ \\
\hline JB292 & $0290822-8061855$ \\
\hline JB293 & $0292682-8061064$ \\
\hline JB294 & $0289853-8060450$ \\
\hline JB295 & $0289737-8060885$ \\
\hline JB296 & $0303665-8072879$ \\
\hline JB297 & $0305207-8068294$ \\
\hline JB298 & $0303285-8062723$ \\
\hline JB299 & $0310287-8072844$ \\
\hline JB300 & $0313643-8075542$ \\
\hline JB301 & $0314275-8071875$ \\
\hline JB302 & $0314650-8071154$ \\
\hline JB303 & $0319742-8052174$ \\
\hline JB304 & $0328666-8053420$ \\
\hline JB305 & $0326118-8047513$ \\
\hline JB306 & $0319344-8049058$ \\
\hline JB307 & $033875-805928$ \\
\hline & \\
\hline$x 1$ & $03387-80592$ \\
\hline
\end{tabular}




\section{Appendix II}

AMS-

Orientation in

data

geographic system

\begin{tabular}{|c|c|c|c|c|c|c|c|c|c|c|}
\hline Sample & rient. & ISC. ${ }^{*} 10-6 \mathrm{SI}$ & L & $F$ & $P^{\prime}$ & $\mathrm{T}$ & $U$ & K1 & $\mathrm{K} 2$ & K3 \\
\hline$x 1$ & $32 / 17$ & 594.36 & 1.041 & .099 & .148 & .409 & 0.38 & $58 / 4$ & $66 / 86$ & $148 / 2$ \\
\hline$x 3$ & $340 / 7$ & 588.82 & .006 & 1.11 & .133 & .886 & 0.88 & $89 / 36$ & $250 / 52$ & $352 / 9$ \\
\hline$x 4$ & $306 / 3$ & 1225.18 & 1.15 & .402 & 1.634 & 0.415 & 0.313 & $214 / 35$ & $32 / 55$ & $123 / 1$ \\
\hline$x 5$ & $232 / 4$ & 2857.66 & $\begin{array}{l}1.127 \\
\end{array}$ & .269 & 1.44 & 0.332 & 0.251 & $228 / 52$ & $35 / 37$ & $130 / 6$ \\
\hline$x 61$ & $338 / 4$ & 7301.56 & 1.21 & 1.513 & 1.856 & 0.369 & 0.234 & $217 / 55$ & $18 / 33$ & $114 / 9$ \\
\hline$x 611$ & $338 / 4$ & 1626.39 & 1.078 & 1.18 & 1.28 & 0.375 & 0.322 & $214 / 48$ & $38 / 42$ & $306 / 2$ \\
\hline x6III & $338 / 4$ & 1212.28 & 1.073 & .211 & 1.311 & 0.46 & 0.408 & $210 / 24$ & $16 / 66$ & $118 / 5$ \\
\hline $\mathrm{x9BI}$ & $70 / 22$ & 2774.82 & 1.23 & .108 & 1.371 & -0.34 & -0.407 & $68 / 17$ & $164 / 18$ & $297 / 65$ \\
\hline x9II & $64 / 21$ & 4685.06 & 1.351 & 1.043 & 1.453 & -0.753 & -0.788 & $41 / 15$ & $139 / 25$ & $283 / 60$ \\
\hline $\mathrm{x} 10 \mathrm{I}$ & $48 / 22$ & 3353.35 & 1.279 & 1.077 & 1.398 & -0.537 & -0.592 & $36 / 14$ & $140 / 45$ & $294 / 42$ \\
\hline $\mathrm{x} 10 \mathrm{II}$ & $48 / 22$ & 4848.15 & 1.241 & 1.11 & 1.386 & -0.35 & -0.419 & $40 / 16$ & $131 / 2$ & $228 / 74$ \\
\hline $\mathrm{x} 11 \mathrm{~B}$ & $68 / 30$ & 3516.04 & 1.277 & 1.092 & 1.411 & -0.471 & -0.534 & $68 / 28$ & $161 / 7$ & $264 / 62$ \\
\hline $\mathrm{jb1a}$ & $132 / 6$ & 470.49 & 1.085 & 1.032 & 1.124 & -0.446 & -0.469 & $79 / 3$ & $170 / 4$ & $311 / 85$ \\
\hline jb1c & $128 / 5$ & 442.52 & 1.073 & 1.041 & 1.118 & -0.275 & -0.3 & $82 / 2$ & $351 / 29$ & $177 / 61$ \\
\hline $\mathrm{jb} 2 \mathrm{~b}$ & $54 / 9$ & 3341.58 & 1.557 & 1.286 & 2.02 & -0.276 & -0.429 & $285 / 3$ & $16 / 10$ & $180 / 79$ \\
\hline jb3aA & $86 / 5$ & 919.29 & 1.05 & 1.057 & 1.11 & 0.067 & 0.041 & $81 / 13$ & $172 / 3$ & $275 / 77$ \\
\hline jb3bA & $42 / 12$ & 1145.49 & 1.045 & 1.11 & 1.165 & 0.406 & 0.375 & $123 / 17$ & $216 / 10$ & $334 / 70$ \\
\hline $\mathrm{jb3bB}$ & $6 / 10$ & 914.92 & 1.062 & 1.07 & .136 & 0.056 & 0.024 & $110 / 10$ & $20 / 4$ & $269 / 80$ \\
\hline jb4aA & $57 / 32$ & 707.24 & 1.117 & 1.05 & 1.177 & -0.39 & -0.424 & $78 / 4$ & $294 / 85$ & $168 / 3$ \\
\hline jb4aB & $156 / 30$ & 899.9 & 1.145 & 1.069 & 1.228 & -0.339 & -0.383 & $76 / 3$ & $175 / 73$ & $345 / 17$ \\
\hline $\mathrm{jb} 4 \mathrm{bB}$ & $3 / 77$ & 600.93 & 1.11 & 065 & .184 & -0.25 & 0.288 & $277 / 5$ & $85 / 85$ & $187 / 1$ \\
\hline $\mathrm{jb} 4 \mathrm{bA}$ & $49 / 72$ & 929.06 & 1.13 & 1.052 & 1.194 & -0.415 & -0.45 & $101 / 7$ & $242 / 81$ & $11 / 6$ \\
\hline $\mathrm{jb} 4 \mathrm{cC}$ & $171 / 74$ & 2270.8 & 1.09 & 1.148 & 1.253 & 0.232 & 0.179 & $64 / 3$ & $326 / 69$ & $155 / 21$ \\
\hline $\mathrm{jb} 4 \mathrm{bC}$ & $44 / 75$ & 640.06 & 1.1 & .021 & .132 & -0.649 & -0.666 & $96 / 13$ & $342 / 59$ & $193 / 27$ \\
\hline $\mathrm{jb} 4 \mathrm{cAl}$ & $174 / 70$ & 3430.11 & 1.089 & 1.125 & 1.227 & 0.161 & 0.111 & $236 / 15$ & $10 / 68$ & $142 / 15$ \\
\hline jb4cAll & $4 / 70$ & 3048.98 & 1.098 & .167 & 1.284 & 0.246 & 0.188 & $238 / 12$ & $358 / 66$ & $144 / 20$ \\
\hline $\mathrm{jb} 4 \mathrm{cB}$ & $169 / 75$ & 3285.24 & 1.099 & 1.146 & 1.261 & 0.181 & 0.125 & $53 / 24$ & $285 / 54$ & $155 / 25$ \\
\hline $\mathrm{jb} 5 \mathrm{aC}$ & $146 / 25$ & 399.73 & 1.053 & 1.039 & 1.095 & -0.143 & -0.165 & $294 / 24$ & $50 / 44$ & $185 / 36$ \\
\hline jb5bA & $48 / 27$ & 6240.78 & 1.138 & 1.08 & 1.233 & -0.254 & -0.302 & $260 / 3$ & $350 / 9$ & $148 / 81$ \\
\hline $\mathrm{jb} 5 \mathrm{bC}$ & $52 / 24$ & 4357.11 & 1.042 & 1.07 & 1.116 & 0.245 & 0.219 & $300 / 9$ & $35 / 31$ & $196 / 57$ \\
\hline jb6aAl & $15 / 47$ & 5684 & 1.05 & 1.108 & 1.166 & 0.356 & 0.322 & $99 / 4$ & $8 / 14$ & $206 / 75$ \\
\hline jb6aAll & $15 / 47$ & 4885.85 & 1.06 & 1.08 & 1.145 & 0.143 & 0.109 & $99 / 6$ & $5 / 30$ & $199 / 59$ \\
\hline jb6aAIII & $15 / 47$ & 5037.44 & 1.076 & 1.05 & 1.131 & -0.199 & -0.229 & $109 / 1$ & $18 / 34$ & $200 / 56$ \\
\hline $\mathrm{jb} 6 \mathrm{aB}$ & $16 / 50$ & 5132.77 & 1.078 & 1.032 & 1.116 & -0.405 & -0.428 & $286 / 16$ & $19 / 12$ & $146 / 70$ \\
\hline jb6bA & $268 / 40$ & 5642.12 & 1.056 & 1.062 & 1.121 & 0.049 & 0.021 & $313 / 6$ & $44 / 13$ & $198 / 76$ \\
\hline jb6bBI & $272 / 39$ & 4781.15 & 1.051 & 1.079 & 1.135 & 0.212 & 0.182 & $310 / 2$ & $40 / 9$ & $209 / 81$ \\
\hline jb6bBII & $272 / 39$ & 4434.91 & 1.071 & 1.028 & 1.105 & -0.423 & -0.442 & $143 / 1$ & $53 / 5$ & $243 / 85$ \\
\hline $\mathrm{jb} 7 \mathrm{aA}$ & $36 / 10$ & 4398.08 & 1.121 & 1.117 & 1.252 & -0.017 & -0.073 & $223 / 3$ & $121 / 77$ & $313 / 13$ \\
\hline jb7aBI & $29 / 10$ & 4088.49 & 1.123 & 1.136 & 1.276 & 0.044 & -0.016 & $234 / 8$ & $114 / 74$ & $326 / 13$ \\
\hline jb7aBII & $29 / 10$ & 3094.05 & 1.133 & 1.081 & 1.227 & -0.23 & -0.278 & $235 / 7$ & $132 / 61$ & $329 / 28$ \\
\hline $\mathrm{jb} 7 \mathrm{aC}$ & $30 / 5$ & 4288.58 & 1.155 & 1.131 & 1.307 & -0.08 & -0.146 & $234 / 13$ & $102 / 71$ & $327 / 14$ \\
\hline jb8aAl & $16 / 4$ & 4784.26 & 1.262 & 1.216 & 1.535 & -0.087 & -0.192 & $108 / 12$ & $2 / 54$ & $206 / 34$ \\
\hline jb8aAll & $16 / 4$ & 3499.88 & 1.241 & 1.209 & 1.5 & -0.065 & -0.165 & $105 / 12$ & $358 / 55$ & $203 / 33$ \\
\hline $\mathrm{jb8aBI}$ & $313 / 6$ & 50.28 & 1.141 & 1.232 & 1.41 & 0.226 & 0.144 & $250 / 41$ & $46 / 47$ & $149 / 12$ \\
\hline jb8aBII & $313 / 6$ & 639.45 & 1.027 & 1.129 & 1.17 & 0.644 & 0.622 & $333 / 47$ & $85 / 19$ & $190 / 36$ \\
\hline jb8aBIII & $313 / 6$ & 1061.94 & 1.046 & 1.2 & 1.272 & 0.606 & 0.569 & $101 / 14$ & $349 / 55$ & $199 / 31$ \\
\hline
\end{tabular}




\begin{tabular}{|c|c|c|c|c|c|c|c|c|c|c|}
\hline Sample & Orient. & Susc. ${ }^{*} 10-6 \mathrm{SI}$ & $\bar{L}$ & $\mathrm{~F}$ & $\mathrm{P}^{\prime}$ & $\bar{T}$ & $\bar{U}$ & $\mathrm{~K} 1$ & $\mathrm{~K} 2$ & K3 \\
\hline jb8aBIV & $313 / 6$ & 117.13 & 1.082 & 1.071 & 1.159 & -0.067 & -0.103 & $310 / 46$ & $84 / 34$ & $192 / 25$ \\
\hline $\mathrm{jb8aCl}$ & $347 / 7$ & 1512.3 & 1.158 & 1.215 & 1.408 & 0.139 & 0.055 & $110 / 13$ & $5 / 49$ & $211 / 38$ \\
\hline jb8aCII & $347 / 7$ & 1202.54 & 1.078 & 1.09 & 1.175 & 0.068 & 0.027 & $119 / 4$ & $218 / 65$ & $27 / 24$ \\
\hline jb8aCIII & $347 / 7$ & 48.65 & 1.082 & 1.059 & 1.146 & -0.156 & -0.189 & $64 / 9$ & $334 / 5$ & $216 / 80$ \\
\hline jb8aCIV & $347 / 7$ & 589.62 & 1.08 & 1.169 & 1.267 & 0.34 & 0.288 & $117 / 16$ & $233 / 57$ & $18 / 28$ \\
\hline jb9bA & $216 / 86$ & 2851.16 & 1.179 & 1.067 & 1.266 & -0.437 & -0.483 & $100 / 7$ & $9 / 12$ & $219 / 76$ \\
\hline jb9bB & $220 / 87$ & 2929.25 & 1.184 & 1.056 & 1.262 & -0.511 & -0.551 & $283 / 2$ & $13 / 10$ & $182 / 80$ \\
\hline $\mathrm{jb9bCl}$ & $220 / 83$ & 2073.97 & 1.077 & 1.146 & 1.237 & 0.296 & 0.247 & $85 / 6$ & $354 / 3$ & $234 / 83$ \\
\hline jb9bCII & $220 / 83$ & 3203.84 & 1.207 & 1.087 & 1.32 & -0.387 & -0.443 & $95 / 9$ & $186 / 4$ & $297 / 80$ \\
\hline jb9bD & $214 / 84$ & 2646.72 & 1.173 & 1.07 & 1.263 & -0.402 & -0.449 & $99 / 1$ & $9 / 4$ & $204 / 86$ \\
\hline jb11aB & $314 / 5$ & 1198.14 & 1.131 & 1.06 & 1.203 & -0.359 & -0.398 & $59 / 5$ & $326 / 36$ & $156 / 53$ \\
\hline $\mathrm{jb} 11 \mathrm{aCl}$ & $294 / 5$ & 956.94 & 1.121 & 1.148 & 1.288 & 0.096 & 0.033 & $255 / 4$ & $348 / 39$ & $160 / 51$ \\
\hline jb11aCII & $294 / 5$ & 1361.99 & 1.114 & 1.104 & 1.23 & -0.041 & -0.093 & $257 / 7$ & $353 / 40$ & $159 / 49$ \\
\hline $\mathrm{jb} 12 \mathrm{~b}$ & $242 / 2$ & 326.3 & 1.007 & 1.059 & 1.073 & 0.794 & 0.788 & $60 / 20$ & $322 / 22$ & $188 / 60$ \\
\hline jb12c & $185 / 6$ & 1799.47 & 1.17 & 1.008 & 1.204 & -0.909 & -0.916 & $273 / 1$ & $181 / 54$ & $4 / 36$ \\
\hline $\mathrm{jb} 13 \mathrm{aA}$ & $96 / 25$ & 2625.14 & 1.165 & 1.034 & 1.22 & -0.641 & -0.668 & $258 / 7$ & $164 / 31$ & $0 / 58$ \\
\hline jb13aB & $85 / 27$ & 2915.22 & 1.184 & 1.039 & 1.247 & -0.631 & -0.661 & $81 / 2$ & $172 / 14$ & $341 / 76$ \\
\hline $\mathrm{jb} 13 \mathrm{aC}$ & $94 / 29$ & 2370.61 & 1.138 & 1.055 & 1.208 & -0.412 & -0.45 & $83 / 5$ & $180 / 56$ & $350 / 34$ \\
\hline jb13aD & $78 / 24$ & 2081.83 & 1.191 & 1.043 & 1.259 & -0.609 & -0.642 & $89 / 7$ & $193 / 61$ & $355 / 28$ \\
\hline jb14aAll & $296 / 86$ & 2936.84 & 1.139 & 1.036 & 1.19 & -0.573 & -0.6 & $293 / 1$ & $203 / 32$ & $24 / 58$ \\
\hline jb14aA & $296 / 86$ & 2331.79 & 1.143 & 1.057 & 1.215 & -0.415 & -0.453 & $298 / 4$ & $208 / 2$ & $92 / 86$ \\
\hline jb14aB & $304 / 83$ & 2861.31 & 1.138 & 1.018 & 1.174 & -0.759 & -0.774 & $300 / 8$ & $199 / 54$ & $35 / 35$ \\
\hline $\mathrm{jb14c}$ & $313 / 80$ & 2521.51 & 1.16 & 1.041 & 1.219 & -0.575 & -0.606 & $313 / 7$ & $220 / 24$ & $58 / 65$ \\
\hline jb16aAl & $158 / 85$ & 1236.72 & 1.027 & 1.044 & 1.072 & 0.23 & 0.213 & $25 / 30$ & $137 / 33$ & $263 / 42$ \\
\hline jb16aAll & $158 / 85$ & 1652.44 & 1.022 & 1.064 & 1.091 & 0.48 & 0.464 & $22 / 25$ & $129 / 31$ & $261 / 48$ \\
\hline jb16aAlll & $158 / 85$ & 1705.52 & 1.018 & 1.087 & 1.114 & 0.647 & 0.632 & $43 / 29$ & $144 / 19$ & $263 / 54$ \\
\hline jb16aBI & $162 / 83$ & 1012.8 & 1.032 & 1.026 & 1.059 & -0.112 & -0.126 & $37 / 13$ & $138 / 39$ & $292 / 48$ \\
\hline jb16aBII & $162 / 83$ & 872.03 & 1.01 & 1.041 & 1.055 & 0.606 & 0.598 & $65 / 35$ & $160 / 7$ & $259 / 54$ \\
\hline jb16aBIII & $162 / 83$ & 763.75 & 1.049 & 1.017 & 1.07 & -0.469 & -0.481 & $349 / 4$ & $86 / 57$ & $256 / 32$ \\
\hline jb16aBIV & $162 / 83$ & 1249.74 & 1.04 & 1.024 & 1.066 & -0.255 & -0.27 & $2 / 4$ & $96 / 50$ & $269 / 40$ \\
\hline $\mathrm{jb} 17 \mathrm{a}$ & $334 / 7$ & 2450.18 & 1.056 & 1.038 & 1.096 & -0.191 & -0.213 & $107 / 6$ & $198 / 10$ & $345 / 78$ \\
\hline $\mathrm{jb} 17 \mathrm{bl}$ & $278 / 1$ & 2855.02 & 1.135 & 1.023 & 1.174 & -0.697 & -0.715 & $129 / 2$ & $221 / 44$ & $38 / 46$ \\
\hline jb17bll & $278 / 1$ & 2369.38 & 1.052 & 1.046 & 1.101 & -0.056 & -0.08 & $118 / 10$ & $209 / 4$ & $320 / 80$ \\
\hline $\mathrm{jb} 17 \mathrm{c}$ & $269 / 1$ & 1873.4 & 1.051 & 1.043 & 1.096 & -0.083 & -0.106 & $113 / 4$ & $204 / 14$ & $7 / 76$ \\
\hline JB17d & $288 / 5$ & 1859.41 & 1.05 & 1.044 & 1.097 & -0.066 & -0.089 & $122 / 3$ & $213 / 14$ & $20 / 75$ \\
\hline $\mathrm{jb18a}$ & $90 / 6$ & 975.85 & 1.057 & 1.036 & 1.096 & -0.219 & -0.24 & $101 / 13$ & $204 / 45$ & $358 / 42$ \\
\hline $\mathrm{jb} 18 \mathrm{~b}$ & $44 / 4$ & 682.32 & 1.061 & 1.008 & 1.076 & -0.754 & -0.761 & $95 / 11$ & $262 / 79$ & $4 / 2$ \\
\hline $\mathrm{jb} 18 \mathrm{c}$ & $110 / 6$ & 1139.58 & 1.053 & 1.041 & 1.097 & -0.123 & -0.146 & $110 / 17$ & $214 / 38$ & $2 / 47$ \\
\hline $\mathrm{jb} 18 \mathrm{~d}$ & $271 / 5$ & 1169.05 & 1.06 & 1.032 & 1.095 & -0.302 & -0.322 & $102 / 20$ & $214 / 46$ & $356 / 38$ \\
\hline $\mathrm{jb} 19 \mathrm{a}$ & $72 / 17$ & 287.26 & 1.004 & 1.02 & 1.026 & 0.655 & 0.652 & $21 / 54$ & $124 / 9$ & $220 / 34$ \\
\hline $\mathrm{jb} 19 \mathrm{~b}$ & $78 / 19$ & 879.16 & 1.067 & 1.051 & 1.122 & -0.137 & -0.165 & $121 / 33$ & $9 / 30$ & $247 / 43$ \\
\hline $\mathrm{jb} 19 \mathrm{c}$ & $84 / 19$ & 1331.8 & 1.037 & 1.055 & 1.094 & 0.191 & 0.169 & $119 / 24$ & $24 / 11$ & $272 / 64$ \\
\hline $\mathrm{jb} 19 \mathrm{~d}$ & $52 / 5$ & 2558.65 & 1.054 & 1.034 & 1.091 & -0.222 & -0.243 & $109 / 19$ & $205 / 19$ & $337 / 63$ \\
\hline $\mathrm{jb20a}$ & $106 / 6$ & 1117.05 & 1.11 & 1.092 & 1.212 & -0.082 & -0.129 & $272 / 12$ & $174 / 31$ & $20 / 56$ \\
\hline $\mathrm{jb} 20 \mathrm{~b}$ & $130 / 6$ & 237.88 & 1.021 & 1.054 & 1.079 & 0.434 & 0.419 & $266 / 2$ & $359 / 52$ & $175 / 38$ \\
\hline $\mathrm{jb} 20 \mathrm{~b}$ & $130 / 6$ & 237.49 & 1.035 & 1.045 & 1.082 & 0.127 & 0.108 & $86 / 1$ & $355 / 39$ & $178 / 51$ \\
\hline $\mathrm{jb} 20 \mathrm{c}$ & $152 / 7$ & 119.68 & 1.018 & 1.012 & 1.03 & -0.198 & -0.205 & $171 / 58$ & $341 / 32$ & $74 / 5$ \\
\hline $\mathrm{jb20d}$ & $134 / 8$ & 1690.86 & 1.046 & 1.172 & 1.238 & 0.559 & 0.523 & $259 / 9$ & $167 / 11$ & $29 / 76$ \\
\hline $\mathrm{jb21a}$ & $220 / 1$ & 2341.64 & 1.07 & 1.054 & 1.128 & -0.122 & -0.152 & $290 / 10$ & $21 / 5$ & $137 / 78$ \\
\hline $\mathrm{jb} 21 \mathrm{~b}$ & $281 / 1$ & 3386.26 & 1.076 & 1.023 & 1.106 & -0.521 & -0.539 & $107 / 6$ & $17 / 4$ & $251 / 83$ \\
\hline
\end{tabular}




\begin{tabular}{|c|c|c|c|c|c|c|c|c|c|c|}
\hline Sample & Orient. & Susc. ${ }^{*} 10-6 \mathrm{SI}$ & $\mathrm{L}$ & $\mathrm{F}$ & $\overline{P^{\prime}}$ & $\mathrm{T}$ & $\mathrm{U}$ & $\overline{\mathrm{K} 1}$ & $\mathrm{~K} 2$ & K3 \\
\hline jb21c & $341 / 1$ & 2980.89 & 1.07 & 1.033 & 1.108 & -0.352 & -0.374 & $104 / 7$ & $194 / 7$ & $328 / 80$ \\
\hline jb21d & $35 / 5$ & 4131.92 & 1.093 & 1.046 & 1.146 & -0.33 & -0.359 & $107 / 0$ & $17 / 7$ & $199 / 83$ \\
\hline $\mathrm{jb21e}$ & $70 / 4$ & 3519.71 & 1.07 & 1.035 & 1.109 & -0.322 & -0.345 & $117 / 6$ & $23 / 35$ & $215 / 55$ \\
\hline jb22a & $144 / 10$ & 2425.28 & 1.05 & 1.111 & 1.171 & 0.367 & 0.333 & $42 / 41$ & $213 / 49$ & $309 / 5$ \\
\hline jb22b & $126 / 6$ & 2919.47 & 1.058 & 1.048 & 1.109 & -0.097 & -0.123 & $83 / 36$ & $\begin{array}{ll}196 / 28 \\
\end{array}$ & $313 / 41$ \\
\hline jb22c & $144 / 6$ & 7856.8 & 1.027 & 1.076 & 1.109 & 0.464 & 0.444 & $63 / 9$ & $154 / 6$ & $277 / 79$ \\
\hline jb22d & $136 / 10$ & 8303.94 & 1.026 & 1.144 & 1.188 & 0.675 & 0.653 & $247 / 3$ & $156 / 26$ & $342 / 64$ \\
\hline jb22e & $134 / 11$ & 6121.22 & 1.055 & 1.041 & 1.099 & -0.143 & -0.166 & $71 / 29$ & $188 / 38$ & $315 / 38$ \\
\hline jb23a & $18 / 2$ & 6006.66 & 1.079 & 1.079 & 1.165 & 0.002 & -0.036 & $263 / 7$ & $3 / 55$ & $169 / 34$ \\
\hline $\mathrm{jb23b}$ & $114 / 3$ & 4968.14 & 1.104 & 1.05 & 1.163 & -0.336 & -0.369 & $89 / 2$ & $326 / 87$ & $180 / 3$ \\
\hline jb23c & $16 / 3$ & 4246.81 & 1.073 & 1.081 & 1.159 & 0.048 & 0.011 & $260 / 3$ & $356 / 65$ & $169 / 25$ \\
\hline jb23dl & $50 / 3$ & 3624.84 & 1.072 & 1.075 & 1.153 & 0.022 & -0.014 & $88 / 2$ & $343 / 80$ & $178 / 9$ \\
\hline jb23dll & $21 / 2$ & 4783.7 & 1.082 & 1.079 & 1.168 & -0.021 & -0.06 & $60 / 7$ & $313 / 68$ & $152 / 21$ \\
\hline jb23el & $64 / 4$ & 5257.77 & 1.094 & 1.053 & 1.153 & -0.271 & -0.303 & $268 / 10$ & $9 / 47$ & $169 / 42$ \\
\hline jb23ell & $64 / 4$ & 4001.46 & 1.044 & 1.104 & 1.156 & 0.392 & 0.361 & $269 / 5$ & $16 / 72$ & $177 / 17$ \\
\hline jb23elll & $64 / 4$ & 4470.1 & 1.049 & 1.072 & 1.125 & 0.178 & 0.15 & $272 / 8$ & $28 / 72$ & $179 / 16$ \\
\hline $\mathrm{jb23fl}$ & $53 / 4$ & 3613.16 & 1.056 & 1.081 & 1.142 & 0.174 & 0.142 & $273 / 26$ & $67 / 61$ & $178 / 11$ \\
\hline jb23fll & $53 / 4$ & 5712.18 & 1.074 & 1.059 & 1.138 & -0.111 & -0.142 & $274 / 18$ & $44 / 64$ & $178 / 19$ \\
\hline jb24a & $44 / 1$ & 86.12 & 1.001 & 1.013 & 1.016 & 0.833 & 0.832 & $127 / 33$ & $352 / 47$ & $234 / 24$ \\
\hline jb24b & $198 / 6$ & 2655.16 & 1.01 & 1.02 & 1.031 & 0.343 & 0.337 & $118 / 40$ & $311 / 49$ & $214 / 6$ \\
\hline $\mathrm{jb} 24 \mathrm{c}$ & $174 / 11$ & 941.75 & 1.003 & 1.016 & 1.021 & 0.696 & 0.694 & $97 / 49$ & $274 / 41$ & $5 / 2$ \\
\hline jb24d & $21 / 2$ & 252.11 & 1.004 & 1.013 & 1.018 & 0.533 & 0.53 & $82 / 65$ & $271 / 25$ & $179 / 3$ \\
\hline $\mathrm{jb} 24 \mathrm{e}$ & $221 / 6$ & 1797.02 & 1.015 & 1.011 & 1.027 & -0.179 & -0.185 & $264 / 3$ & $173 / 23$ & $0 / 66$ \\
\hline $\mathrm{jb} 25 \mathrm{bl}$ & $196 / 5$ & 1187.72 & 1.053 & 1.048 & 1.104 & -0.046 & -0.071 & $51 / 21$ & $158 / 37$ & $297 / 46$ \\
\hline jb25bll & $196 / 5$ & 1164.27 & 1.123 & 1.033 & 1.169 & -0.564 & -0.589 & $66 / 40$ & $270 / 47$ & $167 / 12$ \\
\hline jb25bIII & $196 / 5$ & 572.83 & 1.076 & 1.088 & 1.172 & 0.069 & 0.029 & $280 / 6$ & $29 / 72$ & $188 / 17$ \\
\hline $\mathrm{jb25d}$ & $306 / 5$ & 31573.45 & 1.145 & 1.048 & 1.208 & -0.483 & -0.517 & $105 / 25$ & $243 / 58$ & $5 / 19$ \\
\hline $\mathrm{jb25e}$ & $86 / 2$ & 56781.46 & 1.17 & 1.034 & 1.226 & -0.645 & -0.673 & $116 / 15$ & $359 / 59$ & $213 / 26$ \\
\hline $\mathrm{jb26a}$ & $37 / 12$ & 527.7 & 1.038 & 1.061 & 1.103 & 0.226 & 0.203 & $122 / 56$ & $272 / 30$ & $11 / 14$ \\
\hline jb26c & $25 / 3$ & 439.61 & 1.013 & 1.087 & 1.111 & 0.724 & 0.713 & $132 / 62$ & $258 / 17$ & $355 / 21$ \\
\hline $\mathrm{jb27a}$ & $73 / 6$ & 1635.52 & 1.02 & 1.069 & 1.095 & 0.54 & 0.524 & $80 / 1$ & $170 / 2$ & $323 / 88$ \\
\hline $\mathrm{jb27b}$ & $97 / 2$ & 2018.7 & 1.042 & 1.02 & 1.063 & -0.356 & -0.369 & $72 / 17$ & $172 / 28$ & $314 / 56$ \\
\hline $\mathrm{jb} 28 \mathrm{a}$ & $268 / 4$ & 1871.71 & 1.011 & 1.07 & 1.088 & 0.727 & 0.718 & $271 / 10$ & $5 / 22$ & $157 / 66$ \\
\hline $\mathrm{jb28b}$ & $220 / 2$ & 1891.01 & 1.022 & 1.031 & 1.053 & 0.164 & 0.152 & $271 / 34$ & $29 / 34$ & $150 / 37$ \\
\hline jb28c & $274 / 2$ & 4596.04 & 1.063 & 1.056 & 1.123 & -0.055 & -0.084 & $12 / 34$ & $107 / 8$ & $209 / 55$ \\
\hline $\mathrm{jb28d}$ & $267 / 5$ & 2065.11 & 1.031 & 1.031 & 1.063 & 0.006 & -0.009 & $9 / 27$ & $230 / 56$ & $109 / 19$ \\
\hline $\mathrm{jb28e}$ & $288 / 6$ & 2550.52 & 1.007 & 1.095 & 1.116 & 0.853 & 0.846 & $254 / 28$ & $353 / 17$ & $110 / 57$ \\
\hline $\mathrm{jb29a}$ & $41 / 1$ & 552.14 & 1.055 & 1.055 & 1.026 & -0.061 & -0.074 & $104 / 21$ & $214 / 41$ & $354 / 41$ \\
\hline $\mathrm{jb29b}$ & $174 / 2$ & 705.25 & 1.023 & 1.038 & 1.063 & 0.242 & 0.228 & $104 / 21$ & $239 / 61$ & $6 / 19$ \\
\hline $\mathrm{jb} 29 \mathrm{c}$ & $307 / 7$ & 1885.83 & 1.047 & 1.028 & 1.077 & -0.242 & -0.259 & $105 / 11$ & $216 / 62$ & $10 / 26$ \\
\hline jb30al & $108 / 31$ & 30669.53 & 1.113 & 1.108 & 1.026 & -0.494 & -0.513 & $324 / 28$ & $55 / 2$ & $149 / 61$ \\
\hline jb30all & $108 / 31$ & 30290.34 & 1.287 & 1.287 & 1.15 & 0.111 & 0.048 & $329 / 32$ & $228 / 18$ & $114 / 52$ \\
\hline $\mathrm{jb} 30 \mathrm{~b}$ & $114 / 33$ & 4226.34 & 1.067 & 1.013 & 1.087 & -0.665 & -0.676 & $298 / 11$ & $29 / 4$ & $139 / 78$ \\
\hline $\mathrm{jb} 30 \mathrm{~d}$ & $124 / 16$ & 4943.08 & 1.013 & 1.014 & 1.028 & 0.033 & 0.026 & $20 / 0$ & $110 / 52$ & $289 / 38$ \\
\hline jb31a & $274 / 4$ & 1129.68 & 1.031 & 1.057 & 1.091 & 0.297 & 0.277 & $31 / 60$ & $210 / 30$ & $300 / 1$ \\
\hline jb31c & $324 / 6$ & 534.85 & 1.042 & 1.029 & 1.072 & -0.181 & -0.198 & $16 / 46$ & $283 / 3$ & $190 / 43$ \\
\hline $\mathrm{jb} 31 \mathrm{~d}$ & $271 / 4$ & 464.86 & 1.011 & 1.027 & 1.039 & 0.437 & 0.43 & $275 / 18$ & $18 / 34$ & $162 / 50$ \\
\hline jb31d & $271 / 4$ & 366.84 & 1.02 & 1.023 & 1.044 & 0.079 & 0.068 & $268 / 8$ & $8 / 51$ & $172 / 38$ \\
\hline $\mathrm{jb32a}$ & $116 / 3$ & 153.46 & 1.037 & 1.037 & 1.024 & 0.295 & 0.286 & $293 / 6$ & $202 / 5$ & $75 / 82$ \\
\hline jb32b & $36 / 2$ & 68.3 & 1.042 & 1.042 & 1.02 & -0.03 & -0.04 & $100 / 7$ & $0 / 55$ & $194 / 35$ \\
\hline
\end{tabular}




\begin{tabular}{|c|c|c|c|c|c|c|c|c|c|c|}
\hline Sample & Orient. & Susc. ${ }^{*} 10-6 \mathrm{SI}$ & $\mathrm{L}$ & $\mathrm{F}$ & $\overline{P^{\prime}}$ & $\mathrm{T}$ & $\mathrm{U}$ & $\overline{\mathrm{K} 1}$ & $\mathrm{~K} 2$ & K3 \\
\hline jb32c & $322 / 2$ & 131.03 & 1.018 & 1.053 & 1.075 & 0.486 & 0.473 & $330 / 0$ & $240 / 36$ & $60 / 54$ \\
\hline jb33a & $159 / 2$ & 4965.7 & 1.066 & 1.107 & 1.182 & 0.227 & 0.187 & $275 / 22$ & $146 / 58$ & $15 / 22$ \\
\hline jb33b & $258 / 7$ & 1921.23 & 1.061 & 1.101 & 1.17 & 0.235 & 0.198 & $294 / 4$ & $35 / 71$ & $203 / 18$ \\
\hline jb33c & $217 / 2$ & 236.6 & 1.057 & 1.013 & 1.076 & -0.615 & -0.626 & $103 / 16$ & $352 / 52$ & $204 / 34$ \\
\hline $\mathrm{jb} 34 \mathrm{a}$ & $79 / 6$ & 307.57 & 1.023 & 1.03 & 1.054 & 0.136 & 0.123 & $272 / 6$ & $4 / 19$ & $164 / 70$ \\
\hline jb34c & $223 / 6$ & 1553.88 & 1.01 & 1.162 & 1.197 & 0.871 & 0.861 & $37 / 3$ & $307 / 4$ & $162 / 85$ \\
\hline jb35a & $224 / 7$ & 2625.22 & 1.045 & 1.155 & 1.218 & 0.534 & 0.5 & $108 / 20$ & $334 / 63$ & $205 / 18$ \\
\hline jb35b & $192 / 2$ & 1402.6 & 1.071 & 1.046 & 1.121 & -0.202 & -0.229 & $99 / 22$ & $265 / 68$ & $7 / 5$ \\
\hline $\mathrm{jb} 35 \mathrm{c}$ & $39 / 4$ & 940.49 & 1.044 & 1.054 & 1.101 & 0.096 & 0.072 & $106 / 38$ & $295 / 51$ & $199 / 4$ \\
\hline jb36a & $32 / 2$ & 2610.6 & 1.083 & 1.018 & 1.11 & -0.632 & -0.646 & $91 / 12$ & $186 / 21$ & $332 / 65$ \\
\hline jb37aAl & $96 / 7$ & 1494.02 & 1.126 & 1.167 & 1.316 & 0.13 & 0.063 & $290 / 3$ & $189 / 75$ & $20 / 14$ \\
\hline jb37aAll & $96 / 7$ & 1248.43 & 1.05 & 1.033 & 1.085 & -0.211 & -0.231 & $89 / 21$ & $282 / 69$ & $181 / 4$ \\
\hline jb37aAIII & $96 / 7$ & 1247.25 & 1.081 & 1.06 & 1.146 & -0.147 & -0.18 & $278 / 10$ & $160 / 70$ & $11 / 18$ \\
\hline jb37aBI & $100 / 6$ & 711.94 & 1.043 & 1.039 & 1.084 & -0.048 & -0.068 & $62 / 14$ & $321 / 35$ & $170 / 52$ \\
\hline jb37aBII & $100 / 6$ & 581.98 & 1.095 & 1.006 & 1.115 & -0.875 & -0.88 & $93 / 4$ & $228 / 84$ & $3 / 4$ \\
\hline jb37aBIII & $96 / 7$ & 1402.71 & 1.049 & 1.068 & 1.121 & 0.163 & 0.135 & $134 / 11$ & $225 / 5$ & $340 / 77$ \\
\hline jb37aCl & $286 / 85$ & 1185.84 & 1.064 & 1.018 & 1.087 & -0.554 & -0.568 & $186 / 70$ & $297 / 7$ & $29 / 18$ \\
\hline jb37aCl & $106 / 5$ & 1185.84 & 1.064 & 1.018 & 1.087 & -0.554 & -0.568 & $266 / 3$ & $162 / 77$ & $357 / 12$ \\
\hline jb37aCII & $106 / 5$ & 982.88 & 1.065 & 1.049 & 1.117 & -0.142 & -0.169 & $273 / 2$ & $181 / 39$ & $5 / 51$ \\
\hline jb37aD & $104 / 6$ & 1098.1 & 1.029 & 1.031 & 1.061 & 0.046 & 0.032 & $70 / 2$ & $160 / 12$ & $329 / 78$ \\
\hline jb37aDI & $104 / 6$ & 929.22 & 1.048 & 1.06 & 1.112 & 0.109 & 0.082 & $84 / 19$ & $297 / 67$ & $179 / 11$ \\
\hline jb38a & $164 / 6$ & 8728.79 & 1.224 & 1.015 & 1.274 & -0.865 & -0.878 & $89 / 10$ & $191 / 49$ & $351 / 39$ \\
\hline jb38b & $160 / 5$ & 6261 & 1.167 & 1.101 & 1.288 & -0.234 & -0.292 & $106 / 2$ & $198 / 51$ & $14 / 38$ \\
\hline $\mathrm{jb} 38 \mathrm{c}$ & $162 / 6$ & 1303.74 & 1.107 & 1.096 & 1.214 & -0.05 & -0.098 & $224 / 15$ & $122 / 37$ & $332 / 49$ \\
\hline jb38d & $327 / 6$ & 4348.12 & 1.327 & 1.326 & 1.173 & 0.131 & 0.061 & $298 / 2$ & $194 / 81$ & $28 / 8$ \\
\hline jb39a & $136 / 4$ & 355.9 & 1.051 & 1.054 & 1.108 & 0.028 & 0.002 & $280 / 8$ & $12 / 16$ & $165 / 72$ \\
\hline jb39cl & $228 / 2$ & 134.27 & 1.048 & 1.06 & 1.111 & 0.112 & 0.086 & $208 / 42$ & $311 / 14$ & $55 / 45$ \\
\hline $\mathrm{jb} 40 \mathrm{a}$ & $242 / 9$ & 238.92 & 1.016 & 1.029 & 1.046 & 0.28 & 0.27 & $262 / 23$ & $158 / 30$ & $23 / 51$ \\
\hline jb40bl & $165 / 5$ & 194.94 & 1.03 & 1.004 & 1.037 & -0.748 & -0.752 & $246 / 29$ & $109 / 53$ & $348 / 21$ \\
\hline jb40bll & $165 / 5$ & 174.47 & 1.015 & 1.016 & 1.03 & 0.034 & 0.026 & $248 / 34$ & $31 / 50$ & $145 / 19$ \\
\hline $\mathrm{jb} 40 \mathrm{c}$ & $334 / 7$ & 296.3 & 1.04 & 1.014 & 1.057 & -0.467 & -0.478 & $85 / 21$ & $306 / 63$ & $181 / 16$ \\
\hline $\mathrm{jb} 41 \mathrm{a}$ & $208 / 2$ & 1854.74 & 1.089 & 1.04 & 1.135 & -0.367 & -0.394 & $97 / 2$ & $273 / 88$ & $7 / 0$ \\
\hline $\mathrm{jb} 41 \mathrm{c}$ & $26 / 7$ & 2061.63 & 1.064 & 1.012 & 1.083 & -0.687 & -0.697 & $259 / 2$ & $168 / 13$ & $356 / 77$ \\
\hline $\mathrm{jb} 42 \mathrm{a}$ & $188 / 1$ & 530.45 & 1.059 & 1.08 & 1.144 & 0.15 & 0.117 & $189 / 0$ & $99 / 30$ & $280 / 60$ \\
\hline $\mathrm{jb} 42 \mathrm{~b}$ & $154 / 4$ & 2138.23 & 1.086 & 1.046 & 1.137 & -0.296 & -0.324 & $84 / 18$ & $314 / 63$ & $180 / 19$ \\
\hline $\mathrm{jb} 42 \mathrm{c}$ & $309 / 4$ & 1746.33 & 1.038 & 1.065 & 1.106 & 0.26 & 0.236 & $286 / 84$ & $84 / 6$ & $175 / 2$ \\
\hline $\mathrm{jb} 42 \mathrm{~d}$ & $256 / 6$ & 2634.5 & 1.128 & 1.064 & 1.204 & -0.323 & -0.363 & $68 / 11$ & $320 / 58$ & $164 / 29$ \\
\hline $\mathrm{jb} 43 \mathrm{a}$ & $192 / 2$ & 849.91 & 1.128 & 1.02 & 1.165 & -0.715 & -0.732 & $266 / 17$ & $156 / 48$ & $9 / 37$ \\
\hline $\mathrm{jb} 43 \mathrm{~b}$ & $269 / 4$ & 907.69 & 1.042 & 1.045 & 1.088 & 0.034 & 0.013 & $301 / 16$ & $200 / 32$ & $53 / 53$ \\
\hline $\mathrm{jb} 43 \mathrm{c}$ & $180 / 10$ & 232.68 & 1.014 & 1.07 & 1.091 & 0.663 & 0.651 & $278 / 51$ & $98 / 39$ & $188 / 0$ \\
\hline $\mathrm{jb} 44 \mathrm{a}$ & $35 / 3$ & 4598.33 & 1.012 & 1.146 & 1.179 & 0.838 & 0.827 & $333 / 53$ & $83 / 14$ & $182 / 33$ \\
\hline $\mathrm{jb} 44 \mathrm{c}$ & $32 / 5$ & 7470.51 & 1.031 & 1.084 & 1.122 & 0.451 & 0.428 & $337 / 7$ & $71 / 28$ & $234 / 61$ \\
\hline $\mathrm{jb} 44 \mathrm{~d}$ & $96 / 4$ & 132.63 & 1.024 & 1.052 & 1.079 & 0.375 & 0.359 & $8 / 37$ & $192 / 53$ & $99 / 2$ \\
\hline $\mathrm{jb} 45 \mathrm{a}$ & $353 / 4$ & 1999.62 & 1.039 & 1.022 & 1.062 & -0.27 & -0.283 & $306 / 11$ & $216 / 1$ & $123 / 79$ \\
\hline $\mathrm{jb} 45 \mathrm{~b}$ & $278 / 4$ & 1942.43 & 1.042 & 1.01 & 1.056 & -0.608 & -0.616 & $302 / 13$ & $204 / 32$ & $50 / 55$ \\
\hline $\mathrm{jb} 45 \mathrm{~d}$ & $238 / 2$ & 1543.97 & 1.038 & 1.022 & 1.061 & -0.264 & -0.277 & $118 / 2$ & $28 / 20$ & $213 / 69$ \\
\hline $\mathrm{jb} 45 \mathrm{e}$ & $157 / 3$ & 2028.82 & 1.035 & 1.048 & 1.085 & 0.151 & 0.131 & $272 / 11$ & $11 / 40$ & $170 / 48$ \\
\hline $\mathrm{jb} 46 \mathrm{a}$ & $329 / 2$ & 2286.41 & 1.024 & 1.126 & 1.165 & 0.667 & 0.647 & $111 / 17$ & $8 / 36$ & $221 / 49$ \\
\hline $\mathrm{jb} 46 \mathrm{~b}$ & $149 / 1$ & 2055.13 & 1.072 & 1.009 & 1.09 & -0.778 & -0.786 & $99 / 16$ & $7 / 6$ & $257 / 73$ \\
\hline $\mathrm{jb} 46 \mathrm{~d}$ & $225 / 6$ & 1818.26 & 1.041 & 1.049 & 1.092 & 0.083 & 0.061 & $105 / 15$ & $11 / 15$ & $238 / 69$ \\
\hline
\end{tabular}




\begin{tabular}{|c|c|c|c|c|c|c|c|c|c|c|}
\hline Sample & Orient. & Susc. ${ }^{*} 10-6 \mathrm{SI}$ & $\mathrm{L}$ & $\mathrm{F}$ & $\overline{P^{\prime}}$ & $\mathrm{T}$ & $\mathrm{U}$ & $\overline{\mathrm{K} 1}$ & $\mathrm{~K} 2$ & K3 \\
\hline jb47al & $326 / 6$ & 153.09 & 1.015 & 1.035 & 1.052 & 0.407 & 0.397 & $161 / 6$ & $343 / 84$ & $251 / 0$ \\
\hline jb47all & $326 / 6$ & 182.66 & 1.017 & 1.024 & 1.042 & 0.156 & 0.146 & $343 / 10$ & $104 / 72$ & $250 / 15$ \\
\hline jb47cl & $298 / 7$ & 121.99 & 1.06 & 1.059 & 1.038 & 0.302 & 0.289 & $8 / 11$ & $245 / 71$ & $101 / 16$ \\
\hline jb47cll & $298 / 7$ & 137.86 & 1.06 & 1.058 & 1.016 & -0.431 & -0.443 & $10 / 2$ & $277 / 64$ & $101 / 26$ \\
\hline $\mathrm{jb} 47 \mathrm{~d}$ & $280 / 8$ & 118.52 & 1.06 & 1.039 & 1.101 & -0.207 & -0.23 & $1 / 15$ & $240 / 63$ & $97 / 22$ \\
\hline $\mathrm{jb} 47 \mathrm{e}$ & $280 / 8$ & 154.85 & 1.044 & 1 & 1.051 & -0.992 & -0.992 & $349 / 6$ & $258 / 7$ & $119 / 80$ \\
\hline $\mathrm{jb} 48 \mathrm{a}$ & $159 / 1$ & 2072.7 & 1.006 & 1.032 & 1.041 & 0.658 & 0.653 & $30 / 39$ & $126 / 7$ & $224 / 50$ \\
\hline $\mathrm{jb} 48 \mathrm{~b}$ & $331 / 1$ & 951.2 & 1.067 & 1.082 & 1.156 & 0.095 & 0.059 & $360 / 1$ & $91 / 40$ & $269 / 50$ \\
\hline $\mathrm{jb} 48 \mathrm{c}$ & $238 / 2$ & 686.44 & 1.094 & 1.094 & 1.043 & -0.073 & -0.095 & $355 / 5$ & $261 / 34$ & $92 / 56$ \\
\hline $\mathrm{jb} 48 \mathrm{~d}$ & $166 / 4$ & 4507.11 & 1.17 & 1.17 & 1.094 & 0.141 & 0.102 & $163 / 32$ & $306 / 52$ & $61 / 18$ \\
\hline jb49al & $150 / 2$ & 731.93 & 1.054 & 1.129 & 1.195 & 0.392 & 0.355 & $57 / 31$ & $320 / 11$ & $213 / 56$ \\
\hline jb49all & $150 / 2$ & 851.96 & 1.203 & 1.195 & 1.14 & 0.465 & 0.429 & $281 / 5$ & $13 / 25$ & $182 / 64$ \\
\hline jb49bl & $278 / 10$ & 474.12 & 1.441 & 1.397 & 1.343 & 0.764 & 0.728 & $207 / 8$ & $300 / 22$ & $99 / 67$ \\
\hline jb49bll & $278 / 10$ & 581.28 & 1.451 & 1.404 & 1.352 & 0.779 & 0.744 & $226 / 13$ & $322 / 23$ & $109 / 63$ \\
\hline $\mathrm{jb} 49 \mathrm{~d}$ & $281 / 1$ & 171.34 & 1.022 & 1.028 & 1.051 & 0.123 & 0.111 & $211 / 2$ & $309 / 73$ & $120 / 16$ \\
\hline $\mathrm{jb} 49 \mathrm{~d}$ & $281 / 1$ & 148.94 & 1.018 & 1.044 & 1.064 & 0.421 & 0.409 & $216 / 3$ & $314 / 68$ & $125 / 22$ \\
\hline $\mathrm{jb} 50 \mathrm{a}$ & $328 / 6$ & 2215.7 & 1.077 & 1.104 & 1.19 & 0.145 & 0.102 & $77 / 22$ & $306 / 58$ & $176 / 22$ \\
\hline $\mathrm{jb50a}$ & $328 / 6$ & 2566.75 & 1.283 & 1.271 & 1.194 & 0.481 & 0.434 & $256 / 5$ & $1 / 72$ & $164 / 17$ \\
\hline $\mathrm{jb} 50 \mathrm{~b}$ & $1 / 4$ & 2352.82 & 1.117 & 1.098 & 1.227 & -0.086 & -0.136 & $52 / 36$ & $275 / 45$ & $160 / 22$ \\
\hline $\mathrm{jb} 50 \mathrm{~b}$ & $1 / 4$ & 86.94 & 1.082 & 1.081 & 1.053 & 0.318 & 0.301 & $257 / 39$ & $27 / 38$ & $142 / 28$ \\
\hline $\mathrm{jb} 50 \mathrm{c}$ & $348 / 7$ & 4140.03 & 1.178 & 1.16 & 1.143 & 0.793 & 0.779 & $76 / 42$ & $318 / 27$ & $206 / 36$ \\
\hline jb51a & $126 / 9$ & 92.9 & 1.114 & 1.109 & 1.081 & 0.496 & 0.476 & $49 / 47$ & $205 / 40$ & $306 / 12$ \\
\hline $\mathrm{jb51c}$ & $220 / 0$ & 140.78 & 1.016 & 1.114 & 1.145 & 0.742 & 0.728 & $91 / 48$ & $227 / 33$ & $333 / 23$ \\
\hline $\mathrm{jb} 51 \mathrm{~d}$ & $32 / 2$ & 118.99 & 1.025 & 1.134 & 1.175 & 0.669 & 0.647 & $89 / 67$ & $221 / 16$ & $316 / 16$ \\
\hline $\mathrm{jb} 52 \mathrm{a}$ & $212 / 3$ & 27269.81 & 1.155 & 1.112 & 1.286 & -0.154 & -0.215 & $105 / 34$ & $264 / 55$ & $8 / 10$ \\
\hline $\mathrm{jb} 52 \mathrm{~b}$ & $66 / 2$ & 16674.04 & 1.14 & 1.08 & 1.234 & -0.262 & -0.31 & $112 / 50$ & $258 / 35$ & $1 / 17$ \\
\hline $\mathrm{jb} 52 \mathrm{c}$ & $14 / 5$ & 28334.76 & 1.187 & 1.12 & 1.331 & -0.204 & -0.271 & $107 / 37$ & $248 / 46$ & $1 / 21$ \\
\hline jb53a & $20 / 6$ & 511.06 & 1.202 & 1.199 & 1.125 & 0.296 & 0.254 & $90 / 29$ & $350 / 17$ & $233 / 55$ \\
\hline $\mathrm{jb} 53 \mathrm{~b}$ & $310 / 10$ & 1074.07 & 1.034 & 1.225 & 1.291 & 0.717 & 0.688 & $82 / 30$ & $347 / 9$ & $242 / 58$ \\
\hline jb53c & $296 / 3$ & 215.5 & 1.022 & 1.065 & 1.093 & 0.482 & 0.466 & $78 / 32$ & $346 / 3$ & $252 / 58$ \\
\hline jb53d & $293 / 6$ & 240.48 & 1.039 & 1.16 & 1.219 & 0.591 & 0.56 & $72 / 47$ & $164 / 2$ & $256 / 43$ \\
\hline $\mathrm{jb} 54 \mathrm{a}$ & $124 / 3$ & 1297.52 & 1.039 & 1.146 & 1.201 & 0.56 & 0.529 & $347 / 13$ & $82 / 17$ & $222 / 68$ \\
\hline $\mathrm{jb} 54 \mathrm{c}$ & $35 / 10$ & 1236.63 & 1.049 & 1.14 & 1.203 & 0.466 & 0.43 & $358 / 16$ & $97 / 28$ & $242 / 57$ \\
\hline $\mathrm{jb} 54 \mathrm{~d}$ & $178 / 10$ & 836.61 & 1.044 & 1.123 & 1.178 & 0.457 & 0.425 & $5 / 10$ & $96 / 8$ & $227 / 77$ \\
\hline $\mathrm{jb} 55 \mathrm{a}$ & $229 / 7$ & 106.28 & 1.027 & 1.081 & 1.114 & 0.49 & 0.47 & $347 / 17$ & $79 / 6$ & $188 / 72$ \\
\hline $\mathrm{jb} 55 \mathrm{~b}$ & $358 / 11$ & 34.92 & 1.011 & 1.011 & 1.022 & -0.024 & -0.03 & $135 / 9$ & $241 / 60$ & $41 / 28$ \\
\hline $\mathrm{jb} 55 \mathrm{c}$ & $309 / 2$ & 26.46 & 1.012 & 1.076 & 1.096 & 0.726 & 0.716 & $161 / 6$ & $70 / 13$ & $274 / 75$ \\
\hline jb55dl & $267 / 2$ & 32.61 & 1.01 & 1.048 & 1.063 & 0.644 & 0.636 & $157 / 11$ & $248 / 5$ & $2 / 78$ \\
\hline jb55dll & $267 / 2$ & 48.75 & 1.126 & 1.119 & 1.093 & 0.574 & 0.555 & $303 / 2$ & $213 / 5$ & $54 / 85$ \\
\hline jb56al & $48 / 8$ & 1353.62 & 1.096 & 1.119 & 1.227 & 0.101 & 0.05 & $108 / 13$ & $9 / 34$ & $215 / 53$ \\
\hline jb56all & $48 / 8$ & 1245.18 & 1.375 & 1.36 & 1.254 & 0.471 & 0.41 & $100 / 19$ & $7 / 7$ & $258 / 70$ \\
\hline $\mathrm{jb56b}$ & $342 / 32$ & 344.79 & 1.253 & 1.238 & 1.184 & 0.586 & 0.55 & $45 / 23$ & $294 / 40$ & $157 / 41$ \\
\hline $\mathrm{jb} 57 \mathrm{a}$ & $149 / 2$ & 1411.28 & 1.043 & 1.132 & 1.188 & 0.491 & 0.459 & $44 / 19$ & $312 / 5$ & $209 / 70$ \\
\hline jb57c & $85 / 3$ & 2770.55 & 1.075 & 1.171 & 1.264 & 0.373 & 0.323 & $65 / 30$ & $318 / 27$ & $193 / 48$ \\
\hline $\mathrm{jb} 57 \mathrm{~d}$ & $308 / 2$ & 1377 & 1.071 & 1.107 & 1.187 & 0.193 & 0.152 & $29 / 19$ & $120 / 3$ & $219 / 70$ \\
\hline $\mathrm{jb} 57 e$ & $70 / 0$ & 1108.05 & 1.079 & 1.127 & 1.217 & 0.224 & 0.177 & $209 / 17$ & $299 / 1$ & $31 / 73$ \\
\hline $\mathrm{jb} 58 \mathrm{a}$ & $81 / 5$ & 1174.52 & 1.026 & 1.04 & 1.067 & 0.215 & 0.199 & $44 / 38$ & $291 / 27$ & $176 / 40$ \\
\hline $\mathrm{jb} 58 \mathrm{~b}$ & $81 / 6$ & 451.38 & 1.035 & 1.049 & 1.086 & 0.158 & 0.138 & $288 / 53$ & $109 / 37$ & $19 / 1$ \\
\hline jb58c & $120 / 5$ & 275.15 & 1.035 & 1.078 & 1.119 & 0.37 & 0.346 & $259 / 0$ & $350 / 52$ & $169 / 38$ \\
\hline $\mathrm{jb58d}$ & $21 / 1$ & 334.47 & 1.014 & 1.139 & 1.173 & 0.803 & 0.79 & $90 / 32$ & $307 / 52$ & $192 / 18$ \\
\hline
\end{tabular}




\begin{tabular}{|c|c|c|c|c|c|c|c|c|c|c|}
\hline Sample & Orient. & Susc. ${ }^{*} 10-6 \mathrm{SI}$ & $\mathrm{L}$ & $\mathrm{F}$ & $\overline{P^{\prime}}$ & $\mathrm{T}$ & $\bar{U}$ & $\overline{\mathrm{K} 1}$ & $\mathrm{~K} 2$ & K3 \\
\hline $\mathrm{jb59a}$ & $250 / 7$ & 632.02 & 1.098 & 1.014 & 1.124 & -0.736 & -0.748 & $53 / 9$ & $145 / 16$ & $294 / 72$ \\
\hline $\mathrm{jb} 59 \mathrm{a}$ & $244 / 1$ & 1515.98 & 1.115 & 1.114 & 1.242 & -0.002 & -0.056 & $28 / 14$ & $235 / 75$ & $119 / 7$ \\
\hline jb59c & $38 / 7$ & 4301.14 & 1.029 & 1.054 & 1.086 & 0.296 & 0.277 & $261 / 86$ & $94 / 4$ & $4 / 1$ \\
\hline $\mathrm{jb60a}$ & $330 / 3$ & 193.16 & 1.05 & 1.08 & 1.135 & 0.225 & 0.195 & $35 / 8$ & $303 / 14$ & $154 / 74$ \\
\hline $\mathrm{jb} 60 \mathrm{~b}$ & $286 / 5$ & 1671.96 & 1.024 & 1.071 & 1.1 & 0.49 & 0.473 & $163 / 27$ & $57 / 29$ & $288 / 48$ \\
\hline $\mathrm{jb60d}$ & $220 / 0$ & 344.51 & 1.055 & 1.142 & 1.211 & 0.422 & 0.383 & $184 / 4$ & $93 / 17$ & $287 / 72$ \\
\hline $\mathrm{jb} 61 \mathrm{a}$ & $1 / 12$ & 469.56 & 1.131 & 1.1 & 1.244 & -0.129 & -0.182 & $276 / 7$ & $15 / 52$ & $181 / 38$ \\
\hline $\mathrm{jb} 61 \mathrm{~b}$ & $47 / 2$ & 155.8 & 1.106 & 1.078 & 1.193 & -0.15 & -0.193 & $272 / 1$ & $2 / 24$ & $180 / 66$ \\
\hline $\mathrm{jb61c}$ & $46 / 2$ & 518.65 & 1.072 & 1.15 & 1.237 & 0.334 & 0.287 & $96 / 12$ & $341 / 63$ & $191 / 24$ \\
\hline jb61dl & $10 / 2$ & 358.56 & 1.466 & 1.456 & 1.133 & -0.337 & -0.418 & $87 / 40$ & $204 / 28$ & $318 / 37$ \\
\hline jb61dll & $10 / 2$ & 218.32 & 1.098 & 1.101 & 1.209 & 0.016 & -0.031 & $266 / 39$ & $34 / 38$ & $149 / 29$ \\
\hline $\mathrm{jb62a}$ & $29 / 4$ & 1996.73 & 1.095 & 1.095 & 1.2 & 0.001 & -0.045 & $135 / 62$ & $278 / 23$ & $14 / 15$ \\
\hline $\mathrm{jb} 62 \mathrm{~b}$ & $319 / 3$ & 3369.04 & 1.069 & 1.151 & 1.236 & 0.355 & 0.309 & $119 / 52$ & $283 / 37$ & $19 / 8$ \\
\hline jb62c & $40 / 3$ & 2094.67 & 1.151 & 1.099 & 1.267 & -0.195 & -0.251 & $105 / 39$ & $290 / 51$ & $197 / 2$ \\
\hline $\mathrm{jb62d}$ & $56 / 5$ & 4165.62 & 1.136 & 1.084 & 1.233 & -0.226 & -0.275 & $102 / 53$ & $279 / 37$ & $10 / 1$ \\
\hline $\mathrm{jb63a}$ & $25 / 3$ & 817.16 & 1.047 & 1.089 & 1.143 & 0.296 & 0.266 & $59 / 29$ & $310 / 30$ & $184 / 46$ \\
\hline $\mathrm{jb} 63 \mathrm{~b}$ & $140 / 3$ & 671.01 & 1.052 & 1.053 & 1.108 & 0.017 & -0.009 & $240 / 29$ & $126 / 36$ & $359 / 40$ \\
\hline $\mathrm{jb} 63 \mathrm{c}$ & $328 / 2$ & 718.07 & 1.048 & 1.087 & 1.141 & 0.278 & 0.248 & $58 / 21$ & $310 / 39$ & $169 / 43$ \\
\hline $\mathrm{jb63d}$ & $21 / 6$ & 509.73 & 1.035 & 1.039 & 1.076 & 0.051 & 0.033 & $60 / 35$ & $284 / 45$ & $168 / 24$ \\
\hline $\mathrm{jb64a}$ & $192 / 4$ & 3113.3 & 1.083 & 1.12 & 1.214 & 0.174 & 0.127 & $86 / 18$ & $333 / 52$ & $188 / 33$ \\
\hline $\mathrm{jb} 64 \mathrm{~b}$ & $52 / 17$ & 1114.87 & 1.11 & 1.041 & 1.162 & -0.444 & -0.473 & $92 / 21$ & $295 / 67$ & $186 / 8$ \\
\hline jb64c & $285 / 6$ & 1842.38 & 1.054 & 1.075 & 1.134 & 0.157 & 0.127 & $83 / 0$ & $352 / 75$ & $173 / 15$ \\
\hline $\mathrm{jb65a}$ & $135 / 3$ & 3700.41 & 1.077 & 1.14 & 1.231 & 0.276 & 0.228 & $55 / 16$ & $317 / 28$ & $171 / 58$ \\
\hline $\mathrm{jb} 65 \mathrm{~b}$ & $173 / 2$ & 4076.6 & 1.094 & 1.132 & 1.24 & 0.162 & 0.11 & $60 / 19$ & $317 / 34$ & $174 / 50$ \\
\hline $\mathrm{jb} 65 \mathrm{c}$ & $209 / 2$ & 4634.03 & 1.088 & 1.152 & 1.256 & 0.255 & 0.202 & $65 / 12$ & $326 / 37$ & $170 / 51$ \\
\hline $\mathrm{jb65d}$ & $48 / 16$ & 2946.72 & 1.062 & 1.104 & 1.174 & 0.242 & 0.205 & $47 / 33$ & $299 / 25$ & $180 / 46$ \\
\hline $\mathrm{jb66a}$ & $264 / 4$ & 2035.03 & 1.078 & 1.081 & 1.165 & 0.022 & -0.016 & $54 / 17$ & $318 / 21$ & $180 / 62$ \\
\hline $\mathrm{jb66e}$ & $189 / 0$ & 220.63 & 1.024 & 1.035 & 1.06 & 0.179 & 0.165 & $49 / 30$ & $318 / 2$ & $225 / 60$ \\
\hline $\mathrm{jb66f}$ & $230 / 4$ & 604.25 & 1.062 & 1.047 & 1.112 & -0.131 & -0.157 & $38 / 26$ & $300 / 15$ & $184 / 59$ \\
\hline $\mathrm{jb67a}$ & $348 / 19$ & 3618.39 & 1.116 & 1.017 & 1.147 & -0.738 & -0.752 & $273 / 2$ & $14 / 82$ & $182 / 8$ \\
\hline $\mathrm{jb67b}$ & $352 / 24$ & 3853.87 & 1.052 & 1.088 & 1.147 & 0.252 & 0.22 & $275 / 11$ & $34 / 68$ & $182 / 18$ \\
\hline $\mathrm{jb67d}$ & $357 / 23$ & 65.98 & 1.046 & 1.091 & 1.144 & 0.319 & 0.289 & $100 / 15$ & $267 / 74$ & $9 / 3$ \\
\hline jb68aa & $96 / 5$ & 3024.42 & 1.103 & 1.047 & 1.159 & -0.358 & -0.389 & $104 / 17$ & $333 / 65$ & $199 / 18$ \\
\hline $\mathrm{jb} 68 \mathrm{~b}$ & $157 / 6$ & 2975.92 & 1.082 & 1.039 & 1.127 & -0.344 & -0.37 & $102 / 5$ & $4 / 59$ & $194 / 31$ \\
\hline jb68c & $73 / 6$ & 2122.81 & 1.101 & 1.029 & 1.14 & -0.544 & -0.566 & $107 / 6$ & $9 / 52$ & $202 / 38$ \\
\hline $\mathrm{jb68d}$ & $134 / 7$ & 2749.56 & 1.018 & 1.056 & 1.079 & 0.504 & 0.491 & $96 / 13$ & $314 / 74$ & $188 / 10$ \\
\hline $\mathrm{jb} 69 \mathrm{~b}$ & $206 / 7$ & 996.39 & 1.061 & 1.036 & 1.101 & -0.251 & -0.273 & $53 / 20$ & $146 / 10$ & $261 / 68$ \\
\hline $\mathrm{jb} 69 \mathrm{c}$ & $185 / 7$ & 671.86 & 1.082 & 1.012 & 1.104 & -0.734 & -0.744 & $206 / 12$ & $305 / 35$ & $100 / 53$ \\
\hline $\mathrm{jb} 70 \mathrm{~b}$ & $76 / 4$ & 2223.07 & 1.151 & 1.365 & 1.588 & 0.377 & 0.278 & $73 / 29$ & $334 / 16$ & $219 / 56$ \\
\hline $\mathrm{jb} 70 \mathrm{~b}$ & $101 / 3$ & 2238.43 & 1.241 & 1.328 & 1.651 & 0.134 & 0.011 & $58 / 26$ & $323 / 10$ & $214 / 62$ \\
\hline $\mathrm{jb} 70 \mathrm{c}$ & $83 / 5$ & 1790.61 & 1.548 & 1.517 & 1.379 & 0.541 & 0.465 & $54 / 40$ & $319 / 5$ & $224 / 50$ \\
\hline $\mathrm{jb71a}$ & $7 / 3$ & 84.87 & 1.022 & 1.195 & 1.245 & 0.783 & 0.763 & $44 / 42$ & $313 / 1$ & $221 / 48$ \\
\hline jb71c & $9 / 9$ & 418.53 & 1.067 & 1.12 & 1.197 & 0.274 & 0.232 & $93 / 40$ & $334 / 29$ & $220 / 36$ \\
\hline $\mathrm{jb} 71 \mathrm{~d}$ & $321 / 3$ & 1521 & 1.148 & 1.255 & 1.446 & 0.244 & 0.157 & $80 / 40$ & $339 / 12$ & $235 / 47$ \\
\hline $\mathrm{jb} 72 \mathrm{a}$ & $189 / 7$ & 18435.22 & 1.175 & 1.169 & 1.374 & -0.016 & -0.096 & $109 / 4$ & $202 / 41$ & $15 / 49$ \\
\hline $\mathrm{jb} 72 \mathrm{~b}$ & $196 / 8$ & 21254.01 & 1.296 & 1.23 & 1.595 & -0.113 & -0.226 & $115 / 15$ & $209 / 12$ & $336 / 70$ \\
\hline $\mathrm{jb72c}$ & $163 / 10$ & 23158.54 & 1.135 & 1.121 & 1.272 & -0.052 & -0.112 & $118 / 6$ & $28 / 0$ & $297 / 84$ \\
\hline $\mathrm{jb73a}$ & $307 / 7$ & 2614.62 & 1.016 & 1.084 & 1.109 & 0.67 & 0.657 & $58 / 23$ & $311 / 34$ & $175 / 47$ \\
\hline $\mathrm{jb73b}$ & $343 / 18$ & 77.17 & 1.021 & 1.048 & 1.071 & 0.39 & 0.375 & $50 / 20$ & $251 / 69$ & $143 / 7$ \\
\hline $\mathrm{jb} 73 \mathrm{~b}$ & $343 / 18$ & 4792.74 & 1.054 & 1.156 & 1.228 & 0.467 & 0.428 & $62 / 31$ & $297 / 43$ & $173 / 31$ \\
\hline
\end{tabular}




\begin{tabular}{|c|c|c|c|c|c|c|c|c|c|c|}
\hline Sample & Orient. & Susc. ${ }^{*} 10-6 \mathrm{SI}$ & $\mathrm{L}$ & $\mathrm{F}$ & $\overline{P^{\prime}}$ & $\mathrm{T}$ & $\mathrm{U}$ & $\overline{\mathrm{K} 1}$ & $\mathrm{~K} 2$ & K3 \\
\hline jb73c & $340 / 8$ & 2480.28 & 1.023 & 1.115 & 1.152 & 0.651 & 0.631 & $51 / 39$ & $295 / 29$ & $179 / 37$ \\
\hline $\mathrm{jb} 74 \mathrm{c}$ & $71 / 10$ & 175.64 & 1.015 & 1.067 & 1.088 & 0.634 & 0.622 & $266 / 30$ & $46 / 53$ & $164 / 20$ \\
\hline $\mathrm{jb} 74 \mathrm{~d}$ & $162 / 5$ & 107.58 & 1.038 & 1.053 & 1.093 & 0.164 & 0.142 & $251 / 8$ & $138 / 70$ & $344 / 18$ \\
\hline $\mathrm{jb} 75 \mathrm{a}$ & $100 / 20$ & 285.35 & 1.031 & 1.069 & 1.105 & 0.373 & 0.352 & $89 / 6$ & $351 / 53$ & $183 / 36$ \\
\hline $\mathrm{jb} 75 \mathrm{~b}$ & $94 / 27$ & 257.52 & 1.051 & 1.044 & 1.097 & -0.074 & -0.097 & $93 / 19$ & $248 / 69$ & $360 / 8$ \\
\hline $\mathrm{jb} 75 \mathrm{c}$ & $105 / 13$ & 16.22 & 1.023 & 1.033 & 1.057 & 0.174 & 0.161 & $266 / 41$ & $74 / 48$ & $171 / 6$ \\
\hline jb75dl & $109 / 11$ & 229.55 & 1.1 & 1.023 & 1.133 & -0.616 & -0.634 & $94 / 20$ & $241 / 66$ & $360 / 12$ \\
\hline jb75dll & $109 / 11$ & 345.42 & 1.01 & 1.087 & 1.108 & 0.784 & 0.774 & $327 / 76$ & $84 / 7$ & $176 / 12$ \\
\hline $\mathrm{jb76a}$ & $160 / 7$ & 1899.55 & 1.058 & 1.059 & 1.12 & 0.01 & -0.019 & $124 / 3$ & $32 / 26$ & $221 / 64$ \\
\hline $\mathrm{jb} 76 \mathrm{~b}$ & $167 / 8$ & 1723.97 & 1.07 & 1.03 & 1.105 & -0.394 & -0.414 & $113 / 14$ & $12 / 39$ & $219 / 48$ \\
\hline $\mathrm{jb} 76 \mathrm{c}$ & $183 / 14$ & 2233.82 & 1.049 & 1.071 & 1.125 & 0.177 & 0.148 & $131 / 9$ & $37 / 26$ & $238 / 62$ \\
\hline jb76d & $173 / 4$ & 2568.81 & 1.038 & 1.077 & 1.121 & 0.332 & 0.307 & $102 / 9$ & $9 / 13$ & $226 / 74$ \\
\hline jb76dIII & $173 / 4$ & 238.01 & 1.029 & 1.035 & 1.065 & 0.089 & 0.073 & $137 / 13$ & $39 / 34$ & $244 / 53$ \\
\hline $\mathrm{jb} 76 \mathrm{e}$ & $192 / 10$ & 2040.19 & 1.07 & 1.067 & 1.142 & -0.021 & -0.055 & $116 / 7$ & $23 / 21$ & $225 / 68$ \\
\hline $\mathrm{jb} 77 \mathrm{a}$ & $13 / 5$ & 1497.26 & 1.122 & 1.085 & 1.218 & -0.17 & -0.217 & $115 / 3$ & $206 / 13$ & $13 / 77$ \\
\hline $\mathrm{jb} 77 \mathrm{~b}$ & $20 / 6$ & 132.16 & 1.028 & 1.02 & 1.049 & -0.173 & -0.184 & $241 / 18$ & $142 / 27$ & $0 / 57$ \\
\hline $\mathrm{jb} 77 \mathrm{c}$ & $41 / 5$ & 145.55 & 1.034 & 1.013 & 1.048 & -0.454 & -0.463 & $234 / 14$ & $142 / 10$ & $17 / 72$ \\
\hline $\mathrm{jb} 77 \mathrm{~d}$ & $349 / 5$ & 1835.36 & 1.033 & 1.227 & 1.293 & 0.726 & 0.698 & $30 / 15$ & $121 / 3$ & $223 / 74$ \\
\hline $\mathrm{jb78a}$ & $42 / 8$ & 1822.02 & 1.064 & 1.05 & 1.117 & -0.119 & -0.146 & $99 / 14$ & $8 / 2$ & $270 / 76$ \\
\hline $\mathrm{jb} 78 \mathrm{~b}$ & $44 / 10$ & 1443.84 & 1.034 & 1.058 & 1.095 & 0.263 & 0.242 & $111 / 16$ & $18 / 12$ & $253 / 70$ \\
\hline $\mathrm{jb78cl}$ & $40 / 5$ & 1823.04 & 1.061 & 1.071 & 1.136 & 0.075 & 0.043 & $98 / 20$ & $5 / 9$ & $250 / 68$ \\
\hline $\mathrm{jb} 78 \mathrm{cll}$ & $40 / 5$ & 1977.13 & 1.022 & 1.084 & 1.114 & 0.58 & 0.562 & $113 / 17$ & $15 / 24$ & $235 / 60$ \\
\hline $\mathrm{jb78d}$ & $37 / 5$ & 1958.54 & 1.035 & 1.075 & 1.115 & 0.357 & 0.334 & $124 / 7$ & $32 / 16$ & $237 / 73$ \\
\hline $\mathrm{jb79a}$ & $41 / 5$ & 4235.41 & 1.096 & 1.052 & 1.156 & -0.293 & -0.325 & $71 / 28$ & $174 / 22$ & $296 / 53$ \\
\hline $\mathrm{jb} 79 \mathrm{~b}$ & $14 / 5$ & 5172.2 & 1.089 & 1.063 & 1.158 & -0.164 & -0.2 & $105 / 22$ & $202 / 15$ & $323 / 62$ \\
\hline $\mathrm{jb79c}$ & $61 / 4$ & 4158.75 & 1.087 & 1.096 & 1.191 & 0.045 & 0.002 & $108 / 33$ & $209 / 16$ & $321 / 53$ \\
\hline $\mathrm{jb79d}$ & $35 / 6$ & 3317.7 & 1.104 & 1.07 & 1.183 & -0.187 & -0.227 & $99 / 25$ & $200 / 22$ & $327 / 56$ \\
\hline $\mathrm{jb80a}$ & $73 / 0$ & 2623.91 & 1.072 & 1.023 & 1.101 & -0.51 & -0.527 & $291 / 9$ & $28 / 41$ & $191 / 48$ \\
\hline $\mathrm{jb} 80 \mathrm{~b}$ & $47 / 5$ & 3838.34 & 1.079 & 1.039 & 1.123 & -0.332 & -0.357 & $124 / 4$ & $218 / 37$ & $29 / 53$ \\
\hline $\mathrm{jb80d}$ & $20 / 5$ & 3632.13 & 1.1 & 1.029 & 1.138 & -0.543 & -0.564 & $130 / 10$ & $228 / 36$ & $27 / 52$ \\
\hline jb81a & $319 / 5$ & 377.81 & 1.019 & 1.064 & 1.088 & 0.538 & 0.524 & $262 / 45$ & $46 / 39$ & $152 / 19$ \\
\hline $\mathrm{jb81b}$ & $326 / 9$ & 453.15 & 1.038 & 1.036 & 1.075 & -0.022 & -0.04 & $341 / 39$ & $244 / 9$ & $143 / 49$ \\
\hline jb81c & $333 / 9$ & 417.41 & 1.031 & 1.039 & 1.071 & 0.111 & 0.094 & $26 / 41$ & $189 / 48$ & $289 / 8$ \\
\hline $\mathrm{jb81d}$ & $327 / 8$ & 518.78 & 1.017 & 1.005 & 1.024 & -0.536 & -0.54 & $345 / 39$ & $95 / 23$ & $207 / 42$ \\
\hline $\mathrm{jb81e}$ & $328 / 8$ & 741.87 & 1.02 & 1.047 & 1.07 & 0.398 & 0.384 & $307 / 37$ & $50 / 17$ & $160 / 48$ \\
\hline $\mathrm{jb82a}$ & $211 / 8$ & 1037.57 & 1.044 & 1.061 & 1.108 & 0.154 & 0.129 & $48 / 10$ & $148 / 44$ & $308 / 44$ \\
\hline $\mathrm{jb} 82 \mathrm{~b}$ & $200 / 8$ & 1025.13 & 1.007 & 1.119 & 1.143 & 0.878 & 0.871 & $108 / 0$ & $198 / 22$ & $18 / 68$ \\
\hline jb82c & $181 / 9$ & 552.28 & 1.141 & 1.157 & 1.32 & 0.052 & -0.017 & $253 / 77$ & $78 / 13$ & $348 / 1$ \\
\hline $\mathrm{jb82d}$ & $181 / 6$ & 1011.37 & 1.008 & 1.053 & 1.067 & 0.749 & 0.742 & $240 / 37$ & $139 / 14$ & $32 / 49$ \\
\hline $\mathrm{jb83a}$ & $196 / 10$ & 648.57 & 1.102 & 1.007 & 1.124 & -0.863 & -0.869 & $114 / 11$ & $215 / 43$ & $13 / 44$ \\
\hline $\mathrm{jb} 83 \mathrm{~b}$ & $197 / 6$ & 392.47 & 1.069 & 1.016 & 1.091 & -0.615 & -0.628 & $114 / 1$ & $206 / 68$ & $24 / 22$ \\
\hline $\mathrm{jb} 83 \mathrm{c}$ & $208 / 11$ & 303.22 & 1.025 & 1.061 & 1.09 & 0.403 & 0.385 & $128 / 6$ & $224 / 48$ & $32 / 41$ \\
\hline $\mathrm{jb83d}$ & $192 / 9$ & 531.43 & 1.007 & 1.064 & 1.078 & 0.808 & 0.802 & $139 / 15$ & $285 / 72$ & $46 / 10$ \\
\hline $\mathrm{jb} 84 \mathrm{a}$ & $215 / 10$ & 645.47 & 1.036 & 1.059 & 1.098 & 0.242 & 0.221 & $58 / 15$ & $314 / 42$ & $163 / 44$ \\
\hline $\mathrm{jb} 84 \mathrm{~b}$ & $250 / 7$ & 331.5 & 1.036 & 1.067 & 1.106 & 0.295 & 0.272 & $95 / 43$ & $271 / 47$ & $3 / 2$ \\
\hline $\mathrm{jb84c}$ & $244 / 14$ & 225.11 & 1.019 & 1.025 & 1.044 & 0.132 & 0.122 & $305 / 37$ & $116 / 53$ & $212 / 4$ \\
\hline jb84dl & $252 / 10$ & 205.53 & 1.016 & 1.006 & 1.023 & -0.425 & -0.429 & $225 / 74$ & $77 / 14$ & $345 / 8$ \\
\hline jb84dll & $252 / 10$ & 214.53 & 1.023 & 1.018 & 1.042 & -0.1 & -0.11 & $117 / 4$ & $212 / 48$ & $23 / 42$ \\
\hline $\mathrm{jb85a}$ & $188 / 7$ & 584.97 & 1.022 & 1.083 & 1.113 & 0.57 & 0.552 & $63 / 53$ & $299 / 24$ & $195 / 27$ \\
\hline $\mathrm{jb} 85 \mathrm{~b}$ & $189 / 10$ & 403.19 & 1.025 & 1.028 & 1.053 & 0.049 & 0.036 & $74 / 20$ & $237 / 69$ & $342 / 6$ \\
\hline
\end{tabular}




\begin{tabular}{|c|c|c|c|c|c|c|c|c|c|c|}
\hline Sample & Orient. & Susc. ${ }^{*} 10-6 \mathrm{SI}$ & $\mathrm{L}$ & $\mathrm{F}$ & $\overline{P^{\prime}}$ & $\mathrm{T}$ & $\mathrm{U}$ & $\overline{\mathrm{K} 1}$ & $\mathrm{~K} 2$ & K3 \\
\hline $\mathrm{jb} 85 \mathrm{c}$ & $228 / 9$ & 973.39 & 1.056 & 1.021 & 1.081 & -0.45 & -0.465 & $70 / 31$ & $312 / 38$ & $187 / 37$ \\
\hline $\mathrm{jb85d}$ & $229 / 6$ & 681.51 & 1.063 & 1.033 & 1.1 & -0.312 & -0.333 & $262 / 0$ & $352 / 58$ & $171 / 32$ \\
\hline jb86al & $202 / 5$ & 494.44 & 1.024 & 1.026 & 1.05 & 0.044 & 0.032 & $92 / 6$ & $183 / 9$ & $330 / 79$ \\
\hline jb86all & $202 / 5$ & 510.87 & 1.03 & 1.013 & $\begin{array}{l}1.044 \\
\end{array}$ & -0.396 & -0.404 & $94 / 12$ & $186 / 7$ & $306 / 76$ \\
\hline $\mathrm{jb86c}$ & $233 / 4$ & 709.54 & 1.068 & 1.015 & 1.089 & -0.639 & -0.651 & $92 / 17$ & $183 / 3$ & $283 / 73$ \\
\hline jb86c & $233 / 4$ & 381.26 & 1.015 & 1.023 & 1.039 & 0.204 & 0.195 & $141 / 13$ & $50 / 5$ & $298 / 76$ \\
\hline jb86d & $144 / 3$ & 132.54 & 1.006 & 1.036 & 1.046 & 0.69 & 0.685 & $352 / 18$ & $222 / 64$ & $88 / 19$ \\
\hline jb87al & $353 / 3$ & 1586.51 & 1.055 & 1.087 & 1.148 & 0.219 & 0.186 & $297 / 9$ & $34 / 36$ & $195 / 52$ \\
\hline jb87all & $353 / 3$ & 2751.08 & 1.16 & 1.077 & 1.255 & -0.332 & -0.381 & $281 / 6$ & $191 / 3$ & $72 / 83$ \\
\hline jb87bl & $26 / 4$ & 1837.39 & 1.044 & 1.018 & 1.065 & -0.415 & -0.427 & $270 / 4$ & $10 / 64$ & $178 / 26$ \\
\hline $\mathrm{jb87c}$ & $40 / 4$ & 1452.73 & 1.011 & 1.057 & 1.074 & 0.658 & 0.649 & $297 / 13$ & $28 / 0$ & $118 / 77$ \\
\hline jb87d & $36 / 7$ & 2562.1 & 1.015 & 1.035 & 1.051 & 0.393 & 0.383 & $261 / 17$ & $356 / 14$ & $123 / 68$ \\
\hline $\mathrm{jb88a}$ & $240 / 8$ & 2088.56 & 1.051 & 1.045 & 1.098 & -0.065 & -0.088 & $272 / 9$ & $8 / 32$ & $169 / 56$ \\
\hline $\mathrm{jb} 88 \mathrm{~b}$ & $242 / 16$ & 1735.35 & 1.043 & 1.025 & 1.07 & -0.26 & -0.276 & $286 / 15$ & $186 / 31$ & $38 / 54$ \\
\hline jb88cl & $226 / 15$ & 1926.1 & 1.059 & 1.035 & 1.097 & -0.248 & -0.269 & $124 / 1$ & $33 / 18$ & $216 / 72$ \\
\hline jb88cll & $226 / 15$ & 2093.3 & 1.06 & 1.047 & 1.11 & -0.125 & -0.15 & $296 / 1$ & $26 / 11$ & $198 / 79$ \\
\hline $\mathrm{jb88d}$ & $228 / 16$ & 2171.79 & 1.077 & 1.01 & 1.096 & -0.774 & -0.782 & $261 / 7$ & $356 / 36$ & $161 / 53$ \\
\hline $\mathrm{jb89a}$ & $14 / 14$ & 3296.56 & 1.07 & 1.083 & 1.16 & 0.084 & 0.047 & $103 / 21$ & $194 / 2$ & $289 / 69$ \\
\hline $\mathrm{jb} 89 \mathrm{~b}$ & $38 / 11$ & 2117.3 & 1.071 & 1.091 & 1.169 & 0.118 & 0.079 & $106 / 19$ & $198 / 7$ & $307 / 70$ \\
\hline jb89bll & $38 / 11$ & 1347.77 & 1.04 & 1.004 & 1.049 & -0.801 & -0.805 & $90 / 27$ & $341 / 32$ & $211 / 46$ \\
\hline $\mathrm{jb89c}$ & $20 / 12$ & 4860.02 & 1.074 & 1.129 & 1.215 & 0.259 & 0.214 & $90 / 21$ & $181 / 2$ & $276 / 69$ \\
\hline jb89d & $297 / 3$ & 1577.27 & 1.061 & 1.087 & 1.154 & 0.174 & 0.139 & $89 / 11$ & $356 / 13$ & $219 / 73$ \\
\hline jb90al & $198 / 3$ & 1877.69 & 1.032 & 1.051 & 1.085 & 0.22 & 0.201 & $287 / 3$ & $180 / 79$ & $18 / 10$ \\
\hline jb90all & $198 / 3$ & 1757.92 & 1.032 & 1.042 & 1.076 & 0.129 & 0.111 & $114 / 6$ & $227 / 75$ & $22 / 14$ \\
\hline jb90bl & $224 / 5$ & 2259.02 & 1.064 & 1.022 & 1.09 & -0.481 & -0.497 & $84 / 13$ & $316 / 70$ & $177 / 15$ \\
\hline jb90bll & $224 / 5$ & 2582.04 & 1.054 & 1.024 & 1.082 & -0.374 & -0.39 & $95 / 5$ & $190 / 39$ & $359 / 50$ \\
\hline $\mathrm{jb90c}$ & $75 / 4$ & 2016.71 & 1.056 & 1.017 & 1.077 & -0.532 & -0.544 & $277 / 2$ & $15 / 79$ & $187 / 11$ \\
\hline $\mathrm{jb90d}$ & $54 / 3$ & 1340.89 & 1.065 & 1.016 & 1.087 & -0.596 & -0.609 & $98 / 7$ & $2 / 39$ & $196 / 50$ \\
\hline jb91al & $229 / 4$ & 2525.25 & 1.114 & 1.095 & 1.22 & -0.09 & -0.139 & $263 / 51$ & $70 / 38$ & $165 / 6$ \\
\hline jb91all & $229 / 4$ & 3706.17 & 1.129 & 1.12 & 1.265 & -0.034 & -0.093 & $292 / 74$ & $124 / 16$ & $33 / 3$ \\
\hline jb91bl & $228 / 5$ & 4002.95 & 1.274 & 1.085 & 1.401 & -0.495 & -0.554 & $279 / 9$ & $40 / 74$ & $187 / 14$ \\
\hline jb91bll & $228 / 5$ & 5078.1 & 1.107 & 1.089 & 1.206 & -0.086 & -0.133 & $89 / 10$ & $299 / 79$ & $180 / 6$ \\
\hline jb91c & $244 / 4$ & 4791.99 & 1.048 & 1.076 & 1.128 & 0.22 & 0.192 & $93 / 12$ & $284 / 77$ & $183 / 2$ \\
\hline $\mathrm{jb91d}$ & $261 / 6$ & 6361.87 & 1.16 & 1.081 & 1.258 & -0.314 & -0.364 & $100 / 31$ & $288 / 58$ & $193 / 4$ \\
\hline $\mathrm{jb92a}$ & $343 / 4$ & 2862.43 & 1.041 & 1.112 & 1.163 & 0.455 & 0.426 & $81 / 6$ & $171 / 6$ & $309 / 81$ \\
\hline $\mathrm{jb92b}$ & $344 / 3$ & 10773.95 & 1.057 & 1.123 & 1.191 & 0.35 & 0.312 & $95 / 8$ & $191 / 33$ & $353 / 56$ \\
\hline jb92c & $338 / 6$ & 2494.91 & 1.058 & 1.051 & 1.112 & -0.067 & -0.094 & $93 / 14$ & $192 / 31$ & $341 / 55$ \\
\hline jb92d & $335 / 5$ & 2509.96 & 1.066 & 1.067 & 1.138 & 0.008 & -0.024 & $84 / 10$ & $179 / 25$ & $334 / 63$ \\
\hline $\mathrm{jb93a}$ & $40 / 5$ & 2527.99 & 1.081 & 1.085 & 1.173 & 0.022 & -0.018 & $130 / 19$ & $19 / 46$ & $236 / 37$ \\
\hline $\mathrm{jb93b}$ & $324 / 6$ & 2953.07 & 1.049 & 1.114 & 1.173 & 0.383 & 0.349 & $73 / 25$ & $282 / 62$ & $169 / 12$ \\
\hline jb93c & $68 / 9$ & 2106.45 & 1.072 & 1.051 & 1.126 & -0.167 & -0.196 & $95 / 35$ & $315 / 48$ & $200 / 21$ \\
\hline jb93d & $72 / 8$ & 1279.9 & 1.072 & 1.073 & 1.15 & 0.004 & -0.031 & $74 / 40$ & $297 / 41$ & $185 / 23$ \\
\hline jb94al & $3 / 5$ & 67.96 & 1.043 & 1.024 & 1.069 & -0.27 & -0.285 & $85 / 19$ & $301 / 67$ & $179 / 13$ \\
\hline jb94all & $3 / 5$ & 85.01 & 1.04 & 1.018 & 1.06 & -0.388 & -0.4 & $79 / 8$ & $335 / 58$ & $174 / 30$ \\
\hline jb94b & $1 / 4$ & 74.37 & 1.031 & 1.047 & 1.08 & 0.196 & 0.178 & $75 / 17$ & $293 / 69$ & $169 / 12$ \\
\hline $\mathrm{jb94c}$ & $120 / 4$ & 111.75 & 1.122 & 1.077 & 1.21 & -0.22 & -0.265 & $80 / 21$ & $334 / 35$ & $194 / 47$ \\
\hline $\mathrm{jb95a}$ & $182 / 2$ & 1091.95 & 1.013 & 1.085 & 1.108 & 0.719 & 0.708 & $306 / 12$ & $46 / 39$ & $202 / 48$ \\
\hline $\mathrm{jb95b}$ & $295 / 6$ & 714.1 & 1.035 & 1.063 & 1.102 & 0.289 & 0.267 & $322 / 16$ & $61 / 26$ & $203 / 59$ \\
\hline jb95c & $26 / 6$ & 705.71 & 1.06 & 1.079 & 1.143 & 0.131 & 0.098 & $339 / 22$ & $80 / 26$ & $214 / 55$ \\
\hline jb95dl & $28 / 6$ & 734.48 & 1.04 & 1.095 & 1.143 & 0.401 & 0.374 & $307 / 22$ & $47 / 23$ & $179 / 57$ \\
\hline
\end{tabular}




\begin{tabular}{|c|c|c|c|c|c|c|c|c|c|c|}
\hline Sample & Orient. & Susc. ${ }^{*} 10-6 \mathrm{SI}$ & $\bar{L}$ & $\mathrm{~F}$ & $\mathrm{P}^{\prime}$ & $\bar{T}$ & $\bar{U}$ & $\mathrm{~K} 1$ & $\mathrm{~K} 2$ & K3 \\
\hline jb95dll & $28 / 6$ & 587.53 & 1.023 & 1.09 & 1.121 & 0.588 & 0.57 & $71 / 39$ & $325 / 18$ & $216 / 45$ \\
\hline jb96a & $225 / 7$ & 193.9 & 1.015 & 1.005 & 1.021 & -0.468 & -0.472 & $249 / 78$ & $140 / 4$ & $49 / 11$ \\
\hline $\mathrm{jb96b}$ & $171 / 2$ & 496.11 & 1.017 & 1.044 & 1.063 & 0.442 & 0.43 & $70 / 16$ & $337 / 11$ & $214 / 71$ \\
\hline jb96c & $224 / 6$ & 485.33 & 1.06 & 1.018 & 1.083 & -0.54 & -0.553 & $82 / 7$ & $342 / 58$ & $176 / 32$ \\
\hline $\mathrm{jb97a}$ & $265 / 7$ & 2898.02 & 1.209 & 1.01 & 1.253 & -0.897 & -0.907 & $115 / 8$ & $21 / 23$ & $222 / 65$ \\
\hline $\mathrm{jb97b}$ & $257 / 6$ & 4213.01 & 1.057 & 1.072 & 1.133 & 0.111 & 0.08 & $125 / 9$ & $31 / 28$ & $232 / 60$ \\
\hline$\overline{\mathrm{jb}}$ (97c & $281 / 10$ & 2245.88 & 1.066 & 1.03 & 1.1 & -0.361 & -0.382 & $142 / 17$ & $48 / 11$ & $286 / 70$ \\
\hline $\mathrm{jb97d}$ & $281 / 10$ & 1910.42 & 1.065 & 1.023 & 1.093 & -0.463 & -0.48 & $134 / 8$ & $39 / 30$ & $238 / 59$ \\
\hline jb98al & $303 / 5$ & 2074.33 & 1.06 & 1.033 & 1.096 & -0.289 & -0.309 & $90 / 13$ & $359 / 5$ & $248 / 76$ \\
\hline jb98all & $303 / 5$ & 1408.33 & 1.044 & 1.056 & 1.102 & 0.119 & 0.095 & $122 / 11$ & $31 / 8$ & $266 / 76$ \\
\hline jb98bl & $321 / 4$ & 1693.36 & 1.069 & 1.045 & 1.118 & -0.202 & -0.228 & $77 / 13$ & $345 / 10$ & $219 / 73$ \\
\hline jb98bll & $321 / 4$ & 1505.74 & 1.075 & 1.019 & 1.1 & -0.586 & -0.6 & $71 / 10$ & $162 / 7$ & $289 / 78$ \\
\hline jb98c & $20 / 1$ & 1497.22 & 1.06 & 1.054 & 1.118 & -0.048 & -0.075 & $93 / 15$ & $360 / 13$ & $230 / 70$ \\
\hline jb99al & $304 / 9$ & 1093.15 & 1.071 & 1.02 & 1.098 & -0.553 & -0.569 & $87 / 5$ & $356 / 14$ & $195 / 75$ \\
\hline jb99all & $304 / 9$ & 1575.71 & 1.068 & 1.012 & 1.087 & -0.701 & -0.711 & $80 / 12$ & $338 / 43$ & $183 / 45$ \\
\hline jb99c & $356 / 2$ & 4414.52 & 1.086 & 1.015 & 1.11 & -0.689 & -0.701 & $103 / 1$ & $193 / 35$ & $12 / 55$ \\
\hline jb99d & $13 / 0$ & 4038.79 & 1.089 & 1.021 & 1.119 & -0.61 & -0.627 & $284 / 4$ & $15 / 12$ & $179 / 77$ \\
\hline jb100al & $350 / 6$ & 451.66 & 1.004 & 1.065 & 1.078 & 0.881 & 0.877 & $212 / 25$ & $113 / 18$ & $351 / 59$ \\
\hline jb100all & $350 / 6$ & 500.64 & 1.01 & 1.07 & 1.088 & 0.751 & 0.742 & $109 / 17$ & $208 / 25$ & $349 / 58$ \\
\hline $\mathrm{jb} 100 \mathrm{bl}$ & $324 / 5$ & 275.79 & 1.004 & 1.054 & 1.066 & 0.851 & 0.847 & $265 / 3$ & $172 / 41$ & $359 / 49$ \\
\hline jb100bll & $324 / 5$ & 314.84 & 1.011 & 1.06 & 1.077 & 0.691 & 0.682 & $139 / 27$ & $241 / 22$ & $4 / 54$ \\
\hline jb100c & $176 / 7$ & 256.71 & 1.003 & 1.067 & 1.08 & 0.906 & 0.903 & $98 / 3$ & 190/31 & $2 / 58$ \\
\hline $\mathrm{jb} 100 \mathrm{~d}$ & $322 / 7$ & 452.24 & 1.004 & 1.062 & 1.074 & 0.87 & 0.866 & $163 / 36$ & $263 / 13$ & $10 / 51$ \\
\hline $\mathrm{jb} 101 \mathrm{a}$ & $76 / 7$ & 310.19 & 1.018 & 1.027 & 1.046 & 0.188 & 0.177 & $282 / 0$ & $192 / 41$ & $12 / 49$ \\
\hline $\mathrm{jb} 101 \mathrm{~b}$ & $8 / 13$ & 337.41 & 1.023 & 1.025 & 1.048 & 0.059 & 0.047 & $288 / 8$ & $189 / 46$ & $26 / 43$ \\
\hline $\mathrm{jb} 101 \mathrm{cl}$ & $348 / 6$ & 332.97 & 1.018 & 1.031 & 1.05 & 0.247 & 0.236 & $117 / 12$ & $220 / 47$ & $16 / 41$ \\
\hline jb101cll & $348 / 6$ & 321.14 & 1.032 & 1.019 & 1.053 & -0.243 & -0.255 & $278 / 4$ & $186 / 28$ & $16 / 61$ \\
\hline jb101dl & $188 / 3$ & 277.94 & 1.017 & 1.026 & 1.044 & 0.202 & 0.192 & $272 / 9$ & $170 / 52$ & $9 / 36$ \\
\hline jb101dll & $188 / 3$ & 303.71 & 1.024 & 1.019 & 1.044 & -0.13 & -0.14 & $280 / 5$ & $184 / 48$ & $14 / 41$ \\
\hline jb103a & $4 / 24$ & 637.96 & 1.063 & 1.009 & 1.079 & -0.733 & -0.742 & $121 / 18$ & $273 / 70$ & $28 / 9$ \\
\hline $\mathrm{jb} 103 \mathrm{bl}$ & $344 / 13$ & 36.94 & 1.009 & 1.012 & 1.021 & 0.135 & 0.13 & $78 / 0$ & $237 / 90$ & $348 / 0$ \\
\hline jb103bll & $344 / 13$ & 39.97 & 1.011 & 1.011 & 1.022 & -0.011 & -0.016 & $242 / 24$ & $58 / 66$ & $151 / 1$ \\
\hline jb103c & $348 / 25$ & 28.12 & 1.003 & 1.034 & 1.041 & 0.822 & 0.819 & $251 / 1$ & $161 / 38$ & $343 / 52$ \\
\hline $\mathrm{jb} 103 \mathrm{~d}$ & $356 / 23$ & 403.21 & 1.032 & 1.012 & 1.045 & -0.464 & -0.472 & $81 / 10$ & $345 / 33$ & $186 / 55$ \\
\hline jb104a & $332 / 4$ & 680.74 & 1.023 & 1.012 & 1.036 & -0.312 & -0.32 & $254 / 40$ & $62 / 49$ & $159 / 6$ \\
\hline jb104b & $162 / 1$ & 1109.54 & 1.034 & 1.012 & 1.048 & -0.48 & -0.489 & $251 / 25$ & $89 / 64$ & $344 / 7$ \\
\hline jb104c & $345 / 3$ & 884.89 & 1.024 & 1.014 & 1.038 & -0.259 & -0.268 & $272 / 32$ & $7 / 8$ & $110 / 57$ \\
\hline jb104d & $125 / 2$ & 423.57 & 1.02 & 1.02 & 1.04 & -0.007 & -0.016 & $84 / 65$ & $215 / 17$ & $311 / 18$ \\
\hline $\mathrm{jb} 105 \mathrm{a}$ & $56 / 7$ & 18.02 & 1.03 & 1.05 & 1.082 & 0.242 & 0.224 & $260 / 69$ & $86 / 21$ & $355 / 2$ \\
\hline jb105b & $18 / 6$ & 28.98 & 1.012 & 1.009 & 1.022 & -0.13 & -0.135 & $256 / 67$ & $71 / 23$ & $162 / 2$ \\
\hline jb105c & $208 / 7$ & 3110.85 & 1.016 & 1.092 & 1.118 & 0.696 & 0.683 & $249 / 6$ & $4 / 76$ & $158 / 12$ \\
\hline jb106a & $245 / 2$ & 3403.63 & 1.142 & 1.051 & 1.208 & -0.454 & -0.49 & $89 / 31$ & $192 / 20$ & $309 / 52$ \\
\hline $\mathrm{jb} 106 \mathrm{~b}$ & $202 / 3$ & 3508.91 & 1.062 & 1.103 & 1.173 & 0.238 & 0.201 & $75 / 31$ & $181 / 25$ & $303 / 49$ \\
\hline jb106c & $254 / 3$ & 1833.61 & 1.067 & 1.053 & 1.124 & -0.11 & -0.139 & $92 / 31$ & $202 / 30$ & $326 / 44$ \\
\hline jb106d & $74 / 2$ & 1793.16 & 1.04 & 1.038 & 1.079 & -0.025 & -0.044 & $269 / 36$ & $28 / 34$ & $147 / 37$ \\
\hline $\mathrm{jb107a}$ & $215 / 2$ & 2734.21 & 1.051 & 1.074 & 1.13 & 0.18 & 0.15 & $66 / 9$ & $334 / 7$ & $206 / 79$ \\
\hline $\mathrm{jb} 107 \mathrm{~b}$ & $230 / 0$ & 10644.27 & 1.089 & 1.185 & 1.297 & 0.329 & 0.272 & $88 / 1$ & $178 / 5$ & $344 / 85$ \\
\hline jb107c & $229 / 6$ & 2319.88 & 1.066 & 1.056 & 1.126 & -0.082 & -0.112 & $98 / 0$ & $188 / 12$ & $8 / 78$ \\
\hline jb108b & $344 / 4$ & 1098.16 & 1.086 & 1.019 & 1.113 & -0.636 & -0.651 & $214 / 3$ & $121 / 42$ & $308 / 48$ \\
\hline $\mathrm{jb} 108 \mathrm{bl}$ & $344 / 4$ & 1342.22 & 1.077 & 1.051 & 1.133 & -0.203 & -0.233 & $289 / 9$ & $112 / 81$ & $19 / 0$ \\
\hline
\end{tabular}




\begin{tabular}{|c|c|c|c|c|c|c|c|c|c|c|}
\hline Sample & Orient. & Susc. ${ }^{*} 10-6 \mathrm{SI}$ & $\mathrm{L}$ & $\mathrm{F}$ & $\mathrm{P}^{\prime}$ & $T$ & $\bar{U}$ & $\overline{\mathrm{K} 1}$ & $\mathrm{~K} 2$ & K3 \\
\hline jb108bll & $344 / 4$ & 1274.75 & 1.093 & 1.036 & 1.137 & -0.427 & -0.452 & $286 / 6$ & $54 / 79$ & $195 / 8$ \\
\hline $\mathrm{jb108c}$ & $104 / 3$ & 622.32 & 1.027 & 1.037 & 1.065 & 0.165 & 0.149 & $114 / 2$ & $212 / 76$ & $23 / 13$ \\
\hline jb108d & $350 / 2$ & 476.93 & 1.035 & 1.008 & 1.046 & -0.63 & -0.636 & $284 / 32$ & $152 / 47$ & $31 / 25$ \\
\hline $\mathrm{jb} 109 \mathrm{a}$ & $215 / 10$ & 1017.98 & 1.001 & 1.06 & 1.071 & 0.979 & 0.978 & $298 / 6$ & $191 / 70$ & $30 / 19$ \\
\hline jb109b & $196 / 13$ & 1017.98 & 1.09 & 1.026 & 1.124 & -0.539 & -0.559 & $279 / 25$ & $145 / 57$ & $19 / 21$ \\
\hline jb109c & $241 / 7$ & 1043 & 1.041 & 1.029 & 1.072 & -0.178 & -0.195 & $286 / 33$ & $145 / 50$ & $30 / 19$ \\
\hline jb110a & $336 / 4$ & 424.98 & 1.074 & 1.057 & 1.135 & -0.123 & -0.154 & $286 / 57$ & $40 / 15$ & $139 / 29$ \\
\hline jb110b & $308 / 5$ & 100.57 & 1.005 & 1.01 & 1.015 & 0.336 & 0.333 & $113 / 12$ & $329 / 75$ & $205 / 8$ \\
\hline jb110d & $15 / 3$ & 155.22 & 1.016 & 1.013 & 1.03 & -0.11 & -0.117 & $243 / 11$ & $334 / 4$ & $85 / 78$ \\
\hline jb111a & $313 / 11$ & 3883.92 & 1.008 & 1.092 & 1.112 & 0.829 & 0.822 & $57 / 7$ & $150 / 22$ & $310 / 66$ \\
\hline jb111al & $314 / 10$ & 5034.93 & 1.026 & 1.088 & 1.122 & 0.528 & 0.508 & $60 / 11$ & $153 / 18$ & $298 / 69$ \\
\hline jb111b & $353 / 9$ & 3718.49 & 1.009 & 1.095 & 1.117 & 0.814 & 0.805 & $68 / 13$ & $162 / 16$ & $303 / 69$ \\
\hline jb111c & $318 / 10$ & 5754.97 & 1.007 & 1.096 & 1.116 & 0.861 & 0.855 & $77 / 14$ & 171/16 & $308 / 69$ \\
\hline jb111dll & $314 / 10$ & 4309 & 1.034 & 1.075 & 1.114 & 0.365 & 0.342 & $58 / 16$ & $152 / 14$ & $281 / 69$ \\
\hline jb112b & $190 / 2$ & 690.69 & 1.033 & 1.069 & 1.106 & 0.346 & 0.324 & $290 / 15$ & $185 / 43$ & $34 / 43$ \\
\hline $\mathrm{jb} 112 \mathrm{cl}$ & $302 / 3$ & 515.4 & 1.019 & 1.059 & 1.083 & 0.498 & 0.484 & $220 / 9$ & $125 / 27$ & $326 / 61$ \\
\hline jb112cll & $302 / 3$ & 478.2 & 1.019 & 1.055 & 1.078 & 0.487 & 0.474 & $62 / 18$ & $162 / 28$ & $304 / 55$ \\
\hline jb112d & $56 / 6$ & 476.97 & 1.023 & 1.029 & 1.052 & 0.119 & 0.106 & $267 / 2$ & $176 / 19$ & $3 / 71$ \\
\hline jb113a & $284 / 11$ & 419.06 & 1.118 & 1.115 & 1.034 & -0.393 & -0.416 & $112 / 36$ & $234 / 36$ & $353 / 34$ \\
\hline $\mathrm{jb} 113 \mathrm{~b}$ & $204 / 3$ & 337.22 & 1.076 & 1.076 & 1.03 & -0.177 & -0.195 & $98 / 12$ & $2 / 24$ & $212 / 62$ \\
\hline $\mathrm{jb} 113 \mathrm{c}$ & $184 / 5$ & 955.21 & 1.052 & 1.035 & 1.089 & -0.187 & -0.207 & $90 / 1$ & $181 / 54$ & $359 / 36$ \\
\hline $\mathrm{jb} 114 \mathrm{a}$ & $344 / 4$ & 829.39 & 1.075 & 1.039 & 1.119 & -0.303 & -0.328 & $295 / 27$ & $121 / 63$ & $26 / 3$ \\
\hline jb114b & $320 / 5$ & 791.67 & 1.032 & 1.023 & 1.057 & -0.161 & -0.174 & $94 / 11$ & $194 / 39$ & $351 / 49$ \\
\hline jb114cl & $299 / 5$ & 854.82 & 1.028 & 1.052 & 1.083 & 0.3 & 0.282 & $85 / 4$ & $179 / 41$ & $350 / 49$ \\
\hline jb114cll & $299 / 5$ & 714.44 & 1.06 & 1.042 & 1.105 & -0.164 & -0.188 & $271 / 2$ & $179 / 54$ & $3 / 36$ \\
\hline jb114d & $292 / 6$ & 2410.23 & 1.144 & 1.024 & 1.186 & -0.704 & -0.723 & $108 / 19$ & $314 / 69$ & $201 / 8$ \\
\hline $\mathrm{jb} 114 \mathrm{f}$ & $7 / 7$ & 1571.38 & 1.106 & 1.013 & 1.133 & -0.775 & -0.786 & $276 / 8$ & $172 / 61$ & $10 / 27$ \\
\hline jb115al & $253 / 3$ & 4100.62 & 1.029 & 1.077 & 1.112 & 0.443 & 0.422 & $274 / 2$ & $183 / 28$ & $7 / 62$ \\
\hline jb115all & $253 / 3$ & 4382.42 & 1.064 & 1.07 & 1.139 & 0.045 & 0.012 & $265 / 17$ & $163 / 35$ & $16 / 50$ \\
\hline jb115b & $142 / 4$ & 4369.61 & 1.051 & 1.061 & 1.115 & 0.087 & 0.06 & $282 / 7$ & $187 / 36$ & $21 / 54$ \\
\hline $\mathrm{jb} 115 \mathrm{c}$ & $299 / 2$ & 4283.45 & 1.081 & 1.079 & 1.167 & -0.015 & -0.054 & $279 / 9$ & $184 / 29$ & $25 / 60$ \\
\hline jb115d & $126 / 0$ & 4174.94 & 1.04 & 1.055 & 1.098 & 0.163 & 0.14 & $262 / 4$ & $168 / 49$ & $355 / 41$ \\
\hline jb116al & $292 / 5$ & 146.93 & 1.033 & 1.044 & 1.079 & 0.135 & 0.116 & $260 / 7$ & $169 / 6$ & $42 / 81$ \\
\hline jb116all & $292 / 5$ & 139.7 & 1.032 & 1.032 & 1.065 & -0.012 & -0.027 & $253 / 8$ & $163 / 1$ & $69 / 82$ \\
\hline jb116bl & $320 / 4$ & 133.57 & 1.021 & 1.047 & 1.071 & 0.382 & 0.367 & $275 / 6$ & $184 / 6$ & $51 / 81$ \\
\hline jb116bll & $320 / 4$ & 138.32 & 1.031 & 1.045 & 1.078 & 0.173 & 0.155 & $263 / 7$ & $173 / 3$ & $58 / 82$ \\
\hline jb116c & $302 / 8$ & 137.9 & 1.045 & 1.047 & 1.094 & 0.026 & 0.004 & $260 / 10$ & $170 / 1$ & $72 / 80$ \\
\hline $\mathrm{jb} 116 \mathrm{~d}$ & $325 / 7$ & 135.37 & 1.028 & 1.049 & 1.079 & 0.266 & 0.248 & $255 / 9$ & $164 / 8$ & $33 / 78$ \\
\hline $\mathrm{jb} 117 \mathrm{a}$ & $274 / 4$ & 95.5 & 1.033 & 1.017 & 1.051 & -0.301 & -0.312 & $257 / 4$ & $141 / 81$ & $348 / 8$ \\
\hline $\mathrm{jb} 117 \mathrm{~b}$ & $234 / 1$ & 47.76 & 1.104 & 1.096 & 1.081 & 0.706 & 0.694 & $260 / 16$ & $161 / 30$ & $14 / 55$ \\
\hline $\mathrm{jb117c}$ & $225 / 3$ & 246.17 & 1.063 & 1.09 & 1.16 & 0.168 & 0.132 & $266 / 14$ & $26 / 64$ & $171 / 21$ \\
\hline jb117d & $0 / 6$ & 140.73 & 1.054 & 1.052 & 1.108 & -0.021 & -0.047 & $92 / 11$ & $195 / 50$ & $353 / 38$ \\
\hline $\mathrm{jb} 118 \mathrm{a}$ & $129 / 4$ & 357.04 & 1.067 & 1.025 & 1.097 & -0.442 & -0.46 & $110 / 5$ & $203 / 29$ & $12 / 60$ \\
\hline $\mathrm{jb} 118 \mathrm{~b}$ & $79 / 15$ & 860.06 & 1.106 & 1.045 & 1.16 & -0.396 & -0.426 & $95 / 12$ & $188 / 16$ & $330 / 70$ \\
\hline $\mathrm{jb} 118 \mathrm{c}$ & $77 / 16$ & 661.36 & 1.069 & 1.047 & 1.12 & -0.181 & -0.208 & $87 / 11$ & $181 / 17$ & $325 / 70$ \\
\hline $\mathrm{jb} 118 \mathrm{~d}$ & $118 / 14$ & 433.84 & 1.062 & 1.028 & 1.094 & -0.379 & -0.398 & $101 / 3$ & $8 / 44$ & $194 / 46$ \\
\hline jb119a & $236 / 9$ & 74.35 & 1.004 & 1.021 & 1.027 & 0.653 & 0.649 & $287 / 0$ & $196 / 80$ & $17 / 10$ \\
\hline jb119bl & $214 / 12$ & 96.55 & 1.013 & 1.032 & 1.046 & 0.427 & 0.418 & $297 / 17$ & $91 / 71$ & $205 / 8$ \\
\hline jb119bll & $214 / 12$ & 92.83 & 1.018 & 1.033 & 1.052 & 0.293 & 0.282 & $296 / 30$ & $107 / 60$ & $204 / 4$ \\
\hline jb119c & $220 / 2$ & 90.49 & 1.01 & 1.032 & 1.045 & 0.515 & 0.507 & $289 / 39$ & $115 / 51$ & $22 / 3$ \\
\hline
\end{tabular}




\begin{tabular}{|c|c|c|c|c|c|c|c|c|c|c|}
\hline Sample & Orient. & Susc. ${ }^{*} 10-6 \mathrm{SI}$ & $\mathrm{L}$ & $\mathrm{F}$ & $\overline{P^{\prime}}$ & $T$ & $\bar{U}$ & $\overline{\mathrm{K} 1}$ & $\mathrm{~K} 2$ & K3 \\
\hline jb119dl & $229 / 5$ & 82.19 & 1.021 & 1.014 & 1.035 & -0.208 & -0.217 & $307 / 29$ & $148 / 59$ & $42 / 9$ \\
\hline jb119dll & $229 / 5$ & 58.04 & 1.035 & 1.033 & 1.008 & -0.508 & -0.514 & $303 / 26$ & $188 / 40$ & $56 / 38$ \\
\hline $\mathrm{jb} 120 \mathrm{a}$ & $335 / 3$ & 173.41 & 1.016 & 1.029 & 1.046 & 0.29 & 0.28 & $301 / 42$ & $48 / 17$ & $154 / 43$ \\
\hline jb120b & $338 / 5$ & 185.99 & 1.008 & 1.012 & 1.021 & 0.171 & 0.166 & $321 / 29$ & $221 / 17$ & $104 / 55$ \\
\hline jb120c & $120 / 3$ & 177.32 & 1.012 & 1.025 & 1.038 & 0.331 & 0.323 & $136 / 42$ & $46 / 0$ & $316 / 48$ \\
\hline jb120d & $277 / 5$ & 185.64 & 1.019 & 1.016 & 1.036 & -0.071 & -0.079 & $328 / 36$ & $227 / 15$ & $118 / 50$ \\
\hline jb121al & $162 / 1$ & 127167.51 & 1.039 & 1.019 & 1.059 & -0.339 & -0.351 & $155 / 4$ & $247 / 35$ & $60 / 55$ \\
\hline jb121all & $162 / 1$ & 110748.17 & 1.045 & 1.022 & 1.069 & -0.341 & -0.355 & $336 / 2$ & $244 / 47$ & $68 / 43$ \\
\hline jb121bl & $334 / 2$ & 115897.63 & 1.056 & 1.022 & 1.082 & -0.436 & -0.452 & $149 / 2$ & $240 / 36$ & $56 / 54$ \\
\hline jb121bll & $334 / 2$ & 131833.8 & 1.052 & 1.013 & 1.069 & -0.582 & -0.593 & $151 / 4$ & $244 / 40$ & $55 / 50$ \\
\hline jb121c & $292 / 3$ & 125846.53 & 1.058 & 1.018 & 1.081 & -0.52 & -0.534 & $155 / 3$ & $248 / 55$ & $63 / 34$ \\
\hline jb121d & $277 / 3$ & 126087.98 & 1.055 & 1.012 & 1.073 & -0.627 & -0.637 & $332 / 0$ & $242 / 55$ & $62 / 35$ \\
\hline jb122al & $276 / 2$ & 43763.59 & 1.039 & 1.022 & 1.063 & -0.273 & -0.287 & $233 / 17$ & $333 / 31$ & $118 / 54$ \\
\hline jb122all & $276 / 2$ & 44084.29 & 1.034 & 1.027 & 1.062 & -0.104 & -0.119 & $223 / 15$ & $324 / 36$ & $114 / 50$ \\
\hline jb122bl & $84 / 3$ & 39929.65 & 1.028 & 1.018 & 1.047 & -0.227 & -0.238 & $221 / 3$ & $313 / 41$ & $128 / 49$ \\
\hline jb122bll & $84 / 3$ & 43259.98 & 1.02 & 1.023 & 1.043 & 0.061 & 0.05 & $222 / 4$ & $316 / 38$ & $127 / 51$ \\
\hline jb122c & $166 / 0$ & 43176.95 & 1.025 & 1.027 & 1.053 & 0.045 & 0.032 & $295 / 5$ & $202 / 26$ & $35 / 63$ \\
\hline $\mathrm{jb123a}$ & $330 / 15$ & 1576.34 & 1.049 & 1.027 & 1.078 & -0.289 & -0.306 & $276 / 30$ & $32 / 37$ & $159 / 38$ \\
\hline jb123b & $309 / 15$ & 1935.46 & 1.07 & 1.03 & 1.105 & -0.384 & -0.405 & $242 / 20$ & $5 / 57$ & $142 / 25$ \\
\hline jb123c & $314 / 15$ & 3741.48 & 1.062 & 1.006 & 1.076 & -0.829 & -0.834 & $263 / 29$ & $9 / 27$ & $133 / 49$ \\
\hline $\mathrm{jb} 124 \mathrm{a}$ & $80 / 5$ & 70.73 & 1.087 & 1.022 & 1.118 & -0.59 & -0.607 & $344 / 7$ & $239 / 63$ & $78 / 26$ \\
\hline $\mathrm{jb} 124 \mathrm{~b}$ & $155 / 0$ & 174.98 & 1.041 & 1.065 & 1.11 & 0.214 & 0.189 & $271 / 30$ & $42 / 48$ & $165 / 25$ \\
\hline jb124cl & $57 / 5$ & 91.25 & 1.03 & 1.079 & 1.115 & 0.434 & 0.412 & $260 / 8$ & $1 / 53$ & $164 / 36$ \\
\hline jb124cll & $57 / 5$ & 73.26 & 1.033 & 1.011 & 1.046 & -0.51 & -0.518 & $95 / 1$ & $5 / 24$ & $188 / 66$ \\
\hline jb124dl & $36 / 5$ & 142.16 & 1.059 & 1.058 & 1.022 & -0.23 & -0.243 & $84 / 9$ & $179 / 30$ & $339 / 58$ \\
\hline jb124dll & $36 / 5$ & 145.5 & 1.065 & 1.062 & 1.011 & -0.623 & -0.632 & $290 / 6$ & $23 / 27$ & $189 / 62$ \\
\hline jb125al & $269 / 2$ & 181.03 & 1.009 & 1.008 & 1.017 & -0.084 & -0.089 & $227 / 57$ & $73 / 30$ & $337 / 12$ \\
\hline jb125all & $269 / 2$ & 1668.05 & 1.042 & 1.126 & 1.181 & 0.484 & 0.453 & $217 / 14$ & $71 / 73$ & $309 / 9$ \\
\hline jb125alll & $269 / 2$ & 666.98 & 1.046 & 1.081 & 1.133 & 0.268 & 0.239 & $40 / 18$ & $230 / 72$ & $131 / 3$ \\
\hline $\mathrm{jb} 125 \mathrm{c}$ & $224 / 6$ & 229.8 & 1.021 & 1.01 & 1.032 & -0.343 & -0.35 & $69 / 17$ & $170 / 31$ & $314 / 53$ \\
\hline $\mathrm{jb125d}$ & $2 / 3$ & 405.01 & 1.037 & 1.024 & 1.062 & -0.216 & -0.23 & $287 / 56$ & $160 / 22$ & $59 / 25$ \\
\hline $\mathrm{jb} 125 \mathrm{~d}$ & $2 / 3$ & 202.18 & 1.007 & 1.015 & 1.022 & 0.383 & 0.378 & $234 / 43$ & $14 / 40$ & $123 / 21$ \\
\hline jb126al & $54 / 6$ & 79712.76 & 1.021 & 1.048 & 1.072 & 0.387 & 0.373 & $254 / 14$ & $162 / 7$ & $47 / 74$ \\
\hline jb126all & $54 / 6$ & 87882.68 & 1.034 & 1.027 & 1.062 & -0.118 & -0.132 & $261 / 16$ & $164 / 21$ & $25 / 64$ \\
\hline $\mathrm{jb} 126 \mathrm{cl}$ & $54 / 6$ & 80110.19 & 1.036 & 1.037 & 1.074 & 0.003 & -0.015 & $277 / 13$ & $186 / 4$ & $81 / 76$ \\
\hline jb126cll & $54 / 6$ & 85688.91 & 1.028 & 1.022 & 1.051 & -0.113 & -0.126 & $270 / 7$ & $174 / 42$ & $8 / 47$ \\
\hline $\mathrm{jb} 127 \mathrm{a}$ & $136 / 5$ & 2724.97 & 1.014 & 1.051 & 1.069 & 0.561 & 0.551 & $124 / 6$ & $216 / 22$ & $21 / 67$ \\
\hline $\mathrm{jb} 127 \mathrm{~b}$ & $116 / 4$ & 2584.47 & 1.057 & 1.029 & 1.09 & -0.312 & -0.331 & $293 / 4$ & $200 / 43$ & $27 / 47$ \\
\hline $\mathrm{jb127c}$ & $127 / 5$ & 1530.95 & 1.015 & 1.037 & 1.053 & 0.427 & 0.417 & $285 / 3$ & $193 / 22$ & $23 / 68$ \\
\hline $\mathrm{jb} 127 \mathrm{~d}$ & $168 / 9$ & 559.42 & 1.008 & 1.016 & 1.024 & 0.33 & 0.325 & $113 / 12$ & $224 / 60$ & $17 / 27$ \\
\hline $\mathrm{jb128a}$ & $29 / 4$ & 2274.34 & 1.027 & 1.024 & 1.052 & -0.05 & -0.063 & $48 / 57$ & $303 / 9$ & $207 / 31$ \\
\hline jb128bl & $19 / 5$ & 1305.43 & 1.025 & 1.019 & 1.045 & -0.132 & -0.143 & $43 / 58$ & $145 / 8$ & $240 / 31$ \\
\hline jb128bll & $19 / 5$ & 1670.59 & 1.025 & 1.045 & 1.072 & 0.274 & 0.258 & $349 / 54$ & $155 / 35$ & $250 / 7$ \\
\hline jb128blll & $19 / 5$ & 1550.58 & 1.018 & 1.056 & 1.078 & 0.519 & 0.506 & $15 / 49$ & $132 / 21$ & $236 / 33$ \\
\hline $\mathrm{jb} 128 \mathrm{cl}$ & $322 / 5$ & 2287.23 & 1.058 & 1.056 & 1.117 & -0.017 & -0.044 & $32 / 50$ & $127 / 4$ & $220 / 40$ \\
\hline jb128cll & $322 / 5$ & 1672.77 & 1.005 & 1.042 & 1.052 & 0.773 & 0.769 & $44 / 43$ & $300 / 15$ & $195 / 44$ \\
\hline jb128d & $12 / 6$ & 1075.91 & 1.025 & 1.021 & 1.047 & -0.07 & -0.081 & $30 / 53$ & $294 / 5$ & $200 / 36$ \\
\hline jb129al & $113 / 5$ & 147.77 & 1.015 & 1.034 & 1.051 & 0.375 & 0.365 & $61 / 39$ & $296 / 35$ & $181 / 32$ \\
\hline jb129all & $113 / 5$ & 148.23 & 1.004 & 1.028 & 1.035 & 0.725 & 0.721 & $21 / 51$ & $286 / 4$ & $192 / 39$ \\
\hline jb129bl & $348 / 4$ & 545.99 & 1.018 & 1.055 & 1.076 & 0.5 & 0.486 & $88 / 10$ & $343 / 57$ & $184 / 31$ \\
\hline
\end{tabular}




\begin{tabular}{|c|c|c|c|c|c|c|c|c|c|c|}
\hline Sample & Orient. & Susc. ${ }^{*} 10-6 \mathrm{SI}$ & L & $\mathrm{F}$ & $\mathrm{P}^{\prime}$ & $T$ & $\bar{U}$ & $\overline{\mathrm{K} 1}$ & K2 & K3 \\
\hline jb129bll & $348 / 4$ & 501.02 & 1.011 & 1.053 & 1.07 & 0.652 & 0.643 & $276 / 8$ & $20 / 60$ & $182 / 29$ \\
\hline jb130al & $354 / 6$ & 2018.8 & 1.017 & 1.016 & 1.033 & -0.039 & -0.047 & $139 / 1$ & $47 / 52$ & $230 / 38$ \\
\hline jb130all & $354 / 6$ & 1852.23 & 1.035 & 1.018 & 1.055 & -0.328 & -0.34 & $109 / 6$ & $16 / 21$ & $214 / 68$ \\
\hline jb130bl & $333 / 11$ & 3779.21 & 1.054 & 1.015 & 1.073 & -0.555 & -0.567 & $280 / 19$ & $188 / 7$ & $77 / 70$ \\
\hline jb130bll & $333 / 11$ & 4946.16 & 1.071 & 1.018 & 1.096 & -0.583 & -0.597 & $283 / 14$ & $142 / 72$ & $16 / 11$ \\
\hline jb130c & $349 / 14$ & 2461.87 & 1.018 & 1.045 & 1.066 & 0.41 & 0.397 & $263 / 19$ & $166 / 20$ & $33 / 62$ \\
\hline jb130e & $346 / 17$ & 3291.06 & 1.031 & 1.049 & 1.083 & 0.223 & 0.204 & $275 / 13$ & $181 / 18$ & $38 / 68$ \\
\hline jb131a & $86 / 3$ & 7055.89 & 1.145 & 1.125 & 1.289 & -0.071 & -0.134 & $277 / 43$ & $104 / 47$ & $10 / 4$ \\
\hline jb131b & $142 / 5$ & 4808.72 & 1.139 & 1.079 & 1.232 & -0.26 & -0.308 & $282 / 38$ & $119 / 51$ & $18 / 9$ \\
\hline jb132al & $283 / 5$ & 3221.22 & 1.033 & 1.109 & 1.152 & 0.524 & 0.499 & $267 / 33$ & $70 / 55$ & $172 / 8$ \\
\hline jb132all & $283 / 5$ & 2793.64 & 1.062 & 1.082 & 1.15 & 0.137 & 0.103 & $269 / 47$ & $65 / 40$ & $165 / 12$ \\
\hline jb132bl & $254 / 3$ & 2805.22 & 1.036 & 1.093 & 1.136 & 0.428 & 0.402 & $269 / 45$ & $61 / 41$ & $164 / 14$ \\
\hline jb132bll & $254 / 3$ & 3325.77 & 1.055 & 1.086 & 1.147 & 0.217 & 0.184 & $271 / 54$ & $63 / 33$ & $162 / 13$ \\
\hline jb132c & $307 / 3$ & 3488.59 & 1.052 & 1.086 & 1.145 & 0.237 & 0.205 & $268 / 37$ & $64 / 50$ & $169 / 12$ \\
\hline jb132d & $271 / 3$ & 3654.81 & 1.047 & 1.087 & 1.14 & 0.287 & 0.257 & $268 / 66$ & $54 / 20$ & $149 / 12$ \\
\hline jb133a & $230 / 5$ & 4996.01 & 1.044 & 1.048 & 1.094 & 0.044 & 0.022 & $245 / 10$ & $81 / 79$ & $336 / 3$ \\
\hline jb133bl & $234 / 5$ & 6238.88 & 1.109 & 1.035 & 1.155 & -0.498 & -0.524 & $256 / 4$ & $5 / 79$ & $165 / 11$ \\
\hline jb133bll & $234 / 5$ & 6010.16 & 1.127 & 1.089 & 1.229 & -0.166 & -0.216 & $241 / 16$ & $72 / 74$ & $332 / 3$ \\
\hline jb133blll & $234 / 5$ & 6698.76 & 1.032 & 1.059 & 1.095 & 0.289 & 0.268 & $242 / 5$ & $97 / 84$ & $332 / 3$ \\
\hline $\mathrm{jb133c}$ & $210 / 5$ & 8979.72 & 1.063 & 1.064 & 1.131 & 0.007 & -0.024 & $242 / 7$ & $119 / 77$ & $333 / 11$ \\
\hline jb133d & $192 / 3$ & 7468.1 & 1.08 & 1.037 & 1.122 & -0.363 & -0.387 & $246 / 8$ & $31 / 80$ & $155 / 6$ \\
\hline jb134al & $1 / 10$ & 405.17 & 1.012 & 1.028 & 1.041 & 0.412 & 0.404 & $262 / 4$ & $155 / 76$ & $353 / 13$ \\
\hline jb134all & $1 / 10$ & 437.25 & 1.015 & 1.018 & 1.033 & 0.099 & 0.091 & $260 / 13$ & $29 / 70$ & $166 / 15$ \\
\hline jb134b & $18 / 13$ & 340.45 & 1.02 & 1.012 & 1.033 & -0.252 & -0.26 & $265 / 4$ & $98 / 86$ & $355 / 1$ \\
\hline $\mathrm{jb134c}$ & $4 / 11$ & 263.91 & 1.014 & 1.02 & 1.035 & 0.175 & 0.167 & $283 / 7$ & $24 / 55$ & $188 / 34$ \\
\hline jb135al & $217 / 8$ & 84.68 & 1.007 & 1.017 & 1.025 & 0.391 & 0.385 & $260 / 41$ & $21 / 30$ & $134 / 34$ \\
\hline jb135all & $217 / 8$ & 74.86 & 1.004 & 1.011 & 1.015 & 0.49 & 0.488 & $237 / 78$ & $65 / 11$ & $335 / 2$ \\
\hline jb135bl & $101 / 5$ & 73.77 & 1.012 & 1.023 & 1.036 & 0.313 & 0.305 & $276 / 46$ & $35 / 25$ & $143 / 34$ \\
\hline jb135bll & $101 / 5$ & 79.32 & 1.004 & 1.014 & 1.019 & 0.591 & 0.588 & $46 / 29$ & $285 / 44$ & $157 / 33$ \\
\hline $\mathrm{jb} 135 \mathrm{c}$ & $222 / 4$ & 78.02 & 1.015 & 1.007 & 1.023 & -0.337 & -0.342 & $296 / 61$ & $80 / 24$ & $177 / 15$ \\
\hline $\mathrm{jb135d}$ & $298 / 3$ & 70.16 & 1.01 & 1.014 & 1.024 & 0.168 & 0.162 & $285 / 39$ & $78 / 48$ & $184 / 14$ \\
\hline jb136a & $328 / 7$ & 128.42 & 1.017 & 1.019 & 1.036 & 0.058 & 0.05 & $270 / 56$ & $109 / 32$ & $13 / 9$ \\
\hline jb136b & $309 / 13$ & 111.81 & 1.016 & 1.008 & 1.025 & -0.331 & -0.336 & $277 / 61$ & $148 / 19$ & $50 / 21$ \\
\hline jb136c & $326 / 6$ & 133.17 & 1.017 & 1.025 & 1.042 & 0.188 & 0.178 & $66 / 64$ & $191 / 16$ & $287 / 20$ \\
\hline $\mathrm{jb136d}$ & $3 / 3$ & 127.86 & 1.008 & 1.02 & 1.029 & 0.4 & 0.394 & $309 / 26$ & $167 / 58$ & $48 / 17$ \\
\hline jb137al & $334 / 13$ & 144.11 & 1.012 & 1.007 & 1.019 & -0.298 & -0.302 & $260 / 21$ & $100 / 67$ & $353 / 7$ \\
\hline jb137all & $334 / 13$ & 115.63 & 1.018 & 1.01 & 1.028 & -0.291 & -0.297 & $285 / 40$ & $56 / 39$ & $170 / 27$ \\
\hline jb137bl & $337 / 12$ & 118.86 & 1.017 & 1.012 & 1.03 & -0.162 & -0.169 & $281 / 22$ & $46 / 55$ & $179 / 26$ \\
\hline jb137bll & $337 / 12$ & 115.99 & 1.009 & 1.018 & 1.027 & 0.358 & 0.353 & $274 / 16$ & $51 / 69$ & $180 / 14$ \\
\hline jb137c & $330 / 14$ & 126.44 & 1.016 & 1.007 & 1.024 & -0.378 & -0.383 & $281 / 30$ & $31 / 31$ & $157 / 44$ \\
\hline $\mathrm{jb137d}$ & $355 / 14$ & 106.24 & 1.009 & 1.019 & 1.029 & 0.37 & 0.364 & $294 / 42$ & $101 / 47$ & $199 / 7$ \\
\hline jb138al & $150 / 3$ & 866.82 & 1.037 & 1.058 & 1.099 & 0.213 & 0.19 & $206 / 1$ & $296 / 40$ & $115 / 50$ \\
\hline jb138all & $150 / 3$ & 1075.01 & 1.074 & 1.025 & 1.105 & -0.484 & -0.502 & $7 / 58$ & $211 / 30$ & $115 / 11$ \\
\hline jb138bl & $195 / 7$ & 1016.2 & 1.018 & 1.038 & 1.057 & 0.359 & 0.347 & $352 / 46$ & $238 / 21$ & $131 / 37$ \\
\hline jb138bl & $195 / 7$ & 982 & 1.016 & 1.041 & 1.059 & 0.442 & 0.43 & $352 / 46$ & $240 / 20$ & $133 / 37$ \\
\hline jb138bll & $195 / 7$ & 886.7 & 1.019 & 1.013 & 1.032 & -0.181 & -0.188 & $318 / 52$ & $209 / 15$ & $108 / 34$ \\
\hline jb138c & $350 / 6$ & 399.57 & 1.024 & 1.022 & 1.046 & -0.038 & -0.049 & $5 / 63$ & $253 / 11$ & $157 / 25$ \\
\hline jb138d & $248 / 3$ & 607.4 & 1.037 & 1.017 & 1.056 & -0.355 & -0.366 & $322 / 48$ & $231 / 0$ & $141 / 42$ \\
\hline $\mathrm{jb} 139 \mathrm{a}$ & $113 / 6$ & 1087.33 & 1.008 & 1.045 & 1.058 & 0.691 & 0.685 & $349 / 59$ & $210 / 24$ & $111 / 18$ \\
\hline jb139b & $135 / 3$ & 1351.66 & 1.022 & 1.043 & 1.068 & 0.315 & 0.301 & $348 / 73$ & $230 / 8$ & $138 / 15$ \\
\hline
\end{tabular}




\begin{tabular}{|c|c|c|c|c|c|c|c|c|c|c|}
\hline Sample & Orient. & Susc. ${ }^{*} 10-6 \mathrm{SI}$ & L & $\mathrm{F}$ & $\mathrm{P}^{\prime}$ & T & $U$ & K1 & K2 & K3 \\
\hline jb139cl & $351 / 3$ & 1095.35 & 1.012 & 1.061 & 1.079 & 0.667 & 0.657 & $2 / 61$ & $217 / 24$ & $120 / 14$ \\
\hline jb139cll & $351 / 3$ & 910.12 & 1.007 & 1.045 & 1.057 & 0.74 & 0.734 & $207 / 2$ & $305 / 78$ & $117 / 12$ \\
\hline jb139dl & $329 / 6$ & 2554.02 & 1.013 & 1.016 & 1.029 & 0.096 & 0.089 & $244 / 10$ & 118/74 & $336 / 13$ \\
\hline jb139dll & $329 / 6$ & 2755.93 & 1.019 & 1.038 & 1.059 & 0.325 & 0.312 & $44 / 22$ & $231 / 67$ & $135 / 2$ \\
\hline jb140al & $346 / 6$ & 1602.22 & 1.037 & 1.051 & 1.09 & 0.155 & 0.133 & $237 / 15$ & $342 / 45$ & $134 / 42$ \\
\hline jb140all & $346 / 6$ & 848.04 & 1.032 & 1.032 & 1.065 & -0.006 & -0.022 & $229 / 22$ & $350 / 51$ & $125 / 30$ \\
\hline jb140b & $354 / 6$ & 721.92 & 1.015 & 1.026 & 1.041 & 0.273 & 0.264 & $218 / 9$ & $319 / 53$ & $121 / 36$ \\
\hline $\mathrm{jb} 140 \mathrm{c}$ & $44 / 5$ & 944.75 & 1.031 & 1.037 & 1.07 & 0.091 & 0.075 & $225 / 26$ & $341 / 42$ & $113 / 36$ \\
\hline jb140d & $354 / 5$ & 1251.56 & 1.021 & 1.044 & 1.067 & 0.36 & 0.346 & $219 / 13$ & $321 / 41$ & $115 / 47$ \\
\hline jb140d & $354 / 5$ & 1437.19 & 1.026 & 1.062 & 1.092 & 0.411 & 0.393 & $229 / 22$ & $342 / 44$ & $120 / 38$ \\
\hline jb141a & $275 / 6$ & 86.24 & 1.008 & 1.004 & 1.013 & -0.33 & -0.333 & $24 / 77$ & $270 / 6$ & $179 / 12$ \\
\hline jb141bll & $290 / 6$ & 85.97 & 1.013 & 1.036 & 1.051 & 0.472 & 0.462 & $76 / 75$ & $292 / 12$ & $200 / 9$ \\
\hline jb141cl & $110 / 4$ & 96.29 & 1.01 & 1.002 & 1.014 & -0.609 & -0.611 & $293 / 60$ & $159 / 22$ & $61 / 20$ \\
\hline jb141cll & $110 / 4$ & 84.42 & 1.006 & 1.006 & 1.012 & 0.012 & 0.009 & $254 / 14$ & $16 / 64$ & $158 / 21$ \\
\hline jb141d & $66 / 10$ & 89.21 & 1.006 & 1.009 & 1.015 & 0.185 & 0.181 & $254 / 42$ & $85 / 48$ & $349 / 6$ \\
\hline jb141e & $76 / 8$ & 106.25 & 1.01 & 1.005 & 1.015 & -0.331 & -0.334 & $315 / 82$ & $208 / 2$ & $118 / 8$ \\
\hline $\mathrm{jb} 142 \mathrm{a}$ & $29 / 7$ & 3908.32 & 1.02 & 1.011 & 1.032 & -0.277 & -0.284 & $18 / 39$ & $274 / 16$ & $167 / 46$ \\
\hline jb142bl & $25 / 7$ & 3423.71 & 1.024 & 1.004 & 1.031 & -0.707 & -0.711 & $344 / 25$ & $94 / 35$ & $227 / 44$ \\
\hline jb142bll & $25 / 7$ & 4513.26 & 1.015 & 1.05 & 1.068 & 0.536 & 0.525 & $304 / 31$ & $38 / 5$ & $137 / 59$ \\
\hline jb142bIII & $25 / 7$ & 4458.07 & 1.008 & 1.033 & 1.044 & 0.592 & 0.586 & $329 / 53$ & $66 / 5$ & $160 / 37$ \\
\hline jb142c & $30 / 7$ & 3919.94 & 1.032 & 1.03 & 1.063 & -0.021 & -0.036 & $331 / 39$ & $230 / 14$ & $125 / 48$ \\
\hline $\mathrm{jb} 142 \mathrm{~d}$ & $3 / 4$ & 4525.67 & 1.038 & 1.018 & 1.058 & -0.357 & -0.369 & $271 / 23$ & $19 / 36$ & $156 / 46$ \\
\hline jb143a & $47 / 6$ & 740.25 & 1.028 & 1.03 & 1.059 & 0.044 & 0.03 & $287 / 9$ & $30 / 55$ & $191 / 34$ \\
\hline jb143bl & $2 / 5$ & 1374.03 & 1.026 & 1.047 & 1.075 & 0.291 & 0.274 & $359 / 43$ & $258 / 12$ & $156 / 44$ \\
\hline jb143bll & $2 / 5$ & 1696.88 & 1.019 & 1.047 & 1.068 & 0.424 & 0.411 & $267 / 22$ & $13 / 34$ & $151 / 47$ \\
\hline jb143c & $49 / 4$ & 1033.91 & 1.005 & 1.071 & 1.086 & 0.854 & 0.849 & $36 / 11$ & $298 / 35$ & $141 / 52$ \\
\hline jb143d & $53 / 5$ & 1542.12 & 1.035 & 1.035 & 1.071 & 0.001 & -0.016 & $294 / 42$ & $40 / 17$ & $146 / 43$ \\
\hline $\mathrm{jb} 144 \mathrm{a}$ & $84 / 2$ & 112.04 & 1.011 & 1.01 & 1.021 & -0.047 & -0.052 & $271 / 50$ & 110/38 & $12 / 9$ \\
\hline jb144b & $130 / 2$ & 99.25 & 1.005 & 1.007 & 1.012 & 0.218 & 0.215 & $209 / 21$ & $304 / 12$ & $63 / 66$ \\
\hline jb144cll & $131 / 6$ & 105.14 & 1.008 & 1.015 & 1.023 & 0.277 & 0.272 & $276 / 47$ & $97 / 43$ & $7 / 1$ \\
\hline jb144dl & $100 / 7$ & 104.26 & 1.003 & 1.009 & 1.013 & 0.448 & 0.445 & $112 / 49$ & $241 / 28$ & $346 / 27$ \\
\hline jb144dII & $100 / 7$ & 107.58 & 1.009 & 1.015 & 1.024 & 0.252 & 0.247 & $301 / 46$ & $36 / 5$ & $130 / 44$ \\
\hline jb145al & $297 / 2$ & 389.86 & 1.016 & 1.089 & 1.115 & 0.681 & 0.668 & $119 / 64$ & $294 / 26$ & $25 / 2$ \\
\hline jb145all & $297 / 2$ & 212.92 & 1.012 & 1.036 & 1.051 & 0.484 & 0.475 & $211 / 73$ & $109 / 4$ & $18 / 17$ \\
\hline jb145bl & $234 / 6$ & 121.21 & 1.027 & 1.049 & 1.079 & 0.291 & 0.273 & $220 / 62$ & $315 / 3$ & $47 / 28$ \\
\hline jb145bll & $234 / 6$ & 128.13 & 1.015 & 1.035 & 1.052 & 0.383 & 0.372 & $275 / 61$ & $120 / 27$ & $25 / 11$ \\
\hline $\mathrm{jb} 145 \mathrm{c}$ & $234 / 2$ & 147.9 & 1.04 & 1.008 & 1.052 & -0.666 & -0.673 & $265 / 62$ & $74 / 28$ & $166 / 4$ \\
\hline $\mathrm{jb} 145 \mathrm{~d}$ & $260 / 4$ & 354.34 & 1.007 & 1.059 & 1.073 & 0.785 & 0.779 & $236 / 76$ & $110 / 8$ & $19 / 11$ \\
\hline jb146al & $2 / 2$ & 1845.41 & 1.005 & 1.006 & 1.012 & 0.084 & 0.082 & $313 / 21$ & $217 / 14$ & $95 / 65$ \\
\hline jb146all & $2 / 2$ & 1968.28 & 1.004 & 1.005 & 1.009 & 0.078 & 0.076 & $304 / 32$ & $210 / 7$ & $110 / 57$ \\
\hline jb146bl & $10 / 1$ & 3525.3 & 1.006 & 1.014 & 1.02 & 0.424 & 0.42 & $295 / 14$ & $39 / 44$ & $192 / 42$ \\
\hline jb146bll & $10 / 1$ & 2872.65 & 1.006 & 1.001 & 1.007 & -0.682 & -0.683 & $319 / 15$ & $56 / 25$ & $201 / 60$ \\
\hline $\mathrm{jb146c}$ & $356 / 7$ & 2865.78 & 1.008 & 1.006 & 1.014 & -0.195 & -0.198 & $312 / 5$ & $42 / 9$ & $192 / 80$ \\
\hline jb146d & $331 / 4$ & 8112.63 & 1.01 & 1.007 & 1.017 & -0.159 & -0.163 & $315 / 16$ & $221 / 14$ & $90 / 68$ \\
\hline jb147al & $351 / 9$ & 77087.43 & 1.044 & 1.006 & 1.055 & -0.775 & -0.779 & $0 / 3$ & $262 / 68$ & $91 / 22$ \\
\hline jb147all & $351 / 9$ & 82657.55 & 1.04 & 1.013 & 1.056 & -0.518 & -0.528 & $183 / 5$ & $92 / 4$ & $325 / 83$ \\
\hline jb147bl & $98 / 5$ & 79098.27 & 1.055 & 1.013 & 1.073 & -0.612 & -0.622 & $49 / 9$ & $315 / 24$ & $158 / 64$ \\
\hline jb147bll & $98 / 5$ & 79510.38 & 1.044 & 1.014 & 1.062 & -0.511 & -0.522 & $37 / 12$ & $277 / 68$ & $131 / 19$ \\
\hline jb148a & $48 / 9$ & 1792.55 & 1.018 & 1.036 & 1.055 & 0.319 & 0.307 & $286 / 17$ & $30 / 37$ & $176 / 48$ \\
\hline jb148c & $90 / 3$ & 2091.04 & 1.018 & 1.026 & 1.045 & 0.172 & 0.161 & $285 / 23$ & $23 / 19$ & $150 / 60$ \\
\hline
\end{tabular}




\begin{tabular}{|c|c|c|c|c|c|c|c|c|c|c|}
\hline Sample & Orient. & Susc. ${ }^{*} 10-6 \mathrm{SI}$ & $\bar{L}$ & $\mathrm{~F}$ & $\mathrm{P}^{\prime}$ & $\bar{T}$ & $\bar{U}$ & $\mathrm{~K} 1$ & $\mathrm{~K} 2$ & K3 \\
\hline jb148dl & $74 / 3$ & 2783.55 & 1.009 & 1.027 & 1.038 & 0.509 & 0.502 & $301 / 14$ & $34 / 12$ & $164 / 71$ \\
\hline jb148dll & $74 / 3$ & 2354.47 & 1.007 & 1.025 & 1.035 & 0.553 & 0.548 & $318 / 17$ & $50 / 7$ & $161 / 72$ \\
\hline jb148dIII & $74 / 3$ & 2288.74 & 1.017 & 1.029 & 1.046 & 0.256 & 0.245 & $302 / 24$ & $43 / 24$ & $172 / 56$ \\
\hline jb149al & $173 / 7$ & 1834.78 & 1.055 & 1.023 & 1.082 & -0.413 & -0.429 & $295 / 17$ & 181/53 & $36 / 31$ \\
\hline jb149all & $173 / 7$ & 3547.11 & 1.036 & 1.069 & 1.11 & 0.306 & 0.282 & $297 / 31$ & $137 / 57$ & $33 / 9$ \\
\hline jb149bl & $168 / 10$ & 2524.2 & 1.031 & 1.047 & 1.08 & 0.194 & 0.175 & $281 / 41$ & $149 / 38$ & $36 / 26$ \\
\hline jb149bll & $168 / 10$ & 5111.96 & 1.102 & 1.039 & 1.15 & -0.432 & -0.46 & $292 / 23$ & $31 / 21$ & $159 / 58$ \\
\hline jb149c & $179 / 7$ & 3126.71 & 1.04 & 1.071 & 1.114 & 0.275 & 0.25 & $310 / 28$ & $170 / 56$ & $50 / 18$ \\
\hline jb149d & $186 / 8$ & 3846.69 & 1.063 & 1.06 & 1.127 & -0.018 & -0.048 & $285 / 33$ & $127 / 55$ & $22 / 10$ \\
\hline jb150al & $128 / 5$ & 208.99 & 1.013 & 1.015 & 1.028 & 0.083 & 0.076 & $280 / 5$ & $11 / 12$ & $169 / 77$ \\
\hline jb150all & $128 / 5$ & 247.05 & 1.015 & 1.037 & 1.054 & 0.407 & 0.396 & $110 / 1$ & $19 / 42$ & $202 / 48$ \\
\hline jb150b & $48 / 4$ & 1428.91 & 1.085 & 1.14 & 1.239 & 0.233 & 0.183 & $324 / 33$ & $60 / 9$ & $163 / 56$ \\
\hline jb150c & $84 / 2$ & 412.83 & 1.036 & 1.031 & 1.068 & -0.07 & -0.087 & $289 / 43$ & $28 / 10$ & $129 / 45$ \\
\hline jb150d & $87 / 2$ & 456.14 & 1.036 & 1.027 & 1.064 & -0.151 & -0.166 & $285 / 39$ & $185 / 11$ & $82 / 49$ \\
\hline jb151a & $354 / 3$ & 788.49 & 1.048 & 1.043 & 1.092 & -0.054 & -0.076 & $121 / 74$ & $290 / 16$ & $21 / 3$ \\
\hline jb151al & $354 / 3$ & 1609.74 & 1.191 & 1.117 & 1.333 & -0.227 & -0.293 & $145 / 65$ & $313 / 24$ & $45 / 5$ \\
\hline jb151all & $354 / 3$ & 714.93 & 1.015 & 1.052 & 1.071 & 0.537 & 0.525 & $138 / 49$ & $281 / 35$ & $24 / 19$ \\
\hline jb151bl & $334 / 3$ & 630.75 & 1.031 & 1.03 & 1.061 & -0.017 & -0.032 & $123 / 52$ & $344 / 31$ & $242 / 20$ \\
\hline jb151bll & $334 / 3$ & 609.35 & 1.1 & 1.025 & 1.135 & -0.592 & -0.611 & $209 / 77$ & $102 / 4$ & $11 / 13$ \\
\hline $\mathrm{jb151c}$ & $330 / 6$ & 1371.21 & 1.042 & 1.118 & 1.171 & 0.456 & 0.426 & $162 / 70$ & $260 / 3$ & $351 / 20$ \\
\hline jb151d & $313 / 6$ & 821.28 & 1.063 & 1.033 & 1.099 & -0.309 & -0.33 & $136 / 84$ & $291 / 5$ & $21 / 2$ \\
\hline jb152al & $296 / 2$ & 642.44 & 1.043 & 1.016 & 1.061 & -0.459 & -0.47 & $310 / 42$ & $171 / 40$ & $61 / 22$ \\
\hline jb152all & $296 / 2$ & 438.03 & 1.031 & 1.012 & 1.045 & -0.45 & -0.458 & $55 / 0$ & $324 / 74$ & $145 / 16$ \\
\hline jb152bl & $147 / 3$ & 238.87 & 1.076 & 1.044 & 1.125 & -0.257 & -0.284 & $243 / 16$ & $147 / 20$ & $8 / 64$ \\
\hline jb152bll & $147 / 3$ & 244.21 & 1.017 & 1.01 & 1.027 & -0.245 & -0.252 & $286 / 12$ & $193 / 15$ & $55 / 71$ \\
\hline jb152cl & $242 / 2$ & 336.69 & 1.045 & 1.046 & 1.093 & 0.016 & -0.006 & $257 / 51$ & $16 / 21$ & $119 / 31$ \\
\hline jb152cll & $242 / 2$ & 392.38 & 1.036 & 1.034 & 1.071 & -0.032 & -0.05 & $262 / 40$ & $93 / 50$ & $357 / 5$ \\
\hline jb153al & $6 / 2$ & 156 & 1.024 & 1.023 & 1.048 & -0.031 & -0.043 & $280 / 67$ & $136 / 19$ & $42 / 13$ \\
\hline jb153all & $6 / 2$ & 168.11 & 1.026 & 1.029 & 1.056 & 0.06 & 0.046 & $82 / 76$ & $196 / 6$ & $287 / 13$ \\
\hline jb153bl & $28 / 3$ & 74.62 & 1.003 & 1.012 & 1.015 & 0.618 & 0.616 & $326 / 17$ & $220 / 42$ & $73 / 43$ \\
\hline $\mathrm{jb} 153 \mathrm{c}$ & $342 / 3$ & 234.87 & 1.043 & 1.013 & 1.059 & -0.543 & -0.552 & $317 / 54$ & $224 / 2$ & $132 / 36$ \\
\hline jb153d & $126 / 0$ & 52.81 & 1.009 & 1.007 & 1.016 & -0.077 & -0.081 & $313 / 21$ & $201 / 44$ & $61 / 39$ \\
\hline jb154al & $44 / 4$ & 3412.42 & 1.033 & 1.044 & 1.079 & 0.14 & 0.121 & $319 / 49$ & $78 / 23$ & $183 / 32$ \\
\hline jb154all & $44 / 4$ & 3564.75 & 1.034 & 1.053 & 1.09 & 0.219 & 0.199 & $320 / 51$ & $68 / 14$ & $168 / 36$ \\
\hline $\mathrm{jb} 154 \mathrm{~b}$ & $200 / 8$ & 4655.35 & 1.029 & 1.045 & 1.076 & 0.218 & 0.2 & $338 / 45$ & $100 / 28$ & $210 / 32$ \\
\hline jb154cl & $109 / 2$ & 3658.05 & 1.023 & 1.043 & 1.068 & 0.292 & 0.277 & $323 / 31$ & $89 / 44$ & $212 / 30$ \\
\hline jb154cll & $109 / 2$ & 2855.92 & 1.018 & 1.046 & 1.067 & 0.434 & 0.421 & $15 / 66$ & $285 / 0$ & $194 / 24$ \\
\hline jb154clll & $109 / 2$ & 2890.03 & 1.027 & 1.052 & 1.082 & 0.319 & 0.302 & $324 / 50$ & $96 / 29$ & $201 / 24$ \\
\hline jb154dl & $97 / 4$ & 5224.95 & 1.057 & 1.008 & 1.071 & -0.75 & -0.757 & $340 / 61$ & $140 / 27$ & $235 / 8$ \\
\hline jb154dII & $97 / 4$ & 3408.4 & 1.011 & 1.055 & 1.071 & 0.672 & 0.663 & $332 / 26$ & $99 / 52$ & $228 / 26$ \\
\hline jb154dIII & $97 / 4$ & 4307.16 & 1.012 & 1.088 & 1.11 & 0.751 & 0.74 & $118 / 14$ & $352 / 67$ & $212 / 18$ \\
\hline jb155al & $321 / 5$ & 134.27 & 1.029 & 1.058 & 1.09 & 0.333 & 0.314 & $66 / 30$ & $171 / 24$ & $293 / 50$ \\
\hline jb155all & $321 / 5$ & 134.77 & 1.023 & 1.062 & 1.089 & 0.45 & 0.433 & $69 / 31$ & $173 / 22$ & $292 / 50$ \\
\hline jb155bll & $23 / 7$ & 133.31 & 1.02 & 1.062 & 1.086 & 0.511 & 0.496 & $68 / 26$ & $170 / 22$ & $295 / 55$ \\
\hline $\mathrm{jb155c}$ & $340 / 4$ & 125.88 & 1.027 & 1.061 & 1.092 & 0.378 & 0.36 & $61 / 29$ & $163 / 20$ & $283 / 54$ \\
\hline $\mathrm{jb} 155 \mathrm{~d}$ & $48 / 2$ & 134.7 & 1.021 & 1.065 & 1.091 & 0.512 & 0.497 & $60 / 27$ & $161 / 20$ & $282 / 55$ \\
\hline jb156bl & $82 / 2$ & 1808.86 & 1.158 & 1.031 & 1.209 & -0.659 & -0.684 & $89 / 14$ & $348 / 38$ & $195 / 49$ \\
\hline jb156bll & $82 / 2$ & 1074.11 & 1.161 & 1.024 & 1.207 & -0.724 & -0.744 & $97 / 10$ & $347 / 62$ & $192 / 26$ \\
\hline $\mathrm{jb} 156 \mathrm{c}$ & $46 / 2$ & 1123.59 & 1.143 & 1.034 & 1.194 & -0.603 & -0.629 & $101 / 8$ & $6 / 33$ & $203 / 56$ \\
\hline $\mathrm{jb} 156 \mathrm{~d}$ & $16 / 3$ & 3020.97 & 1.128 & 1.082 & 1.222 & -0.212 & -0.26 & $101 / 4$ & $252 / 86$ & $11 / 2$ \\
\hline
\end{tabular}




\begin{tabular}{|c|c|c|c|c|c|c|c|c|c|c|}
\hline Sample & Orient. & Susc. ${ }^{*} 10-6 \mathrm{SI}$ & $\bar{L}$ & $\mathrm{~F}$ & $\mathrm{P}^{\prime}$ & $\bar{T}$ & $\bar{U}$ & $\mathrm{~K} 1$ & $\mathrm{~K} 2$ & K3 \\
\hline jb157a & $342 / 4$ & 1194.26 & 1.056 & 1.107 & 1.171 & 0.301 & 0.265 & $302 / 47$ & $115 / 42$ & $209 / 4$ \\
\hline jb157bl & $14 / 1$ & 1204.95 & 1.086 & 1.027 & 1.121 & -0.514 & -0.534 & $222 / 69$ & $116 / 6$ & $24 / 20$ \\
\hline jb157bll & $14 / 1$ & 1062.97 & 1.079 & 1.069 & 1.154 & -0.066 & -0.101 & $48 / 64$ & $278 / 17$ & $182 / 18$ \\
\hline jb157c & $2 / 4$ & 1105.12 & 1.018 & 1.103 & 1.132 & 0.695 & 0.68 & $288 / 38$ & $102 / 51$ & $195 / 3$ \\
\hline $\mathrm{jb} 157 \mathrm{~d}$ & $24 / 4$ & 1223.83 & 1.031 & 1.103 & 1.144 & 0.523 & 0.499 & $273 / 27$ & $128 / 58$ & $11 / 16$ \\
\hline jb201a & $168 / 2$ & 1725.42 & 1.044 & 1.116 & 1.172 & 0.434 & 0.403 & $20 / 75$ & $117 / 2$ & $207 / 15$ \\
\hline jb201b & $141 / 5$ & 372.14 & 1.041 & 1.078 & 1.125 & 0.305 & 0.278 & $168 / 4$ & $78 / 2$ & $324 / 86$ \\
\hline jb204 & $90 / 1$ & 415.03 & 1.039 & 1.031 & 1.071 & -0.111 & -0.128 & $80 / 4$ & $347 / 34$ & $176 / 56$ \\
\hline $\mathrm{jb204b}$ & $90 / 1$ & 539.57 & 1.075 & 1.023 & 1.105 & -0.529 & -0.546 & $61 / 38$ & $178 / 31$ & $295 / 37$ \\
\hline jb204c & $90 / 1$ & 581.76 & 1.052 & 1.031 & 1.086 & -0.244 & -0.263 & $91 / 27$ & $340 / 36$ & $209 / 42$ \\
\hline $\mathrm{jb205}$ & $302 / 7$ & 445.68 & 1.075 & 1.078 & 1.159 & 0.015 & -0.022 & $15 / 15$ & $106 / 3$ & $206 / 75$ \\
\hline jb205b & $302 / 7$ & 1230.62 & 1.015 & 1.025 & 1.04 & 0.259 & 0.249 & $144 / 7$ & $239 / 36$ & $44 / 53$ \\
\hline $\mathrm{jb} 207$ & $274 / 75$ & 3695.37 & 1.177 & 1.017 & 1.22 & -0.814 & -0.828 & $133 / 5$ & $231 / 57$ & $40 / 32$ \\
\hline $\mathrm{jb} 207 \mathrm{~b}$ & $274 / 75$ & 3940.38 & 1.123 & 1.057 & 1.191 & -0.361 & -0.392 & $126 / 5$ & $31 / 40$ & $221 / 50$ \\
\hline jb207c & $274 / 75$ & 4827.55 & 1.178 & 1.067 & 1.266 & -0.433 & -0.479 & $133 / 1$ & $42 / 22$ & $225 / 68$ \\
\hline $\mathrm{jb} 210$ & $282 / 80$ & 4498.77 & 1.45 & 1.111 & 1.651 & -0.558 & -0.636 & $242 / 12$ & $339 / 30$ & $134 / 57$ \\
\hline $\mathrm{jb} 210 \mathrm{a}$ & $282 / 80$ & 3521.91 & 1.228 & 1.068 & 1.326 & -0.517 & -0.565 & $238 / 10$ & $329 / 7$ & $96 / 78$ \\
\hline $\mathrm{jb} 210 \mathrm{~b}$ & $282 / 80$ & 2503.46 & 1.272 & 1.075 & 1.389 & -0.537 & -0.591 & $235 / 5$ & $325 / 8$ & $115 / 81$ \\
\hline $\mathrm{jb} 212 \mathrm{~A}$ & $127 / 3$ & 3446.17 & 1.183 & 1.515 & 1.824 & 0.424 & 0.3 & $252 / 29$ & $132 / 42$ & $4 / 34$ \\
\hline $\mathrm{jb212B}$ & $135 / 4$ & 2060.69 & 1.203 & 1.382 & 1.673 & 0.274 & 0.154 & $235 / 38$ & $116 / 31$ & $360 / 36$ \\
\hline jb212c & $149 / 5$ & 814.11 & 1.077 & 1.134 & 1.223 & 0.259 & 0.212 & $270 / 43$ & $150 / 28$ & $39 / 34$ \\
\hline $\mathrm{jb} 213$ & $208 / 32$ & 105.19 & 1.024 & 1.011 & 1.036 & -0.367 & -0.375 & $291 / 1$ & $200 / 39$ & $23 / 51$ \\
\hline $\mathrm{jb213a}$ & $208 / 32$ & 254.05 & 1.02 & 1.026 & 1.047 & 0.128 & 0.117 & $113 / 7$ & $218 / 65$ & $20 / 24$ \\
\hline $\mathrm{jb} 218$ & $92 / 25$ & 1189.98 & 1.139 & 1.052 & 1.205 & -0.435 & -0.471 & $145 / 11$ & $354 / 77$ & $236 / 6$ \\
\hline $\mathrm{jb} 218 \mathrm{~b}$ & $92 / 25$ & 1593.7 & 1.158 & 1.052 & 1.227 & -0.484 & -0.521 & $150 / 16$ & $49 / 33$ & $262 / 52$ \\
\hline $\mathrm{jb} 220$ & $92 / 25$ & 1668.33 & 1.049 & 1.06 & 1.112 & 0.103 & 0.077 & $146 / 19$ & $271 / 60$ & $48 / 23$ \\
\hline $\mathrm{jb} 220 \mathrm{~b}$ & $92 / 25$ & 2358.27 & 1.106 & 1.078 & 1.192 & -0.146 & -0.189 & $317 / 0$ & $226 / 68$ & $47 / 22$ \\
\hline $\mathrm{jb} 257$ & $333 / 4$ & 2008.25 & 1.182 & 1.134 & 1.342 & -0.142 & -0.213 & $261 / 26$ & $134 / 52$ & $5 / 26$ \\
\hline $\mathrm{jb} 257 \mathrm{a}$ & $340 / 2$ & 2058.4 & 1.116 & 1.114 & 1.243 & -0.01 & -0.065 & $75 / 62$ & $288 / 24$ & $192 / 14$ \\
\hline $\mathrm{jb} 257 \mathrm{~b}$ & $358 / 2$ & 2028.65 & 1.227 & 1.122 & 1.382 & -0.281 & -0.354 & $263 / 24$ & $149 / 42$ & $13 / 38$ \\
\hline jb257c & $334 / 1$ & 2112.63 & 1.159 & 1.165 & 1.35 & 0.019 & -0.056 & $265 / 34$ & $137 / 43$ & $17 / 29$ \\
\hline jb258A & $152 / 1$ & 3699.67 & 1.255 & 1.103 & 1.396 & -0.399 & -0.465 & $98 / 7$ & $194 / 34$ & $358 / 55$ \\
\hline jb258B & $154 / 2$ & 3728.7 & 1.254 & 1.133 & 1.427 & -0.29 & -0.368 & $95 / 6$ & $189 / 32$ & $355 / 57$ \\
\hline jb258c & $179 / 2$ & 4439.81 & 1.259 & 1.059 & 1.356 & -0.599 & -0.644 & $111 / 6$ & $211 / 60$ & $18 / 30$ \\
\hline jb258cb & $179 / 2$ & 3044.2 & 1.187 & 1.073 & 1.283 & -0.419 & -0.468 & $107 / 1$ & $198 / 42$ & $16 / 48$ \\
\hline $\mathrm{jb} 259 \mathrm{a}$ & $42 / 2$ & 3660.5 & 1.143 & 1.042 & 1.2 & -0.532 & -0.563 & $268 / 3$ & $359 / 19$ & $170 / 71$ \\
\hline $\mathrm{jb} 259 \mathrm{~B}$ & $46 / 0$ & 2642.01 & 1.178 & 1.025 & 1.227 & -0.742 & -0.763 & $270 / 8$ & $0 / 5$ & $123 / 80$ \\
\hline $\mathrm{jb} 260 \mathrm{~A}$ & $348 / 1$ & 5551.13 & 1.161 & 1.231 & 1.432 & 0.163 & 0.075 & $275 / 1$ & $6 / 40$ & $185 / 50$ \\
\hline $\mathrm{jb} 260 \mathrm{~B}$ & $284 / 1$ & 5512.06 & 1.242 & 1.206 & 1.498 & -0.072 & -0.173 & $85 / 10$ & $347 / 40$ & $186 / 49$ \\
\hline $\mathrm{jb} 260 \mathrm{c}$ & $111 / 0$ & 2632.06 & 1.061 & 1.08 & 1.147 & 0.129 & 0.096 & $281 / 4$ & $17 / 52$ & $188 / 37$ \\
\hline jb261 & $346 / 18$ & 2488.89 & 1.115 & 1.099 & 1.225 & -0.072 & -0.122 & $332 / 4$ & $242 / 9$ & $85 / 81$ \\
\hline $\mathrm{jb} 261 \mathrm{~A}$ & $338 / 13$ & 4575.07 & 1.172 & 1.21 & 1.419 & 0.094 & 0.007 & $284 / 9$ & $15 / 8$ & $145 / 78$ \\
\hline $\mathrm{jb} 261 \mathrm{~b}$ & $346 / 18$ & 2097.78 & 1.12 & 1.072 & 1.202 & -0.24 & -0.283 & $332 / 2$ & $242 / 13$ & $69 / 77$ \\
\hline jb261B & $346 / 4$ & 3520.25 & 1.153 & 1.255 & 1.452 & 0.229 & 0.141 & $277 / 8$ & $9 / 13$ & $157 / 74$ \\
\hline jb261c & $346 / 18$ & 1747.28 & 1.103 & 1.114 & 1.228 & 0.049 & -0.003 & $322 / 5$ & $230 / 17$ & $67 / 72$ \\
\hline $\mathrm{jb} 273$ & $129 / 24$ & 55.54 & 1.05 & 1.016 & 1.07 & -0.511 & -0.523 & $315 / 7$ & $45 / 6$ & $176 / 80$ \\
\hline $\mathrm{jb} 273 \mathrm{~b}$ & $129 / 24$ & 72.41 & 1.044 & 1.077 & 1.126 & 0.261 & 0.234 & $315 / 28$ & $76 / 44$ & $205 / 33$ \\
\hline jb273c & $129 / 24$ & 99.43 & 1.102 & 1.051 & 1.162 & -0.322 & -0.355 & $119 / 18$ & $219 / 29$ & $1 / 55$ \\
\hline $\mathrm{jb} 296$ & $350 / 44$ & 779.85 & 1.014 & 1.097 & 1.122 & 0.746 & 0.734 & $307 / 19$ & $44 / 19$ & $174 / 62$ \\
\hline $\mathrm{jb} 304$ & $54 / 24$ & 2330.74 & 1.075 & 1.162 & 1.255 & 0.351 & 0.301 & $115 / 5$ & $24 / 9$ & $231 / 80$ \\
\hline
\end{tabular}




\begin{tabular}{|c|c|c|c|c|c|c|c|c|c|c|}
\hline Sample & Orient. & Susc. ${ }^{*} 10-6 \mathrm{SI}$ & $\mathrm{L}$ & $\mathrm{F}$ & $\mathrm{P}^{\prime}$ & $\mathrm{T}$ & $\mathrm{U}$ & $\mathrm{K} 1$ & $\mathrm{~K} 2$ & $\mathrm{~K} 3$ \\
\hline jb304b & $54 / 24$ & 1775.8 & 1.065 & 1.094 & 1.167 & 0.177 & 0.14 & $121 / 9$ & $212 / 4$ & $327 / 80$ \\
\hline $\mathrm{jb304c}$ & $54 / 24$ & 1857.9 & 1.098 & 1.113 & 1.223 & 0.067 & 0.016 & $133 / 11$ & $223 / 0$ & $315 / 79$ \\
\hline jb304d & $54 / 24$ & 1201.48 & 1.112 & 1.045 & 1.167 & -0.418 & -0.449 & $130 / 7$ & $221 / 4$ & $342 / 82$ \\
\hline jb305a & $205 / 16$ & 560.09 & 1.036 & 1.089 & 1.133 & 0.414 & 0.389 & $121 / 19$ & $251 / 62$ & $24 / 20$ \\
\hline jb305b & $205 / 16$ & 524.88 & 1.041 & 1.074 & 1.121 & 0.278 & 0.252 & $122 / 24$ & $255 / 57$ & $22 / 21$ \\
\hline jb305c & $205 / 16$ & 532.07 & 1.039 & 1.08 & 1.125 & 0.333 & 0.307 & $120 / 18$ & $244 / 60$ & $22 / 24$ \\
\hline jb306 & $4 / 6$ & 4072.84 & 1.095 & 1.076 & 1.179 & -0.111 & -0.151 & $288 / 13$ & $35 / 52$ & $189 / 35$ \\
\hline jb306b & $4 / 6$ & 6759.13 & 1.083 & 1.103 & 1.195 & 0.099 & 0.055 & $287 / 6$ & $30 / 64$ & $194 / 25$ \\
\hline jb306c & $4 / 6$ & 4752.16 & 1.084 & 1.09 & 1.182 & 0.036 & -0.006 & $286 / 10$ & $32 / 58$ & $190 / 30$ \\
\hline jb306d & $4 / 6$ & 4566.98 & 1.089 & 1.078 & 1.174 & -0.066 & -0.106 & $292 / 10$ & $30 / 38$ & $190 / 50$ \\
\hline jb308 & $161 / 10$ & 280.15 & 1.074 & 1.014 & 1.096 & -0.67 & -0.682 & $24 / 16$ & $120 / 20$ & $258 / 64$ \\
\hline jb308b & $161 / 10$ & 254.83 & 1.013 & 1.023 & 1.036 & 0.271 & 0.263 & $225 / 28$ & $110 / 37$ & $341 / 40$ \\
\hline jb308c & $161 / 10$ & 289.38 & 1.057 & 1.035 & 1.095 & -0.235 & -0.256 & $251 / 4$ & $140 / 78$ & $342 / 11$ \\
\hline jb309a & $209 / 1$ & 3420.68 & 1.229 & 1.17 & 1.441 & -0.135 & -0.223 & $316 / 16$ & $219 / 25$ & $76 / 60$ \\
\hline jb309b & $209 / 1$ & 1767.65 & 1.193 & 1.208 & 1.441 & 0.034 & -0.058 & $320 / 17$ & $221 / 26$ & $79 / 58$ \\
\hline jb309c & $209 / 1$ & 2504.41 & 1.238 & 1.133 & 1.408 & -0.262 & -0.34 & $322 / 14$ & $224 / 28$ & $76 / 58$ \\
\hline jb310 & $296 / 1$ & 5534.93 & 1.083 & 1.096 & 1.187 & 0.074 & 0.031 & $324 / 14$ & $60 / 23$ & $204 / 62$ \\
\hline jb310b & $296 / 1$ & 6846.85 & 1.101 & 1.09 & 1.201 & -0.056 & -0.101 & $319 / 16$ & $54 / 18$ & $189 / 66$ \\
\hline jb310c & $296 / 1$ & 6507.17 & 1.103 & 1.088 & 1.201 & -0.077 & -0.123 & $317 / 17$ & $55 / 24$ & $195 / 60$ \\
\hline jb310d & $296 / 1$ & 5239.51 & 1.091 & 1.088 & 1.186 & -0.016 & -0.059 & $321 / 17$ & $58 / 22$ & $196 / 62$ \\
\hline
\end{tabular}




\section{Appendix III}

HFA-data

Orientation of respective axes ( $\mathrm{P}=$ para, $\mathrm{F}=$ ferri)

Geographic system

\begin{tabular}{|c|c|c|c|c|c|c|c|c|c|c|}
\hline \begin{tabular}{|l|} 
Sample \\
\end{tabular} & Upara & Uferri & eDens.para & $\begin{array}{r}\text { eDens.ferri } \\
{[\mathrm{J} / \mathrm{M} 3]}\end{array}$ & PK1 & PK2 & PK3 & FK1 & FK2 & FK3 \\
\hline JB28d & 0.32 & \begin{tabular}{l|l|}
-0.01 \\
\end{tabular} & 0.1270 & 1.1200 & $242 / 35$ & $356 / 32$ & $117 / 40$ & 10/27 & $229 / 56$ & $109 / 18$ \\
\hline JB146all & 0.48 & 0.05 & 0.1410 & 0.1540 & $350 / 25$ & $243 / 31$ & $111 / 47$ & $303 / 32$ & $210 / 6$ & $110 / 57$ \\
\hline JB136c & -0.02 & $\begin{array}{l}-0.87 \\
\end{array}$ & 0.0003 & 8.2800 & $67 / 11$ & $158 / 08$ & $284 / 76$ & 70/07 & \begin{tabular}{l|l|}
$164 / 34$ \\
\end{tabular} & $331 / 55$ \\
\hline JB99al & -0.42 & \begin{tabular}{|c|}
-0.57 \\
\end{tabular} & 0.3260 & 1.2000 & $094 / 04$ & $003 / 06$ & $218 / 83$ & $087 / 05$ & $355 / 14$ & $195 / 75$ \\
\hline JB96a & -0.77 & $\begin{array}{l}-0.12 \\
\end{array}$ & 0.3910 & 0.0551 & $226 / 04$ & $133 / 27$ & $325 / 63$ & $269 / 81$ & $138 / 05$ & $047 / 07$ \\
\hline JB74C & 0.18 & 0.52 & 1.7800 & 0.1370 & $270 / 03$ & $005 / 66$ & $178 / 23$ & $272 / 59$ & $51 / 24$ & 149/18 \\
\hline JB46b & -0.36 & \begin{tabular}{|c|}
-0.11 \\
\end{tabular} & 0.2670 & 2.0800 & $185 / 00$ & $15 / 1$ & $169 / 89$ & $103 / 4$ & $301 / 86$ & 194/2 \\
\hline JB25bl & -0.56 & -0.05 & 0.3910 & 1.4100 & $42 / 28$ & $285 / 40$ & $155 / 37$ & $51 / 21$ & \begin{tabular}{|l|}
$158 / 37$ \\
\end{tabular} & $297 / 45$ \\
\hline JB24c & 0.51 & 0.76 & 0.3310 & 0.3220 & $129 / 22$ & $348 / 62$ & $226 / 16$ & $96 / 48$ & $271 / 42$ & $3 / 2$ \\
\hline JB8aBIII & 0.64 & 0.57 & 0.0001 & 2.8100 & $291 / 9$ & $34 / 54$ & $195 / 34$ & $101 / 14$ & $349 / 55$ & $200 / 31$ \\
\hline JB19b & -0.37 & \begin{tabular}{|c|}
-0.14 \\
\end{tabular} & 0.4870 & 1.2700 & $163 / 37$ & $63 / 13$ & $318 / 50$ & 119/32 & $7 / 30$ & $245 / 43$ \\
\hline JB44a & -0.06 & 0.81 & 1.9000 & 8.4900 & $92 / 12$ & $317 / 74$ & $184 / 11$ & $335 / 54$ & $83 / 13$ & $182 / 33$ \\
\hline JB56all & 0.01 & 0.38 & 0.9970 & 4.5500 & $357 / 7$ & $91 / 33$ & $255 / 56$ & $99 / 19$ & $7 / 7$ & $258 / 70$ \\
\hline JB73a & 0.50 & 0.66 & 0.7500 & 3.3200 & $76 / 13$ & $335 / 42$ & $179 / 45$ & $57 / 23$ & 310/33 & $175 / 48$ \\
\hline JB63d & -0.25 & 0.04 & 0.1210 & 0.4450 & $88 / 30$ & $327 / 42$ & $201 / 33$ & 059/35 & $284 / 46$ & $187 / 24$ \\
\hline JB57a & 0.54 & 0.45 & 2.0100 & 2.7900 & $44 / 21$ & $314 / 1$ & $222 / 70$ & $43 / 19$ & $312 / 5$ & $209 / 70$ \\
\hline JB53a & 0.59 & 0.03 & 5.1700 & 0.8440 & $81 / 34$ & $346 / 9$ & $242 / 55$ & $092 / 26$ & $350 / 22$ & $226 / 55$ \\
\hline JB48c & 0.01 & -0.12 & 1.1600 & 0.7840 & $344 / 8$ & $249 / 32$ & $86 / 56$ & $356 / 5$ & $263 / 34$ & $93 / 55$ \\
\hline JB42a & -0.16 & 0.12 & 0.0484 & 0.7700 & $369 / 49$ & $148 / 34$ & $252 / 21$ & $9 / 0$ & $99 / 30$ & $280 / 60$ \\
\hline $\mathrm{x} 1$ & 0.72 & 0.09 & 4.3100 & 0.7880 & $56 / 37$ & $234 / 54$ & $325 / 1$ & $240 / 1$ & $345 / 85$ & $149 / 5$ \\
\hline JB128bll & 0.16 & 0.2 & 0.7610 & 1.2300 & $172 / 57$ & $327 / 31$ & $65 / 12$ & $380 / 53$ & $154 / 36$ & $249 / 8$ \\
\hline JB140al & -0.07 & 0.12 & 0.6030 & 1.3600 & $148 / 34$ & $257 / 27$ & $19 / 45$ & $272 / 18$ & $163 / 44$ & $18 / 41$ \\
\hline JB133d & -0.16 & -0.03 & 1.4800 & 9.0400 & $254 / 23$ & $130 / 52$ & $356 / 27$ & $72 / 9$ & $292 / 77$ & $163 / 9$ \\
\hline JB116bl & 0.14 & 0.04 & 4.4300 & 0.0450 & $269 / 8$ & $359 / 0$ & $90 / 82$ & $156 / 78$ & $356 / 7$ & $266 / 8$ \\
\hline JB108bll & -0.86 & $\begin{array}{l}-0.45 \\
\end{array}$ & 0.6810 & 2.1800 & $281 / 37$ & $20 / 11$ & $124 / 50$ & $287 / 5$ & $48 / 79$ & $196 / 9$ \\
\hline JB125all & 0.02 & 0.26 & 0.7480 & 3.2800 & $59 / 27$ & $199 / 56$ & $318 / 18$ & $39 / 17$ & $234 / 73$ & $131 / 5$ \\
\hline JB123b & -0.36 & -0.4 & 0.3160 & 2.5600 & $261 / 29$ & $87 / 61$ & $353 / 2$ & $213 / 12$ & $4 / 57$ & $142 / 25$ \\
\hline
\end{tabular}




\section{Appendix IV}

\section{Geochemistry (major elements)}

\begin{tabular}{|c|c|c|c|c|c|c|c|c|c|c|c|c|}
\hline Sample & \%SiO2 & \%TiO2 & \%Al2O3 & \%Fe2O3 & $\% \mathrm{MnO}$ & $\% \mathrm{MgO}$ & $\% \mathrm{CaO}$ & $\% \mathrm{Na} 2 \mathrm{O}$ & \%K2O & \%P2O5 & \%LOI & \%TOTAL \\
\hline $\mathrm{CH} 10$ & 73.07 & 0.14 & 13.59 & 1.59 & 0.06 & 0.47 & 1.07 & 3.89 & 5.73 & 0.03 & 0.46 & 100.12 \\
\hline $\mathrm{CH} 11$ & 68.12 & 0.48 & 14.60 & 3.24 & 0.10 & 2.35 & 2.88 & 4.74 & 3.16 & 0.18 & 0.59 & 100.44 \\
\hline $\mathrm{CH} 16 \mathrm{~A}$ & 73.29 & 0.32 & 13.84 & 2.52 & 0.07 & 0.85 & 2.07 & 3.45 & 2.59 & 0.07 & 1.01 & 100.10 \\
\hline $\mathrm{CH} 18$ & 67.40 & 0.53 & 14.81 & 3.34 & 0.09 & 2.54 & 3.04 & 5.01 & 2.93 & 0.19 & 0.55 & 100.43 \\
\hline $\mathrm{CH} 19$ & 59.14 & 0.77 & 13.98 & 7.53 & 0.12 & 5.58 & 6.18 & 4.29 & 1.86 & 0.26 & 0.51 & 100.22 \\
\hline $\mathrm{CH} 21 \mathrm{~A}$ & 68.78 & 0.40 & 14.81 & 2.62 & 0.07 & 1.55 & 2.53 & 4.23 & 4.05 & 0.13 & 0.56 & 99.73 \\
\hline $\mathrm{CH} 21 \mathrm{~B}$ & 70.16 & 0.41 & 14.26 & 3.06 & 0.07 & 1.38 & 1.54 & 3.12 & 5.67 & 0.24 & 0.57 & 100.49 \\
\hline $\mathrm{CH} 23$ & 73.20 & 0.34 & 13.68 & 2.97 & 0.07 & 0.77 & 2.75 & 5.07 & 1.21 & 0.09 & 0.30 & 100.47 \\
\hline JB 77 & 73.68 & 0.31 & 12.66 & 2.64 & 0.06 & 0.59 & 2.54 & 4.66 & 1.28 & 0.08 & 0.36 & 98.85 \\
\hline JB 108 & 72.17 & 0.29 & 14.39 & 2.10 & 0.07 & 0.56 & 2.17 & 4.83 & 3.09 & 0.08 & 0.24 & 99.98 \\
\hline JB 109 & 69.94 & 0.51 & 14.18 & 3.68 & 0.08 & 1.18 & 2.45 & 4.47 & 3.35 & 0.19 & 0.47 & 100.51 \\
\hline JB 200 & 74.24 & 0.22 & 13.79 & 1.68 & 0.07 & 0.44 & 1.65 & 4.04 & 3.92 & 0.06 & 0.23 & 100.36 \\
\hline JB 202 & 73.67 & 0.24 & 13.67 & 1.94 & 0.08 & 0.51 & 1.91 & 4.12 & 3.74 & 0.06 & 0.38 & 100.32 \\
\hline JB 206 & 73.74 & 0.19 & 13.50 & 1.23 & 0.06 & 0.12 & 0.84 & 3.15 & 6.03 & 0.03 & 0.18 & 99.06 \\
\hline JB 207 & 71.90 & 0.23 & 14.55 & 1.88 & 0.05 & 0.29 & 1.12 & 3.64 & 6.17 & 0.04 & 0.47 & 100.34 \\
\hline JB 209 & 73.83 & 0.20 & 13.83 & 1.55 & 0.05 & 0.26 & 1.26 & 3.88 & 5.28 & 0.03 & 0.19 & 100.38 \\
\hline JB 210 & 67.45 & 0.43 & 15.89 & 3.13 & 0.08 & 1.48 & 3.01 & 4.16 & 4.07 & 0.14 & 0.51 & 100.35 \\
\hline JB 211 & 69.42 & 0.32 & 14.99 & 2.31 & 0.08 & 1.15 & 2.12 & 4.21 & 4.21 & 0.11 & 0.88 & 99.81 \\
\hline JB 212 & 72.26 & 0.26 & 14.79 & 2.48 & 0.08 & 0.55 & 2.01 & 4.17 & 3.41 & 0.07 & 0.30 & 100.38 \\
\hline JB 213 & 65.14 & 0.49 & 13.82 & 3.47 & 0.12 & 2.66 & 3.16 & 4.35 & 4.47 & 0.16 & 0.99 & 98.83 \\
\hline JB 214A & 72.07 & 0.32 & 14.24 & 2.91 & 0.08 & 0.81 & 2.64 & 4.82 & 1.94 & 0.10 & 0.16 & 100.09 \\
\hline JB 214B & 74.04 & 0.13 & 14.56 & 0.83 & 0.05 & 0.37 & 1.94 & 5.00 & 3.41 & 0.04 & 0.14 & 100.50 \\
\hline JB 215 & 72.58 & 0.27 & 14.08 & 2.24 & 0.07 & 0.76 & 2.06 & 4.31 & 3.37 & 0.08 & 0.27 & 100.10 \\
\hline JB 216 & 70.46 & 0.38 & 14.39 & 3.54 & 0.08 & 0.78 & 2.01 & 4.58 & 3.84 & 0.08 & 0.18 & 100.33 \\
\hline JB 208 & 75.47 & 0.24 & 12.43 & 1.77 & 0.04 & 0.38 & 1.01 & 3.58 & 5.05 & 0.06 & 0.36 & 100.39 \\
\hline JB 217A & 59.53 & 0.45 & 16.38 & 5.97 & 0.10 & 4.91 & 5.22 & 2.10 & 3.03 & 0.13 & 2.00 & 99.82 \\
\hline JB 217B & 58.84 & 0.78 & 14.80 & 7.47 & 0.11 & 5.42 & 6.29 & 3.46 & 1.83 & 0.25 & 0.91 & 100.16 \\
\hline
\end{tabular}




\section{Appendix V}

Geochemistry

(Isotopes)

\begin{tabular}{|c|c|c|c|c|c|c|c|c|}
\hline Isotopes & $\mathrm{CH} 10$ & $\mathrm{CH} 11$ & $\mathrm{CH} 16 \mathrm{~A}$ & $\mathrm{CH}-18$ & $\mathrm{CH} 19$ & $\mathrm{CH}-21 \mathrm{~A}$ & $\mathrm{CH} 21 \mathrm{~B}$ & $\mathrm{CH} 23$ \\
\hline $\mathrm{Sc}$ & 3.715 & 7.295 & 26.674 & 7.277 & 6.831 & 5.669 & 8.299 & 16.689 \\
\hline $\mathrm{Rb}$ & 344.048 & 238.297 & 74.390 & 201.391 & 182.190 & 116.165 & 175.928 & 69.344 \\
\hline $\mathrm{Sr}$ & 157.771 & 323.526 & 473.324 & 308.272 & 488.398 & 74.657 & 278.889 & 470.085 \\
\hline $\mathrm{Y}$ & 11.771 & 11.764 & 20.577 & 9.445 & 10.618 & 14.647 & 18.269 & 18.160 \\
\hline $\mathrm{Zr}$ & 148.025 & 150.619 & 207.344 & 124.565 & 175.119 & 145.640 & 127.493 & 208.230 \\
\hline $\mathrm{Nb}$ & 6.164 & 8.508 & 8.771 & 9.933 & 8.320 & 6.909 & 5.071 & 5.597 \\
\hline Mo & 0.655 & 0.411 & 0.516 & 0.386 & 0.364 & 0.867 & 0.676 & 0.558 \\
\hline Cs & 2.954 & 5.617 & 8.096 & 4.232 & 4.807 & 1.276 & 2.176 & 6.996 \\
\hline $\mathrm{Ba}$ & 690.825 & 607.592 & 696.414 & 566.795 & 1037.962 & 480.818 & 2248.014 & 680.110 \\
\hline $\mathrm{La}$ & 50.515 & 49.125 & 42.777 & 50.525 & 50.384 & 42.448 & 72.374 & 38.274 \\
\hline $\mathrm{Ce}$ & 110.392 & 82.619 & 97.799 & 88.798 & 104.395 & 72.561 & 140.671 & 81.346 \\
\hline $\mathrm{Pr}$ & 11.272 & 8.806 & 10.802 & 9.073 & 9.585 & 7.388 & 13.149 & 9.885 \\
\hline $\mathrm{Nd}$ & 40.154 & 30.173 & 43.392 & 30.799 & 35.276 & 25.030 & 48.538 & 38.224 \\
\hline $\mathrm{Sm}$ & 6.576 & 4.409 & 7.706 & 4.425 & 4.878 & 4.398 & 6.633 & 6.632 \\
\hline $\mathrm{Eu}$ & 0.779 & 1.251 & 1.924 & 1.262 & 1.727 & 0.955 & 2.850 & 1.763 \\
\hline $\mathrm{Gd}$ & 5.316 & 2.871 & 4.299 & 2.482 & 3.542 & 2.680 & 5.718 & 3.854 \\
\hline $\mathrm{Tb}$ & 0.540 & 0.371 & 0.755 & 0.378 & 0.405 & 0.457 & 0.634 & 0.647 \\
\hline Dy & 2.703 & 2.023 & 4.033 & 1.773 & 2.088 & 2.413 & 3.672 & 3.415 \\
\hline $\mathrm{Ho}$ & 0.411 & 0.371 & 0.772 & 0.320 & 0.378 & 0.498 & 0.660 & 0.672 \\
\hline $\mathrm{Er}$ & 0.809 & 1.046 & 2.640 & 0.953 & 1.027 & 1.494 & 1.497 & 1.828 \\
\hline $\mathrm{Tm}$ & 0.122 & 0.174 & 0.314 & 0.129 & 0.158 & 0.235 & 0.234 & 0.277 \\
\hline $\mathrm{Yb}$ & 0.839 & 1.262 & 1.883 & 0.839 & 1.112 & 1.579 & 1.693 & 1.713 \\
\hline Lu & 0.129 & 0.182 & 0.293 & 0.138 & 0.156 & 0.264 & 0.223 & 0.258 \\
\hline $\mathrm{Hf}$ & 5.581 & 4.200 & 5.490 & 3.497 & 4.943 & 4.908 & 3.621 & 5.496 \\
\hline $\mathrm{Ta}$ & 14.221 & 16.919 & 0.046 & -0.227 & 1.249 & 0.098 & 1.398 & 1.058 \\
\hline $\mathrm{W}$ & 1.151 & 2.257 & 1.034 & 0.702 & 0.238 & 0.229 & 1.143 & 0.459 \\
\hline $\mathrm{Pb}$ & 51.503 & 26.552 & 7.378 & 25.938 & 37.398 & 29.573 & 46.211 & 6.729 \\
\hline $\mathrm{Th}$ & 108.678 & 23.702 & 8.877 & 24.323 & 31.619 & 32.760 & 41.748 & 9.275 \\
\hline $\mathrm{U}$ & 15.807 & 2.215 & 2.478 & 3.172 & 9.612 & 4.728 & 3.611 & 2.019 \\
\hline
\end{tabular}

\begin{tabular}{|r|r|r|r|r|r|r|r|r|}
\hline SiO2 & 73.334 & 68.222 & 73.978 & 67.481 & 59.312 & 69.356 & 70.223 & 73.090 \\
\hline
\end{tabular}

\begin{tabular}{|r|r|r|r|r|r|r|r|r|}
\hline Number & $\mathrm{CH} \mathrm{10}$ & $\mathrm{CH} 11$ & $\mathrm{CH} \mathrm{16A}$ & $\mathrm{CH} 18$ & $\mathrm{CH} 19$ & $\mathrm{CH} 21 \mathrm{~A}$ & $\mathrm{CH} 21 \mathrm{~B}$ & $\mathrm{CH} 23$ \\
\hline $\mathrm{ppm} \mathrm{Cu}$ & & 2 & & 7 & & & & \\
\hline $\mathrm{ppm} \mathrm{Zn}$ & 27 & 58 & 53 & 52 & 41 & 27 & 37 & 52 \\
\hline
\end{tabular}

\begin{tabular}{|l|r|r|r|r|r|r|r|r|}
\hline$\left(\mathrm{Eu} / \mathrm{Eu}^{*}\right) \mathrm{N}$ & 0.429 & 1.146 & 1.089 & 1.240 & 1.354 & 0.906 & 1.507 & 1.136 \\
\hline
\end{tabular}




\begin{tabular}{|r|r|r|r|r|r|r|r|r|}
\hline Isotopes & JB-77 & JB-108 & JB 109 & JB 200 & JB 202 & JB 206 & JB 207 & JB 208 \\
\hline $\mathrm{Sc}$ & 5.356 & 2.281 & 6.274 & 2.481 & 2.402 & 2.863 & 4.449 & 4.433 \\
\hline $\mathrm{Rb}$ & 104.376 & 162.286 & 98.252 & 211.258 & 214.535 & 240.880 & 305.999 & 307.876 \\
\hline $\mathrm{Sr}$ & 125.869 & 187.023 & 187.341 & 99.866 & 95.214 & 43.408 & 82.986 & 75.924 \\
\hline $\mathrm{Y}$ & 9.770 & 4.705 & 20.488 & 10.498 & 11.658 & 5.373 & 11.518 & 23.182 \\
\hline $\mathrm{Zr}$ & 172.909 & 126.280 & 186.412 & 128.850 & 120.638 & 96.136 & 186.036 & 151.232 \\
\hline $\mathrm{Nb}$ & 12.215 & 7.061 & 14.921 & 5.473 & 7.392 & 2.704 & 5.417 & 8.844 \\
\hline $\mathrm{Mo}$ & 0.876 & 1.407 & 0.453 & 0.279 & 0.585 & 0.242 & 0.664 & 0.116 \\
\hline $\mathrm{Cs}$ & 9.430 & 6.332 & 2.084 & 3.963 & 6.165 & 4.149 & 4.770 & 2.566 \\
\hline $\mathrm{Ba}$ & 142.004 & 616.720 & 706.620 & 707.723 & 730.513 & 247.257 & 443.283 & 461.548 \\
\hline $\mathrm{La}$ & 11.355 & 26.967 & 37.553 & 31.058 & 32.508 & 37.611 & 72.648 & 49.438 \\
\hline $\mathrm{Ce}$ & 20.174 & 43.673 & 72.226 & 52.666 & 59.908 & 84.740 & 162.485 & 104.151 \\
\hline $\mathrm{Pr}$ & 2.224 & 4.100 & 7.095 & 4.658 & 5.141 & 8.483 & 15.162 & 10.449 \\
\hline $\mathrm{Nd}$ & 8.186 & 13.384 & 26.351 & 15.672 & 18.282 & 30.375 & 54.446 & 37.113 \\
\hline $\mathrm{Sm}$ & 1.950 & 2.125 & 5.312 & 2.512 & 3.180 & 4.692 & 7.699 & 6.457 \\
\hline $\mathrm{Eu}$ & 0.591 & 0.973 & 1.566 & 0.972 & 0.986 & 0.466 & 0.754 & 0.676 \\
\hline $\mathrm{Gd}$ & 1.539 & 1.319 & 3.609 & 2.255 & 2.892 & 3.294 & 5.564 & 6.335 \\
\hline $\mathrm{Tb}$ & 0.300 & 0.195 & 0.680 & 0.302 & 0.403 & 0.302 & 0.583 & 0.800 \\
\hline $\mathrm{Dy}$ & 1.754 & 0.937 & 4.001 & 1.850 & 2.354 & 1.292 & 2.916 & 4.808 \\
\hline $\mathrm{Ho}$ & 0.337 & 0.160 & 0.774 & 0.349 & 0.420 & 0.186 & 0.448 & 0.828 \\
\hline $\mathrm{Er}$ & 0.938 & 0.458 & 2.534 & 0.849 & 1.140 & 0.440 & 1.032 & 1.632 \\
\hline $\mathrm{Tm}$ & 0.135 & 0.067 & 0.319 & 0.143 & 0.184 & 0.067 & 0.135 & 0.249 \\
\hline $\mathrm{Yb}$ & 0.859 & 0.378 & 1.863 & 1.035 & 1.296 & 0.430 & 0.864 & 1.695 \\
\hline $\mathrm{Lu}$ & 0.141 & 0.054 & 0.308 & 0.152 & 0.185 & 0.074 & 0.130 & 0.219 \\
\hline $\mathrm{Hf}$ & 4.235 & 3.481 & 5.202 & 3.965 & 3.735 & 3.480 & 6.546 & 5.456 \\
\hline $\mathrm{Ta}$ & -0.118 & 0.041 & -0.228 & 9.900 & 3.102 & -0.465 & 1.354 & 4.324 \\
\hline $\mathrm{W}$ & 0.865 & 0.504 & 0.492 & 0.663 & 7.473 & 0.443 & 1.375 & 0.731 \\
\hline $\mathrm{Pb}$ & 15.667 & 19.366 & 19.108 & 25.996 & 28.640 & 45.251 & 55.903 & 46.085 \\
\hline $\mathrm{Th}$ & 6.844 & 12.073 & 15.723 & 31.940 & 30.191 & 43.836 & 108.677 & 69.511 \\
\hline $\mathrm{U}$ & 1.500 & 2.904 & 2.930 & 6.800 & 3.648 & 9.660 & 24.318 & 16.793 \\
\hline $\mathrm{SiO} 2$ & 74.802 & 72.351 & 69.919 & 74.158 & 73.714 & 74.568 & 71.994 & 75.447 \\
\hline
\end{tabular}

\begin{tabular}{|r|r|r|r|r|r|r|r|r|}
\hline Number & JB 77 & JB 108 & JB 109 & JB 200 & JB 202 & JB 206 & JB 207 & JB 208 \\
\hline ppm Cu & & & 2 & & 4 & & & \\
\hline ppm Zn & 49 & 38 & 51 & 26 & 32 & 22 & 30 & 35 \\
\hline
\end{tabular}

\begin{tabular}{|l|l|l|l|l|l|l|l|l|}
\hline$\left(\mathrm{Eu} / \mathrm{Eu}^{*}\right) \mathrm{N}$ & 1.111 & 1.893 & 1.165 & 1.330 & 1.059 & 0.386 & 0.375 & 0.344 \\
\hline
\end{tabular}




\begin{tabular}{|c|c|c|c|c|c|c|c|c|c|}
\hline Isotopes & JB 210 & JB 211 & JB 212 & JB 213 & JB-214A & JB 214B & JB 215 & JB 216 & JB 217A \\
\hline Sc & 6.453 & 4.945 & 2.129 & 9.343 & 6.114 & 0.250 & 3.825 & 8.158 & 12.906 \\
\hline $\mathrm{Rb}$ & 164.417 & 179.386 & 158.039 & 221.060 & 99.803 & 155.898 & 145.664 & 129.589 & 3347.623 \\
\hline $\mathrm{Sr}$ & 478.051 & 391.245 & 88.911 & 306.121 & 122.298 & 60.772 & 125.446 & 118.187 & 410.348 \\
\hline $\mathrm{Y}$ & 12.078 & 18.426 & 13.851 & 26.122 & 9.761 & 10.760 & 7.414 & 41.536 & 9.322 \\
\hline $\mathrm{Zr}$ & 184.727 & 108.727 & 131.347 & 118.679 & 185.158 & 77.110 & 142.689 & 209.716 & 60.731 \\
\hline $\mathrm{Nb}$ & 8.720 & 9.247 & 15.424 & 14.050 & 16.195 & 4.584 & 10.588 & 10.276 & 2.234 \\
\hline Mo & 0.922 & 0.558 & 0.740 & 0.401 & 0.432 & 0.392 & 0.659 & 0.608 & 0.277 \\
\hline Cs & 4.339 & 1.853 & 2.777 & 4.194 & 4.505 & 1.977 & 0.625 & 4.319 & 1442.485 \\
\hline $\mathrm{Ba}$ & 943.971 & 883.316 & 565.124 & 655.355 & 93.150 & 111.831 & 438.678 & 890.629 & 470.025 \\
\hline $\mathrm{La}$ & 48.156 & 36.889 & 28.861 & 31.373 & 10.372 & 40.274 & 25.097 & 22.137 & 10.416 \\
\hline $\mathrm{Ce}$ & 99.300 & 72.173 & 51.895 & 66.369 & 18.513 & 79.842 & 49.084 & 39.771 & 18.919 \\
\hline $\operatorname{Pr}$ & 9.644 & 7.664 & 4.834 & 7.069 & 1.986 & 7.813 & 4.231 & 5.428 & 2.236 \\
\hline $\mathrm{Nd}$ & 36.034 & 28.503 & 17.358 & 27.633 & 7.302 & 28.517 & 15.148 & 24.222 & 9.838 \\
\hline $\mathrm{Sm}$ & 5.322 & 4.726 & 3.648 & 4.991 & 1.888 & 6.141 & 2.942 & 6.427 & 2.142 \\
\hline $\mathrm{Eu}$ & 1.782 & 1.405 & 0.957 & 1.219 & 0.564 & 0.506 & 0.945 & 1.658 & 1.039 \\
\hline $\mathrm{Gd}$ & 3.949 & 3.992 & 2.603 & 5.035 & 1.449 & 3.387 & 1.793 & 5.117 & 1.953 \\
\hline $\mathrm{Tb}$ & 0.451 & 0.503 & 0.517 & 0.713 & 0.284 & 0.567 & 0.298 & 1.118 & 0.287 \\
\hline Dy & 2.475 & 3.249 & 2.856 & 4.826 & 1.696 & 2.755 & \begin{tabular}{ll|}
1.581 \\
\end{tabular} & 6.768 & 1.626 \\
\hline $\mathrm{Ho}$ & 0.430 & 0.604 & 0.494 & 0.889 & 0.333 & 0.444 & 0.290 & 1.468 & 0.346 \\
\hline $\mathrm{Er}$ & 1.067 & 1.437 & 1.555 & 2.115 & 0.939 & 1.449 & 1.068 & 4.640 & 0.922 \\
\hline $\mathrm{Tm}$ & 0.167 & 0.253 & 0.167 & 0.375 & 0.132 & 0.138 & 0.098 & 0.621 & 0.137 \\
\hline $\mathrm{Yb}$ & 1.263 & 2.106 & 0.908 & 2.814 & 0.855 & 0.754 & 0.508 & 3.480 & 0.937 \\
\hline Lu & 0.182 & 0.243 & 0.160 & 0.322 & 0.136 & 0.122 & 0.085 & 0.552 & 0.142 \\
\hline $\mathrm{Hf}$ & 5.227 & 3.242 & 3.913 & 3.397 & 4.648 & 3.706 & 4.195 & 5.782 & 1.748 \\
\hline $\mathrm{Ta}$ & 1.780 & 17.933 & -0.464 & 4.986 & -0.089 & 0.031 & 0.099 & -0.073 & 0.193 \\
\hline $\mathrm{W}$ & 0.342 & 0.961 & 0.278 & 0.327 & 0.342 & 0.620 & 0.809 & 1.674 & 1.492 \\
\hline $\mathrm{Pb}$ & 32.769 & 32.611 & 39.376 & 32.981 & 14.796 & 46.628 & 33.874 & 28.144 & 5.205 \\
\hline Th & 28.985 & 29.262 & 22.771 & 19.592 & 4.698 & 44.715 & 18.081 & 12.013 & 3.216 \\
\hline $\mathrm{U}$ & 6.023 & 5.630 & 6.561 & 4.434 & 1.312 & 13.242 & 2.161 & 1.968 & 0.664 \\
\hline
\end{tabular}

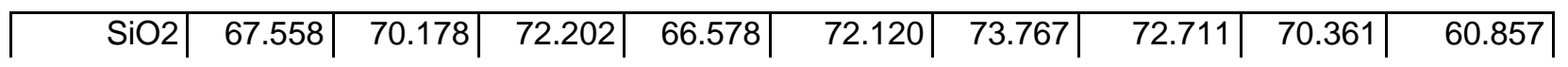

\begin{tabular}{|r|r|r|r|r|r|r|r|r|r|} 
Number & JB 210 & JB 211 & JB 212 & JB 213 & JB 214A & JB 214B & JB 215 & JB 216 & JB 217A \\
\hline ppm Cu & & & & & & & & & 32 \\
\hline ppm Zn & 41 & 35 & 53 & 51 & 44 & 18 & 40 & 63 & 82 \\
\hline
\end{tabular}

\begin{tabular}{|l|r|r|r|r|r|r|r|r|r|}
\hline$\left(\mathrm{Eu} / \mathrm{Eu}^{\star}\right) \mathrm{N}$ & 1.266 & 1.054 & 1.012 & 0.792 & 1.112 & 0.362 & 1.341 & 0.942 & 1.655 \\
\hline
\end{tabular}




\section{Curriculum vitae}

Geboren wurde ich am 21.04.1971 in Düsseldorf. Von 1977 bis 1981 besuchte ich die Grundschule, anschließend das Max-Planck Gymnasium in Düsseldorf, wo ich 1990 die allgemeine Hochschulreife erlangte. Meinen Wehrdienst leistete ich von 1990 bis 1991 in Lingen an der Ems. Im Oktober 1991 begann ich mein Studium der Geologie/ Paläontologie an der Universität Göttingen, das ich 1997 abschloß. Die Diplomarbeit hatte den Titel „Gesteinsmagnetische und gefügekundliche Untersuchungen an Graniten des Ardara Plutons (Irland).“, die Diplomkartierung hatte den Titel „Kartierung des Gebietes zwischen Thale und Neinstedt an der Harznordrand-Störung (Maßstab 1:10000)“. Danach (April 1997) begann ich die vorliegende Dissertation mit dem Titel „The emplacement of the Chinamora

Batholith (Zimbabwe) inferred from field observations, magnetic- and microfabrics.“. 